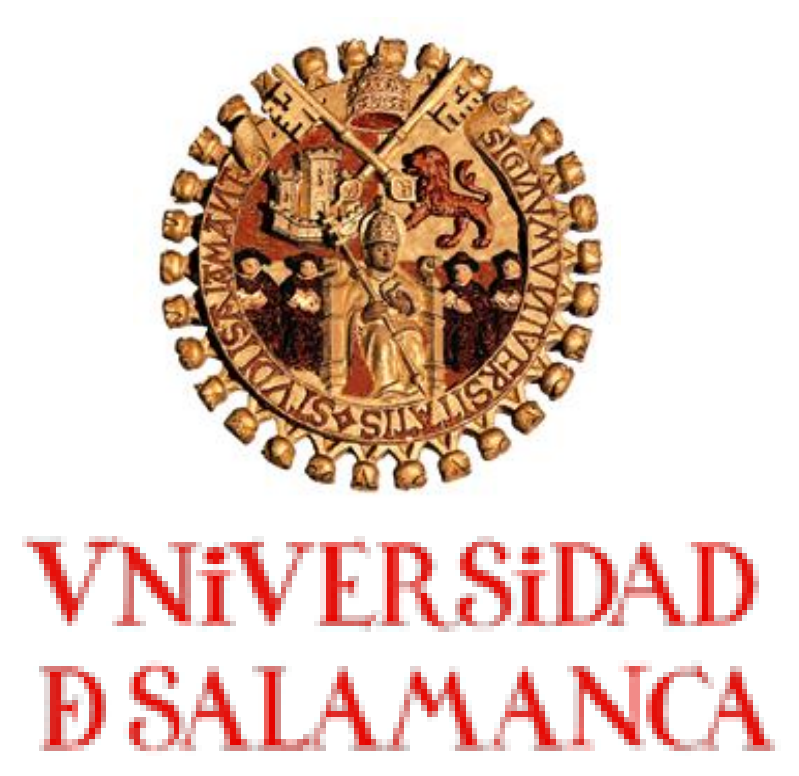

FACULTAD DE PSICOLOGÍA

DEPARTAMENTO DE PSICOLOGÍA BÁSICA, PSICOBIOLOGÍA Y METODOLOGÍA

\author{
TESIS DOCTORAL
}

VALIDACIÓN DE LA VERSIÓN PORTUGUESA DE LA ESCALA

DE ANSIEDAD DE BECK - BAI

Sónia dos Reis Quintão 


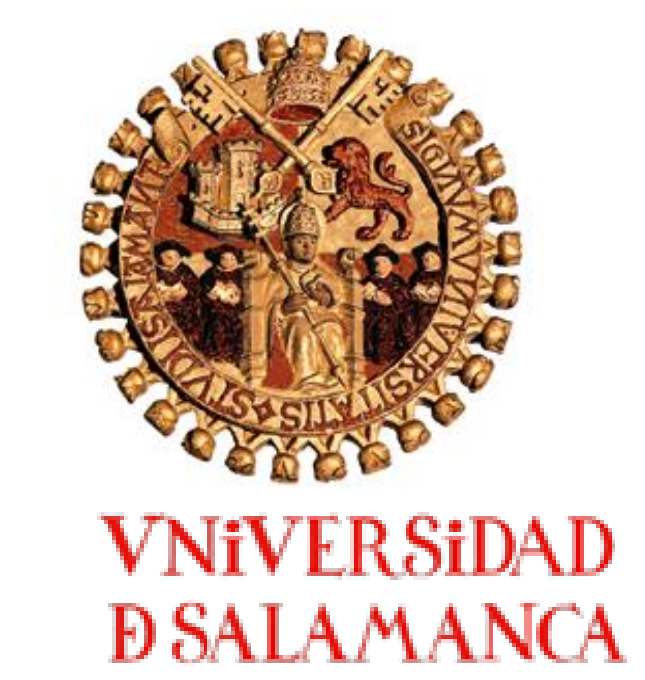

FACULTAD DE PSICOLOGÍA

DEPARTAMENTO DE PSICOLOGÍA BÁSICA, PSICOBIOLOGÍA Y METODOLOGÍA

\section{VALIDACIÓN DE LA VERSIÓN PORTUGUESA DE LA ESCALA DE ANSIEDAD DE BECK - BAI}

Trabajo presentado para optar al título de Doutor en Psicología, por Dña. Sónia dos Reis Quintão bajo la dirección del profesor Dr. Gerardo Prieto y de la profesora Dra. Dña. Ana R. Delgado.

Dr. D. Gerardo Prieto Dra. Dña. Ana R. Delgado Directores

Fdo. Dña. Sónia dos Reis Quintão Doutoranda 
"Puedo tener defectos, vivir ansioso y enojado a veces, pero no me olvido de que mi vida es la mayor compañía del mundo. Y yo puedo impedir su quiebra.

Ser feliz es reconocer que vale la pena vivir la vida, a pesar de todos los desafíos. Ser feliz es no ser una víctima de las circunstancias y ser autor de su propia historia. Es cruzar desiertos fuera de ti mismo, pero ser capaz de encontrar un oasis escondido en el alma. Es dar gracias a Dios cada mañana por el milagro de la vida. Ser feliz es no tener miedo de sus sentimientos. Es saber hablar de sí mismo. Es tener coraje para oír un "no". Es tener la seguridad para recibir una crítica, aunque sea injusta.

¿Rocas en el camino? Las guardo todas, un día voy a construir un castillo con ellas...."

Incógnito 
A mi querida hija Joana

A Fernando

A mi madre 


\section{Agradecimientos y Reconocimientos}

Este trabajo sólo fue posible gracias a la ayuda de algunas personas, a quienes quiero expresar mi más sincero y profundo reconocimiento:

Quiero agradecer en primer lugar a los directores de mi tesis, Dr. Don Gerardo Prieto y Dra. Doña Ana Rosa Delgado, por toda la sabiduría, la presencia y el apoyo que me han aportado en este largo viaje. Gracias por el constante estímulo y la reconocida competencia con que han guiado mi trabajo.

Al Profesor Dr. Ricardo Gusmão por los incentivos que, sobre todo en el periodo final, me ha dado, incentivándome a alcanzar mis objetivos. Gracias por su ayuda en la búsqueda de algunos artículos, y gracias por el "Despacha-te!".

A mis compañeros Paulo Lopes y Joana Rosa, por el incentivo dado para completar la tesis y por la compañía en los largos viajes a Salamanca.

A mi familia, que ha sido privada de mí muchas veces y que ha hecho gala de paciencia en espera de mejores días.

A Fernando por hacerme creer que soy especial. Es bueno sentir que es así a tus ojos...

A mi madre, que siempre tuvo un gran orgullo en mí.

Y a ti, hija, por quien soy capaz de mover montañas...

Por último, a todos los que han formado parte de la muestra, porque sin su contribución este trabajo habría sido más difícil. 


\section{Resumen}

Los trastornos emocionales, como la ansiedad, son frecuentes y revisten una gran importancia, dada su injerencia en el funcionamiento psicosocial. El estudio de los factores relacionados con la ansiedad ha demostrado que hay un número importante de variables que influyen en la determinación de su origen, desarrollo, mantenimiento y modificación. Sin embargo, se necesitan instrumentos adecuados para realizar investigaciones creíbles. Por lo tanto, la validación de una de las escalas de ansiedad más utilizadas a nivel internacional es de suma importancia. Así, el objetivo de esta investigación fue llevar a cabo un estudio de validación del Inventario de Ansiedad de Beck (BAI, acrónimo inglés, que emplearemos a lo largo de este trabajo por hallarse muy extendido) en Portugal. Se ha analizado el BAI con el Modelo de Escalas de Clasificación con el fin de evaluar su calidad psicométrica, para lo cual se han puesto a prueba las categorías de respuesta y se han estimado los parámetros del modelo, su precisión, el grado de ajuste de los datos, la unidimensionalidad y la ausencia de funcionamiento diferencial de los Ítems. Se han comparado asimismo las puntuaciones del BAI con las de otros marcadores de la ansiedad empleados en Portugal. La muestra se compone de 1160 adultos de ambos géneros (427 hombres y 733 mujeres), con edades comprendidas entre 18 y 82 años (edad media de 33,39 años [DE = 11.85]). Se utilizó un cuestionario demográfico diseñado para esta investigación, con preguntas sobre género, edad, lugar de residencia, origen étnico, nivel educativo, religión, estado civil, número de hijos y ocupación. Los instrumentos de medida de la ansiedad empleados fueron: Inventario de ansiedad de Beck (BAI; Beck, Brown, Epstein, \& Steer; 1988); Inventario de Ansiedad Rasgo-Estado (STAI rasgo, STAI estado; Spielberger, Gorsuch, \& Lushene, 1970); Escala de Ansiedad de Zung (Zung, 1971); e Índice de Sensibilidad a la Ansiedad (ASI; Peterson \& Reiss, 1987).

En relación al BAI, los resultados indican que su sistema de cuatro categorías es adecuado; que la fiabilidad de los ítems es muy alta; que el ajuste de las personas al modelo es 
razonable; que la fiabilidad global de las personas no es excelente, aunque resulta adecuada, presentando un valor similar al $\alpha$ de Cronbach de la teoría clásica de .79. Los resultados muestran igualmente que el nivel de ansiedad de los sujetos analizados es muy bajo y que la mayor parte de las personas se encuentran por debajo del rango de la variable en la que los ítems se sitúan, lo que indica que hay dificultad en permitir medir con alta precisión a las personas con niveles bajos de ansiedad. Los análisis indican asimismo que la medida puede tratarse como unidimensional. El género y la edad no se presentan como amenazas a la validez del BAI. En cuanto al impacto, los participantes varones y aquellos que tienen más de 30 años obtienen menores puntuaciones en el BAI, lo que corrobora la literatura científica sobre el tema. En lo que respecta a la validez convergente, correlaciona significativamente con todas las medidas de ansiedad utilizadas y con la medida de la sensibilidad a la ansiedad.

El resto de las escalas utilizadas muestra resultados similares al BAI, pero es éste el que tiene un menor desajuste de los ítems y un menor porcentaje de personas muy desajustadas, así como el que más se adecúa a una estructura unidimensional, junto con el ASI. Las medidas menos afectadas por el Funcionamiento Diferencial de los Items (DIF, acrónimo inglés, que emplearemos a lo largo de este trabajo por hallarse muy extendido) asociado al género han sido el BAI, el STAI Estado y el STAI Rasgo. En relación a la edad, las escalas con menor DIF son el Inventario de Ansiedad de Beck, la Escala de Ansiedad de Zung y el índice de sensibilidad a la ansiedad.

Se concluye que el BAl ofrece medidas de calidad psicométrica igual, y en algunos casos mejor, que el resto de las escalas de ansiedad utilizadas en la población portuguesa. 


\section{Abstract}

Emotional disorders such as anxiety are frequent and are of great importance because of its interference with psychosocial functioning. The study of anxiety-related factors has shown that there are a large number of variables that affect its origin, development, maintenance and alteration. However, appropriate instruments are needed for credible research. Therefore, the validation of one of the most widely used anxiety scale at the international level is of paramount importance. Thus, the purpose of this research was to conduct a validation study of the Beck Anxiety Inventory (BAI) in Portugal. BAI has been analyzed with the rating scale model to evaluate their psychometric quality, for which we have tested the response categories and estimated the parameters of the model, its precision, the degree of data-model fit, the unidimensionality and the absence of differential item functioning. We compared BAI scores with those of other evaluation instruments of anxiety used in Portugal. The sample consists of 1160 adults of both genders (427 men and 733 women) aged 18-82 years (mean age 33.39 years $[S D=11.85]$ ). We used a demographic questionnaire designed for this research, with questions about gender, age, place of residence, ethnicity, educational level, religion, marital status, number of children and occupation. The instruments for measuring anxiety were: Beck Anxiety Inventory (BAI, Beck, Brown, Epstein, \& Steer, 1988) Trait-State Anxiety Inventory (STAI trait, STAI state, Spielberger, Gorsuch, \& Lushene, 1970), Zung Anxiety Scale (Zung, 1971), and Anxiety Sensitivity Index (ASI, Peterson \& Reiss, 1987).

Concerning the BAI, the results indicate that its system of four categories is appropriate; that the reliability of the items is very high; that data-model fit is reasonable; that the overall reliability of the people is not excellent, although is adequate, with a value similar to Cronbach's alpha of .79. The results also show that the subjects anxiety level is very low and that most people are below the range of the variable in which the items are located, indicating that it is not designed to measure with high precision people with low levels of anxiety. The analyses also indicate that the measure can be treated as unidimensional. 
Gender and age-related DIF are not threats to the validity of the BAI. In terms of impact, male participants and those older than 30 obtained lower BAI scores, which corroborates the literature on the matter. With respect to convergent validity, BAI correlates significantly with all the anxiety measures and with anxiety sensitivity.

The remaining scales showed similar results to the $\mathrm{BAI}$, but it is BAI the one with the lowest item misfit and percentage of very misfit persons, as well as the most suited to onedimensional structure, together with the ASI. Gender-related differential item functioning (DIF) did hardly affect the BAI, the STAI State and STAI Trait . In relation to age, the scales with less FDI were Beck Anxiety Inventory, Zung Anxiety Scale and Anxiety Sensitivity Scale. We conclude that BAI provides measures of good psychometric quality, as good or even better, in some cases, than the rest of the anxiety scales used for the Portuguese population. 


\section{Abreviaturas}

5-HTT - Gen transportador de serotonina

ACE - Grupo de la evaluación, clasificación y epidemiología de la Organización Mundial de la Salud

APA - American Psychiatric Association

ASI - Índice de Sensibilidad a la Ansiedad

AVP - Arginina vasopresina

BAI - Inventario de Ansiedad de Beck

BDI - Beck Depression Inventory

BIS - Sistema de Inhibición Conductual

BNST - Núcleo de la estría terminal

BZD - Benzodiazepinas

CeA - Núcleo amigdaloide central

CRF - Factor liberador de corticotropina

$\mathrm{CRH}$ - Hormona de liberación de corticotrofina

DASS - Escala de depresión, ansiedad y estrés

Di - Localización del ítem

DIF - Funcionamiento diferencial de los ítems

DRN - Núcleo dorsal del rafe

EEG - Electroencefalograma

EMAS - Escala Multidimensional de la Ansiedad de Endler

ERP - Potencial relacionado al evento

Fk - Puntos de transición

fMRI - Imágenes de resonancia magnética funcional

GABA - Ácido gamma-aminobutírico

GABAARs - Receptores A de ácido gamma-aminobutírico 
GABACRs - Receptores $\mathrm{C}$ de ácido gamma-aminobutírico

GAD - Trastorno de ansiedad generalizada

HADS - Escala hospitalaria de ansiedad y depresión

HAS - Escala de ansiedad de Hamilton

HPA - Hipotálamo-pituitaria-adrenal

HSM - Harvard School of Medicine

ICD - Clasificación internacional de enfermedades

ID - Identificación del participante

LA - Núcleo lateral de la amígdala

LC - Locus coeruleus

MeA - Núcleo amigdaloide medial

MEC - Cuestiones de elección múltiple

MGP - Materia gris periacueductal

NE - Orientación norepinefrina

NET - Núcleo de la estría terminal

PAQ - Cuestionario de Ataque de Pánico

SA - Sensibilidad a la ansiedad

SAD - Trastorno de ansiedad social

SCL-90-R - Symptom Checklist

SE - Error típico de medida de los ítems

SPSS - Statistical Package for the Social Sciences

STAI - Inventario de Ansiedad de Rasgo-Estado

WHO - Organización Mundial de la Salud

WMHC - World Mental Health Consortium 


\section{Índice}

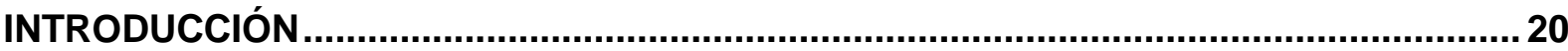

CAPÍTULO I ANSIEDAD: DESCRIPCIÓN Y CLASIFICACIÓN ..........................................24

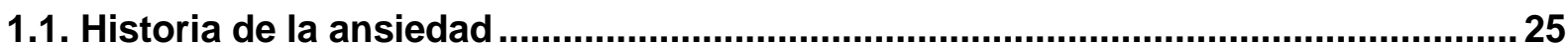

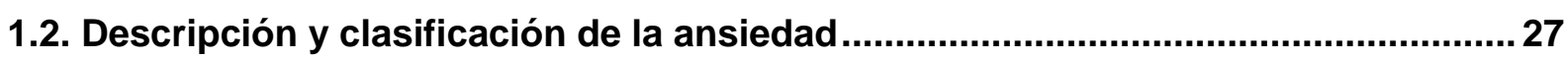

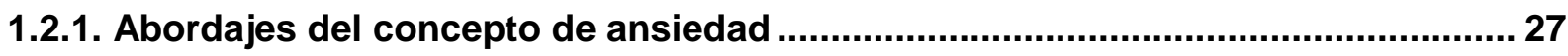

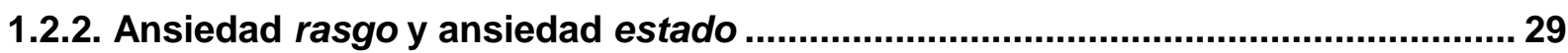

1.2.3. Distinción entre miedo y ansiedad .......................................................................... 31

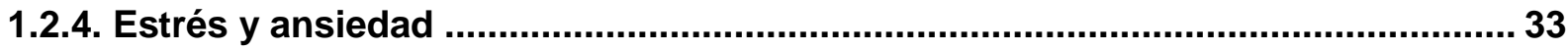

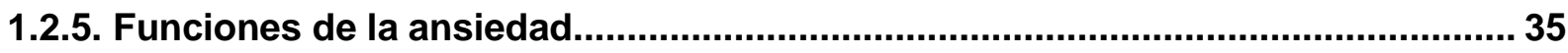

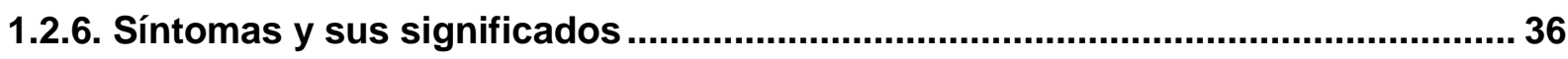

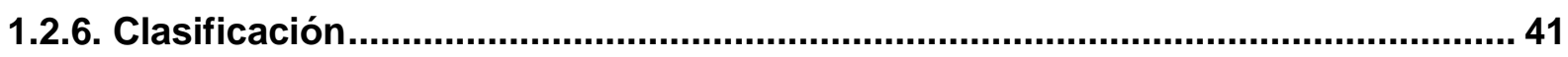

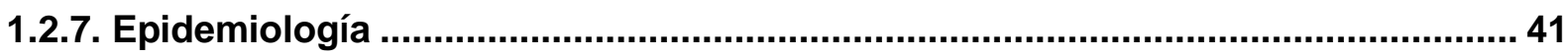

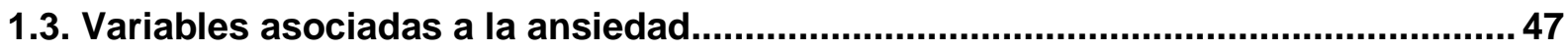

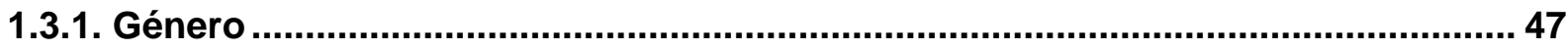

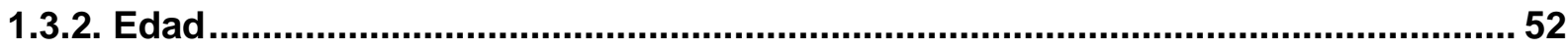

CAPÍTULO II MODELOS EXPLICATIVOS DE LA ANSIEDAD ..........................................55

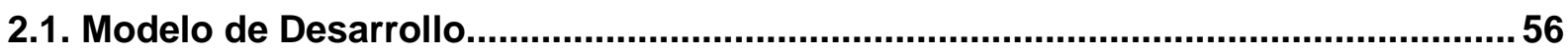

2.2. Modelo Cognitivo Comportamental .....................................................................59

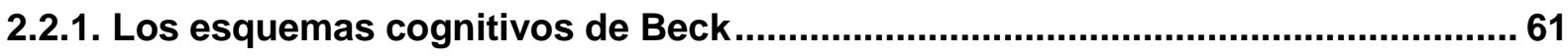

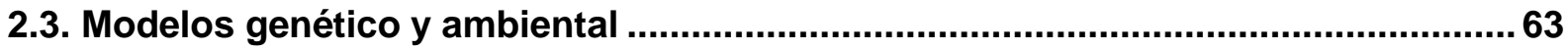

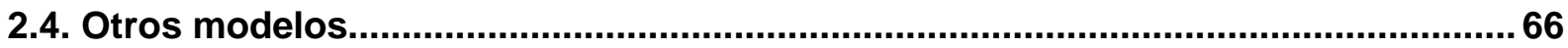

2.4.1. Modelo rasgo-estado de Spielberger.................................................................... 66

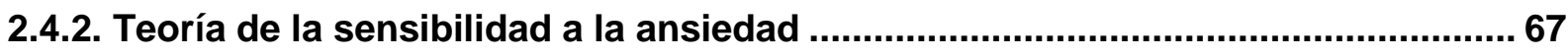

2.4.3. Modelo tripartito de la ansiedad y depresión........................................................ 70

CAPÍTULO III NEUROPSICOLOGÍA DE LA ANSIEDAD.................................................74

3.1. Modelos precursores de los modelos neuropsicológicos actuales.........................75 
3.1.1. Los introvertidos neuróticos de Eysenck. ............................................................. 75

3.1.2. La inhibición comportamental de Gray. ................................................................... 76

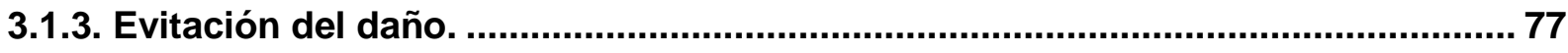

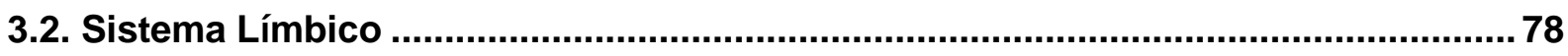

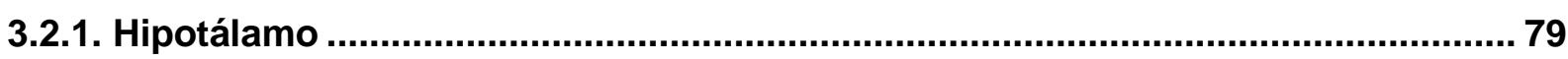

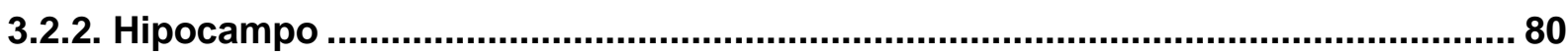

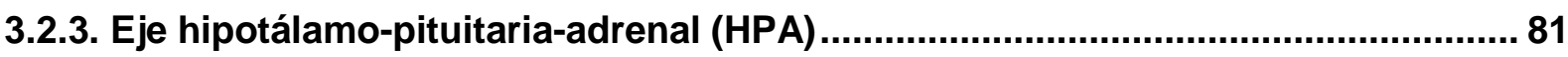

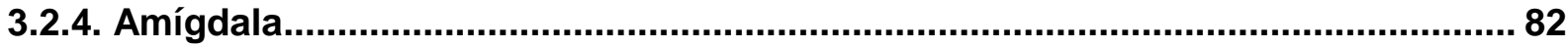

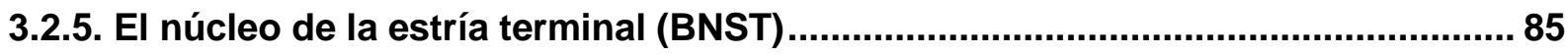

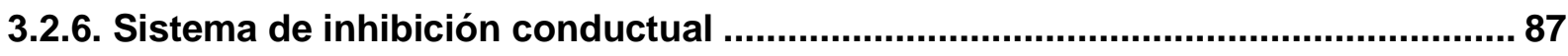

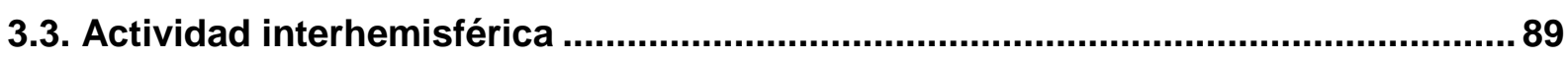

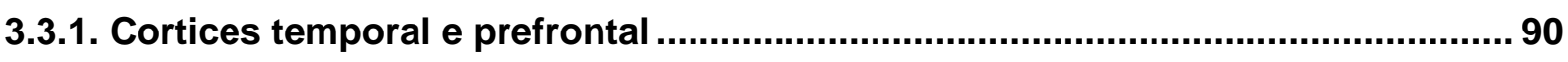

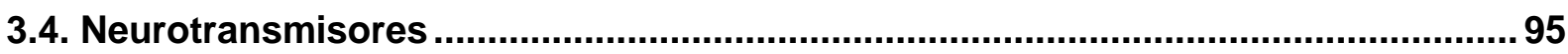

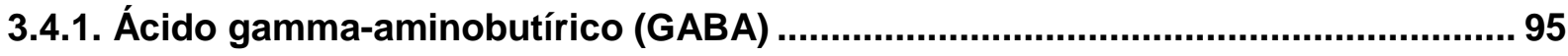

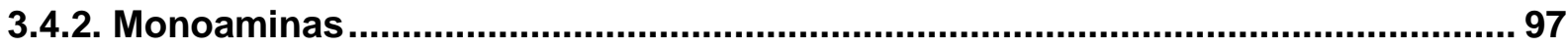

3.5. Diferencias neuronales entre géneros ............................................................... 101

CAPÍTULO IV INSTRUMENTOS Y ESCALAS OBJETIVAS DE MEDICIÓN DE LA

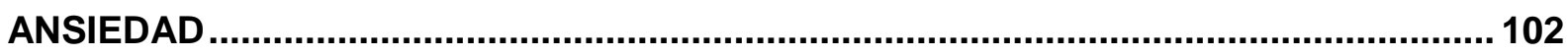

4.1. Inventario de ansiedad de Beck (BAI) ................................................................ 105

4.2. Inventario de ansiedad Rasgo-Estado (STAI) ....................................................113

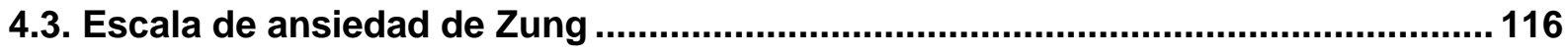

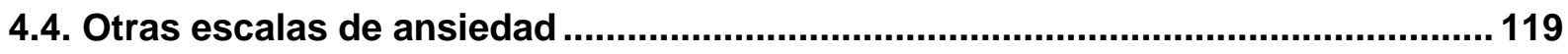

4.4.1. Escala de depresión, ansiedad y estrés (DASS) ......................................... 119

4.4.2. Sub-escala de ansiedad del Symptom Checklist (SCL-90-R)........................... 122

4.4.3. Escala de ansiedad de Hamilton (HAS). ..................................................... 123

4.4.4. Escala de ansiedad manifesta de Taylor ...................................................... 124

4.4.5. Escala hospitalaria de ansiedad y depresión (HADS) .......................................... 124 
4.4.6. Escala multidimensional de la ansiedad de Endler (EMAS) .............................. 126

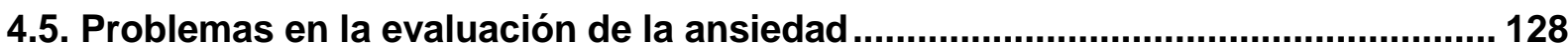

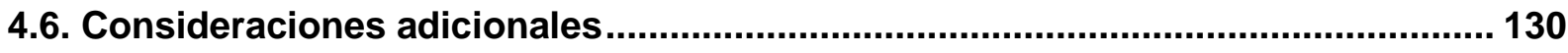

CAPÍTULO V EL MODELO DE RASCH Y EL MODELO DE ESCALAS DE

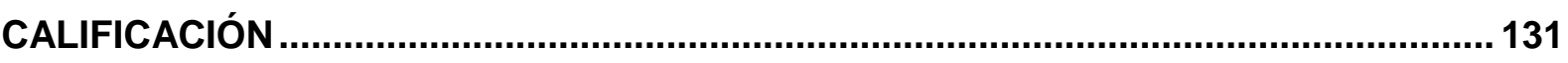

CAPÍTULO VI OBJETIVOS......................................................................................... 136

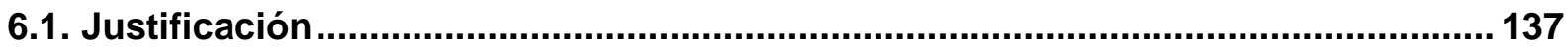

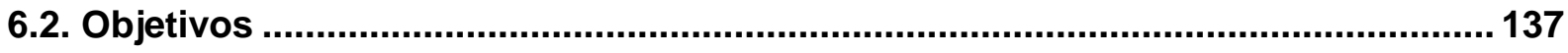

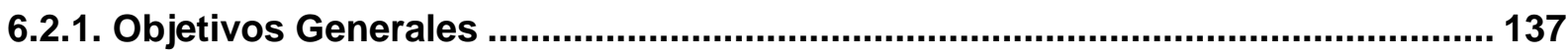

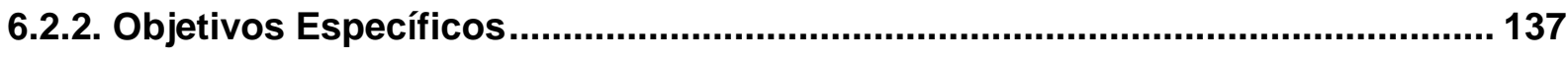

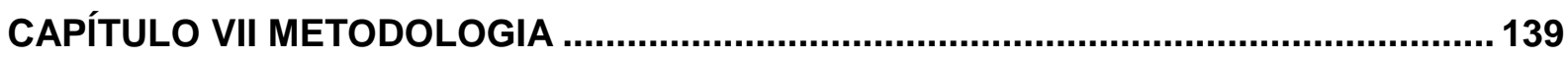

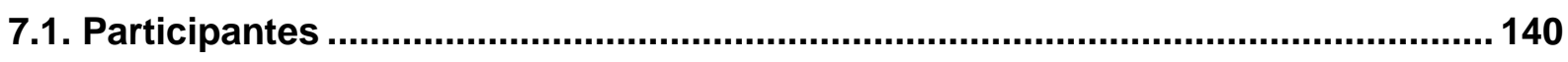

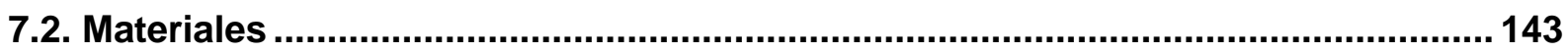

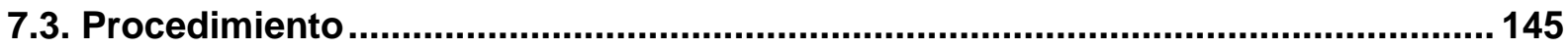

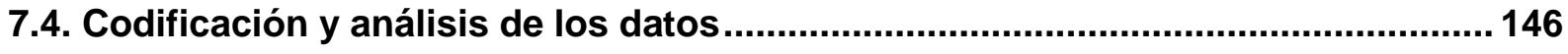

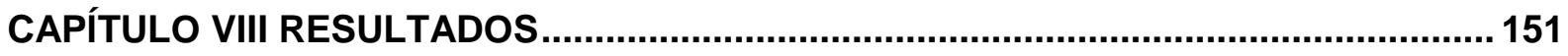

8.1. Análisis de las medidas utilizadas mediante el Modelo de Rasch ........................152

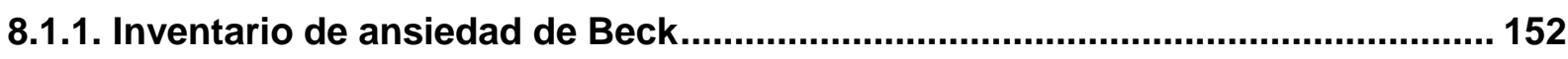

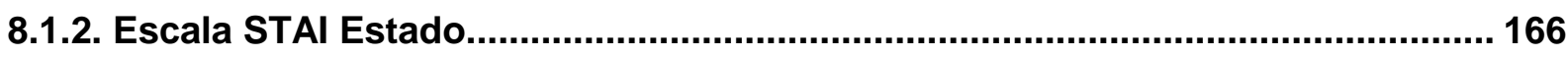

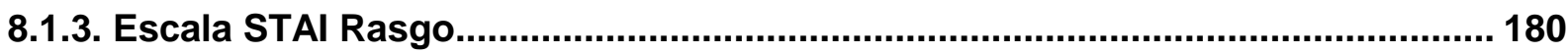

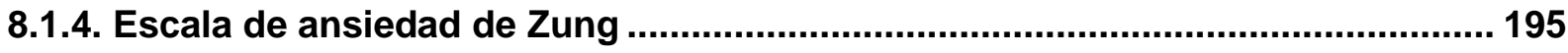

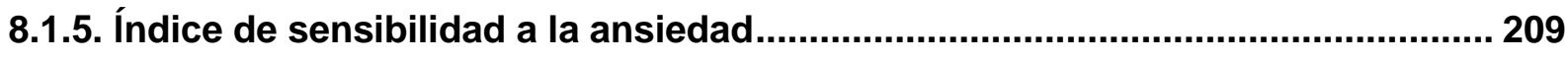

8.2. Correlaciones con las puntuaciones del Modelo de Rasch ............................... 223

8.3. Análisis de Varianza Factorial con las puntuaciones del Modelo de Rasch......... 225

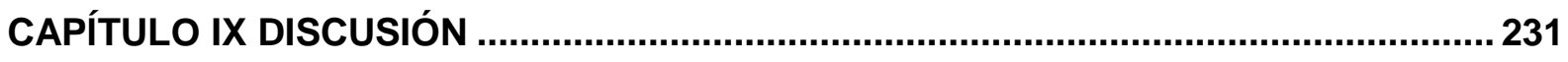

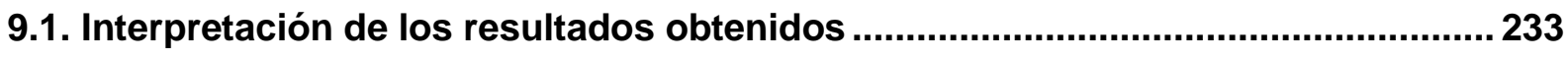


9.1.1. Análisis del Inventario de ansiedad de Beck con el modelo de las escalas de calificación

9.1.2. Comparación de las puntuaciones del BAI con las de otros marcadores de la ansiedad empleados en Portugal: STAI Estado, STAI Rasgo, Zung y ASI. 236

9.2. Limitaciones de la investigación y sugerencias para futuros estudios 240

9.3. Principales contribuciones de la investigación 242

REFERENCIAS BIBLIOGRÁFICAS

APÉNDICES 285

Apêndice I - Cuestionario de Evaluación 286

ANEXOS 292

Anexo I - Autorización para validar el inventario de ansiedad de Beck para Portugal293 


\section{Índice de Tablas}

Tabla 1. Síntomas Cognitivos del trastorno de ansiedad ............................................... 37

Tabla 2. Adjetivos afectivos típicos del desorden de la ansiedad ..................................... 38

Tabla 3. Síntomas Conductuales del trastorno de la ansiedad........................................ 39

Tabla 4. Síntomas Fisiológicos del trastorno de la ansiedad .......................................... 40

Tabla 5. Prevalencia de los trastornos de ansiedad en América y Europa .......................... 42

Tabla 6. Prevalencia de los trastornos de ansiedad en Europa por edad .......................... 43

Tabla 7. Prevalencia de los trastornos de ansiedad en Portugal .................................... 46

Tabla 8. Puntos de corte del BAI por diagnóstico.......................................................... 109

Tabla 9. Sensibilidad y especificidad de los puntos de corte para cada diagnóstico por

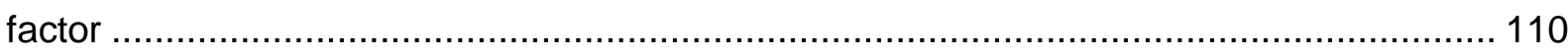

Tabla 10. Porcentaje de ítems del total en cada tipo de síntomas de la ansiedad............. 130

Tabla 11. Características demográficas por género .................................................. 140

Tabla 12. Estadísticos correspondientes a las categorías del BAI ................................. 152

Tabla 13. Características psicométricas de los ítems del BAI ........................................ 154

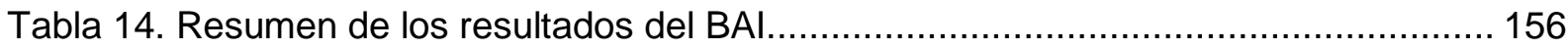

Tabla 15. Representación conjunta de personas e ítems del BAI ................................. 158

Tabla 16. Funcionamiento diferencial de los ítems asociado al sexo para el BAI.............. 160

Tabla 17. Funcionamiento Diferencial de los Ítems asociado a la edad para el BAI .......... 162

Tabla 18. Correspondencia entre las puntuaciones clásicas y los valores Rasch para el

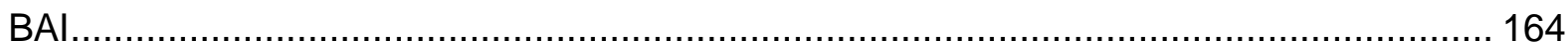

Tabla 19. Estadísticos correspondientes a las categorías del STAI Estado ...................... 166

Tabla 20. Características psicométricas de los ítems del STAI Estado .............................. 168

Tabla 21. Resumen de los resultados del STAI- Estado ........................................... 170

Tabla 22. Representación conjunta de personas e ítems del STAI Estado ....................... 172

Tabla 23. Funcionamiento Diferencial de los Ítems asociado al sexo para el STAI Estado 174 
Tabla 24. Funcionamiento Diferencial de los Ítems asociado a la edad para el STAI

Estado 176

Tabla 25. Correspondencia entre las puntuaciones clásicas y los valores Rasch para el STAI

Estado 178

Tabla 26. Estadísticos correspondientes a las categorías 180

Tabla 27. Características psicométricas de los ítems del STAI Rasgo 182

Tabla 28. Resumen de los resultados del STAI Rasgo 184

Tabla 29. Representación conjunta de personas e ítems del STAI Rasgo 186

Tabla 30. Funcionamiento Diferencial de los Ítems asociado al sexo para el STAI Rasgo. 188

Tabla 31. Funcionamiento Diferencial de los Ítems asociado a la edad para el STAI

Rasgo

Tabla 32. Correspondencia entre las puntuaciones clásicas y los valores Rasch para el STAI Rasgo 192

Tabla 33. Estadísticos correspondientes a las categorías de la Zung ..... 195

Tabla 34. Características psicométricas de los ítems de la Zung 197

Tabla 35. Resumen de los resultados de la Zung 199

Tabla 36. Representación conjunta de personas e ítems de la Zung 201

Tabla 37. Funcionamiento Diferencial de los Ítems asociado al sexo para la Zung. 203

Tabla 38. Funcionamiento Diferencial de los Ítems asociado a la edad para la Zung..... 205

Tabla 39. Correspondencia entre las puntuaciones clásicas y los valores Rasch para la

Zung 207

Tabla 40. Estadísticos correspondientes a las categorías del ASI 209

Tabla 41. Características psicométricas de los ítems del ASI

Tabla 42. Resumen de los resultados del ASI.

Tabla 43. Representación conjunta de personas e ítems del ASI

Tabla 44. Funcionamiento Diferencial de los Ítems asociado al sexo para el ASI. 216

Tabla 45. Funcionamiento Diferencial de los Ítems asociado a la edad para el ASI 218 
Tabla 46. Correspondencia entre las puntuaciones clásicas y los valores Rasch para el ASI........... 220

Tabla 47 - Correlaciones entre las puntuaciones Rasch de cada escala .......................... 223

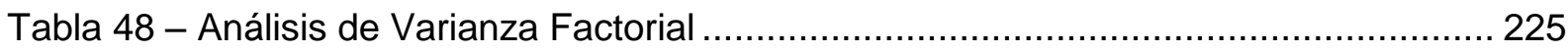

Tabla 49 - Análisis de Varianza Factorial por Sexo - puntuaciones Rasch ...................... 226

Tabla 50 - Análisis de Varianza Factorial por grupos de edad - puntuaciones Rasch....... 227

Tabla 51 - Análisis de Varianza Factorial por sexo - puntuaciones directas .................... 228

Tabla 52 - Análisis de Varianza Factorial por grupos de edad - puntuaciones directas .... 229

Tabla 53. Correlaciones con la edad (puntuaciones Rasch) ......................................... 230 


\section{Índice de Figuras}

Figura 1 - Patrón de la ansiedad en términos de edad 54

Figura 2. Representación gráfica de las curvas características de las categorías del BAI . 153 Figura 3 - Diferencias entre los parámetros de localización de los ítems del BAl de los varones y las mujeres. 161

Figura 4 - Diferencias entre edades para el total del BAI 163

Figura 5. Representación gráfica de las curvas características de las categorías de la escala STAI Estado 167

Figura 6 - Diferencias entre los parámetros de localización de los ítems entre los géneros 175 Figura 7 - Diferencias entre los parámetros de localización de los ítems entre los grupos de diferente edad de la prueba STAI-Estado 177

Figura 8. Representación gráfica de las curvas características de las categorías de la escala STAI Rasgo

Figura 9 - Diferencias de los parámetros de localización de los ítems entre géneros para el STAI Rasgo 189

Figura 10 - Diferencias entre los parámetros de localización de los ítems entre los grupos de diferente edad de la prueba STAI Rasgo 191

Figura 11. Representación gráfica de las curvas características de las categorías de la escala Zung 196

Figura 12 - Diferencias de los parámetros de localización de los ítems entre los géneros 204 Figura 13 - Diferencias de los parámetros de localización de los ítems entre grupos de edad para la Zung 206

Figura 14. Representación gráfica de las curvas características de las categorías del ASI 210 Figura 15 - Diferencias entre los parámetros de los ítems entre los géneros para el ASI.. 217 Figura 16 - Diferencias entre los parámetros de localización de los ítems de los grupos de edad para el ASI 
INTRODUCCIÓN 
El concepto de ansiedad es central en la conceptualización en psicopatología, motivación y personalidad (Alansari, 2006). Su evaluación es un tema de la máxima transcendencia en el ámbito clínico, debido a la gran prevalencia de los trastornos a los que se asocia : miedos, fobias, ataques de pánico, depresión, anorexia, bulimia, obsesiones y compulsiones, problemas sexuales, etc.... Los trastornos de la ansiedad son muy frecuentes en todo el mundo (Alonso et al., 2004; Andlin-Sobocki \& Wittchen, 2005; Apóstolo, Ventura, Caetano, \& Costa, 2008; Balestrieri, Isola, Quartaroli, Roncolato, \& Bellantuono, 2010; Rodrigo, Welgama, Gurusinghe, Wijeratne, Jayananda, \& Rajapakse, 2010; World Health Organization, 2000), por lo que no es de extrañar que la práctica totalidad de los instrumentos de evaluación hayan sido desarrollados por clínicos, para clínicos y desde un ámbito exclusivamente clínico. Por otra parte, la medida de la ansiedad se ha llevado a cabo de manera paralela al desarrollo teórico de este constructo y de acuerdo a los modelos explicativos del mismo (Pérez \& Lago, 2000).

Las características psicométricas del Inventario de Ansiedad de Beck (BAI, acrónimo inglés, que emplearemos a lo largo de este trabajo por hallarse muy extendido) en poblaciones no portuguesas han sido adecuadas, con consistencia interna y fiabilidad testretest elevadas. Permite, además, discriminar los grupos diagnosticados como ansiosos (transtornos de pánico, ansiedad generalizada, etc.) de los grupos diagnosticados como no ansiosos (depresión mayor, depresión atípica, etc.).

Dada la complejidad de las interacciones entre los factores relacionados con la evaluación de los trastornos de ansiedad y por no haber una validación del inventario para Portugal, el objetivo general de esta investigación es la evaluación del Inventario de Ansiedad de Beck, con el fin de evaluar su adecuación, validez y fiabilidad.

La parte teórica de este trabajo está compuesta por tres capítulos, el primero de ellos sobre el constructo ansiedad, su descripción y clasificación. En este capítulo, se tratan los aspectos históricos y se describen y clasifican los tipos de ansiedad, teniendo en cuenta los 
diversos abordajes del concepto, las distinciones entre la ansiedad rasgo y la ansiedad estado, y entre el miedo y la ansiedad, se describen las principales funciones de la ansiedad, los síntomas asociados a ellas y sus significados y un análisis de la prevalencia de los trastornos de ansiedad en Portugal, Europa y el resto del mundo. Este capítulo concluye con una descripción de variables cuya asociación con la ansiedad es conocida, como son el sexo, la edad y el estrés.

En el capítulo II, se abordan los modelos explicativos de la ansiedad. Se describen los modelos de desarrollo, el modelo cognitivo-conductual, los modelos biológicos, los modelos genéticos y ambientales, entre otros.

Debido al contexto en el que se integra esta tesis doctoral y al auge actual de la investigación de orientación neuropsicológica, se ha dedicado el capítulo III a la neuropsicología de la ansiedad, analizando el papel del sistema límbico y sus diferentes áreas, la actividad interhemisférica, los neurotransmisores y las diferencias neuronales entre géneros.

Dado que el objetivo principal de esta tesis es evaluar las propiedades psicométricas del BAI, para lo cual se requiere el uso de otras escalas, en el capítulo IV se presentan y describen diversas escalas de ansiedad, además del BAI: el Inventario de Ansiedad de Rasgo-Estado (STAI), la Escala de Ansiedad de Zung y otras escalas no usadas en la parte empírica de esta tesis pero que son también ampliamente usadas (Escala de Depresión, Ansiedad y Estrés, Subescala de la Ansiedad del Symptom Checklist, Escala de ansiedad de Hamilton, Escala de Ansiedad Manifiesta de Taylor, Escala Hospitalaria de Ansiedad y Depresión y la Escala Multidimensional de la Ansiedad de Endler). Este capítulo presenta finalmente algunos problemas subyacentes a la evaluación de la ansiedad y se tejen algunas consideraciones adicionales acerca de las escalas.

El capítulo $\mathrm{V}$ presenta y describe el modelo de Rasch y el modelo de escalas de calificación y los objetivos generales y específicos se encuentran en el Capítulo VI. 
La metodología utilizada está presente en el Capítulo VII, que describe los participantes en términos de características sociodemográficas, los materiales utilizados, el procedimiento realizado para la realización del estudio, y la codificación y análisis de los datos.

Mediante el modelo de Rasch, se ha puesto a prueba la calidad psicométrica de las categorías de respuesta, el ajuste de los ítems y de las personas, se han estimado los parámetros y evaluado la unidimensionalidad y la fiabilidad de las diversas escalas. En el capítulo VIII se presentan los resultados de estos análisis, así como las representaciones gráficas conjuntas de personas e ítems y los resultados del análisis del DIF asociado al sexo y a dos grupos de edad clásicos en la investigación evolutiva de la personalidad. Posteriormente se presentan las correlaciones entre las diferentes escalas de ansiedad con las puntuaciones Rasch. Por último, se muestran los resultados del análisis de varianza de las puntuaciones Rasch con el sexo y los grupos de edad como variables independientes.

En el capítulo IX, correspondiente a la discusión, los resultados se interpretan de acuerdo a la literatura en términos de modelos teóricos que fueron la base de esta investigación y de los resultados de estudios empíricos previos. También se presentan en este capítulo las limitaciones del trabajo, así como sugerencias para futuros estudios en este ámbito. Al final del capítulo se analizan las implicaciones de estos resultados para la teoría y la práctica clínica, especialmente en lo que concierne a la elección de las medidas de la ansiedad que resulta recomendable para futuras investigaciones.

A lo largo del trabajo, se ha optado por emplear los acrónimos en inglés ya que su uso se encuentra muy extendido. 
CAPÍTULO I

ANSIEDAD: DESCRIPCIÓN Y CLASIFICACIÓN 


\subsection{Historia de la ansiedad}

El ambiente en que los humanos, y en consecuencia la mente humana, se han desarrollado ha sido muy diferente al actual. El noventa y nueve por ciento de nuestra existencia ha transcurrido en sociedades de cazadores y recolectores, durante varios millones de años, antes de la aparición de la agricultura, hace cerca de diez mil años. Según las teorías evolucionistas, es en este contexto donde deberían buscarse las respuestas sobre el funcionamiento psicológico humano. El mundo que actualmente nos es familiar no está en el origen de nuestras respuestas automáticas, rápidas y sin esfuerzo, como las de la ansiedad. Así se comprende que se muestre ansiedad en situaciones que no son verdaderos peligros para nuestra sociedad y que no se muestre en otras que sólo ahora representan peligro, pues antes no existían (Baptista, 2000).

Desde la antigüedad, varios autores se habían referido a la ansiedad, pero anteriormente a Freud (1936), se trataba de filósofos preocupados por conflictos y crisis existenciales de los seres humanos. Freud (1936) puso en evidencia el papel de la ansiedad en la comprensión de los trastornos emocionales y psicológicos (May, 1980).

Freud (1936) consideraba la ansiedad como un estadio o condición emocional desagradable, incluyendo componentes fisiológicas y comportamentales, acompañadas por descargas motoras, consiguientes a una situación de peligro. Además, por su relación con la expectativa, la caracterizó como ansiedad por algo. Su desarrollo se daría siempre que la psique fuera asaltada por estímulos, externos o internos, que dificultaran o impidieran su dominio o descarga. A lo largo de su desarrollo, el ego adquiría la capacidad de producir ansiedad siempre que surgiera una situación de peligro y, más tarde, en anticipación al peligro.

Posteriormente, distintos autores han procedido a la clarificación conceptual del constructo, desde distintas perspectivas (Pérez \& Lago, 2000). 
Las teorías comportamentales sugieren que la ansiedad es una respuesta condicionada a estímulos ambientales específicos (Kaplan \& Sadock, 1993).

De acuerdo con Skinner (1938), las emociones serían productos del control externo y de las ideas modeladas por controles ambientales y, en ese contexto, el miedo y la ansiedad serían formas de defensa del organismo contra la amenaza del peligro. Entretanto, al tiempo que el miedo siempre se instalaría ante una amenaza concreta, la ansiedad sería un estado emocional motivado por un estímulo amenazador anticipado (Rodrigues, 1976).

En el proceso de desarrollo se ha utilizado el mismo término para designar cosas distintas, e incluso aspectos diferentes de lo mismo. Por una parte, se utilizó para describir reacciones fisiológicas transitorias y, por otra, para designar rasgos disposicionales de los individuos. Con el tiempo se ha pasado a considerar la ansiedad como un patrón conductual complejo, que incluye aspectos fisiológicos, cognitivos y instrumentales (American Psychiatric Association [APA], 2002).

En la actualidad, caben dos posturas bien diferenciadas: una considera toda la secuencia emoción-cognición-acción como comportamiento ansioso y otra considera como ansiedad exclusivamente los elementos neurovegetativos de respuesta al estímulo. Esta disparidad de criterios ha dado lugar a distintos instrumentos y estrategias de evaluación de la ansiedad (Pérez \& Lago, 2000). 


\subsection{Descripción y clasificación de la ansiedad}

Etimológicamente el término ansiedad procede del latín angor, que hace referencia a una sensación de angostura, estrechez y opresión. Su raíz griega quiere decir estrangular. En ambos casos se mantiene la idea de opresión. Algunas lenguas disponen de dos vocablos diferentes: en inglés, anguish y anxiety; en francés, angoisse y ansiété. Sin embargo, otras, como el alemán, disponen de un único término para ambas: angst. En medicina, con frecuencia se emplean indistintamente los términos angustia y ansiedad, como si fueran sinónimos (APA, 2002).

Los transtornos de la ansiedad son la clase más frecuente de psicopatología (Kessler, Chiu, Demler, \& Walters, 2005). Con frecuencia estos problemas afectan negativamente a varios aspectos de la vida, tienden a cronificarse, siguen un curso fluctuante y están asociados a tasas elevadas de trastornos psiquiátricos y uso de drogas, además de mostrar comorbilidad con problemas de salud física (Kessler, Chiu, Demler, \& Walters, 2005; Sareen, Cox, Clara, \& Asmundson, 2005).

\subsubsection{Abordajes del concepto de ansiedad}

No existe una definición universal de ansiedad. La ansiedad se refiere a un complejo y variado patrón de comportamientos que se producen como respuesta interna (cognitiva) o externa (al medio) a un estímulo y que puede aparecer en tres canales de respuesta. El primero es el canal subjetivo o instrospectivo; el segundo son patrones de activación somática o visceral, tal como el latido cardiaco acelerado, la respiración agitada, tensión muscular, etc. El tercer canal implica el motor somático del comportamiento, tal como temblar o tartamudear. El problema a la hora de definir la ansiedad es que, muchas veces, 
estos tres canales no correlacionan. Estos componentes observables dependen de una estructura de la memoria, el prototipo emocional, que guarda información a propósito de las situaciones desencadenantes, de su significado, de las respuestas posibles, y que controla el desarrollo y la modificación de la respuesta ansiosa a lo largo del tiempo (Baptista, 2000; Bernstein, 1981).

Aubrey Lewis (1979), después de una larga revisión sobre el origen y el significado de la palabra ansiedad, detalla las siguientes características:

1. Es un estado emocional que incluye la experiencia subjetiva de miedo u otra emoción relacionada, como terror, horror, alarma y pánico.

2. La emoción es desagradable, pudiendo ser una sensación de que la muerte o un colapso son inminentes.

3. Se orienta hacia el futuro. Aunque incluya la sensación de un peligro inminente, no hay un riesgo real o, si dicho riego existe, la emoción es desproporcionadamente intensa.

4. Hay incomodidad corporal durante el estado de ansiedad: sensación de opresión en el pecho, en la garganta, dificultad para respirar, debilidad en las piernas y otras sensaciones subjetivas.

Además, Lewis (1979) destaca que existen manifestaciones corporales involuntarias, como sequedad de la boca, sudores, escalofríos, temblor, vómitos, palpitaciones, dolores abdominales y otras alteraciones biológicas y bioquímicas detectables por métodos apropiados de investigación. Ese mismo autor enumera algunos otros atributos que pueden incluirse en la descripción de la ansiedad. La ansiedad puede:

1. Ser normal o patológica.

2. Ser leve o grave.

3. Ser perjudicial o beneficiosa.

4. Ser episódica o persistente.

5. Tener una causa física o psicológica.

6. Ocurrir sola o asociada. 
7. Afectar o no la a la percepción y a la memoria.

Para Peregrino (1996), la ansiedad es un estado emocional de incomodidad que básicamente consiste en tres condiciones: presentimiento de peligro inminente, actitud de espera en relación al peligro y desestructuración ante el peligro con sensación de estar desprotegido.

Según Carpenito (1997), la ansiedad es un estado que no se presenta con la misma intensidad en todos los pacientes, clasificándola en tres grados: ligera, moderada y grave.

De acuerdo con Andrade y Gorenstein (1998), la ansiedad es un estado emocional con componentes psicológicos y fisiológicos que forma parte del espectro normal de las experiencias humanas impulsando nuestro rendimiento. Pasa a ser patológica cuando es desproporcionada a la situación que la desencadena o cuando no existe un objeto específico al cual se direccione.

La ansiedad se caracteriza por emociones negativas que se hacen excesivas y persistentes. Las personas ansiosas usan más la supresión y tienen una mayor tendencia a juzgar sus emociones negativas como inaceptables (Campbell-Sills, Barlow, Brown, \& Hofmann, 2006).

\subsubsection{Ansiedad rasgo y ansiedad estado}

La ansiedad no es un constructo unitario, sino que está compuesto por varias dimensiones subyacentes a los diferentes aspectos de la vulnerabilidad del fenotipo (Smoller \& Tsuang, 1998). Es común, a partir de Freud (1924), distinguir entre ansiedad rasgo y ansiedad estado.

Ansiedad rasgo es una propensión estable a reaccionar con sentimientos subjetivos de tensión y aprensión, y aumentar la actividad autónoma del sistema nervioso (Spielberger, Gorsuch, \& Lushene, 1970). 
Existen básicamente dos teorías que explican la naturaleza de la ansiedad rasgo: neurofisiológica y cognitiva.

La teoría neurofisiológica pretende caracterizar la ansiedad rasgo en términos del funcionamiento del sistema nervioso central (Calvo \& Cano-Vindel, 1997). Defiende que la susceptibilidad en relación a la ansiedad depende del aumento de reactividad del sistema de inhibición comportamental, que consiste mayoritariamente en el sistema septohipocampal. Esta reactivad hace que los sujetos con ansiedad elevada sean especialmente sensibles a señales de castigo, por ejemplo (Gray \& McNaughton, 1996).

La teoría cognitiva de la ansiedad rasgo defiende que su naturaleza tiene que ver con qué estímulo se procesa preferentemente y cómo se interpreta (Eysenk, 1992; Eysenck, 1997; MacLeod, 1996; Williams, Watts, MacLeod \& Mathews, 1997).

La mayor asunción de esta teoría es que la función más importante de la ansiedad es facilitar la detección rápida de las señales de amenaza o impedir el peligro en ambientes potencialmente amenazadores (Eysenk, 1992).

Una ansiedad rasgo elevada puede caracterizarse como una hipervigilancia de la amenaza, una tendencia a atender selectivamente a los estímulos amenazadores y a interpretar los estímulos ambiguos como amenazadores (Lee \& Khight, 2009; Mathews \& MacLeod, 2005).

La teoría cognitiva de la ansiedad rasgo se basa, en su mayor parte, en la atención a fuentes externas de información (MacLeod, 1996). Pero Eysenck (1997) ha defendido que la atención y la tendencia interpretativa en la ansiedad rasgo también están relacionadas con las fuentes internas de información. Así, los individuos con más ansiedad rasgo prestan una atención preferencial a su propia actividad fisiológica, sus comportamientos y pensamientos, y tienden a percibirlos como peligrosos.

La ansiedad rasgo se refiere a la tendencia disposicional para experimentar la ansiedad estado (Clarke, MacLeod, \& Shirazee, 2008). 
La ansiedad estado es un patrón transitorio de emociones creadas por un ambiente estresante, incluyendo síntomas fisiológicos y de aprensión, preocupación y tensión (Spielberger, 1966; Clarke et al., 2008). Ha sido asociada con sistemas implicados en la detección y vigilancia de la amenaza en el mundo exterior (Gray, 1988), y representa el componente reactivo al ambiente (Spielberger, 1966).

\subsubsection{Distinción entre miedo y ansiedad}

A menudo las definiciones de miedo y ansiedad se confunden, pero hay ventajas obvias en usar dos términos distintos para designar dos fenómenos diferentes.

Para Beck y Emery (1995) el miedo implica una evaluación intelectual del estímulo amenazador y la ansiedad implica la respuesta emocional a esa evaluación.

Cuando una persona dice que tiene miedo de algo, generalmente se está refiriendo a un conjunto de circunstancias que no están presentes pero que pueden ocurrir en el futuro (el miedo está latente). Cuando una persona siente ansiedad experimenta una emoción desagradable caracterizada por sentimientos subjetivos desagradables, tales como tensión, y por síntomas fisiológicos tales como palpitaciones, temblor y náusea. El miedo se activa cuando una persona se expone, física o psicológicamente, al estímulo que considera amenazador; entonces la persona siente ansiedad. Junto a la ansiedad, puede provocarse una variedad de síntomas referentes al sistema nervioso autonómico y somático (Beck \& Emery, 1985).

Por otra parte, con el argumento de que existe el miedo y la ansiedad en los animales y que también para éstos los dos constructos son diferentes, la teoría de Gray y McNaughton (2000) usa una amplia variedad de datos de estudios con animales para suponer que las emociones de miedo y ansiedad son separables. Consideran el miedo y la ansiedad constructos separados, pero defienden que son sistemas cerebrales que se 
relacionan y que juntos permiten que el animal evite amenazas, ofreciéndole una posibilidad razonable de llevar a cabo los actos apetitivos necesarios para el sustento de vida.

Perkins, Kemp y Corr (2007) pusieron a prueba esta hipótesis en dos estudios con humanos. El primer estudio examinó asociaciones entre medidas de miedo, ansiedad, y neuroticismo. El análisis correlacional reveló que el miedo y la ansiedad no son intercambiables. El segundo estudio examinó asociaciones entre medidas de miedo/ansiedad y el rendimiento en una formación militar. El análisis de regresión reveló que el miedo presentó relaciones con el rendimiento que la ansiedad no presentó. Estos resultados implican que las hipótesis sacadas de datos de animales pueden sostener implicaciones importantes para entender la emoción humana y la motivación, sobre todo en relación al miedo y la ansiedad.

Rapee y Coplan (2010), en un estudio muy reciente, concluyen igualmente que es metodológicamente muy difícil comparar el temperamento miedoso con el trastorno de ansiedad debido a las diferencias en la conceptualización. Según estos autores, las diferencias son artefactos y se deben a la suposición de que el trastorno es temporal y categórico, mientras que el temperamento es estable y distribuido en forma continua. Así, las aparentes diferencias pueden reflejar simplemente las características diferentes de un mismo constructo subyacente. A pesar de estas dificultades teóricas y metodológicas y de una evidencia empírica limitada, la revisión de Rapee y Coplan, ha determinado una serie de indicaciones de que es útil distinguir el temperamento temeroso de los trastornos de ansiedad. Tal vez lo más convincente es la evidencia de que algunas personas pueden encontrar que obtienen puntuaciones altas en los tipos de temperamento miedoso, pero no cumplen los criterios de un trastorno de ansiedad. Igualmente convincente es que los datos, actualmente limitados, que sugieren que las intervenciones psicológicas tienen un efecto más fuerte sobre los trastornos de ansiedad que en los temperamentos miedosos.

Además, Rapee y Coplan añaden que el grado de solapamiento entre el temperamento de miedo y el trastorno de ansiedad parece diferir entre los trastornos 
específicos. El trastorno de pánico, el trastorno de ansiedad de separación y las fobias específicas parecen tener un número de características que los distinguen claramente del temperamento temeroso. Además, el trastorno de pánico por lo general tiene un comienzo claro, generalmente no aparece hasta la edad adulta temprana, y el trastorno de pánico y las fobias específicas parecen compartir poca variación genética con el neuroticismo. Por otra parte, distinguir el temperamento temeroso del trastorno de ansiedad generalizada (GAD, en inglés) y en especial del de ansiedad social (SAD, en inglés) es mucho más difícil. EI SAD, en particular, comparte muchas características con la conceptualización de la timidez o inhibición conductual y sus medidas están muy correlacionadas. El GAD y el SAD son trastornos muy estables que aparecen temprano en la vida y la coincidencia genética con el neuroticismo es alta. Por lo tanto, es posible que el SAD y el GAD puedan ser conceptualizados como equivalentes a las manifestaciones extremas de temperamento temeroso. Por otra parte, el trastorno de pánico, el trastorno de ansiedad de separación y las fobias específicas reflejan constructos más alejados de éste.

\subsubsection{Estrés y ansiedad}

Los términos estrés, estado de ansiedad y estado de miedo, demuestran un estado de respuesta y deben ser diferenciados del rasgo de la ansiedad, que es una disposición individual relativamente estable a la ansiedad (Spielberger, Gorsuch, Lushene, Vagg, \& Jacobs, 1983).

El estrés es un potente modulador de comportamiento emocional y está implicado en la etiología de los trastornos del estado de ánimo como la ansiedad, la depresión y las fobias (Pêgo, 2007).

Individuos con elevados niveles de ansiedad rasgo son especialmente temerosos en situaciones interpersonales que envuelven amenazas a la autoestima o de otro tipo. Sin 
embargo, las diferencias individuales en el rasgo de la ansiedad no predicen adecuadamente la forma como los individuos van a reaccionar ante situaciones de amenaza física, que son mejor explicadas por medidas específicas de la situación (Auerbach \& Gramling, 1998; Spielberger et al., 1983).

La exposición de estrés crónico induce un comportamiento parecido a la ansiedad (Shekhar, Truit, Rainnie, \& Sajdyk, 2005; Bondi, Rodriguez, Gould, Frazer, \& Morilak, 2007) y baja el umbral de respuesta a estímulos anxiogénicos (Pêgo, Morgado, Pinto, Cerqueira, Almeida, \& Sousa, 2008).

Según el DSM-IV-TR (APA,2002) después de la exposición a un estrés extremo, la presencia de algunos síntomas, disociativos o otros, es natural y no requiere ningún diagnóstico. Si los síntomas duran al menos dos días, pero no más de un mes nos enfrentaremos a un trastorno por estrés agudo. Cuando los síntomas persisten más de un mes, el diagnóstico de trastorno de post-estrés puede ser apropiado.

La neurobiología del estrés está considerablemente implicada en la causalidad y el desarrollo de los transtornos de ansiedad. Los estresores crónicos contribuyen a las enfermedades afectivas y traumáticas, y los estresores agudos provocan el inicio de estos transtornos (Heim \& Nemeroff, 2001; Paykel, 2003). Pêgo (2007) señaló que el estrés crónico induce el comportamiento ansioso, sin afectar el comportamiento de miedo o de la actividad exploratoria/locomotora.

El efecto de sensibilización al estrés está relacionado con los transtornos de ansiedad, esencialmente por dos razones:

1 - Las alteraciones neurobiológicas, especialmente alteraciones en el eje hipotálamo-pituitaria-adrenal (HPA), que se piensa están asociadas a la exposición a adversidades en los primeros años de vida, parecen implicar un riesgo acrecido para sufrir transtornos de la ansiedad (Espejo, Hammen, Connolly, Brennan, Najman, \& Bor, 2006; IEM \& Nemeroff, 2001; Young, Abelson, \& Cameron, 2004; Schneider, 2004). 
2 - Una exposición profunda, en los primeros años de vida, a un ambiente incontrolable, caracterizado por estresores imprevisibles y/o protección paternal exagerada parece estar relacionada con percibir las situaciones futuras como incontrolables (Espejo, et al., 2006; Schneider, 2004).

\subsubsection{Funciones de la ansiedad}

Cuando se consideran las reacciones, como por ejemplo la ansiedad, la inhibición o el desfallecimiento, no es muy claro cuál es su función. Sin embargo, cuando pensamos que esos síntomas tuvieron su función en la evolución de las especies, su presencia empieza a tener sentido. El término adaptabilidad es usado para referir comportamientos que tuvieron un valor de supervivencia en el sentido evolutivo (Lorenz, 1980) y también puede ser aplicado al comportamiento que promociona los objetivos importantes para el organismo: supervivencia, crecimiento, reproducción, conservación y dominio (Beck \& Emery, 1985).

Cuando consideramos los miedos comunes de la infancia (a caer, hacerse daño, ahogarse, la oscuridad, aguas profundas, etc.), podemos ver que al menos algunos de ellos son útiles para evitar que los niños se aventuren en lugares no familiares o peligrosos antes de ser capaces de sobrevivir sin problemas (por ejemplo la habilidad para nadar). Los miedos interpersonales, tales como el miedo a desconocidos o a la separación de sus cuidadores, pueden ser vistos de un modo similar (Beck \& Emery, 1985).

La función de la ansiedad puede ser comparada a la del dolor. La experiencia del dolor lleva a la persona a hacer algo para parar o reducir el dolor. No obstante, el dolor no es la enfermedad. De forma similar, la ansiedad no es la causa del trastorno psicológico. En los trastornos de la ansiedad, ésta no resulta eficaz para reducir el supuesto peligro que activa la respuesta ansiosa: cuando el problema no es un peligro real, sino una mala interpretación o una exageración del peligro, sentir ansiedad no es adaptativo (Beck, 1976). 


\subsubsection{Síntomas y sus significados}

Los síntomas son expresiones de un funcionamiento excesivo del sistema del sujeto, o de una interferencia en el funcionamiento de un subsistema particular. Los síntomas del trastorno de la ansiedad pueden clasificarse en cognitivos, afectivos, conductuales y fisiológicos. Se trata de cuatro sistemas funcionales que se coordinan para producir respuestas adaptativas en situaciones peligrosas.

El sistema cognitivo integra inputs, selecciona un plan apropiado y activa el resto del aparato. El sistema cognitivo se vale de los órganos sensoriales para construir patrones perceptivos, ya que lo que oímos y observamos son relaciones de sonidos, ondas visuales, etc.. Este aparato hace evaluaciones de las configuraciones del ambiente y de las estrategias disponibles para enfrentarse al mismo, determina cuándo existe un peligro claro y presente, y pone en acción los sistemas afectivos, conductuales y fisiológicos. El componente afectivo (ansiedad) sirve para acelerar la reacción, aumentando el sentimiento de urgencia. El componente conductual consiste en activar o inhibir los patrones de acción. El sistema fisiológico incluye los componentes autonómicos (Beck \& Emery, 1985).

En la Tabla 1 puede verse los síntomas cognitivos del trastorno de ansiedad según Beck y Emery (1985). 
Tabla 1. Síntomas Cognitivos del trastorno de ansiedad

1. Sensoperceptivos

"Mente": borrosa, nublada, confusa

Los objetos parecen manchados/distantes

El ambiente parece diferente/irreal

Sentimientos de irrealidad

Conciencia de sí

Hipervigilancia

2. Dificultades en el pensamiento

No acordarse de cosas importantes

Confusión

Incapacidad de controlar el pensamiento

Dificultad de concentración

Distracción

Obstrucción

Dificultad en ser razonable

Pérdida de objetividad y de perspectiva

3. Conceptual

Distorsión cognitiva

Miedo de perder el control

Miedo de no ser capaz de adaptarse

Miedo a sufrir daños físicos o a la muerte

Miedo al trastorno mental

Miedo de las valoraciones negativas

Imágenes visuales aterrorizantes

Ideación medrosa repetitiva 
Los síntomas sensoperceptivos no se incluyen por su severidad o interferencia en el funcionamiento general, sino porque resultan poco familiares e incontrolables y sugieren a la persona que está "perdiendo el juicio".

Las dificultades de pensamiento pueden producirse por una variedad de factores, pero se deben especialmente al hecho de que la capacidad cognitiva de la persona está tan ocupada intentando enfrentarse al miedo que le quedan pocos recursos para satisfacer las exigencias de los otros procesos cognitivos (Beck \& Emery, 1985).

La tabla 2 muestra los adjectivos típicos del desorden de la ansiedad según Beck y Emery (1985).

Tabla 2. Adjetivos afectivos típicos del desorden de la ansiedad

\begin{tabular}{ll}
\hline Irritable & Atemorizado \\
Impaciente & Tímido \\
Penoso & Asustado \\
Nervioso & Alarmado \\
Tenso & Aterrorizado \\
Ansioso & $\ldots$ \\
\hline
\end{tabular}

Los tipos de síntomas de la ansiedad varían de acuerdo con la naturaleza del problema. Si es inmediato y severo, la persona experimenta el pánico. Si el problema es crónico es más probable que la persona experimente sentimientos de dificultad (Beck \& Emery, 1985).

La tabla 3 muestra los síntomas conductuales del trastorno de la ansiedad según Beck y Emery (1985). 
Tabla 3. Síntomas Conductuales del trastorno de la ansiedad
Inhibición
Inmovilidad tónica
Huída
Evitación
Alteración del discurso
Descoordinación
Retracción
Colapso postural
Hiperventilación

Los síntomas conductuales suelen reflejar hiperactividad o inhibición del sistema comportamental.

Inmovilidad tónica es una expresión de la reacción de congelamiento, en cuanto comportamientos como temblores representan la movilización del cuerpo para la acción. Los temblores pueden representar la preparación para una estrategia de ataque en función de la supervivencia (Beck \& Emery, 1985).

Por fin, los mismos autores (Beck \& Emery, 1985) listaran los síntomas fisiológicos del desorden de la ansiedad, que están presentados en la Tabla 4. 
Tabla 4. Síntomas Fisiológicos del trastorno de la ansiedad

Cardiovasculares (taquicardia, palpitaciones)

Respiración (disnea, bolo faríngeo, dolor o molestias en el pecho)

Vegetativos (mareos, sequedad de las mucosas, diaforesis,

frialdad o accesos repentinos de calor)

Neuromusculares (mialgia, rigidez, mioclonías, sensaciones de

parálisis, insomnio)

Gastrointestinales (dolor epigástrico, náuseas, vómitos, diarrea, problemas en tragar)

Urogenitales (urgencia urinaria, frigidez, impotencia, eyaculación prematura)

Parestesias (Sensaciones cutáneas subjetivas, por ejemplo frío, calor, hormigueo, presión, rostro pálido, rubor, etc.)

Sudoración

Temblor o estremecimiento

Agitación ...

Los síntomas fisiológicos reflejan una lectura del organismo total para la autoprotección. La rama simpática del sistema nervioso autonómico facilita el uso de las estrategias de coping. El aumento del ritmo cardíaco y de la presión sanguínea ayudan a la persona a defenderse activamente o a escapar. Los síntomas del sistema parasimpático, en contraste, facilitan la estrategia de colapso, una expresión que demuestre que la persona no tiene estrategias de doping activas para enfrentarse a la amenaza. Algunos de los síntomas fisiológicos se derivan de reacciones comportamentales (Beck \& Emery, 1985; Ginsburg, Riddle, \& Davies, 2006; Masi, Favilla, Millepiedi, \& Mucci, 2000; Muris \& Meesters, 2004). 


\subsubsection{Clasificación}

La clasificación de la ansiedad tiene un largo pasado pero una historia muy reciente. Mientras que las observaciones de los fenómenos fóbicos, obsesivo-compulsivos y otros basados en la ansiedad se remontan a las primeras observaciones del comportamiento humano, sólo recientemente han sido definidos y incluidos en los sistemas nosológicos. Por ejemplo, en 1959, sólo tres de nueve sistemas de clasificación de los trastornos psiquiátricos en varios países, trataban las fobias como un diagnóstico independiente (Marks, 1969). El propio término ansiedad no aparecía en la clasificación internacional de enfermedades (ICD) hasta su séptima revisión, publicada en 1955. Hasta entonces, la lista incluía "reacción ansiosa sin mención de síntomas somáticos" bajo el epígrafe "transtornos psiconeuróticos" (Jablensky, 1985).

Los trastornos de ansiedad en el DSM-IV-TR (APA, 2002) se dividen en: Trastorno de pánico sin agorafobia, Trastorno de pánico con agorafobia; Agorafobia sin trastorno de pánico; Fobias específicas; Fobia social; Trastorno Obsesivo-Compulsivo; Trastorno de estrés postraumático; Trastorno de estrés agudo; Trastorno de ansiedad generalizada; Trastorno de ansiedad secundario a una condición física general; Trastorno de ansiedad inducido por sustancias; y Trastorno de ansiedad no especificado.

\subsubsection{Epidemiología}

Un estudio de la Organización Mundial de la Salud, realizado en siete países de distintas zonas del mundo --América del Norte (Canadá y EEUU), América Latina (Brasil y México) y Europa (Alemania, Países Bajos y Turquía)-- con una muestra de 29.644 personas mostró las siguientes tasas de prevalencia, presentadas en la Tabla 5 (WHO, 2000): 
Tabla 5. Prevalencia de los trastornos de ansiedad en América y Europa

\begin{tabular}{lccc}
\hline & En la vida & Los últimos 12 meses & Los últimos 30 días \\
\hline Alemania & 9.5 & 7.1 & 2.7 \\
Brasil & 17.4 & 10.9 & 8.7 \\
Canadá & 21.3 & 12.4 & 6.2 \\
EEUU & 25.0 & 17.0 & 10.3 \\
México & 5.6 & 4.0 & 2.3 \\
Países Bajos & 20.1 & 12.7 & 9.8 \\
Turquía & 7.4 & 5.8 & 5.0 \\
\hline
\end{tabular}

Fuente: WHO (2000).

Más recientemente, un estudio europeo (Alonso et al., 2004) de los trastornos mentales (proyecto ESEMeD) incluyó a 21.425 encuestados mayores de 18 años de Bélgica, Francia, Alemania, Italia, Países Bajos y España. Los resultados mostraron una prevalencia del $13,6 \%$ para los trastornos de ansiedad durante toda la vida $(9,5 \%$ para los hombres y $17,5 \%$ para las mujeres) y del $6,4 \%$ para los trastornos de ansiedad en el último año (3,8\% para los hombres y $8,7 \%$ para las mujeres). En cuanto a los porcentajes de los trastornos de ansiedad por edad, son los presentados en la Tabla 6: 
Tabla 6. Prevalencia de los trastornos de ansiedad en Europa por edad

\begin{tabular}{lc}
\hline Edad & Prevalencia \\
\hline $18-24$ & $9.2 \%$ \\
$25-34$ & $7.0 \%$ \\
$35-49$ & $6.5 \%$ \\
$50-64$ & $6.8 \%$ \\
+ de 65 & $3.6 \%$ \\
\hline
\end{tabular}

Fuente: Alonso et al. (2004).

Resulta claro, entonces, que el grupo de edad con mayor incidencia de trastornos de ansiedad es el de los adultos jóvenes, mientras que la menor incidencia se da en las personas mayores.

En Italia, en un estudio nacional epidemiológico con 554 pacientes de consultas de medicina general, se encontró una prevalencia del 17,0\% en los trastornos de ansiedad (Rucci et al., 2003). Otro estudio realizado en Italia, más reciente, con una muestra de 21.644 pacientes de atención primaria, mostró que el 14,8\% tenía un trastorno de ansiedad. Estos casos se clasificaron en función de las principales variables demográficas: sexo (32,2\% en los varones y $67,8 \%$ en las mujeres); edad (39,4\% en los menores de 45 años, $37,7 \%$ entre 45 y 65 años y $22,9 \%$ en los mayores de 65 años); estado civil (19,0\% en los solteros, $66,9 \%$ en casados, $4,2 \%$ en separados o divorciados y $9,9 \%$ viudos); categoría profesional (45,1\% activos) (Balestrieri, Isola, Quartaroli, Roncolato, \& Bellantuono, 2010).

Otro estudio europeo presentó como prevalencia anual de los trastornos de ansiedad un porcentaje de 12.0 (16.3 en mujeres y 7.8 en varones) (Andlin-Sobocki \& Wittchen, 2005).

Un estudio realizado en escuelas en Sri Lanka, con 445 estudiantes de edades comprendidas entre 14 y 18 años, presentó como resultados una prevalencia del $28 \%$ de casos graves de ansiedad y entre el $51,1 \%$ y el $68,6 \%$ de casos de ansiedad moderada, 
dependiendo de la edad, siendo los estudiantes de 17 años quienes presentaban una mayor prevalencia (Rodrigo, Welgama, Gurusinghe, Wijeratne, Jayananda, \& Rajapakse, 2010).

En Portugal es escasa la investigación sobre Salud Mental y Epidemiología Psiquiátrica, especialmente en relación a la ansiedad; sin embargo, algunos estudios recogen ese tipo de información.

En una encuesta RTP/periódico Público organizada por la Universidad Católica (2004), los resultados indican que la ansiedad afecta al 15 por ciento de los portugueses.

Rabasquinho y Pereira (2007) realizó un estudio epidemiológico de los trastornos mentales en Portugal, con una muestra de 483 usuarios seleccionados aleatoriamente de un universo de 2.447 usuarios de un servicio psicológico (la especialidad de Psicología de la consulta externa del Departamento de Psiquiatría y Salud Mental del Hospital Amato Lusitano de Castelo Branco). En este estudio, la ansiedad se encontró en el 11,2\% de la muestra como diagnóstico principal $(\mathrm{N}=55)$ y el $17,7 \%$ secundaria a otro trastorno $(\mathrm{N}=86)$, con un alto índice de comorbilidad con la depresión (36,5\%). Los autores afirman que estos porcentajes podrán revelar que, cuando coexisten, la depresión es el diagnóstico primario. Como trastornos de ansiedad se consideraron: trastornos de ansiedad generalizada, ansiedad secundaria a una enfermedad física o mental, fobia social, trastorno de pánico con o sin agorafobia, trastorno obsesivo-compulsivo y trastornos de ansiedad sin otra especificación. Las mujeres tienen una tasa del 64\% y los hombres del 36\% (diagnóstico principal). Cruzando el género con el estado civil, eran las mujeres, los individuos solteros y los hombres divorciados quienes presentaron más ansiedad.

En otro estudio (Apóstolo, Ventura, Caetano, \& Costa, 2008) llevado a cabo con 192 usuarios de atención primaria, entre 18 a 81 años, los autores informan que sólo el 43,75\% de los pacientes tenían niveles normales de ansiedad y el 29,17\% de los asistentes tuvieron un nivel grave o muy grave.

En marzo de 2010 se finalizó el primer estudio epidemiológico nacional de la salud mental y los primeros resultados fueron presentados en la Facultad de Ciencias Médicas de 
la Universidade Nova de Lisboa en marzo de este año (World Mental Health Consortium [WMHC], 2010). Este estudio es parte del proyecto "The EU Contribution to the World Mental Health (WMH) Surveys Initiative", un proyecto europeo financiado por la DG SANCO con duración entre 2008 a 2010. El "WMH Survey Initiative" es un proyecto del grupo de la evaluación, clasificación y epidemiología (ACE) de la Organización Mundial de la Salud (WHO), para coordinar la aplicación y el análisis de estudios epidemiológicos de la población general, de trastornos mentales, uso de drogas y trastornos de conducta en los países en todas las regiones de la OMS. El Consorcio del WMH Survey incluye 28 países, que representan todas las regiones del mundo (Harvard School of Medicine [HSM], 2005).

En Portugal, este estudio se llevó a cabo en 258 localidades de todo el país, y la muestra final estuvo compuesta por 3.849 encuestados.

De los resultados de este estudio se desprende que, en términos de prevalencia anual, comparando los países de Europa, Estados Unidos de América y México, son los Estados Unidos los que tienen mayor prevalencia de trastornos de ansiedad, con una tasa del $18,2 \%$, seguido de Portugal, con una tasa del 16,5\%. Los países con tasas más bajas fueron Italia y España, con menos del 6\% cada uno de ellos.

Los trastornos de ansiedad más frecuentes en Portugal son la fobia social y el trastorno obsesivo-compulsivo, como se puede observar en la Tabla 7. 
Tabla 7. Prevalencia de los trastornos de ansiedad en Portugal

\begin{tabular}{lc}
\hline Trastorno & Prevalencia \\
\hline Trastorno de pánico & $.9 \%$ \\
Trastorno de ansiedad generalizada & $2.1 \%$ \\
Fobia social & $3.1 \%$ \\
Fobia especifica & $8.6 \%$ \\
Agorafobia sin pánico & $.7 \%$ \\
Trastorno del estrés post-traumático & $2.3 \%$ \\
Trastorno obsesivo-compulsivo & $4.4 \%$ \\
Trastorno de la ansiedad de separación en adultos & $1.2 \%$ \\
\hline
\end{tabular}

Con respecto a la gravedad de los trastornos de ansiedad, la prevalencia es de: $5.3 \%$ para leves, $8.0 \%$ moderadas y $3.2 \%$ severas.

La prevalencia en la vida del trastorno de ansiedad encontrada fue del $25.8 \%$ (WMHC, 2010). 


\subsection{Variables asociadas a la ansiedad}

\subsubsection{Género}

Las diferencias de género en la ansiedad se han estudiado en diversas edades y culturas (Altemus, 2006; Muris \& Ollendick, 2002).

Varios trabajos indican que las mujeres presentan mayores niveles de ansiedad que los varones (Abdel-Khalek \& Lester, 2006; Alansari, 2006; Costello, Eger, \& Angold, 2004; Dell'Osso et al., 2003; Ginsburg \& Silverman, 2000; Ollendick, King, \& Muris, 2002; Mackinaw-Koons \& Vasey, 2000) y que presentan al menos dos veces más transtornos de la ansiedad, incluyendo trastorno de pánico, trastorno postraumático, ansiedad generalizada, ansiedad social y fobias (Altemus, 2006).

Estas diferencias entre géneros están presentes en muchos países y diferentes culturas y sugieren una base biológica (Alansari, 2006; Altemus, 2006). La preponderancia de la ansiedad en las mujeres ha sido una conclusión consistente, tanto en niños, como en adolescentes, estudiantes, ancianos y pacientes con trastornos de ansiedad así como en cuestionarios pasados en la comunidad (Alansari, 2006).

Además, estas diferencias de género surgen temprano: a los seis años las niñas presentan el doble del prevalencia de la ansiedad que los niños (Muris, Merckelbach, Ollendick, King, \& Bogie, 2002; Muris \& Ollendick, 2002).

Hay diferencias entre los cerebros de hombres y mujeres que están influidas por las hormonas prenatales inicialmente y más tarde por otras hormonas en el transcurso de la vida, pero el desarrollo del cerebro humano también es alterado por las experiencias de la vida, incluido el medio ambiente prenatal (Halpern, Benbow, Geary, Gur, Hyde, \& Gernsbacher, 2007). 
Asi, se sugieren dos explicaciones para esta preponderancia: una es que existen diferencias genéticas y biológicas entre los dos sexos, y otra es que los papeles estereotipados de género para las mujeres, que implican pocos recursos y dependencia, provoca en ellas una mayor preocupación y una tendencia a evitar un amplio conjunto de situaciones. Algunos autores defienden que en países donde el status social y económico es similar entre géneros, las diferencias en el nivel de ansiedad son menores (Alansari, 2006; Lewinsohn, Gotlib, Lewinsohn, Seeley, \& Allen, 1998).

Comparando la evolución de los trastornos de ansiedad, las mujeres tienen un desarrollo más rápido que los hombres, pero no hay diferencias en la duración de la recuperación (Lewinsohn, Gotlib, Lewinsohn, Seeley, \& Allen, 1998).

La evidencia procedente de estudios con animales indica que las hembras son relativamente resistentes a los efectos conductuales y neurobiológicos del estrés agudo o crónico. Por ejemplo, mientras que después de 21 días el estrés crónico produce atrofia reversible de las dendritas apicales de las neuronas hipocampales y piramidales en machos, este efecto no es visible en las hembras (Conrad, Magarinos, LeDoux, \& McEwen, 1999; Galea, McEwen, Tanapat, Deak, Spencer, \& Dhabhar, 1997).

En estudios realizados con ratas, éstas no muestran deterioro de la memoria espacial o memoria de reconocimiento de objetos después de un estrés crónico restrictivo, lo que es característico en machos (Luine, 2002). En los machos, el estrés agudo aumenta el guiño de ojos (un reflejo aprendido que no implica miedo), pero en las hembras no tiene efecto (Shors, Lewezyk, Pacynski, Mathew, \& Pickett, 1998). Por otro lado, las ratas hembras tienen la hormona adrenocorticotropica $(\mathrm{ACTH})$ y la corticosterona, en respuesta al estrés, más elevadas (McCormik, Linkroum, Sallinen, \& Millar, 2002).

Una diferencia similar entre géneros en humanos ha sido encontrada en el aumento de los condicionantes del miedo en situaciones de estrés inducido (Jackson, Payne, Nadel, \& Jacobs, 2005). 
En humanos, los varones parecen tener en el eje hipotálamo-pituitaria-suprarrenal (HPA) respuestas al estrés más grandes, y cuando los esteroides gonadales circulantes son retirados, éstos tienen respuestas del eje HPA mayores que las mujeres (Kudielka, BuskeKirschbaum, Hellhammer, \& Kirschbaum, 2004; Roca et. al, 2003).

Los datos procedentes de estudios con animales y con humanos coinciden en sugerir que las dosis fisiológicas de estradiol suprimen las respuestas del eje HPA al estrés (Komesaroff, Ester, \& Sudhir, 1999; Young, Altemus, Parkinson, \& Shastry, 2001).

Comparados con los varones, las mujeres están sujetas a mayores flujos en hormonas reproductivas durante su vida. Modificaciones de las hormonas reproductivas en el útero, durante la pubertad, el ciclo menstrual, embarazo, y menopausia alteran claramente la estructura y funcionamiento del cerebro y es probable que tengan un papel importante en la superioridad de trastornos afectivos en las mujeres (Altemus, 2006).

La respuesta del eje HPA aumenta (Kirschbaum, Kudielka, Gaab, Schommer, \& Hellhammer, 1999) y la sensibilidad del feedback glucocorticode (Altemus et al., 1997), y los contenidos cerebrales del ácido gamma-aminobutírico (GABA) disminuyen (Epperson, et al., 2002) en la fase lútea del ciclo menstrual. Este sistema homeostático parece estar desestabilizado en mujeres vulnerables (Epperson et al., 2002; Roca et al., 2003). Por otra parte, la respuesta del eje HPA y del sistema catecolaminérgico se suprimen durante el embarazo (Matthews \& Rodin, 1992) y la lactancia (Heinrichs, et al., 2001; Mezzacappa, Yu, \& Myers, 2003).

Hasta hace poco tiempo, las mujeres pasaban gran parte de su vida adulta embarazadas o amamantando. Actualmente, se ha reducido ese tiempo, lo que expone a las mujeres a una mayor activación del sistema de respuesta al estrés (Altemus, 2006). Algunos estudios indican que el número de síntomas somáticos en las mujeres es mayor que en los los varones (Muris \& Meesters, 2004). Sin embargo, otros no encuentran diferencias sexuales en la frecuencia de los síntomas somáticos de la ansiedad (Ginsburg, Riddle, \& Davies, 2006; Masi, et al., 2000). 
Toufexis (2007), en una reciente revisión sobre modelos animales, usando el reflejo como una medida operacional de estados aversivos, comparó diferencias sexuales en dos tipos de respuesta aversiva: ansiedad, un estado sostenido debido a una amenaza incierta, y miedo, una respuesta defensiva a un peligro real. Sus estudios de reflejos en roedores indican que la hembra es más reactiva en modelos experimentales de ansiedad sostenida pero no en modelos de miedo (en que los síntomas terminan después de la desaparición del estímulo amenazante).

Pêgo (2007) ha referido que el núcleo de la estría terminal (NET) está implicado en la ansiedad y en respuestas a estímulos contextualizados. Además, el NET está directamente implicado en la regulación del eje hipotálamo-pituitaria-suprarrenal (HPA), siendo una importante estación de paso para la información proveniente del sistema límbico. Toufexis (2007) concluyó que el NET potenciado por la ansiedad, pero no por el miedo, está aumentado en ratas hembras, en comparación a machos.

Grillon (2008) examinó pruebas de una diferencia sexual similar en humanos, utilizando también el susto como una medida de estados de aversión. Sus resultados no encontraron ninguna diferencia sexual en el miedo-potenciado por el susto en respuesta a una señal de amenaza, pero encontró una mayor potenciación por el contexto del susto en las mujeres. Esta diferencia sexual es paralela a las ratio subjetivss de miedo y ansiedad.

Para Grillon (2008), entre otros factores biológicos, los mecanismos genéticos no relacionados con efectos hormonales pueden ser la base de la diferenciación sexual en el comportamiento y en la función cerebral.

En cualquier caso, no está claro si las diferencias sexuales en ansiedad se deben a factores biológicos o psicosociales. Por ejemplo, Toufexis (2007) revisó los resultados relativos a las hormonas sexuales y concluyó que las diferencias en ansiedad podrían deberse al efecto inhibitorio de la testosterona o a las hormonas ováricas femeninas, como estrógeno y progesterona, que afectan aspectos diferentes del miedo y ansiedad. Otros modelo de la ansiedad indican que las ratas ovariectomizadas tratadas con estrógeno pero 
no con progesterona muestran una reducción de las respuestas defensivas (Hiroi \& Neumaier, 2005). Estos resultados señalan un efecto complejo de las hormonas ováricas en la ansiedad, posiblemente asociado a la naturaleza de la prueba.

Tampoco la hipótesis de que las mujeres están fisiológicamente más predispuestas a experimentar ansiedad ha sido corroborada. Varios estudios han encontrado que varones y mujeres muestran niveles similares de reactividad en diversas medidas: ritmo cardíaco durante situaciones sociales desafiantes (Kelly, Tyrka, Anderson, Price, \& Carpenter, 2008), reactividad electrodermal, latido cardíaco durante inhalación de CO2 (Kelly, Forsyth, \& Karekla (2006) y latido cardiaco durante un examen oral (Rohrmann, Netter, Hennig, \& Hodapp, 2003). Sin embargo, con respecto al sistema nervioso autónomo que responde al estrés agudo, una revisión reciente de Kajantie y Phillips (2006) concluyó que las diferencias de género entre adultos son marcadas: las mujeres muestran un eje HPA menor así como menos reactividad autonómica comparada a los hombres.

Según McLean y Anderson (2009) la evidencia asociada a la reactividad fisiológica parece depender de cómo se mida la reactividad fisiológica. Los varones muestran una mayor respuesta cuando la reactividad se define como la conducción de la piel durante el condicionamiento/extinción, tensión arterial durante un desafío, y reactividad HPA durante el desafío; las mujeres muestran mayor respuesta cuando la reactividad se define como el ritmo cardíaco durante el reto, y se observan pocas diferencias cuando la reactividad se relaciona con el ritmo cardíaco durante el desafío.

Pudiera ser que la vulnerabilidad genética se amplificara por elementos sociales/ambientales experimentados por las mujeres. Esta hipótesis es consecuente con los resultados de un estudio con gemelos recientemente conducido por Hettema, Prescott, Myers, Neale y Kendler (2005). En una muestra de más de 5.000 participantes, se empleó un modelo de ecuaciones estructurales para examinar las posibles causas de la comorbilidad de los transtornos de ansiedad. Los resultados mostraron que, a pesar del 
predominio de la ansiedad observado en las mujeres, casi el doble que en los varones, los factores de riesgo genético y ambiental eran similares para ambos sexos. Es decir, aunque los factores de riesgo genético no son diferentes, su impacto relativo puede ser mayor en las mujeres.

McLean y Anderson (2009) concluyen que, aunque las mujeres no sean más propensas a experimentar traumas en general, sí hay mayor probabilidad de que experimenten ciertos tipos de trauma, incluyendo abuso sexual y carencia de redes sociales, que pueden ser claros factores de riesgo para la ansiedad. También es más probable que, en adelante, en respuesta a acontecimientos aversivos, las mujeres utilicen una estrategia orientada por la emoción, que es menos eficaz que las estrategias de adaptación orientadas a la solución de problemas. Las niñas, de pequeñas, están más protegidas por los padres y por lo tanto pueden tener menos oportunidad de ejercer control sobre su entorno. Por consiguiente, las mujeres pueden percibirse como menos capaces de enfrentarse a situaciones potencialmente amenazadoras. Esta percepción de pobre autoeficacia puede motivar, por su parte, una estrategia evitativa en situaciones de incertidumbre. La evitación es coherente con los papeles de género tradicionales, en los cuales se espera que varones y mujeres respondan a la amenaza de forma diferente

\subsubsection{Edad}

Los trastornos de ansiedad, particularmente las fobias, tienden a persistir durante toda la vida. No obstante, hay diferencias entre los subtipos de ansiedad, pues los estados fóbicos tienden a ser bastante estables y no progresivos, pero la ansiedad generalizada tiende a ser menos específica y menos estable. Estudios epidemiológicos en adultos revelan que la ansiedad está presente en todos los estadios de la vida, si bien sus trastornos por lo general se producen en la infancia y al inicio de la edad adulta, y después tienden a 
disminuir con la edad (Alonso, et al., 2004; Balestrieri, et al., 2010; Laurent \& Ettelson, 2001;Merikangas \& Pine, 2002; Mesman \& Koot, 2001; Spence, Rapee, McDonald, \& Ingram, 2001).

Ciertas características de temperamento pueden predisponer a los niños a experimentar síntomas de ansiedad en la tierna infancia. La inhibición comportamental, definida como la tendencia de reaccionar a la novedad con miedo, cautela y retracción, ha sido el más extensivamente estudiado en relación a síntomas concurrentes y posteriores de ansiedad (Hirshfeld-Becker, Biederman, \& Rosenbaum, 2004). La inhibición comportamental evaluada durante la infancia temprana parece guardar relación con el riesgo aumentado de sufrir transtornos de ansiedad posteriormente (Biederman et al., 2001), en particular fobia social (Gladstone, Parker, Mitchell, Wilhelm, \& Malhi, 2005; Hirshfeld-Becker, et al., 2004).

La ansiedad en la infancia tiene mucho que ver con la recurrencia de problemas de ansiedad más tarde en la infancia y la adolescencia (Kovacs \& Devlin, 1998; Mesman \& Koot, 2001). El trastorno de ansiedad es más frecuente en niños que en adolescentes (Costello, Mustillo, Erkanli, Keeler, \& Angold, 2003; Merikangas \& Pine, 2002), aunque los datos indican que los adolescentes reportan un mayor número de síntomas físicos, en comparación a aquellos (Ginsburg, et al., 2006). Los transtornos de ansiedad son en también comunes en ancianos por otra parte sanos, algo que también ocurre en animales (McEwen, 2003; Bessa, et al., 2005; Mohlman \& Price, 2006; Riedel-Heller, Busse, \& Angermeyer, 2006; Weissman \& Levine, 2007).

La edad se asocia con cambios de comportamiento, incluyendo aumento de la ansiedad, pero este aumento no se puede atribuir a cambios en el volumen o en el número de neuronas en la amígdala y BNST (Pêgo, Morgado, Cerqueira, Almeida, \& Sousa, 2006).

Según Mirowsky y Schieman (2008) en un estudio cuyo objetivo fue examinar las tendencias y trayectorias de la ansiedad en términos de género y edad, aunque las mujeres tienen valores siempre superiores a los hombres, el patrón en términos de edad es similar 
para ambos sexos, hay una disminución de la ansiedad a medida que aumenta la edad. Este patrón puede verse en la figura 1.

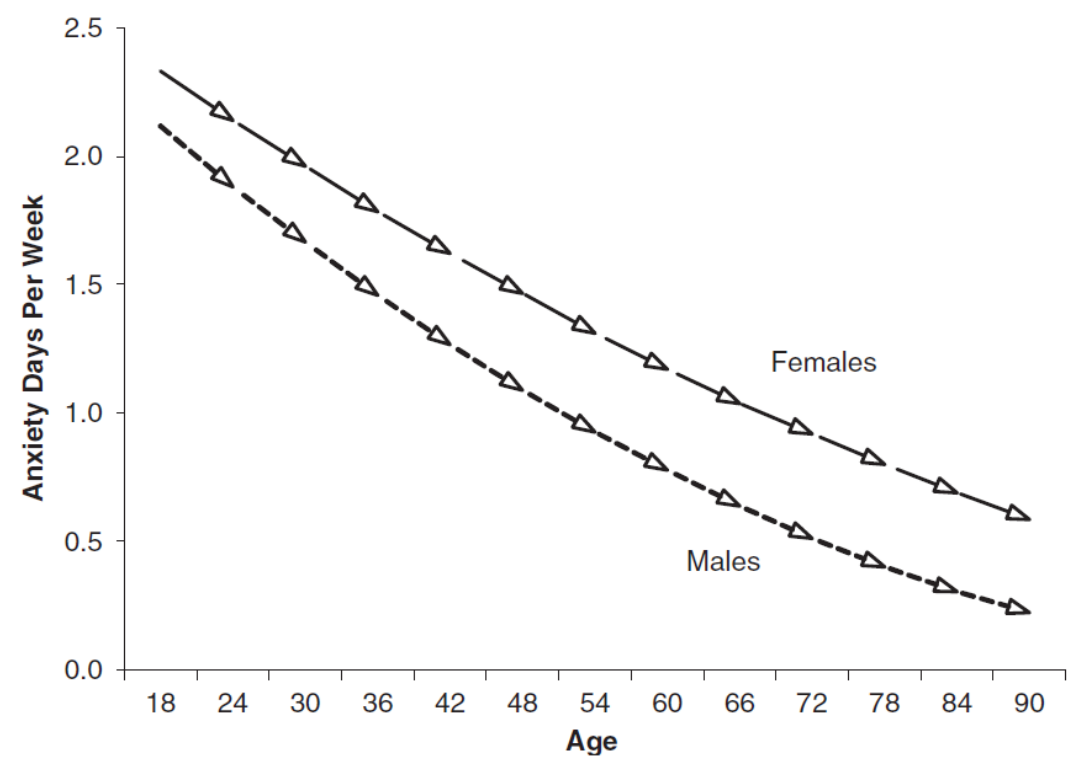

Figura 1 - Patrón de la ansiedad en términos de edad

Fuente: Mirowsky \& Schieman, 2008. 
CAPÍTULO II MODELOS EXPLICATIVOS DE LA ANSIEDAD 


\subsection{Modelo de Desarrollo}

Según la perspectiva de desarrollo, dos modelos pueden ayudar a definir la ansiedad:

1 - Watson y Tellegan (1985) defienden que los afectos se pueden organizar en dos dimensiones independientes, que denominaron afectividad positiva y afectividad negativa. En la afectividad negativa se encuentran la ansiedad y la depresión, así como la culpa, cólera, etc. Para distinguir la ansiedad de la depresión se ha creado el modelo tripartito, que se describe más adelante.

Estas emociones, que habitualmente están correlacionadas, comparten un factor de malestar general, pero se diferencian por su nivel de activación. A la ansiedad le corresponden niveles de activación elevada, mientras que con la depresión ocurre lo contrario, caracterizándose por una apatía, anhedonia y ausencia de activación. De esta forma la ansiedad es definida subjetivamente por descriptores hedónicos negativos que son acompañados por elevados niveles de activación fisiológica observados (Baptista, 2000; Clark \& Watson, 1991; Watson \& Tellegan, 1985).

2 - Teoría bio-informacional de las emociones:

La teoría bioinformacional fue desarrollada para dar cuenta de las observaciones realizadas en el ámbito de la conducta emocional, especialmente en relación con el miedo. Esta teoría incluye la idea de que un modelo global de comportamiento emocional debe incluir, además de un nivel conceptual, un nivel de motor de procesamiento (Lang, 1979).

Lang (1979) propone que una emoción incluye tres categorías de información: 1) Información sobre los estímulos externos: una proposición de estímulo; 2) la información que define el significado de estímulos y respuestas: el sentido de la proposición; y 3) la información acerca de la respuesta: proposición de respuesta. Este último tipo de información incluye un componente importante, la experiencia somática y visceral. 
Aunque el autor afirma que estos tres tipos de proposiciones se organizan en una red semántica (llamado un esquema o prototipo emocional), están funcionalmente organizados a fin de dar lugar a una respuesta motora. Por lo tanto, las proposiciones de significado, estímulo y respuesta sólo se pueden activar en el plano semántico, pero el modelo predice que la retroalimentación estará doblemente codificada: en el nivel semántico y en el nivel eferente, siendo el último tipo de información el que permite la activación del programa motor (Lang, 1979). Al proponer esta diferenciación, el modelo explica la posibilidad de que la información relacionada con una emoción pueda ser procesada sin la experiencia correspondiente (Lang, 1979).

Esta teoría pretende integrar los aspectos comportamentales observables de la respuesta ansiosa con los aspectos no observables de procesamiento de información relevante para su organización y control. De acuerdo con esta teoría podemos hablar de ansiedad cuando el sujeto presenta competencias que le permitan relatar verbalmente su malestar y la activación autonómica del modelo tripartito, y también comportamiento motor de huída o escape (Baptista, 2000; Lang, 1979).

La escasez de espacio en el útero materno hace que el recién nacido tenga un tamaño reducido, implicando un largo periodo de desarrollo. Se piensa que lo mismo pasa con el desarrollo del comportamiento emocional. En relación al miedo no se encuentran señales antes de los seis meses de vida. En el primer año de vida los miedos se relacionan con adultos no familiares y con la separación de las figuras de apego (Baptista, 2000).

A pesar de que algunos de estos miedos pueden persistir y reflejarse en la reluctancia a entrar en situaciones sociales nuevas y en la timidez, típica del inicio de la adolescencia, este miedo empieza, de un modo general, a disminuir después del segundo año de vida (Marks, 1987). 
Otro miedo típico de las fases iníciales de la vida es el desencadenado por la separación de las figuras de apego. Tiene su punto máximo entre nueve y trece meses, y empieza a disminuir a partir del decimotercer mes (Bowlby, 1973).

Los miedos típicos de la infancia tienden a disminuir durante la edad preescolar, apareciendo entonces los miedos relacionados con animales, sangre o heridas, oscuridad, criaturas imaginarias y tempestades naturales. Después de esta edad, la mayoría de esos miedos disminuye, apareciendo posteriormente, con inicio en la adolescencia, los miedos relacionados con situaciones interpersonales, de evaluación y con la sexualidad (Campbell, 1986; Marks, 1987; Sandín, 1997).

Los miedos parecen tener una secuencia previsible de aparición, mantenimiento y, por último, de disminución. Analizando las situaciones que los desencadenan, podemos concluir que aparecen en momento en que funcionan como factores protectores, de defensa o de alarma para ayudar al individuo a desempeñar funciones típicas de ese periodo específico de desarrollo (Baptista, 2000).

Aún, la experiencia de adversidades en los primeros años de vida está asociada a la existencia de transtornos de ansiedad posteriormente (Kessler, Davis, \& Kendler, 1997; Phillips, Hammen, Brennan, Najman, \& Bor, 2005). 


\subsection{Modelo Cognitivo Comportamental}

En este modelo, se considera que la ansiedad es una respuesta compleja, cuyo componente fisiológico se inicia, tras la percepción de un estímulo, interno o externo, que el individuo valora cognitivamente como perjudicial o potencialmente perjudicial para él o para personas o elementos apreciados por él (sus bienes materiales, sus seres queridos, etc.). Esta valoración conlleva, de inmediato, una nueva respuesta cognitiva, de temor a sufrir un daño, cierto o probable, y, por consiguiente, favorece el inicio de una secuencia motora, de huída o evitación, que constituye el componente instrumental de respuesta al estímulo.

En la mayoría de los casos, el individuo es plenamente consciente del ambiente en que se encuentra y del que forma parte, que constituye el estímulo antecedente de la respuesta fisiológica. No obstante, en algunos casos, la percepción de la reacción emocional no queda asociada claramente a ningún elemento estimular antecedente, lo que favorece la aparición de un complejo de respuestas cognitivas con las que trata de explicar sus sensaciones fisiológicas y con las cuales se modula la intensidad de las mismas (Pérez \& Lago, 2000).

Los resultados de las terapias basadas en la teoría cognitivo-comportamental en el tratamiento de la ansiedad son muy positivos (James, Soler, \& Weatherall, 2005). Su eficacia ha sido corroborada en varios formatos: individual (Flannery-Schroeder \& Kendall, 2000; Manassis, Mendelowitz, Scapillato, Avery, Fiskenbaum, \& Freire, 2002; Nauta, Scholing, Emmelkamp, \& Mindera, 2003), en grupo y con la implicación de los padres (Manassis, et al., 2002; Muris, Mayer, Bartelds, Tierney, \& Bogie, 2001; Muris, Meesters, \& Van Melick, 2002).

El objetivo de la terapia cognitivo-comportamental es ayudar a identificar posibles déficits y distorsiones cognitivas, testarlas, y después enseñar nuevas capacidades y a 
desafiar los pensamientos y creencias irracionales, y sustituirlas por pensamientos más racionales, cambiando su conducta (Kendall, Reber, McLeer, Epps, \& Ronan, 1990).

Las estrategias comportamentales incluyen: modelado, exposición a la realidad, roleplaying y entrenamiento de relajación. El tratamiento comportamental se basa en la premisa de que el miedo o la ansiedad son respuestas aprendidas (condicionamiento clásico) que pueden ser invertidas. Un elemento del tratamiento conocido como desensibilización sistemática implica cruzar el estímulo ansioso, en vivo o en la imaginación, en una jerarquía creciente de dificultad con estímulos relajantes como imágenes agradables o relajación muscular (James, et al., 2005).

Durante las dos últimas décadas, psicopatólogos experimentales han aplicado cada vez más los conceptos y métodos de la psicología cognitiva para explicar bases cognitivas asociadas con la ansiedad (Mobini \& Grant, 2007).

Una de estas áreas de investigación que ha llamado la atención tanto de psicólogos clínicos como de experimentales es el patrón de atención en los transtornos emocionales (Beck \& Clark, 1997; Gelder, 2001; Mathews, 2001).

Los modelos cognitivos sugieren que el proceso de la información cause, mantenga y exacerbe los síntomas de ansiedad porque los individuos ansiosos dejan de ocuparse de la información que significa la seguridad o que proporciona la información para hacer una interpretación más realista y logística de la situación (Beck, Emery, \& Greenberg, 1985; Mathews \& MacLeod, 2002).

Durante mucho tiempo se ha asumido que emociones como el miedo y la ansiedad dirigen la atención enfatizando los estímulos afectivamente entonados en el ambiente que son significativos para los individuos (Oatley \& Jenkins, 1996). Es ampliamente aceptado ahora que los individuos ansiosos selectivamente se ocupan de la información relacionada con la amenaza en el ambiente (Bar-Haim, Lamy, Pergamin, Bakermans-Kranenburg \& van ljzendoorn, 2007; Gotlib, Kasch, Traill, Arnow, Joormann, \& Johnson, 2004). 
Mucha de la literatura ha descrito la tendencia de la atención expuesta por individuos clínicamente o no clínicamente ansiosos (Bar-Haim et al., 2007). Los investigadores han estudiado patrones de la atención en una variedad de transtornos de ansiedad, postulando que tales patrones podrían desempeñar un papel en la etiología y el mantenimiento de problemas asociados con transtornos de ansiedad (Mobini \& Grant, 2007).

Según Eysenck, Santos, Derakshan y Calvo (2007) la asunción de que la ansiedad aumenta la atención prestada a estímulos relacionados con la amenaza (y a la decisión de cómo responder en las circunstancias que provocan ansiedad) significa que la ansiedad típicamente reduce el foco de atención en la tarea corriente, a menos que esto implique estímulos amenazantes. Más expresamente, la ansiedad perjudica el control de atención. Resulta que los individuos ansiosos preferentemente asignan recursos atencionales a estímulos relacionados con la amenaza, internos (p. ej., pensamientos inquietantes) o externos (p. ej., amenazando distractores irrelevantes para la tarea). Los niveles altos de la preocupación a menudo tienen que ver con niveles bajos de rendimiento.

\subsubsection{Los esquemas cognitivos de Beck}

Beck (1985) reconoce las emociones en general y la ansiedad en particular como respuestas biopsicosociales complejas con componentes debidos a la evolución, biológicos, afectivos y cognitivos. Cuando las emociones son inapropiadas, exageradas y fuera de contexto, Beck resalta la importancia de los factores cognitivos.

Más específicamente (Beck, 1985; Beck \& Emery, 1985), el foco del problema en los transtornos de la ansiedad no está en el sistema afectivo, sino en esquemas cognitivos que interpretan continuamente la realidad como peligrosa. La información acerca de sí mismo, del mundo y del futuro (la tríada cognitiva) es continuamente procesada, de una forma 
distorsionada, como peligrosa. Por consiguiente, los estados de ansiedad se asocian a pensamientos automáticos e imágenes asociados a su vez al peligro. Para Beck, estos pensamientos e imágenes, resultantes del procesamiento distorsionado de la información, inician los comportamientos motores, fisiológicos y afectivos inadecuados de la respuesta ansiosa. Esta teoría no es propiamente una teoría de la ansiedad, sino una teoría de los trastornos de la ansiedad, pues Beck se muestra de acuerdo en que la ansiedad y el miedo son adaptativos en algunas circunstancias. 


\subsection{Modelos genético y ambiental}

Según Silberg, Rutter, Neale, y Eaves (2001) hay un efecto de mediación del ambiente entre los acontecimientos de la vida y la ansiedad, mientras que los factores genéticos desempeñan un importante papel en las diferencias individuales en la susceptibilidad a los riesgos ambientales.

La importancia de los factores de riesgo-genéticos y ambientales- para el desarrollo de la ansiedad ha sido bien demostrada por análisis genéticos/comportamentales (Eley \& Gregory, 2004). Se considera que el riesgo para la existencia de patología ansiosa es función de la resistencia y de los factores personales genéticos y no genéticos de vulnerabilidad, los factores de riesgo o protectores del ambiente, y la interacción entre estos factores (Schmidt, Storey, Greenberg, Santiago, Li, \& Murphy, 2000; Silberg, Rutter, Neale, \& Eaves, 2001).

En términos genéticos, los comportamientos de ansiedad no son causados por alteraciones en genes individuales, sino que son el resultado de alteraciones más sutiles en múltiples genes, cada uno contribuyendo parcialmente a la expresión del comportamiento. La magnitud de la contribución genética es relativamente moderada e inferior a otros trastornos psiquiátricos, como por ejemplo la esquizofrenia o transtornos neurológicos como Hungtingon's (Leonardo \& Hen, 2006).

El escaso éxito en descubrir los genes para la ansiedad se debe a su gran complejidad. Diversas investigaciones han estudiado los componentes de la ansiedad tanto en humanos como en animales.

Las diferencias cerebrales de los individuos muy ansiosos probablemente se habrán desarrollado a consecuencia de diferencias tanto en la genética como en el ambiente que les ha rodeado durante su vida. Los estudios con gemelos corroboran esta hipótesis. Un análisis de la frecuencia de ansiedad en gemelos monocigóticos y dicigóticos reveló que 
aproximadamente de un 30 a un $40 \%$ de la varianza de ocurrencia puede ser atribuida a la variación genética (Hettema, Neale, \& Kendler, 2001; Leonardo \& Hen, 2006; Sullivan, Neale, \& Kendler, 2000).

Los estudios con gemelos han corroborado también la influencia de los factores genéticos en las manifestaciones somáticas de la ansiedad. Estos estudios demuestran que respuestas fisiológicas tales como el pulso, la respiración y las respuestas galvánicas de la piel son más semejantes en los gemelos monocigóticos que en los dicigóticos. También se da una elevada heredabilidad en las reacciones ansiosas. Dada la precocidad del desarrollo de la ansiedad, estudios con niños de padres ansiosos se han convertido en una importante fuente de información: estos niños sufren más síntomas de ansiedad que el resto (Hettema et al., 2001; Merikangas \& Pine, 2002).

Mientras las estimaciones humanas de heredabilidad confían en métodos epidemiológicos, los análisis de rasgos conductuales complejos en ratones se basan generalmente en el uso cepas que se diferencian en un comportamiento de interés. En particular, existe un trabajo sobre la llamada "emotividad" que se piensa está relacionada con la ansiedad en los humanos (Crawley, 2000). Los modelos de ansiedad en animales estudian los circuitos y los factores fisiológicos homólogos a ambas especies (animal y humana). Tal como en los humanos, los animales responden a la presencia de una potencial amenaza con respuestas autonómicas características y comportamientos defensivos (Leonardo \& Hen, 2006).

Los resultados de los estudios con animales apoyan el origen genético de la ansiedad. Experiencias de procreación selectiva con mamíferos muestran que la actividad emocional análoga a la ansiedad está controlada por múltiples genes (Merikangas \& Pine, 2002).

Un gen candidato (que puede estar implicado en la patología debida a la función y/o localización del gen) a la influencia genética en la ansiedad incluye un polimorfismo funcional localizado en la región promotora del gen transportador de serotonina (gen 5-HTT), 
que ha sido relacionada con medidas del neuroticismo, evitación del peligro y ansiedad. Como el 5-HTT ha sido implicado en la ansiedad y en la ansiedad patológica, se espera que la desregulación de la transmisión 5-HTT lleve a una vulnerabilidad para el desarrollo del desorden de ansiedad (Lesch et al, 1996; Schmidt, Storey, Greenberg, Santiago, Li, \& Murphy, 2000).

Por otro lado, la ansiedad estado es ampliamente influida por el ambiente, con contribuciones tanto de los factores del ambiente específico no-compartido o individual, como de los factores ambientales compartidos o familiares. En comparación, la ansiedad rasgo ha mostrado una casi igualdad entre las contribuciones genéticas y de los ambientes no-compartidos (Eley \& Gregory, 2004; Legrand, McGue, \& Lacono, 1999; Warren, Scmitz, \& Ende, 1999).

En términos de géneros, según Hettema, Prescott, Myers, Neale y Kendler (2005), en un estudio con más de 5.000 gemelos, la estructura subyacente de los factores de riesgo genético y ambiental para los trastornos de ansiedad es similar para varones y mujeres. 


\subsection{Otros modelos}

\subsubsection{Modelo rasgo-estado de Spielberger}

El modelo Estado/Rasgo de la ansiedad fue desarrollado inicialmente por Cattell y Scheer (1961) y más tarde por Spielberger (1972). Este modelo distingue dos aspectos fundamentales de la ansiedad: la ansiedad como un estado emocional transitorio y la ansiedad como un estado más permanente, que corresponde a un rasgo de la personalidad.

Se considera que la ansiedad estado es un estado emocional transitorio sensible a los cambios ambientales y que la ansiedad rasgo es un rasgo de características relativamente permanentes $\mathrm{y}$, por lo tanto, menos sensible a los cambios ambientales (Cattell \& Scheier, 1961).

La ansiedad estado puede ser descrita, así, como sentimientos subjetivos conscientemente percibidos como inadecuados y la tensión acompañada de un aumento de la activación (excitación) en el sistema nervioso autónomo, es decir, una condición emocional transitoria del cuerpo humano, que varía en intensidad y es inestable con el tiempo. La ansiedad estado se conceptualiza como un estado o condición emocional transitoria del organismo humano que se caracteriza por sensaciones desagradables de tensión y temor, conscientemente percibidas, y por la mayor actividad del sistema nervioso autónomo. Las puntuaciones de ansiedad-estado pueden variar en intensidad según la intensidad del peligro percibido y oscilar en el tiempo (Hackfort \& Schwenkmezger, 1993).

La ansiedad rasgo se define como una predisposición en el comportamiento, independiente del tiempo, lo que lleva a una persona a ver situaciones que, en principio, objetivamente no son no muy peligrosas como amenazas; es decir, una tendencia a percibir una amplia gama de situaciones como peligrosas o amenazantes. Así, la ansiedad rasgo se 
refiere a las diferencias individuales relativamente estables en la propensión a la ansiedad. Las puntuaciones de ansiedad rasgo son menos sensibles a los cambios debido a situaciones ambientales y se mantienen relativamente constantes a lo largo del tiempo (Hackfort \& Schwenkmezger, 1993).

Según estos autores (Cattell \& Scheer, 1961; Spielberger, 1972), no existe una relación consistente entre altos niveles de ansiedad rasgo y manifestaciones de la ansiedad estado en situaciones de riesgo. Sin embargo, en situaciones que ponen en duda la adecuación y autoestima de la persona, los individuos con ansiedad rasgo elevada son más susceptibles (ya que, en estos individuos, a menudo están presentes pensamientos en relación con el miedo al fracaso). La amenaza percibida por la persona es el resultado de la combinación de las experiencias del pasado, de sus características personales y del estímulo actual.

\subsubsection{Teoría de la sensibilidad a la ansiedad}

Actualmente se considera que la sensibilidad a la ansiedad (SA) constituye un factor de riesgo importante para desarrollar trastornos de ansiedad (McLaughlim \& Hatzenbuehler, 2009; Sandín, Valiente, Chorot, \& Santed, 2005) y que comprende influencias genéticas y ambientales (Merikangas \& Pine, 2002).

El concepto de sensibilidad a la ansiedad es un aspecto central de la teoría de expectativa de la ansiedad, y consiste en el miedo a los síntomas de ansiedad, el cual se supone debido a la creencia de que la ansiedad y sus sensaciones poseen consecuencias peligrosas o dañinas (Stein, Jang, \& Livesley, 1999). La sensiblilidad a la ansiedad fue propuesta como un factor de predisposición al desarrollo de los trastornos de ansiedad (Reiss, 1991). 
La sensibilidad a la ansiedad es considerada como una respuesta a diferencias individuales en el temor general y como una disposición para varios tipos de trastorno de ansiedad, incluso trastorno de pánico, desorden de ansiedad social, fobia específica, y desorden de estrés postraumático. Esto es porque SA es un amplificador de ansiedad: cuando personas muy sensibles a la ansiedad se preocupan, se alarman sobre sus sensaciones relacionadas con la excitación, que en adelante intensifica su ansiedad. Consecuente con esta formulación son las pruebas que muestran que el SA es elevado en las personas con varios tipos de la ansiedad en comparación con los participantes de control, y el nivel actual de AS de la persona predice el riesgo de futuros síntomas de ansiedad (Taylor, 1999).

Así, la sensibilidad a la ansiedad presenta una estrecha relación con los miedos y los trastornos de ansiedad en general (Valiente, Sandín, \& Chorot, 2002), pero tiene un papel mucho más específico en el trastorno de pánico, siendo un factor de riesgo para el desarrollo de esta patología (Cox, 1996; McNally \& Eke, 1996; Schmidt, Lerew, \& Jackson, 1997) y tiene un componente muy fuerte de herencia (Stein, Jang, \& Livesley, 1999).

La sensibilidad a la ansiedad permite predecir futuros ataques de pánico en adolescentes (Hayward, Killen, Kraemer, \& Taylor, 2000; Weems, Hayward, Killen, \& Taylor, 2002) y adultos (Scmidt, Lerew, \& Jackson, 1999). Existen también algunos estudios que sugieren que la sensibilidad a la ansiedad está asociada a un futuro desarrollo de patología ansiosa (Maller \& Reiss, 1992; Schmidt, Zvolensky, \& Maner, 2006; Taylor \& Cox, 1998).

McLaughlim y Hatzenbuehler (2009), en un estudio realizado con 1065 adolescentes, concluyeron que la sensibilidad a la ansiedad es un mediador de la relación longitudinal entre los acontecimientos estresantes y la sintomatología ansiosa, porque para estos autores la existencia de tales eventos es un buen predictor del desarrollo de la sensibilidad a la ansiedad.

Los factores que han sido mostrados para modular el susto (scare, en inglés), como la afectividad negativa, pueden mediar la diferencia sexual presente en la ansiedad 
contextual. Aunque las pruebas para diferencias de género en afectividad negativa sean inconsecuentes, las mujeres tienden a marcar valores más altos en afectividad negativa que los hombres (Jex, Adams, \& Ehler, 2002; Stewart, Conrod, Gignac, \& Pihl, 1998). Por supuesto, los factores biológicos y psicosociales pueden relacionarse; las diferencias sexuales en la valoración de amenaza contribuyen a las diferencias sexuales en respuestas del sistema hipotálamo-pituitaria-adrenal a acontecimientos estresores (Rasmusson \& Friedman, 2002).

Varios estudios han encontrado pruebas de mayor SA entre mujeres tanto en muestras no clínicas de adolescentes (Bernstein, Zvolensky, Stewart, Comeau, \& LeenFelder, 2006) como de adultos (Deacon, Abramowitz, Woods, \& Tolin, 2003; Zvolensky, McNeil, Porter, \& Stewart, 2001). La investigación con muestras clínicas, sin embargo, ha sido menos consecuente. Schmidt y Koselka (2000) encontraron considerablemente mayor SA entre mujeres con desorden de pánico que en hombres con el mismo desorden, mientras que Foot y Koszycki (2004) no encontraron ningunas diferencias de género. La medida de $\mathrm{SA}$, las características de la muestra y los métodos eran similares en ambos estudios y, por lo tanto, la discrepancia de las conclusiones es difícil de interpretar.

Las diferencias de género más consecuentes han sido encontradas dentro de ciertas dimensiones de SA. Aunque estudios taxométricos de SA dan una estructura de factores similar para hombres y mujeres (Dehon, Weems, Stickle, Costa, \& Berman, 2005), las mujeres relatan mayor miedo de las consecuencias físicas de la ansiedad (Stewart, Taylor, \& Baker, 1997), mientras que los hombres relatan mayor miedo de las consecuencias sociales de la ansiedad (Foot \& Koszycki, 2004).

Otra explicación posible para las diferencias de género dentro de una dimensión particular de SA consiste en que los síntomas físicos son experimentados por hombres y mujeres igualmente, pero las mujeres reciben el refuerzo más positivo por expresar preocupación en relación a estos síntomas. Con el tiempo, tal refuerzo podría aumentar la 
atención autoenfocada, que contribuiría a diferencias reales en la experiencia de síntomas físicos (McLean \& Anderson, 2009).

Según Grillon (2008) la sensibilidad elevada de las mujeres a la ansiedad contextual puede contribuir a un riesgo más alto de transtornos de ansiedad en las mujeres en comparación a los hombres.

\subsubsection{Modelo tripartito de la ansiedad y depresión}

La diferencia cognitiva principal entre ansiedad y depresión es que la depresión presenta una auto-apreciación negativa en términos globales y evasivos; y la ansiedad implica déficits personales selectivos y específicos (Beck, Emery, \& Greenberg, 1985).

La ansiedad está orientada hacia el futuro (amenazador e incierto) y la depresión hacia el pasado (Beck, Brown, Steer, Eidelson, \& Riskind, 1987).

Los pensamientos automáticos de pérdida y fracaso están asociados a la depresión, mientras que las cogniciones de un futuro peligroso son reflejo de la ansiedad (Clark, 1986).

El constructo de desesperanza es específico de la depresión pero no de la ansiedad (Clark, Beck, \& Brown, 1989).

Sin embargo, existe una comorbilidad entre los síntomas de depresión y ansiedad (Kim, Braun, \& Kunik, 2001; Lenze, Mulsant, Shear, Schulberg, Dew, \& Begley, 2000), y esta comorbilidad es mayor en los adultos más mayores que en los más jóvenes (Krasucki, Howard, \& Mann, 1998; Wetherell, Gatz, \& Pedersen, 2001; Zeiss, Lewinsohn, Rhode, \& Seeley, 1996).

Ansiedad y depresión pueden existir en varias formas, incluyendo trastornos distintos con síntomas combinados o un solo trastorno secundario a un problema médico (Lydiard \& Brawman-Mintzer, 1998). 
Según Rapaport (2001) la ansiedad y la depresión coexisten con tanta frecuencia que la comorbilidad puede ser más la regla que la excepción.

Los trastornos de ansiedad aumentan la probabilidad de subsiguientes trastornos depresivos, más que a la inversa (Avenevoli, Stolar, Li, Dierker, \& Merikangas, 2001; De Graaf, Bijl, Have, Beekman, \& Vollebergh, 2004; Merikangas, Zhang, Avenevoli, Acharyya, Neuenschwander, \& Angst, 2003; Stein, Fuetsch, Muller, Hofler, Lieb, \& Wittchen, 2001; Wetherell, Gatz, \& Pedersen, 2001; Woodward \& Fergusson, 2001), aunque algunos subtipos de ansiedad, tales como la fobia social y el pánico, raramente preceden a la depresión (Lewinsohn, Zinbarg, Seeley, Lewinsohn, \& Sack, 1997).

En la literatura especializada se encuentran tres perspectivas sobre la relación entre ansiedad y depresión: la tradicional, la comorbilidad entre ansiedad y depresión, y la perspectiva de la mezcla ansiedad/depresión (Stahl, 1997).

La perspectiva tradicional defiende que las dos condiciones son transtornos independientes que deben ser claramente separados en términos de conceptualización y diagnóstico (Claghorn, 1970; Downing \& Rickels, 1974; Mountjoy \& Roth, 1982; Roth, Curney, Garsige, \& Kerr, 1972). Se basa en los resultados de estudios que indican que cada uno de estos trastornos tiene un patrón distinto en términos de tasas de superioridad, perfil de síntomas, curso longitudinal y respuesta al tratamiento (Rivas-Vazquez, Saffa-Biller, Ruiz, Blais, \& Rivas-Vazquez, 2004).

En la perspectiva de la comorbilidad entre ansiedad y depresión, los dos transtornos ocurren simultáneamente como síndromes separados. Así, ni uno ni otro trastorno son vistos como una parte del otro, sino que son percibidos como teniendo una tendencia a ocurrir conjuntamente. Cuando ambos están presentes, cada condición es diagnosticada y tratada simultáneamente (Rivas-Vazquez, et al., 2004).

La perspectiva de la mezcla ansiedad/depresión postula que los dos transtornos ocurren a lo largo de un continuo. Existen rellanos a lo largo de ese continuo y esos rellanos y sub-rellanos existen en múltiples combinaciones. Estos rellanos son síndromes o 
conjuntos de síndromes que no cumplen los criterios completos del DSM en términos de número y duración de los síntomas (Helmchen \& Linden, 2000). En esta perspectiva, la ansiedad y la depresión son diagnosticadas en sus rellanos y sub-rellanos, y el tratamiento es individualizado y atribuido a la combinación de ansiedad y depresión específica del paciente (Rivas-Vazquez, et al., 2004). La superposición entre ansiedad y depresión se debería a un conjunto de genes comunes que influyen sobre ambas perturbaciones (Eley \& Stevenson, 1999; Thapar \& McGuffin, 1997). No obstante, para algunos autores (Eley \& Stevenson, 1999; Silberg, Rutter, \& Eaves, 2001; Silberg, Rutter, Neale, \& Eaves, 2001), los factores ambientales también tienen su importancia en niños, aunque no en adultos.

La frecuente comorbilidad entre ansiedad y depresión se refleja de forma consistente en las elevadas correlaciones entre las medidas de ansiedad y depresión. Este hecho ha llevado a Clark y Watson (1991) a la formulación del modelo tripartito de la ansiedad y la depresión (Watson, 2000).

El modelo tripartito de la ansiedad y depresión ha sido estudiado por varios autores (Brown, Chorpita, \& Barlow, 1998; Burns \& Eidelson, 1998; Clark \& Watson, 1991; Creamer, Foran, \& Bell, 1995; Luten, Ralph, \& Mineka, 1997; McCormik \& Strauss, 1995; Steer, Clark, \& Ranieri, 1994) y permite comprender tanto los síntomas comunes a ambos transtornos como aquellos que son característicos de cada uno. De acuerdo con este modelo, estos dos constructos comparten una dimensión -el afecto negativo- que incluye varios aspectos del estrés emocional general, como tristeza, enfado, autocrítica y miedo (Mineka, Watson, \& Clark, 1998).

El modelo también postula que la ansiedad y la depresión pueden distinguirse por otras dos dimensiones: afecto positivo e hiperexcitación fisiológica (Cook, Orvaschel, Simco, Hersen, \& Joiner, 2004; Voelz \& Joiner, 2002).

El afecto positivo se define por cuestiones relacionadas con la adaptación al medio y la energía. Una falta del afecto positivo es defendida como específicamente relativa a la depresión. La hiperexcitación fisiológica es una tensión somática (como mareos, 
hiperventilación) y está asociada específicamente a la ansiedad (Cook, et al., 2004; Voelz \& Joiner, 2002). Sin embargo, algunas investigaciones sugieren que la hiperexcitación fisiológica, no es tanto una característica de todos los transtornos de la ansiedad, sino que está particularmente relacionada con el trastorno de pánico (Brown, Chorpita, \& Barlow, 1998; Mineka, Watson, \& Clark, 1998).

Aunque haya sido desarrollado para la población adulta, diversos estudios apuntan a que el modelo tiene aplicabilidad en niños y adolescentes y en poblaciones psiquiátricas y no psiquiátricas (Brown, et al., 1998; Chorpita, Albano, \& Barlow, 1998; Chorpita, Plummer, \& Moffitt, 2000; Cook, et al., 2004; Laurent \& Ettelson, 2001; Lonigan, Phillips, \& Hooe, 2003; Sharon, McCreary, Joiner, Schmidt, \& Ialongo, 2004).

Clark, Steer y Beck (1994), Steer, Beck, Clark y Ranieri (1995) y Watson y colaboradores (1995), obtuvieron resultados que mostraron una gran consistencia con el modelo tripartito ya existente y con los modelos cognitivos (Beck, 1967; 1976; Beck, Emery, \& Greenberg, 1985), concluyéndose que los síntomas motivacionales y cognitivos son más específicos de la depresión, mientras que los síntomas de manifestaciones somáticas se asocian más directamente a la ansiedad. 
CAPÍTULO III

NEUROPSICOLOGÍA DE LA ANSIEDAD 
Comportamientos emitidos en situaciones de ansiedad tienen una amplia distribución y continuidad filogenética, sugiriendo que la ansiedad es un sistema comportamental con el mismo origen evolutivo en mamíferos y otros animales. Ya desde los trabajos pioneros de Charles Darwin (1872) en el siglo XIX, las semejanzas entre los aspectos comportamentales de las emociones fueron resaltadas en diversas especies. De esta forma, las bases neurales responsables de tales estados serían áreas cerebrales embriológicamente antiguas, y preservadas en muchas especies (Garcia et al., 2007).

Las estructuras generalmente investigadas son el sistema septo-hipocampal (con la amígdala) y los córtex temporal y prefrontal (Garcia et al., 2007; Leonardo \& Hen, 2006). Por ejemplo, estudios estructurales con imágenes de resonancia magnética (MRI) han revelado correlaciones neurales importantes de los trastornos de ansiedad con el hipocampo, la amígdala y la corteza prefrontal (Hasler, Drevets, Manji, \& Charney, 2004).

Estas estructuras funcionan como una interfaz, recibiendo informaciones que llegan desde los diferentes sistemas sensoriales, asociándolas con las memorias ya almacenadas por el hipocampo e interpretándolas como emocionalmente relevantes o no, para posteriormente coordinar la emisión de respuestas (Garcia et al., 2007).

\subsection{Modelos precursores de los modelos neuropsicológicos actuales}

\subsubsection{Los introvertidos neuróticos de Eysenck.}

Esta teoría (Eysenck, 1967, 1981) se basa en diferentes niveles o intensidades de estimulación cortical. El autor sugiere que las emociones positivas o agradables aparecen asociadas a niveles moderados de estimulación, y que las emociones negativas o 
desagradables aparecen asociadas a niveles de estimulación tanto muy bajos como muy elevados. Dimensionalmente hallamos el neuroticismo en un extremo y en otro la estabilidad emocional. El factor biológico subyacente a estas dimensiones de la personalidad es la reactividad del sistema nervioso autonómico, que influye en la actividad del sistema límbico. Las personas neuróticas tienen una actividad del sistema nervioso autonómico intensa y niveles de habituación muy bajos.

Esta teoría tuvo un papel preponderante tanto por sí misma como por ejercer una fuerte influencia en las teorías posteriores (Barlow, 1988).

\subsubsection{La inhibición comportamental de Gray.}

Gray (1982) propone que la personalidad y las emociones son determinadas por dos sistemas afectivo-motivacionales. En su modelo, el sistema primario es el sistema de inhibición comportamental, que es regido por el septo hipocampal. Después de un estímulo especifico (particularmente señales de castigo, novedad,...), el sistema de inhibición comportamental reprime el comportamiento y orienta la atención hacia el estímulo relevante. Desde el punto de vista de Gray, un sistema de inhibición comportamental que reacciona exageradamente a la novedad y al castigo es la base biológica de la ansiedad. Un sistema complementario responde a señales de recompensa (señales de seguridad) facilitando la aproximación. Estos dos sistemas regulan buena parte del comportamiento del organismo. 


\subsubsection{Evitación del daño.}

Cloninger (1986) acepta la evidencia del modelo de dos sistemas de Gray (especialmente el sistema de inhibición comportamental y el sistema de activación comportamental). Pero prefiere hablar de "evitación del daño" en lugar de "ansiedad" (sistema de inhibición comportamental muy activo) y "demanda elevada de novedad" en vez de "impulsividad" (sistema de activación comportamental fuerte). A esto Cloninger añade un tercer rasgo identificado anteriormente por teóricos de la personalidad como Eysenck en análisis factoriales, pero que asumían posiciones poco relevantes en esas teorías. Este rasgo fue denominado por Eysenck "psicoticismo". Cloninger lo denominó "dependencia de la recompensa" y lo describe como una tendencia heredada a responder intensamente a la recompensa y a mantener el comportamiento recompensado.

Este autor propone que cada uno de los rasgos hereditarios de personalidad se encuentra fuertemente relacionado con variaciones de los caminos del neurotransmisor monoaminérgico específico. Especialmente, una elevada evitación del daño (o ansiedad) se asocia a una elevada actividad serotonérgica; una elevada demanda de innovación está asociada a una baja actividad dopaminérgica basal; y una elevada dependencia de recompensa está asociada a una baja actividad noradrenérgica. Cloninger sugiere que cuando la elevada evitación del daño se combina con baja dependencia y baja demanda de novedad, las personas desarrollan un patrón muy fuerte de reconocimiento de amenazas ocultas y de relaciones inciertas, y presuponen un riesgo potencial demasiado elevado en circunstancias normales. Estos individuos se hacen demasiado sensibles y desarrollan ansiedad crónica, con patrones fuertes de ansiedad anticipatoria, preocupación rumiante e introversión social (Cloringer, 1986). 


\subsection{Sistema Límbico}

Hay un interés creciente en relación al papel de la regulación de la emoción en el desarrollo de síntomas de ansiedad y sus transtornos (Bosquet \& Egeland, 2006; Muris, 2006). Las áreas del cerebro relacionadas con los diferentes componentes de la emoción se encuentran en el sistema límbico. En la actualidad, se acepta que las emociones son controladas por un circuito nervioso que amplifica y mantiene las reacciones emocionales. Este circuito integra el hipotálamo, desde donde parten las reacciones viscerales (hambre, sed, temperatura, sueño, libido,...), la amígdala, que controla la expresión del comportamiento, la corteza cingulada, que produce la conciencia de la emoción, y el hipocampo, que participa en la memoria de las emociones (Castro-Sierra, León, Domínguez, \& Riviera, 2007; Jeannerod, 2005)

El tálamo recibe las aportaciones de casi todos los sistemas sensoriales y después, tras evaluarlas, proyecta esta información a las áreas corticales adecuadas. Es una estrutura clave entre los sentidos y la corteza. El mal funcionamiento del tálamo puede ser motivo de sobrecarga sensorial, o de que la corteza malinterprete o no reciba información vital, causando problemas en la comprensión de las señales sociales, y en la interpretación del lenguaje sensorial (Jeannerod, 2005; Tirapu, Ríos, \& Maestú, 2008).

El hipocampo es un órgano que procesa una mezcla de señales relacionadas con los sentidos y los recuerdos recientes. Esto puede tener que ver con el poder de los sentidos para evocar recuerdos y las emociones experimentadas. El hipocampo también parece tener un papel a la hora de decidir si vale la pena o no almacenar la información recibida de los sentidos (Castro-Sierra, et al., 2007; Jeannerod, 2005).

El sistema septo-hipocampal es el principal componente del sistema de inhibición comportamental, encargado de respuestas como la de evaluación de riesgo. Ya en el caso del miedo, cuando la amenaza es real y próxima, el sistema regulador sería denominado 
sistema de activación conductual, formado por estructuras como el hipotálamo, la amígdala y la sustancia gris peri-acueductal, que controlan respuestas como huída y lucha (Garcia, et al., 2007).

\subsubsection{Hipotálamo}

El sistema endocrino es formado por una serie de glándulas en el cuerpo que secretan hormonas directamente al torrente sanguíneo y tienen la tarea de vigilar el medio ambiente interior no sólo de cada órgano, sino de todo el cuerpo. En una situación percibida como peligrosa, el hipotálamo ordena la liberación de adrenalina en la sangre, que es la hormona mensajera más rápida y que actúa en el sentido de preparar nuestro cuerpo para luchar o para huir de inmediato. El corazón trabaja más rápido, la respiración se acelera y aumenta la sudoración para enfriar el cuerpo y las pupilas se dilatan para mejorar la visión (Jeannerod, 2005).

El centro de mando del sistema endocrino es el hipotálamo, que es responsable de la homeostasis, pues transmite la información al sistema nervioso autónomo, que trata de mantener el equilibrio en algunas funciones de regulación del cuerpo. El hipotálamo es responsable de transmitir la información a la glándula pituitaria o hipófisis, que es un puente de comunicación entre el sistema endocrino y nervioso, y que hace la interpretación de estos mensajes para después transmitir las informaciones descodificadas a su glándula en el organismo responsable de producir las hormonas que regulan las funciones biológicas que desee. El hipotálamo, por lo tanto, regula el sistema endocrino a través de la hipófisis, que luego hace la comunicación y dirige directamente a las demás glándulas del cuerpo con las interpretaciones de los mensajes venidas del hipotálamo (Tirapu, Ríos, \& Maestú, 2008). 


\subsubsection{Hipocampo}

El hipocampo ha sido implicado en la regulación de los procesos de la ansiedad (Bertoglio, Joca, \& Guimarães, 2006). Existe una evidencia considerable para sugerir que el hipocampo puede ser diferenciado entre los polos dorsal y ventral (Bannerman, Rawlins, McHugh, Deacon, Yee, \& Bast, 2004). Comportamientos defensivos relacionados con la ansiedad son preferentemente regulados por el polo ventral (Bertoglio et al., 2006; Pentkowski, Blanchard, Lever, Litvin, \& Blanchard, 2006). El mecanismo con el cual el polo ventral puede regular los comportamientos incondicionados de defensa es a través de las conexiones con el hipotálamo y el complejo amigdaloide (Pentkowski et al., 2006).

Un estudio con MRI volumétrico relató el volumen hipocampal más pequeño de lo normal como un factor de vulnerabilidad preexistente para el trastorno de estrés pós traumático después de la exposición al trauma psicológico (Gilbertson, et al., 2002). Basado en este descubrimiento notable, los individuos sanos que son vulnerables para desarrollar transtornos de ansiedad deberían mostrar el volumen hipocampal más pequeño que el normal.

Además, un estudio con animales relató una correlación negativa entre volumen hipocampal y ansiedad rasgo en ratas con comportamiento de ansiedad normal (Kalisch, et al., 2006).

Un trabajo de Yamasue y colegas (2008), con una muestra relativamente grande de personas jóvenes y sanas, halló evidencia de que un hipocampo derecho más pequeño está asociado a mayor ansiedad rasgo en los dos géneros. Por otra parte, este estudio reveló una significativa asociación entre la evitación del daño y el volumen de la corteza prefrontal izquierda anterior, pero sólo en las mujeres. 


\subsubsection{Eje hipotálamo-pituitaria-adrenal (HPA)}

El eje HPA ha sido implicado en la patogénesis de la ansiedad. Pruebas significativas sugieren que los factores tempranos ambientales establecen la reactividad del eje HPA que puede ser definido para toda la vida y puede ser transmitido epigenéticamente a las generaciones siguientes (Leonardo \& Hen, 2006).

En humanos, alteraciones de la fisiología y la función del eje HPA han sido consecuentemente encontradas en individuos con ansiedad (Strohle \& Holsboer, 2003).

La hormona de liberación de corticotrofina $(\mathrm{CRH})$ es el mediador primario de la actividad HPA. El estrés induce la liberación de CRH del hipotálamo, que causa la liberación de adrenocorticotrofina de la glándula pituitaria y por último conduce a la liberación de hormonas glucocorticoides del estrés de la glándula suprarrenal (Miller \& O'Callaghan, 2002). El CRH también modula la ansiedad al ser inyectada directamente en el cerebro (Dunn \& Swiergiel, 1999). Los estudios en ratones modificados genéticamente han examinado también el papel posible de dos receptores $\mathrm{CRH}$ en relación a la ansiedad (Keck, Holsboer, \& Muller, 2004).

Vuong, Oliver, Scholl, Oliver y Forster (2010) estudió el efecto liberador de la corticotrofina, a fin de entender su efecto sobre la ansiedad, más concretamente, el efecto sobre la ansiedad provocada por la abstinencia de las anfetaminas. El factor liberador de corticotrofina (CRF) es liberado de la amígdala en respuesta a factores de estrés, y aumenta las conductas similares de la ansiedad en los roedores. Asimismo, los psicoestimulantes activan las neuronas del CRF, y las alteraciones de los niveles de CRF en todo el sistema límbico se han observado durante la abstinencia de psicoestimulantes. La abstinencia de psicoestimulantes aumenta los estados de ansiedad, y las ratas tratadas por anfetamínicos muestran un aumento de los receptores serotoninérgicos CRF2 en la región del cuerpo de la célula, el núcleo dorsal del rafe (DRN). Los datos de este estudio sugieren que el tratamiento crónico de anfetaminas en ratas da lugar a un estado de mayor ansiedad que 
persiste después de la abstinencia de drogas, y que el antagonismo de los receptores CRF2 dentro de la DRN invierte este estado de ansiedad. En general, los resultados sugieren que el antagonismo de los receptores CRF2 puede ser un nuevo objetivo farmacológico para los estados de ansiedad durante la abstinencia de drogas.

\subsubsection{Amígdala}

De Olmos y colegas (2004) propusieron una subdivisión de la amígdala en:

i) el sistema olfativo caudal (el núcleo de la extensión olfativa lateral, núcleo cortical y postpiriforme y áreas amígdalo-piriforme);

ii) una extensión ventral del claustrum (núcleos laterales, básicos y posteriores) que forman un sistema frontotemporal;

iii) una extensión ventromedial especializada del striatum (núcleos amigdaloides central [CeA] y medial [MeA], y área amigdaloide anterior).

Los sistemas olfativos se parecen menos al aspecto nuclear de las divisiones del resto de la amígdala, pero muestran el aspecto laminar típico de áreas corticales. Ellos forman la parte caudal del lóbulo piriforme, recibiendo proyecciones originadas en los lóbulos olfativos accesorios y principales. Esta modalidad sensorial representa un modulador principal del comportamiento animal, en el comportamiento reproductivo y social en particular (Moffatt, 2003).

El sistema frontotemporal es la división más extensivamente estudiada de la amígdala. Forma la parte de las capas corticales más profundas de los lóbulos temporal, endopiriforme y frontales, recibe la información privilegiada de varias modalidades sensoriales (somato-sensorial, auditivo, visual) (LeDoux, 2007) y está intrincadamente relacionado con el hipocampo y la corteza prefrontal (Petrovich, Canteras, \& Swanson, 
2001; Akirav \& Maroun, 2007). Es activado por señales específicas que tienen que ver con situaciones adversas, montando una respuesta rápida a amenazas inminentes, por la activación de varios centros autonómicos y centros de neuroendocrina (áreas hipotalamicas), principalmente por CeA (Pêgo, 2007).

Típicamente este sistema de respuesta inmediato sólo es activado de forma pasajera, desempeñando un papel significativo para la supervivencia del individuo. Es importante que sus neuronas muestran capacidades plásticas (Fuchs, Flugge, \& Czeh, 2006; Kim, Song, \& Kosten, 2006; Sigurdsson, Doyere, Cain, \& LeDoux, 2007) que tienen un papel supuesto en la formación de memorias temerosas y en el comportamiento condicionado; por lo tanto creando un sistema de clasificación de valor en la interpretación de situaciones por su comparación con experiencias pasadas. Además, la actividad de la división frontotemporal se ve afectada por la respuesta ejecutiva (Akirav \& Maroun, 2007) y sistema mnésico (hipocampo); estos, por su parte, son modulados por el valor emocional de las experiencias por los caminos recíprocos que interconectan el amígdala y aquellas regiones cerebrales (Bishop, 2007; McEwen, 2007).

El sistema amígdalo-estriatal forma una extensión caudoventral del striatum (Swanson \& Petrovich, 1998). Su proyección gabaérgica de neuronas forma una salida inhibitoria que modula la actividad básica del tallo cerebral y núcleos cerebrales delanteros básicos. El núcleo CeA es la salida principal de la retransmisión de la información tratada de la amígdala de la mayor parte de los núcleos amigdaloides. Esto es responsable de varias respuestas vegetativas (taquicardia, hipertensión, susto, etc.) que son provocados por estímulos emocionalmente cargados (Pêgo, 2007).

El núcleo MeA recibe entradas directas del bulbo olfativo accesorio, y es visto como la parte de un sistema olfativo accesorio que modula la información feromonal y proyecta al núcleo de la estría terminal y áreas hipotalámicas. Esto muestra algún grado de dimorfismo sexual y está implicado en el control de neuroendocrina del comportamiento sexual y reproductivo (Swanson \& Petrovich, 1998). 
Así, la amígdala no puede ser vista como una unidad estructural o funcional, sino antes bien como una red compleja de sistemas (olfativo, autonómico y frontotemporal) que comunican la información relevante para la supervivencia (Pêgo, 2007).

Las estructuras de la amígdala son centrales para la emoción y la ansiedad (McClure, et al., 2006; Straube, Mentzel, \& Miltner, 2006).

La amígdala está relacionada con la capacidad de expresar el miedo y está estrechamente vinculada con otras estructuras nerviosas relacionadas con la memoria, incluyendo la corteza del lóbulo temporal y el hipocampo, que opera principalmente en la fijación de los recuerdos explícitos, que son objeto de una memoria consciente. La amígdala interviene en la memorización de las respuestas implícitas (inconscientes) del miedo, como el miedo condicionado. Por lo tanto, se pueden imaginar situaciones en las que la amígdala 'recuerda' tener miedo y el hipocampo 'había olvidado' el contexto en el que el miedo se ha hecho sentir: el sujeto presentaría reacciones vegetativas de miedo en respuesta a un estímulo que, además, no evocaría un recuerdo consciente. Este tipo de situación puede presentarse durante el desarrollo del niño. Si el sistema implícito (la amígdala) alcanza la madurez antes que el sistema consciente (el hipocampo), las emociones experimentadas en una edad muy temprana pueden tener efectos duraderos sin dejar huellas tan conscientes (Jeannerod, 2005).

Los estudios de neuroimagen funcionales recientes han revelado que las diferencias individuales en rasgos de ansiedad tienen que ver con diferencias en la respuesta neuronal a la activación emocional en la amígdala y regiones prefrontales entre individuos sanos (Hariri, et al., 2005; Milad, Pitman, Orr, Fischl, \& Rauch, 2005; Pezawas, et al., 2005; Most, Chun, Johnson, \& Kiehl, 2006).

En un estudio con adolescentes a los cuales se presentaron caras expresando temor ante las que se les pidió que se centraran en acontecimientos personales que provocan miedo, Beesdo y colegas (2009) refieren que los participantes con ansiedad muestran una mayor activación de la amígdala que los participantes sanos. 
Así, el aumento de las respuestas de la amígdala ante pistas emocionales ha sido demostrado en pacientes con ansiedad social (Killgore \& Yurgelun-Todd, 2005), estrés postraumático (Armony, Corbo, Clement, \& Brunet, 2005) y fobias específicas (Straube, et al., 2006).

\subsubsection{El núcleo de la estría terminal (BNST)}

La organización anatómica del núcleo de la estría terminal (BNST) ha sido objeto de una revisión constante y su parcelación no es, aún, consensual. Johnston (1923) al principio lo describió como una extensión del pallidum ventral, un área considerada parte de la substantia inominata, y que forma una serie continua que se extiende del tubérculo olfativo y del nucleus accumbens anteriormente, hasta la amígdala posteriormente. Esto recibe proyecciones masivas de áreas adyacentes incluyendo la amígdala por el bulto de fibras que forman la estría terminalis. De hecho, sus partes laterales y mediales forman dos pasillos de neuronas sublenticulares que están en la continuidad con los núcleos centrales y mediales de la amígdala. Comparten características comunes, neuroquímicas y de arquitectura neuronal y tienen la designación de amígdala extendida central y medial (Alheid, 2003).

Swanson (1998) ha propuesto una parcelación en las principales divisiones anterior y posterior (en relación con las fibras principales de la estría terminal), la primera puede ser más parcelada en zona dorsal, lateral y ventral, en relación con las fibras de la comisura anterior. Sin embargo, en una revisión posterior de la anatomía, los grupos de células de la división anterior se organizaron en grupos medial y laterales (Dong, Petrovich, \& Swanson, 2001).

La división medial, que incluye las áreas anterodorsal y anteroventral (Dong \& Swanson, 2006), se caracteriza por densas proyecciones a las regiones del hipotálamo estrechamente asociadas con el control neuroendocrino. El grupo lateral de la división 
anterior (que incluye la zona anterolateral) se caracteriza por las proyecciones a las áreas del hipotálamo relacionadas con la homeostasis autonómica y energética y el comportamiento de alimentación (Dong \& Swanson, 2004). Es importante señalar que la BNST se continúa con la MeA y la CeA y que estas estructuras, en conjunto, funcionan como una vía paralela a la de la zona adyacente del estriado. Estas relaciones anatómicas y funcionales apoyan la inclusión de la BNST, así como la sustancia innominada, en la llamada "amígdala extendida" (Alheid, 2003).

En una visión global, la amígdala extendida parece ser crítica para la mediación del comportamiento y de las respuestas autonómicas (CeA), reproductivas (MeA) y neuroendocrinas (BNST) (Swanson \& Petrovich, 1998).

El papel de la BNST en la activación del eje HPA y sus conexiones anatómicas con el hipotálamo neuroendocrino, así como con otras regiones del cerebro tales como el tronco cerebral, las áreas que regulan los comportamientos defensivos, sexuales, de ingestión, y los de exploración, se han establecido previamente (Choi, Furay, Evanson, Ostrander, Ulrich-Lai, \& Herman, 2007; Dong \& Swanson, 2006).

El papel de la BNST en el comportamiento emocional ha sido ampliamente explorado. Aunque existen semejanzas en la expresión fenotípica de BNST y de las actividades de la amígdala, también hay diferencias responsables por la función distinta de estas estructuras en el comportamiento emocional. La participación del BNST es evidente en los paradigmas en que el comportamiento está influenciado por estímulos de larga duración y en los paradigmas que evalúan los efectos comportamentales persistentes de incluso un estresor breve incondicionado (Pêgo, 2007).

A pesar de los resultados del comportamiento, cuya forma a menudo es similar (es decir, aumento de la alarma), no se ha demostrado que el BNST sirve para mediar en los comportamientos específicos provocados por las amenazas de corto duradera en la cual el periodo de peligro tiene un claro desplazamiento. Estas características de comportamiento dependiente del BNST sugieren un papel especial en la ansiedad, en lugar de en el miedo, 
en la medida que la ansiedad, a diferencia del miedo, se ve típicamente como un estado constante de temor no relacionado con los peligros ambientales inmediatos (Walker, Toufexis, \& Davis, 2003).

Mientras que la amígdala se activa transitoriamente en el condicionamiento de miedo (un estado emocional provocado por la neutralidad de pistas explícitas), la ansiedad (un estado emocional similar cree que es provocado por la difusión pistas contextuales) parece ser el resultado de la activación persistente de los BNST (Pêgo, 2007).

\subsubsection{Sistema de inhibición conductual}

Gray y McNaughton (2000) y McNaughton y Corr (2004) indican que la amígdala tiene un papel central en la ansiedad debido a su participación en el procesamiento de advertencias de castigo y en la promoción de la reacción de excitación del Sistema de Inhibición Conductual (BIS).

La teoría de Gray (1982) sobre las funciones del septo-hipocampal coloca el hipocampo en el centro de un sistema de estructuras relacionadas entre sí que constituyen el sistema de inhibición conductual, que tiene como funciones principales responder a las señales de la novedad, el castigo y de no refuerzo. Los puntos fuertes de esta teoría son que los fármacos ansiolíticos producen efectos conductuales similares a los producidos por las lesiones en el sistema y por el cambio de control de la actividad theta del hipocampo.

Existe una fuerte evidencia en el sentido de que las benzodiazepinas actúan alterando la función del hipocampo que se encuentra como la principal vía final común de acción en relación a los aspectos cognitivos y inhibitorios de la ansiedad (Leonardo \& Hen, 2006).

La hiperfunción del hipocampo puede conducir a la ansiedad como resultado de una mayor percepción del nivel de amenaza en situaciones que involucran estímulos conflictivos 
o de respuesta alternativa de conflictos y una represión cada vez mayor de acciones positivas y conocimientos (y no, como en otros modelos, para aumentar la producción de las acciones o las cogniciones negativas) (Leonardo \& Hen, 2006).

Una perspectiva importante sobre este aspecto hipocámpico de la ansiedad y que se aparta de las perspectivas cognitivas tradicionales se centra en el hecho de que hay que señalar que los trastornos de ansiedad, por lo menos algunos de ellos, pueden reflejar una disfunción que es fundamentalmente emocional, y sólo secundariamente cognitiva. Es decir, la hiperfunción del hipocampo podría producir una tendencia general para resolver los conflictos en términos de un sesgo negativo importante, incluso en tareas de memoria que no muestran un claro componente de amenaza (Leonardo \& Hen, 2006).

Para los mismos autores (Leonardo \& Hen, 2006), según las pruebas actuales sobre el funcionamiento del hipocampo y amigdalina, no es muy obvio que los trastornos de ansiedad sean puramente emocionales, a pesar de que puede haber subtipos más o menos cognitivos (principalmente de origen del hipocampo) y más o menos emocional (principalmente de origen amigdalino), convergiendo con los últimos avances en la psicología de la ansiedad que hacen hincapié en la importancia de cambiar el sesgo de procesamiento de la información. Un enlace final entre la memoria y la ansiedad que nos es dado por el hecho de que, en los pacientes con ansiedad, tanto las benzodiazepinas como la buspirona tarden un cierto número de días en producir sus efectos ansiolíticos. Considerando que los efectos inmediatos de estas sustancias en función del hipocampo y la adquisición del aprendizaje inhibitorio, se puede interpretar este retraso en el efecto terapéutico como extinción (o falta de memoria) como consecuencia de la eliminación de estas sustancias, lo que en realidad es un mecanismo de refuerzo. Esta separación entre los efectos rápidos y lentos también puede ser la base de la retención aparente de sesgo en el procesamiento, incluso cuando, en general, las altas dosis de benzodiazepinas reducen la retención de la información. 


\subsection{Actividad interhemisférica}

En los últimos veinticinco años, hemos asistido a una explosión de investigaciones sobre la asimetría de los hemisferios cerebrales relacionada con algunas dimensiones de la emoción, personalidad y psicopatología. La disminución de la motivación y/o de la afectividad negativa, funciones del córtex frontal derecho, sugieren que las personas con ansiedad presentan un mayor patrón de activación del lado derecho del córtex frontal (Thibodeau, Jorgensen, \& Kim, 2006).

Para comprender el papel neuronal en la ansiedad, numerosos investigadores se han concentrado en la comparación de niveles de la actividad entre el hemisferio izquierdo y el hemisferio derecho (Banich, 2003; Coan \& Allen, 2003; Heller, Koven, \& Miller, 2003; MacLeod \& Rutherford, 2004). Así, los dos hemisferios están masivamente interconectados por el cuerpo calloso, que transfiere y filtra la información intercambiada entre los dos lados del cerebro (Compton, Carp, Chaddock, Fineman, Quandt, \& Ratliff, 2008).

La investigación previa indica que la dinámica de la comunicación interhemisférica puede ceder perspicacias sobre el proceso de información que puede no ser evidente estudiando niveles de la actividad en un solo hemisferio (Banich, 2003). Por ejemplo, la comunicación interhemisférica contribuye a la atención selectiva, probablemente facilitando la transferencia de información relevante de la tarea e inhibiendo la transferencia de información irrelevante (Mikels \& Reuter-Lorenz, 2004). El estudio de la dinámica interhemisférica es importante, en particular porque la ansiedad se caracteriza por tendencias a una atención selectiva (MacLeod \& Rutherford, 2004; Mineka, Rafaeli, \& Yovel, 2003).

El fenómeno básico de sesgo atencional consiste en la atención preferente hacia estímulos indicadores de peligro o amenaza potencial, en comparación con estímulos emocionalmente neutros, particularmente cuando unos y otros se presentan de modo concurrente (Calvo \& González, 2000). 


\subsubsection{Cortices temporal e prefrontal}

Los subtipos de transtornos de ansiedad (como el pánico y ansiedad generalizada) pueden ser caracterizados por patrones distintos de actividad frontal y parietotemporal, según su nivel o tipo de excitación (Engels, et al., 2007).

Los investigadores han identificado dos subtipos principales de ansiedad, a saber excitación ansiosa y aprensión ansiosa. La excitación ansiosa se refiere a un estado de la excitación somática y tiene que ver con la aparición de mareos, incremento de los latidos cardiacos, excitación autonómica e hipervigilancia. Es la más estrechamente ligada a las sensaciones de pánico de la ansiedad. En contraste, la aprensión ansiosa describe los síntomas cognoscitivos de la preocupación verbal que anticipa amenazas y preocupaciones, y está más estrechamente ligada al fenómeno de preocupación (Nitschke, Heller, \& Miller, 2000).

La investigación ha mostrado que la excitación ansiosa y la aprensión ansiosa tienen diferentes correlaciones neuronales, dadas sus características cognoscitivas y conductuales diferentes. La excitación ansiosa tiene que ver con la actividad en el hemisferio derecho posterior, una región conocida por estar implicada en la vigilancia. En contraste, la aprensión ansiosa tiene que ver con la actividad del hemisferio izquierdo aumentada, en particular en el lóbulo frontal, consistente con la naturaleza verbal de la preocupación (Nitschke, et al., 2000).

Mathersul, Williams, Hopkinson y Kemp (2008), en un estudio que investigó las relaciones entre la ansiedad y la actividad lateralizada frontal y parietotemporal, agrupando a participantes sobre la base de humor negativo y electroencefalografía alfa. Las conclusiones claves de este estudio incluyen una mayor lateralización frontal derecha en participantes ansiosos y una mayor lateralización izquierda en participantes de control sanos; y 
lateralización frontal derecha en participantes de excitación ansiosa, pero lateralización frontal izquierda y parietotemporal derecha en participantes de aprensión ansiosa. Así, la asimetría parietotemporal derecha tuvo que ver con aprensión ansiosa, pero no con excitación ansiosa.

La corteza prefrontal anterolateral izquierda, cerca del área 46 de Brodmann, es la responsable por la auto-distracción de la ansiedad anticipatoria y la disminución de la ansiedad anticipatoria ha sido asociada a la activación de la corteza prefrontal anterolateral derecha, cerca de las áreas 10/46 de Brodmann (Kalisch, Wiech, Herrmann, \& Dolan, 2006).

En un estudio reciente, Hannesdóttir, Doxie, Bell, Ollendick y Wolfe (2010) se proponían investigar si la actividad eléctrica cerebral durante la niñez temprana se asoció con síntomas de ansiedad y la regulación de las emociones en una situación de estrés durante la infancia media. Los resultados de este estudio longitudinal indicaron que los niños que presentaban una asimetría frontal derecha en la primera infancia experimentaron más excitación fisiológica (aumento de la frecuencia cardíaca, disminución de la variabilidad de la frecuencia cardíaca) durante una tarea de discurso a los 9 años y menos capacidad para regular sus emociones, según lo informado por sus padres. Los resultados de este estudio sugieren que el patrón de asimetría frontal en la niñez temprana puede asociarse con el miedo, la ansiedad y la regulación de las emociones de la infancia.

A nivel cognoscitivo, una teoría influyente de aprensión ansiosa propone que la preocupación actúa como una estrategia de la evitación de la amenaza (Borkovec, Alcaine, \& Behar, 2004).

En términos neuronales, la evitación cognoscitiva por las personas preocupadas puede ser vista como una tendencia a favorecer el procesamiento verbal del hemisferio izquierdo en detrimento del hemisferio derecho, en particular cuando las amenazas de la información están presentes (Engels, et al., 2007).

Engels y colegas (2007) examinaron la actividad cerebral usando imágenes de resonancia magnética funcional (fMRI) con participantes que intentaban no hacer caso de 
palabras distractoras, negativas, positivas y neutras. Los participantes con aprensión ansiosa elevada mostraron actividad aumentada en la región de Broca en el hemisferio izquierdo durante la condición de palabra negativa. En contraste, participantes con marcadores altos en la excitación ansiosa mostraron una mayor actividad en el lóbulo temporal derecho inferior. Hofmann y colegas (2005), en un estudio con electroencefalogramas (EEG) concluyeron igualmente sobre la activación izquierda frontal en aprensión ansiosa.

Además, como el hemisferio derecho está especializado en el control de la excitación autonómica (Craig, 2005; Dalton, Kalin, Grist, \& Davidson, 2005), la excitación autonómica reducida como una consecuencia de preocupación podría deberse a un hemisferio derecho relativamente menos activo.

Se conoce que regiones de lóbulo frontal ejercen el control top-down sobre regiones subcorticales y corticales, incluso regiones de la corteza temporal que representan imágenes visuales como caras (Gazzaley, et al., 2007). Tal control fronterizamente mediado puede establecer un juego mental que influye en la forma como la información es tratada en regiones posteriores (Miller \& Cohen, 2001). Por lo tanto, una estrategia cognoscitiva de la evitación de amenaza en las personas propensas a preocupación puede implicar la activación de los sistemas izquierdos frontales que cambian el procesamiento en las regiones temporales que procesan la información de imagen visual.

Los resultados del estudio de Compton y colegas (2008) demuestran que individuos con elevados niveles de la aprensión ansiosa tienden a hacer más despacio la transferencia de información (de cara enfadada) de la izquierda al hemisferio derecho, en comparación con individuos con niveles inferiores de aprensión ansiosa. Los grupos no se diferenciaron en la transferencia interhemisférica de caras felices o neutras. Además, la ansiedad estado no estuvo correlacionada con los tiempos de transferencia interhemisféricos, indicando que el efecto era específico a aspectos relacionados con la preocupación de la ansiedad. Estos resultados apoyan la idea de que el cambio de la comunicación interhemisférica de 
información de amenaza puede ser un mecanismo neuronal de evitación cognoscitiva en individuos propensos a preocuparse.

Los resultados de este estudio complementan y amplían las conclusiones previas, manifestándose que no se trata sólo niveles regionales de actividad cerebral, sino también de comunicación de la información entre regiones cerebrales, que se diferencian entre individuos propensos o no propensos a preocuparse (Compton, et al., 2008).

Sin embargo, el cambio interhemisférico con poca probabilidad será el único mecanismo neuronal que contribuye a la evitación en ansiedad. Por ejemplo, un estudio (Hoehn-Saric, Lee, McLeod, \& Wong, 2005) encontró que durante una condición de preocupación inducida, el flujo de sangre cerebral aumentó en la región del lóbulo frontal izquierdo y ha disminuido en estructuras límbicas como la amígdala. Estos resultados de neuroimagen sugieren que la preocupación puede implicar la regulación top-down de regiones subcorticales por regiones frontales, una posibilidad que no es mutuamente exclusiva con el mecanismo interhemisférico descrito.

Es importante concebir la comunicación interhemisférica como un proceso dinámico. Por ejemplo, Mikels y Reuter-Lorenz (2004) han concebido el cuerpo calloso como un filtro selectivo que puede controlar, adaptándose al flujo de información entre los hemisferios. Estudios con métodos behaviorísticos han mostrado que la comunicación interhemisférica es modulada por el cambio de las demandas de tarea (Weissman \& Banich, 2000) y factores circunstanciales como evaluación del estrés (Compton, Wilson, \& Wolf, 2004). En contraste, la mayor parte de los estudios de ERP (potencial relacionado al evento) han tendido a ver el tiempo de la transferencia interhemisférica como relativamente fijado en la persona, y las diferencias individuales en tiempo de transferencia a menudo eran vistas como el reflejo anatómico de las diferencias entre las personas (Moes, Brown, \& Minnema, 2007; Patston, Kirk, Rolfe, Corballis, \& Tippett, 2007). 
Compton y colegas (2008) sugieren que las diferencias individuales en el tiempo de transferencia pueden ser dependientes del tipo de estímulo, porque de los resultados relacionados con la ansiedad sólo fueron significativos los limitados a caras enfadadas. 


\subsection{Neurotransmisores}

Los neurotransmisores son sustancias químicas especiales que cruzan el espacio sináptico y se unen a los receptores en la membrana de otras neuronas. Cuando algunos neurotransmisores se liberan en la sinapsis, se une a los receptores en el receptor de membrana de la célula y, como resultado de esta unión, se produce un ligero cambio en la membrana eléctrica. Si se estimulan los receptores suficientes, el cambio empieza un potencial de acción eléctrica en la célula receptora y delante, hasta que la información llegue a los órganos que tienen el poder de relacionarlos y procesarlos. Cuando los neurotransmisores excitadores son causa de que las células meta sean más sensibles a los potenciales de acción, y cuando son inhibidoras, de que la neurona meta sea menos sensible a los umbrales del potencial de acción (Jeannerod, 2005).

\subsection{1. Ácido gamma-aminobutírico (GABA)}

Estudios realizados sobre todo en los años 60 con los benzodiazepínicos (sustancias que interactúan con receptores gabaérgicos) demostraron que el principal neurotransmisor inhibitorio - el ácido gamma-aminobutírico (GABA) - estaba relacionado con la regulación del estado de ansiedad. La acción del GABA, según estos estudios, sería la de inhibir estructuras inductoras de ansiedad (Kalueff \& Nutt, 2007). Posteriormente, otros estudios mostraron que la serotonina también es parte importante de la neurotransmisión en esos sistemas. El aumento generalizado de la acción serotonérgica en las estructuras implicadas en la modulación de la ansiedad con el uso de fármacos en la clínica inhibe la aparición del estado de ansiedad (Garcia, et al., 2007).

Los receptores de benzodiazepinas (BZD) y GABA están presentes en todas partes en el sistema nervioso central, que afectan a varios sistemas funcionales. Sin embargo, los 
sistemas neurales implicados en la regulación de la ansiedad, según las pruebas experimentales, son particularmente los núcleos lateral y basolateral de la amígdala, que son ricas en receptores de BZD (Margis, Picon, Cosner, \& Silveira, 2003).

El núcleo lateral de la amígdala (LA) es un lugar clave de la plasticidad en que se basa el aprendizaje del miedo (Maren \& Quirk, 2004), y los circuitos inhibitorios en la estructura desempeñan un papel importante en la regulación de la memoria del miedo y su extinción (Zhang \& Cranney, 2008).

Los resultados de un estudio realizado por Cunha, Monfils y LeDoux (2010) indican que el GABACRs está involucrado en intra-LA comunicación neuronal mediante la modulación de una fracción considerable de las corrientes postsinápticas. Para estos autores esto sugiere que el GABACRs podría estar situado en la parte presináptica de los axones de las interneuronas y actuar como auto-inhibidores para reducir la liberación del GABA sináptico. Los resultados demuestran un nuevo papel del GABACRs, que hace avanzar la comprensión de la función de GABACRs en el cerebro, el conocimiento de los circuitos de la LA, y los mecanismos por los cuales los recuerdos del miedo se forman y almacenan. Los agonistas GABAérgicos (por ejemplo, benzodiazepinas), son fármacos comúnmente utilizados para tratar los trastornos relacionados con la ansiedad, sobre todo apuntando a GABAARs. Sin embargo, más allá de sus potentes propiedades ansiolíticas, estos medicamentos también dan lugar a efectos secundarios que incluyen sedación, daños motores y daños en la memoria. Estos efectos secundarios son, en parte, debidos al hecho de que el GABAARs se distribuye ubicuamente por todo el cerebro de los mamíferos. Otro problema es que estos fármacos a menudo conducen a la dependencia. Un tercer problema es que la desensibilización del GABAARs puede explicar por qué los pacientes con trastorno de ansiedad generalizada o trastorno de pánico presentan una menor vinculación a las benzodiazepinas en algunas áreas del cerebro anterior. Debido a los efectos no específicos de las benzodiazepinas, su potencial de dependencia, y su tendencia a desensibilizar, GABAARs no son óptimas como objetivo para el tratamiento a largo plazo de pacientes con 
trastornos de ansiedad. Como resultado, ha habido una demanda continua de ansiolíticos nuevos, más específicos, ya sea por la modulación indirecta de GABAARs través de la orientación norepinefrina (NE), serotonina y dopamina, o por la investigación por alteración de las subunidades específicas del GABAARs. Dado que el procesamiento de la amígdala se encuentra alterado en los trastornos de ansiedad (LeDoux, 2007; Monk, 2008), los resultados de Cunha, Monfits y LeDoux (2010) sugieren que GABACRs en la amígdala podría ser una alternativa útil para el desarrollo de las drogas para la ansiedad.

\subsubsection{Monoaminas}

Sabemos que los sistemas monoaminérgicos desempeñan un papel significativo porque las medicinas que afectan monoaminas, como serotonina y norepinefrina, son eficaces en el tratamiento de la ansiedad. La exacerbación del funcionamiento de las estructuras reguladoras de la ansiedad interfiere de manera significativa en el organismo como un todo, dando lugar a respuestas exageradas ante estímulos amenazadores e intensificando sensaciones desagradables. Así, amenazas que serían leves o insignificantes para otros individuos pasan a producir respuestas fisiológicas y comportamentales equivalentes a amenazas graves (Garcia et al., 2007).

Se conoce, así, que el sistema serotonérgico del cerebro desempeña un papel importante en la modulación de la ansiedad. Mientras que el papel de serotonina (5-HT) en estructuras subcorticales está bien investigado, poco se conoce sobre la función de los corticales 5-HT. En un estudio con ratas el papel de los 5-HT en el corteza prefrontal medial se mostró importante en la modulación de ansiedad (Pum, Huston, \& Muller, 2009). En este estudio, la reducción de 5-HT en la corteza prefrontal medial aumentó el comportamiento ansioso no condicionado, pero no había ninguna indicación de un efecto de la disminución del 5-HT en la corteza entorrinal o en la corteza occipital en la ansiedad. Además, los 
autores han dicho que la corteza prefrontal medial parece regular el aumento de los niveles de 5-HT en los núcleos del rafe inducidos por la ansiedad.

La distribución de los receptores 5-HT1A en el cerebro está bien correlacionada con una función en la modelación de los procesos emocionales y es comparable entre especies, incluyendo los humanos. Los receptores 5-HT1A están presentes en gran densidad en las áreas límbicas como el hipocampo, septo, algunos de los núcleos de la amígdala y la corteza entorrinal (Strobel, Gutknecht, Rothe, Broche, \& Lesch, 2005).

Como el receptor 5-HT1A ha sido implicado en mediar los efectos de agentes serotonérgicos en la ansiedad, en un estudio con ratones que han sido genéticamente creados para carecer del receptor 5-HT1A, sus autores (Klemenhagen, Gordon, David, Hen, \& Gross, 2006) argumentan que estos ratones presentaron una ansiedad aumentada en varias pruebas, incluyendo tareas hipocampal-dependientes.

A fin de probar para las exigencias espaciales y temporales específicas del receptor en mediar comportamientos deseosos, los investigadores generaron un ratón knockout (alterado genéticamente) que permitía el rescate selectivo de los receptores postsinápticos. Esta estrategia fue usada para mostrar que, mientras que la represión de la expresión de receptor en el adulto es ineficaz en la modulación de la ansiedad, la represión de la expresión de receptor hasta cuatro semanas en mayores de edad es suficientes para producir a ratones adultos un comportamiento aumentado relacionado con la ansiedad. Este descubrimiento indica que 5-HT es esencial para el establecimiento del recorrido normal que modula ansiedad en el cerebro durante el desarrollo postnatal (Leonardo \& Hen, 2006).

Los datos genéticos que apoyan un papel para el receptor 5-HT1A en mediar la ansiedad no son limitados con la literatura de roedores. Los estudios de asociación recientes en humanos han encontrado correlaciones entre un polimorfismo funcional sólo en el promotor del receptor 5-HT1A y ansiedad rasgo (Strobel, et al. 2003).

Como los inhibidores selectivos de consumo de serotonina (SSRIs) son eficaces en el trato de una amplia variedad de transtornos de ansiedad, no es sorprendente que el 
transportador de serotonina (5-HTT), el objetivo primario de SSRIs, ha sido el objeto del estudio intensivo tanto en modelos de animales como en humanos (Leonardo \& Hen, 2006).

Ratones que carecen de genes 5-HTT exhiben comportamientos relacionados con la ansiedad (Holmes, Lit, Murphy, Gold, \& Crawley, 2003). Estos resultados al principio parecen paradójicos, cuando el tratamiento con SSRIs durante la edad adulta causa disminución de la ansiedad. En este sentido, Ansorge y colegas (2004) trataron ratones jóvenes (entre 4 a 21 días tras el nacimiento) con fluoxetina, imitando así el efecto de la eliminación genética por medios farmacológicos. Los ratones tratados durante este periodo mostraron fenotipos de la ansiedad adulta similares a aquella de la eliminación de toda la vida del gen 5-HTT. Este experimento sugiere que el sistema serotonérgico esté implicado en la modulación del desarrollo del recorrido neuronal que es responsable de mediar los comportamientos parecidos a la ansiedad en el ratón.

También los modelos de la experiencia adversa temprana en primates no humanos sugieren que el transportador de serotonina puede mediar los efectos de estrés en la vida temprana en ansiedad posterior (Barr, et al., 2003).

En conclusión, se cree actualmente que la serotonina tiene una doble función en la regulación de la conducta de la defensa. Las señales de peligro estimulan el sistema de defensa a través de la amígdala y, al mismo tiempo, activan las neuronas serotoninérgicas del núcleo dorsal del rafe. Estos, por vías nerviosas diferentes, comunican las amígdalas y la materia gris periacueductal (MGP). La serotonina facilita las reacciones de defensa activa en la amígdala y las inhibe en el MGP. Las respuestas mediadas por la serotonina, tienen un sentido de adaptación, dado que para los niveles de peligro potencial o distal es deseable que los comportamientos de lucha y de vuelo se inhiban, lo que permite al individuo elegir las estrategias más adecuadas, como la exploración cuidadosa, y la inhibición del comportamiento. Se podría decir también que la serotonina aumenta la ansiedad, actuando en la amígdala (Margis, et al., 2003). 
El sistema noradrenalinérgico central puede estar implicado en los trastornos de ansiedad, especialmente en el trastorno de pánico y estrés post-traumático, debido a que el agonista a2adrenérgico, clonidina, es eficaz en el alivio de los síntomas de ansiedad, mientras que el antagonista $\alpha 2$ adrenérgico los aumenta (Charney, 2003).

Según Itoi y Sugimoto (2010) el locus coeruleus (LC) es el más grande de todos los núcleos noradrenérgicos centrales, y se ha implicado en los trastornos de ansiedad y depresión. Numerosos estudios se han llevado a cabo, utilizando animales, para explorar si el sistema de noradrenérgico está relacionado con estas enfermedades. Sin embargo, todavía no podemos entender cómo el mecanismo de este sistema modifica la percepción y el procesamiento de los eventos estresantes y emocionales en el cerebro. Algunas discrepancias observadas en estudios con animales pueden deberse en parte a las diferencias entre las especies, mientras que otras serían imputables a las diferencias en los paradigmas experimentales. Recientemente, la LC ha sido implicada en la recuperación de recuerdos relacionados con los fenómenos emocionales, por análisis de imágenes funcionales del cerebro humano.

Los inputs LC-Noradrenérgicos a la amígdala lateral basal se han propuesto para desempeñar un papel importante en este contexto. Los núcleos medulares noradrenérgicos envían los terminales del axón en el hipotálamo y median en los diversos tipos de entradas de tensión a las neuronas neuroendocrinas. La vía noradrenérgica parece esencial en la transmisión de algunas señales de estrés en el hipotálamo neuroendocrino, pero comprende sólo una parte de las vías neurales que convergen en el hipotálamo neuroendocrino. Los neuropéptidos, colocalizados en las neuronas medulares noradrenérgicas como PrRP, también pueden estar implicados en la transmisión de señales de estrés en el hipotálamo. Debido a los avances en la técnica de imagen, eventos emocionales son ahora capaces de visualizarse en seres humanos, pero los estudios en animales también son indispensables para los estudios más invasivos y analíticos (Itoi \& Sugimoto, 2010). 


\subsection{Diferencias neuronales entre géneros}

El núcleo de la estría terminal (BNST) media tipos específicos de las respuestas al estrés y la ansiedad y constituye una de las regiones más sexualmente dimorfas del cerebro mamífero (Walter, Toufexis, \& Davis, 2003). El BNST, así como el núcleo medial de la amígdala, muestran un dimorfismo sexual pronunciado en aquel número de neuronas que expresan arginina vasopresina (AVP), y la cantidad del mensaje AVP dentro de aquellas neuronas que es considerablemente más alta en ratas macho en comparación con ratas hembra (Millar, Vician, Clifton, \& Dorsa, 1989). Esta diferencia sexual es mediada por efectos organizativos tempranos de la testosterona en machos (Han \& De Vries, 2003).

En este sentido, varios estudios indican que la testosterona puede tener efectos ansiolíticos en varias medidas de la ansiedad en ratas (Toufexis, Davis, Hammond, \& Davis, 2005). La testosterona también ha sido mostrada para reducir la activación del eje hipotálamo-pituitaria-suprarrenal (HPA) en ratas, proporcionando otro mecanismo posible de investigación por el cual la testosterona reduce los índices de la ansiedad (Viau, 2002).

Entre los individuos sanos, uno de los principales factores que contribuyen a las diferencias individuales en la ansiedad relacionados con la ansiedad rasgo es la diferencia de género. Estudios previos han relatado dimorfismo tanto en los rasgos relacionados con la ansiedad (Farmer, Mahmood, Redman, Harris, Sadler, \& McGuffin, 2003) como con la anatomía del cerebro (Lüders, et al. 2004).

Otro estudio con personas sanas reveló que el volumen cerebral regional en la corteza prefrontal anterior izquierda mostró una correlación negativa con la evitación, pero sólo en el grupo femenino (Yamasue, et al., 2008). 
CAPÍTULO IV

INSTRUMENTOS Y ESCALAS OBJETIVAS DE MEDICIÓN DE LA

ANSIEDAD 
Se ha realizado un gran esfuerzo para tratar de definir operativamente y evaluar el constructo ansiedad. Según Andrade y Gorenstein (1998), las escalas de ansiedad miden varios aspectos que pueden ser agrupados de acuerdo con: humor, cognición, comportamiento, estado de hiperalerta, síntomas somáticos, entre otros.

El término ansiedad, como se ha señalado en apartados anteriores, abarca sensaciones de miedo, sentimientos de inseguridad y anticipación negativa, contenido de pensamiento dominado por catástrofe o incompetencia personal, aumento de vigilia o alerta, un sentimiento de opresión respiratoria que lleva a la hiperventilación y sus consecuencias, tensión muscular que causa dolor, temblor e inquietud y una variedad de formas de incomodidad somática consecuentes de la hiperactividad del sistema nervioso autonómico. Algunas escalas intentan cubrir todos esos aspectos da ansiedad, pero la mayoría enfatiza uno u otro (Andrade \& Gorenstein, 1998).

Cuando se escoge una determinada escala para medir la ansiedad, se debe tener en cuenta cuáles son los aspectos que estará midiendo la escala en cuestión. Existen escalas que miden la ansiedad normal y escalas que miden la ansiedad patológica. Además, otra distinción importante se establece entre escalas o instrumentos con finalidad diagnóstica y escalas de cuantificación de intensidad o gravedad en sujetos ya diagnosticados, utilizadas para la evaluación de tratamientos. La interpretación de los resultados puede ser muy diferente si es utilizada una escala $u$ otra. Es necesario disponer de las informaciones básicas sobre los valores normativos en diferentes grupos (edad, sexo, grupo étnico, presencia o no de diagnóstico) y sensibilidad de la escala a cambios (Andrade \& Gorenstein, 1998).

En general, los instrumentos de medición se pueden clasificar en instrumentos que miden exclusivamente los componentes neurovegetativos de la respuesta ansiosa y los que combinan la evaluación de estos componentes fisiológicos con los cognitivos e incluso los motores (Pérez \& Lago, 2000). 
Para Keedwell y Snaith (1996), las escalas de ansiedad miden varios aspectos que pueden ser agrupados de acuerdo con los siguientes tópicos:

Humor: la experiencia de una sensación de miedo no asociado a ninguna situación o circunstancia específica; la aprensión en relación a alguna catástrofe posible o no identificada;

Cognición: preocupación con la posibilidad de que se produzca algún evento adverso a sí mismo o a otros; pensamientos persistentes de inadecuación o de incapacidad de ejecutar sus tareas de forma adecuada;

Comportamiento: inquietud o incapacidad de mantenerse quieto y relajado más de algunos minutos, andando de un lado a otro, apretando las manos $u$ otros movimientos repetitivos sin finalidad;

Estado de hiperalerta: aumento de la vigilancia, exploración del ambiente, respuesta aumentada a estímulos (sustos), dificultad de adormecer (no debida a inquietud o a preocupación);

Síntomas somáticos: sensación de opresión respiratoria, hiperventilación y sus consecuencias, tales como espasmo muscular y dolor (sin otra causa conocida), temblores; manifestaciones somáticas de, por ejemplo., hiperactividad del sistema nervioso autónomo (taquicardias, sudores, aumento de la frecuencia urinaria);

Otros: esta categoría residual puede incluir estados como despersonalización, baja concentración y olvido, así como síntomas que se refieren a una falta de comodidad, no necesariamente específica de la ansiedad;

A continuación se presentan algunas escalas de ansiedad. La selección se hizo por criterios de estar validadas y / o traducidas en Portugal y por su frecuencia de uso en la investigación. 


\subsection{Inventario de ansiedad de Beck (BAI)}

El inventario de ansiedad de Beck fue creada por Beck, Brown, Epstein y Steer (1988) con base en 86 ítems de varios instrumentos de autoevaluación, usados en el “Center for Cognitive Therapy" para medir aspectos de ansiedad (Beck \& Steer, 1993), de los cuales fueron seleccionados los 21 ítems que pasaron a componer el inventario. EI BAI es una escala clínica de autoevaluación que mide la intensidad de los síntomas de la ansiedad (Beck, Brown, Epstein, \& Steer, 1988).

La escala fue diseñada para diferenciar los síntomas conductuales, emocionales y fisiológicos en personas con ansiedad y depresión. Con objeto de lograr este objetivo, los autores han incorporado elementos específicos de los síntomas fisiológicos y la ansiedad cognitiva específica que eran independientes de la depresión (Leyfer, Ruberg, \& WoodruffBorden, 2006). El inventario ha sido diseñado para evaluar el estado general de la ansiedad e incluye elementos cognitivos como miedo a morir, miedo a perder el control, miedo a que suceda lo peor,... (Pérez \& Lago, 2000).

El inventario está constituido por 21 ítems, que son afirmaciones descriptivas de síntomas de la ansiedad y que deben ser evaluados por el sujeto con referencia a sí mismo, en una escala de Likert de 4 puntos (0. absolutamente não; 3. gravemente: dificilmente pude suportar). La medida permite un resultado total, que varía de 0 a 63 en sentido de un mayor nivel de ansiedad (Beck, Brown, Epstein, \& Steer, 1988; Cunha, 2001).

EI BAI requiere sólo un nivel de lectura básico, puede ser usado con individuos que tienen discapacidades intelectuales, y puede ser completado en apenas 5 a 10 minutos (Cunha, 2001).

El inventario tiene buenas características psicométricas, teniendo una consistencia interna elevada, con a de Cronbach con un valor de .92 y una fiabilidad test-retest para un intervalo de una semana de .75. El BAI discrimina los grupos diagnosticados como ansiosos (transtornos de pánico, ansiedad generalizada, etc.) de los grupos diagnosticados como no 
ansiosos (depresión mayor, depresión atípica, etc.). Esta escala presenta una correlación moderada con la escala de ansiedad de Hamilton, con un valor de .51 y una correlación débil con la escala de depresión de Hamilton, con un valor de .21. La correlación entre los resultados del BAI con el BDI (Beck Depression Inventory; Beck, Steer, \& Garbin, 1988) es moderadamente alta, con un valor de .48, pero es más baja que entre otras escalas de ansiedad, por ejemplo en relación al STAI, con un valor de .73 (Spielberger, Gorsuch, \& Lushene, 1970), o a la Escala de ansiedad de Zung, con un valor de .71 (Zung, 1971), o a la Escala de ansiedad manifiesta de Taylor (Taylor, 1953) (Beck, Brown, Epstein, \& Steer, 1988).

En el estudio de la versión brasileña de la escala había fiabilidad adecuada, con a de Cronbach promedio de .91 para muestras psiquiátricas, .86 para muestras clínicas-médicas, y de .86 para muestras no clínicas. La estimación de la correlación entre el test y retest del BAI, con una semana de diferencia, osciló entre .53 para una muestra de 115 estudiantes universitarios y .99 para una muestra de 65 sujetos de la población general (Cunha, 2001).

Se realizaron varios análisis factoriales, con participantes con enfermedad psiquiátrica, con resultados que van de dos a cuatro factores (Beck et al., 1988; Beck \& Steer, 1990, 1991; Cox, Cohen, Direnfeld, \& Swinson, 1996; Cunha, 2001; Sanz \& Navarro, 2003; Steer, Ranieri, Beck \& Clarck, 1993).

El primer análisis de factor principal (Beck et al., 1988) fue hecho con una muestra de 160 pacientes externos psiquiátricos. Esto reveló dos factores: somático, que incluyó los 12 ítems que describen síntomas fisiológicos, como "entumecimiento u hormigueo," "vértigos con sensación de mareo" y otros; y la ansiedad subjetiva y el pánico, que incluyó los restantes nueve ítems del BAI, como "el miedo a que suceda lo peor" y "ser incapaz de relajarse." Sin embargo, las cargas de factor para algunos ítems eran bastante bajas.

Otro estudio (Sanz \& Navarro, 2003) examinó las propiedades psicométricas de una versión española del Inventario de Ansiedad de Beck en una muestra de 590 estudiantes de universidad españoles. El BAI demostró un nivel alto del consistencia interna, con un $\alpha$ de 
Cronbach de .88 y los análisis de factor revelaron una dimensión de ansiedad general formada por dos factores muy interrelacionados, correspondiente a somático y síntomas afectivo-cognoscitivos. Tomando el DSM-IV como el estándar, la validez de contenido del BAI era adecuada pues sus ítems cubrieron el $45 \%$ de los criterios sintomáticos específicos de transtornos de ansiedad y el 78\% de los síntomas de ataques de pánico.

Otro análisis de factor exploratorio (Beck \& Steer, 1990), usando una muestra de 393 adultos de consulta externa, presentó una estructura de cuatro factores, correspondiente a componentes de la ansiedad neurofisiológicos, subjetivos, autonómicos y de pánico. Los individuos con el desorden de pánico presentaron valores más altos en todos los cuatro factores que aquellos con otros transtornos de ansiedad. Los cuatro factores -subjetivo, neurofisiológico, autonómico y pánico- también surgieron en un estudio por Steer y colegas (1993) en una muestra de consulta externa de 470 individuos con una variedad de transtornos de DSM-III-R. Los resultados eran casi idénticos al estudio anterior.

En otro estudio de las propiedades BAI, usando una muestra de 367 pacientes externos adultos con transtornos de ansiedad, Beck y Steer (1991) encontró que los ítems del BAI cargaron en cuatro factores, que fueron conceptuados para ser representativos de síntomas subjetivos, neurofisiológicos, autonómicos y de pánico. En general, los cuatro factores explicaron aproximadamente el $59 \%$ del desacuerdo total.

Un análisis factorial confirmatorio conducido por Osman, Barrios, Aukes, Osman y Markway (1993) fue incapaz de generalizar el modelo de dos factores de Beck et al. (1988) a su muestra no clínica de 225 adultos. Sin embargo, cuando condujeron un análisis de componentes principal exploratorio, los ítems BAI cargados en cuatro factores, explicaron el $64.6 \%$ de la varianza total. En un estudio posterior, Osman, Kooper, Barrios, Osman y Wade (1997) fueron capaces de confirmar el modelo de cuatro factores por medio de un análisis de factor confirmativo.

Cox y colegas (1996) combinaron los ítems del BAI con los ítems del Cuestionario de Ataque de Pánico (PAQ; Norton, Dorward, \& Cox, 1986) sujetos a un análisis factorial. El 
análisis sugirió una solución de tres factores, que explicó el 46.9 \% de la varianza total. El primer factor consistió en ítems relacionados con sentir mareo o vértigos, incluyendo ítems como "el temblor de manos" e "inestable" del BAI, que puede estar relacionado con los síntomas producidos por la hiperventilación. El segundo factor consistió en "cogniciones/miedo catastróficas", incluyendo el BAI "miedo a que suceda lo peor". El tercer factor estuvo relacionado con los síntomas respiratorios, incluyendo el BAI "los sentimientos de ahogo," "respiración difícil y cardiológicos," incluso el ítem del BAI "sentimientos de ahogo", "dificultad en la respiración" y otros.

En el estudio de validación de la escala en Brasil, con 379 pacientes con trastornos de ansiedad, el análisis factorial varimax encontró una solución factorial con cuatro factores que explican el $57,79 \%$ de la varianza total (Cunha, 2001).

Para Leyfer, Ruberg y Woodruff-Borden (2006) el BAI no es un instrumento de diagnóstico, pero su brevedad y simplicidad hacen de él un instrumento ideal para el uso como una prepantalla para presencia de un desorden de ansiedad. Además, los cuatro factores del BAI pueden ser representativos de los tipos diferentes de la ansiedad y cada factor puede tener la utilidad específica en la proyección de un desorden de ansiedad particular.

Leyfer y colegas (2006) examinaron si el valor total de BAI y los valores de cada uno de los cuatro factores diferían en pacientes con cinco diferentes diagnósticos de ansiedad y un grupo control sin ansiedad. Un análisis de varianza mostró que la medida difiere significativamente en el caso de los participantes sin un diagnóstico en relación a los participantes con cualquier diagnóstico de ansiedad. Sin embargo, el valor de la escala es significativamente mayor para los participantes con diagnóstico de trastorno de pánico que el valor de las personas con trastorno de ansiedad generalizada, fobia o sin diagnóstico. Los resultados muestran también distinguir mejor a los participantes con trastorno de pánico de los que tienen trastornos de ansiedad. Estos resultados pueden deberse al hecho de que el BAI se ha creado no sólo para acceder a la ansiedad, sino también para ser independiente 
de los síntomas de la depresión, ya que excluye a los síntomas que se superponen a los de la depresión.

En el estudio de Leyfer y colegas (2006) encontró puntos de corte para la escala total para los trastornos de pánico, trastorno de ansiedad generalizada, fobias y cualquier diagnóstico de ansiedad, como se muestra en la Tabla 8.

Tabla 8. Puntos de corte del BAl por diagnóstico

Sensibilidad Especificidad

Trastorno de pánico

$\begin{array}{lll}5.50 & .97 & .86 \\ 7.50 & .94 & .94 \\ 8.50 & .89 & .97\end{array}$

Trastorno de ansiedad

generalizada

2.50

.89

4.50

.68

Fobias

5.50

.68 .86

Cualquier diagnóstico de ansiedad 
Por ejemplo, para el trastorno de pánico se ha encontrado un punto de corte de 8,5, que corresponde a una sensibilidad de .89 y una especificidad de .97 , lo que sugiere que un valor superior a 8 en el BAI identificará al $89 \%$ de los pacientes con trastorno de pánico y no incluye el $97 \%$ de las personas sin este trastorno.

La Tabla 9 muestra la sensibilidad y especificidad de los puntos de corte por cada diagnóstico por factor.

Tabla 9. Sensibilidad y especificidad de los puntos de corte para cada diagnóstico por factor

Punto de corte Sensibilidad Especificidad

Trastorno de pánico

Subjetivo

1.63

Neurofisiológico

2.06

.89

.91

Neurofisiológico

.66

.89

.89

.71

.86

.89

.94

.83

.92

Pánico

.24

.89

.83

.79

.78

.97

Autonómico

.59

.86

.78

.66

.83

.84

1.19

.69

.92

Trastorno de ansiedad generalizada

Subjetivo

.98

.84

.69

1.63

.75

.81

.95

.66

.84

Neurofisiológico

.55

.50

.83

.71 
Tabla 9 (Cont.)

Punto de corte Sensibilidad Especificidad

\begin{tabular}{lccc}
\hline Pánico & .24 & .46 & .93 \\
& .49 & .36 & .91 \\
Autonómico & .18 & .75 & .66 \\
& .59 & .68 & .78
\end{tabular}

Fobia

Subjetivo

Neurofisiológico

.72

.76

.67

.98

.73

.69

.66

.73

.86

70

.70

.89

Pánico

.24

.60

.83

.49

.41

.91

Autonómico

.18

.73

.86

.59

.68

.78

Cualquier diagnóstico de ansiedad

Subjetivo

.98

.84

.67

1.63

.79

.79

Neurofisiológico

.23

.71

.74

.55

.69

.80

Pánico

.24

.64

.80

.49

.51

.88

Autonómico

.18

.78

.64

.59

.72

.76 
De los cuatro factores, el factor componentes subjetivos tiene la sensibilidad y los niveles de precisión más altos (ver la Tabla 9). Un resultado de corte de 2.06 fue encontrado para tener una sensibilidad de .89 y la precisión de .91 , sugiriendo que un resultado mayor que 2.06 identifica el $89 \%$ de casos con trastorno de pánico y el $91 \%$ de casos sin dicho trastorno. Un resultado de corte de .66 en el factor componentes neurofisiológicos identificará el $89 \%$ de casos con desorden de pánico y el $86 \%$ de casos sin él. Un resultado ligeramente más alto en el factor (.71), identificará el 89\% de casos sin desorden de pánico, pero sólo el 86 \% de casos con desorden de pánico. En el factor de pánico, un resultado de .24 identificará correctamente el $89 \%$ de casos con desorden de pánico y el $83 \%$ de casos sin. En el factor autonómico un resultado de .66 identifica correctamente $83 \%$ de casos con desorden de pánico y $84 \%$ de casos sin. Los puntos de corte para el resto de los diagnósticos, así como para cualquier diagnóstico de ansiedad, no son tan sensibles y específicos como estos con desorden de pánico (Leyfer, et al., 2006).

En la versión americana (Beck \& Steer, 1993), los puntos de corte utilizados son los siguientes: 0 a 7 - nivel mínimo; 8 a 15 - nivel ligero; 16 a 25 - nivel moderado; y 26 a 63 nivel grave.

Para la versión brasileña (Cunha, 2001), los puntos de corte son diferentes: 0 a 10 nivel mínimo; 11 a 19 - nivel ligero; 20 a 30 - nivel moderado; y 31 a 63 - nivel grave. 


\subsection{Inventario de ansiedad Rasgo-Estado (STAI)}

El Inventario de ansiedad rago-estado (STAI) fue creado por Spielberger, Gorsuch y Lushene (1970) y ha sido traducido y validado para la población portuguesa por Silva (2006).

Este cuestionario está compuesto por dos bloques de 20 afirmaciones, evaluadas en una escala Likert de cuatro puntos (1-Nada; 4 - Mucho), en relación a las cuales los sujetos deben responder, sin tardar mucho en cada ítem, hasta qué punto cada uno dellos corresponde a su manera de sentir en el momento (Forma 1 - subescala ansiedad-estado que evalúa ansiedad transitoria o momentánea), o a su manera de sentirse habitualmente (Forma 2 - subescala ansiedad-rasgo que evalúa la tendencia a la ansiedad o la ansiedad en general, reflejando una característica estable de la persona que reacciona con ansiedad ante situaciones consideradas amenazadoras o estresantes). Estos ítems representan estados que podremos considerar como positivos (por ejemplo " Me siento tranquilo" o " Me siento seguro"), o como negativos (por ejemplo "Me siento nervioso" o "Me siento confundido"). La cotización de los primeros tendrá que ser invertida (un =cuatro, dos = tres, tres $=$ dos, cuatro $=$ un) antes de procederse al cómputo final del cuestionario, que podrá obtener valores, entre 20 y 80 , para cada Forma, en el sentido de un mayor nivel de ansiedad-estado o ansiedad-rasgo.

El desarrollo del STAI ha sido ampliamente influenciado por la escala de ansiedad manifiesta de Taylor (Taylor, 1953), y tanto uno como el otro tienen alta correlación con escalas de emoción y neuroticismo (por ejemplo, la escala $\mathrm{N}$ del inventario de personalidad de Eysenck; Eysenck y Eysenck (1964)) (Lader \& Marks, 1974).

La escala presenta buenas cualidades psicométricas en relación a su consistencia interna, con valores de $\alpha$ de Cronbach que varían de .86 a .95 , para la subescala ansiedadestado y de .89 a .91 para la ansiedad-rasgo (Spielberger, Gorsuch, \& Lushene, 1970). 
Russel, Peplau y Cutrona (1980) indican una consistencia interna con as de Cronbach entre .83 y .92, respectivamente al nivel de la subescala STAI-D (ítems más asociados a la depresión) y de la subescala STAI-A (ítems más asociados a la ansiedad). Los mismos autores refieren valores para test-retest entre .73 y .76.

En una investigación más reciente de la fiabilidad del STAI, las medidas manifestaron consistencia interna excelente (un promedio de la $\alpha$ de Cronbach de .89), y el STAI rasgo ha evidenciado fiabilidad de test-retest excelente (un promedio de $r=.88$ ) en intervalos de tiempo múltiples (Barnes, Harp, \& Jung, 2002).

El estudio de consistencia interna, en Portugal, da valores de a de Cronbach de .91 y .93 para la subescala de ansiedad-estado en los hombres y mujeres, respectivamente, y de .89 para la subescala de ansiedad-rasgo, tanto para los hombres como para las mujeres. En cuanto a la consistencia interna de los ítems, calculando el punto de correlación ítem-total corregido, los resultados también son buenos, desde valores de correlación en la subescala de ansiedad-estado entre .35 y .70 en los hombres y entre .37 y .71 en las mujeres. Los valores de la subescala de ansiedad-rasgo varían de .34 y .66 en los hombres y entre .31 y .72 en las mujeres (Silva, 2006).

Las medidas muestran la validez convergente y discriminante adecuada con otras medidas de ansiedad estado y ansiedad rasgo y han demostrado diferenciar al paciente de muestras de control en el STAI de rasgo y participantes en situaciones muy estresantes ( $p$. ej., reclutas militares) de muestras de control (p. ej., muestras de estudiante) en el STAI de estado (Spielberger, 1983).

Sin embargo, a pesar de estas características psicométricas generalmente positivas, las medidas originales de Rasgo y Estado del STAI han sido criticadas por su incapacidad de discriminar suficientemente entre los síntomas de ansiedad y depresión; sus propiedades psicométricas en poblaciones más jóvenes y menos cultas; y su estructura de dos factores de ansiedad-presente y ansiedad-ausente. A pesar de una revisión para tratar con algunas 
de estas preocupaciones (Spielberger, 1983), las críticas del STAI han persistido (Bieling, Antony, \& Swinson, 1998; Caci, Bayle, Dossios, Robert, \& Boyer, 2003).

En particular, Bieling y colegas (1998) sostuvo que el STAI Rasgo no evalúa la ansiedad pura; mejor dicho, ellos encontraron una solución de factor jerárquica, con un factor de orden superior de Afecto Negativo y los factores de orden inferior: Ansiedad, caracterizada por rumiación, preocupación e ítems de pensamientos dolorosos, y Depresión, caracterizada por humor disfórico e ítems de autoevaluación negativos. Según Bieling y colegas (1998) y Fioravanti, Santos, Maisonette, Cruz y Landeira-Fernández (2006), los ítems que Spielberger (1983) ha descrito como presencia de ansiedad y ausencia de la ansiedad realmente reflejarían una separación entre los factores de Ansiedad y Depresión. 


\subsection{Escala de ansiedad de Zung}

La Escala de Ansiedad de Zung (Zung, 1971) evalúa el estado de ansiedad y no la ansiedad rasgo, es decir, permite evaluar la reacción situacional de ansiedad y no la ansiedad como un rasgo de la personalidad.

En la construcción de esta escala, Zung (1971) tuvo en cuenta las principales manifestaciones de la ansiedad, que se describe en los libros de texto de Psiquiatría y también consideró los registros realizados por los propios pacientes. Su objetivo consistía en encontrar un formato fácil de usar, que no requiriese mucho tiempo y que pudiera ser rellenada por el propio individuo, al tiempo que permitiera una mejor comprensión de las variables implicadas (Ponciano, Serra, \& Relvas, 1982).

La escala está compuesta por 20 afirmaciones evaluadas por una escala de Likert de cuatro puntos (1 - Ninguna o rara vez; 4 - La mayoría o todo el tiempo), en relación a las cuales debe ser dada una respuesta en cada ítem, y de acuerdo con la manera de sentir en el momento. Presenta una puntuación mínima de 20 y máxima de 80 , siendo los valores más altos los que corresponden a más ansiedad. En los ítems 5, 9, 13, 17 y 19, como son declaraciones positivas (sin síntomas o ansiedad), su puntuación se efectúa en orden inverso. Estos ítems se distribuyen en cuatro subescalas de ansiedad: Cognitiva (ítems 1 a 5), Motora (ítems 6 a 9), Vegetativa (ítems 10 a 18) y Ansiedad del Sistema Nervioso Central (ítems 19 e 20. Presenta puntuaciones diferentes a nivel de sexo y grupo de edad, considerándose que resultados superiores o iguales a 40 son valores indicadores de patología (Cruz, 2008). Se considera que la versión americana posee buena validez y fiabilidad (Ponciano, et al., 1982).

Ponciano y colegas (1982) realizaron un estudio con una muestra de la población portuguesa para evaluar la escala de autoevaluación de Zung. En esta muestra eran predominantes los participantes en la educación secundaria y en la universidad. El objetivo 
fue conocer los valores de la población general, de forma que puedan ser comparados con otras poblaciones. Los resultados de este estudio ponen de relieve el hecho de que las mujeres (44\%) tienen valores más altos que los hombres (40\%), y los niveles promedio fueron del $41 \%$ para ambos sexos. Por otra parte, hubo importantes variaciones con la edad, aunque la muestra era predominantemente joven (en las edades más jóvenes y mayores, es mayor la ansiedad). Los autores consideran un punto de corte, según el cual las puntuaciones por encima de 37 indican que la persona tiene ansiedad y por encima de los 40 el individuo está enfermo. La validación de esta escala fue cuidadosa, teniendo en cuenta que se ha tenido cuidado en el proceso de traducción, cognitive debriefing, la validez de contenido idéntico al original, la validez del criterio y del constructo, la consistencia interna, prueba de fiabilidad test-retest, la sensibilidad entre las poblaciones y la sensibilidad al cambio (Ribeiro, 2007).

Los autores de la validación de la población de Portugal (Serra, Ponciano, \& Relvas, 1982) la consideran una escala con buena validez, fiabilidad y discriminación.

En un estudio, también portugués, pero más reciente, se evaluaron las características psicométricas de esta escala, especialmente en términos de poder discriminativo de los ítems, su estructura factorial y la consistencia interna (Cruz, 2008).

\section{(1) Poder discriminativo de los ítems}

Se calcularon los porcentajes de las opciones de cada una de las alternativas de respuesta a fin de evaluar el poder discriminativo de los ítems de la Escala de ansiedad de Zung. Sólo tres ítems tienen en la respuesta alternativa (no o rara vez) más del $70 \%$ pero inferior al $90 \%$ (ítems 11, 12 y 14). Todos los elementos tienen una tasa de respuesta en las diferentes alternativas, salvo el ítem 14 en una de ellas (la mayor parte o todo el tiempo). A pesar de estas características, en general, los ítems de la escala tienen una capacidad de discriminación razonable. Las respuestas a la escala obtuvieron un promedio de $38,5 \%$ con una desviación estándar de 7,6\%. 
(2) Estructura factorial

Teniendo en cuenta que la autora sólo consideró la escala total - estado de ansiedad, procedió al análisis de componentes principales. Esto resultó en un factor principal que explica el $24,3 \%$ de la varianza con valor propio de 4.8 como en el estudio de validación.

(3) Consistencia interna

La consistencia interna fue evaluada por el $\alpha$ de Cronbach, y la autora concluye que la escala tiene buena consistencia interna de .81 , un valor que nos permite utilizarla para diferenciar a los individuos y los grupos (Cruz, 2008). 


\subsection{Otras escalas de ansiedad}

\subsubsection{Escala de depresión, ansiedad y estrés (DASS).}

La Escala de depresión, ansiedad y estrés (DASS, Lovibond \& Lovibond, 1996) es un instrumento de autoevaluación del estrés, ansiedad y depresión, compuesta por 42 ítems que miden otros tantos síntomas emocionales negativos en una escala tipo Likert de 4 puntos que varía de 0 ("No se aplicó nada a mí) a 3 (“Se aplicó a mí la mayor parte del tiempo"). Los ítems de la DASS se agrupan en tres dimensiones: estrés, ansiedad y depresión, siendo el resultado de cada subescala dado por la suma de los resultados para los 14 ítems relevantes para cada una de ellas.

La subescala de depresión mide la pérdida de la autoestima y estímulo (disforia, desesperanza, devaluación de la vida, auto-depreciación, pérdida de interés, pérdida de placer, inercia). La subescala de ansiedad hace hincapié en la relación entre un estado permanente de ansiedad y la respuesta de miedo intenso, con síntomas somáticos y subjetivos, además de medir la ansiedad situacional (síntomas autonómicos, los efectos musculoesqueléticos, ansiedad situacional, la experiencia específica de afecto ansioso). subescala del estrés mide un estado persistente de alta tensión y elevación autonómica, con un umbral bajo para la frustración (dificultad para relajarse, nerviosismo, irritabilidad, impaciencia, facilidad para la frustración, agitación, hiperactividad).

La escala, en su formato original, mostró poseer propiedades psicométricas satisfactorias. El análisis de componentes principales para probar la validez estructural da DASS reveló tres factores específicos que explicaron el $41,3 \%$ de la varianza. El análisis factorial confirmatorio corroboró la existencia de tres factores correspondientes a las tres subescalas. Han sido obtenidos coeficientes a de Cronbach de .91 para la escala de 
depresión, .84 para la escala de ansiedad y de .90 para la escala de estrés. En lo que se refiere al estudio de su validez, han sido obtenidas correlaciones de .81 entre la subescala de ansiedad del DASS y el BAI y de .74 entre la subescala de depresión del DASS y el BDI (Lovibond \& Lovibond, 1995).

En un estudio (Lovibond \& Lovibond, 1995) en que se determinaron los componentes principales de la escala, los autores encontraron una gran superposición entre las escalas ansiedad y estrés, y concluyeron que el punto de división entre ellas puede ser arbitrario. Los ítems que presentaron mayor superposición han sido los ítems que miden el nerviosismo (tensión nerviosa y energía nerviosa). Esa superposición sugiere que existe una continuidad natural entre los síndromes evaluados por las escalas ansiedad y estrés. Los autores concluyen que la superposición, que también ocurre con la escala depresión, no es resultado de baja discriminación de la escala, sino de un factor de vulnerabilidad común, como el neuroticismo, o afecto negativo y/o un desencadenante ambiental común.

La traducción y validación da escala para la población portuguesa ha sido realizada por Alves, Carvalho y Baptista (1999). El análisis de componentes principales mostró una solución de tres factores que explicó cerca del $60 \%$ de la varianza total, habiendo sido replicada la estructura original. El estudio de la consistencia interna mostró valores a de Cronbach de .96 para la depresión, .77 para la ansiedad y .94 para el estrés. Las intercorrelaciones entre las tres subescalas han sido de .64 (ansiedad y depresión), .77 (estrés y depresión) y .65 (ansiedad y estrés). El estudio de la validez concurrente mostró asociaciones entre todas sus dimensiones y la HADS (Alves, Carvalho, \& Baptista, 1999).

La validación para Portugal de su versión reducida de 21 ítems fue realizada por Apóstolo, Mendes, \& Azeredo (2006). La DASS-21 también se compone de tres subescalas de siete ítems cada uno, dispuestos en una escala de Likert de cuatro puntos de 0 a 3.

La escala obtuvo una adecuada consistencia interna con valores $\alpha$ de Cronbach de .90 para la depresión, .86 para la ansiedad, .88 para el estrés y .95 para la escala total. 
Su análisis factorial arrojó una estructura de dos factores: uno para la ansiedad y el estrés y el otro para la depresión, explicando el modelo de dos factores $58,54 \%$ de la varianza (Apóstolo, Mendes, \& Azeredo, 2006).

En otro estudio portugués que quería estudiar las propiedades psicométricas de la DASS-21 y los compara con los de la DASS original, los resultados mostraron una alta correlación existente entre las mismas escalas y la versión 21 y de 42 ítems, con varianzas explicadas de $89 \%$, 90 \% y 96\% respectivamente para el estrés, la ansiedad y la depresión. Y la correlación entre cada escala y las otras, en la versión reducida y completa, es idéntica. Estos resultados apuntan a una identidad de las medidas de la versión de 21 y 42 ítems (Pais-Ribeiro, Honrado, \& Leal, 2004). 


\subsubsection{Sub-escala de ansiedad del Symptom Checklist (SCL-90-R).}

El Symptom Checklist (SCL-90-R; Derogatis \& Lazarus, 1994) se subdivide en nueve dimensiones específicas: somatización, obsesiones-compulsiones, sensibilidad interpersonal, depresión, ansiedad, hostilidad, ansiedad fóbica, ideación paranoide y psicoticismo.

El cuestionario también se compone de tres índices: el nivel global de los síntomas que coinciden con la información sobre el número de los síntomas con la intensidad; el total de síntomas positivos que refleja sólo el número de síntomas presentes; y el índice de síntomas que es una medida positiva la intensidad ajustada por el número de síntomas presentes.

En cuanto a las características psicométricas, la SCL-90-R mostró niveles de consistencia interna evaluada por el $\alpha$ de Cronbach que van desde .84 (sensibilidad interpersonal) a .90 (depresión). La estabilidad temporal evaluada por la test-retest, con un intervalo de una semana, presentó coeficientes de correlación de .78 (hostilidad) y .90 (ansiedad fóbica) (Derogatis \& Lazarus, 1994).

La subescala de la ansiedad es una medida de autoevaluación que busca la evaluación de la ansiedad, en 10 ítems, con un formato de respuesta politómico, (0. nunca; 4. extremamente). La medida permite un resultado total, que varía de 0 a 40 en el sentido de un mayor nivel de ansiedad.

En términos de características psicométricas, en la población portuguesa, la escala presenta niveles adecuados de homogeneidad y de consistencia interna ( $\alpha$ de Cronbach por encima de .70). La fiabilidad test-retest presenta valores bajos en las escalas Ansiedad Fóbica y Ansiedad, estando todos los demás por encima de .70. En relación a la validez, los resultados de las subescalas se asocian del modo esperado, esto es, con una correlación 
elevada con los constructos más próximos y más reducida con los constructos más distantes, desde el punto de vista patológico (Baptista, 1993).

\subsubsection{Escala de ansiedad de Hamilton (HAS).}

La escala de ansiedad de Hamilton (HAS; Hamilton, 1959) ha sido una de las primeras entrevistas clínicas semi-estructuradas desarrollada para evaluar la severidad de los síntomas de la ansiedad (Kobak, Reynolds, \& Greist, 1993). Diseñada originalmente para ser usada en pacientes ya con diagnóstico de desorden de ansiedad, la HAS incluye elementos muy variados: miedos, preocupaciones, trastornos del sueño, síntomas vegetativos, gastrointestinales, ... y comportamiento instrumental durante la entrevista (Pérez \& Lago, 2000).

El inventario está constituido por 14 ítems, en una escala de Likert de 5 puntos ( 0. nada; 4. muy severo). La medida permite un resultado total, que varía de 0 a 56 en sentido de un mayor nivel de ansiedad (Brown, Di Nardo, \& Barlow, 1994; Kobak, Reynolds y Greist, 1993).

El análisis factorial de los ítems distingue un factor general de ansiedad y un factor bipolar, que separa los ítems en dos factores: un factor psíquico que consiste en tensión, miedos, insomnio, ansiedad, cambios intelectuales (cognitivos), depresión y comportamiento durante la entrevista; y un factor somático (gastrointestinal, genitourinario, respiratorio, cardiovascular, sensorio, muscular y síntomas autonómicos) (Hamilton, 1959).

Su consistencia interna es elevada, presentando un valor a de Cronbach de .92. Las correlaciones ítem-total varían entre .43 y .81. La fiabilidad test-retest es elevada con un valor de .96 (Kobak, et al., 1993). 


\subsubsection{Escala de ansiedad manifesta de Taylor}

La escala de ansiedad manifiesta de Taylor (Taylor, 1953) incluye apreciaciones de características personales, comparativas con los demás: "tengo poco miedo en comparación a mis amigos", "me gustaría ser tan feliz como creo que son los demás",..., además de otros elementos cognitivos: "me preocupo por el dinero y los negocios", "me preocupo bastante por posibles desgracias", ... (Pérez \& Lago, 2000).

La escala presenta cinco subescalas: Agitación, Vergüenza, Sensibilidad, Ansiedad Fisiológica y Seguridad en sí mismo (Moore, Kinsman, \& Dirks, 1984) y fue al principio desarrollado como un dispositivo para seleccionar sujetos para la inclusión en experimentos psicológicos en estrés, motivación e interpretación humana. Ha sido usado posteriormente como un indicador general de la ansiedad como un rasgo de personalidad, pero no es una medida específica de la ansiedad como una entidad clínica (Taylor, 1953).

Para la versión de 50 artículos original, se obtuvieron correlaciones test-retest de .89, .82, y .81 sobre intervalos de tres semanas, cinco meses y nueve a 17 meses. Las correlaciones ítem-total parecen bajas: un estudio encontró sólo 20 de los 50 artículos con correlaciones ítem-total de aproximadamente .4, otro estudio encontró sólo 16 preguntas. La variedad de correlaciones ítem-total es amplia: .01 a .70 en un estudio. Las correlaciones también pueden variar por grupo étnico y nivel educativo. Un coeficiente $\alpha$ de Cronbach de .70 fue obtenido para una muestra de estudiantes de graduado (Kendall, 1954).

\subsubsection{Escala hospitalaria de ansiedad y depresión (HADS)}

La escala hospitalaria de ansiedad y depresión (HADS; Zigmond \& Snaith, 1983) ha sido diseñada para detectar estados de ansiedad y depresión en servicios hospitalarios de 
consulta externa no psiquiátrica. Incluye, asimismo, elementos cognitivos (Pérez \& Lago, 2000).

La escala está constituida por 14 ítems, en una escala tipo Likert de 4 puntos, divididos en dos subescalas que miden la depresión y la ansiedad. Su fuerza particular es que evita específicamente los ítems que miden las manifestaciones de la depresión que pueden llevar a la inflación de las puntuaciones. La escala de depresión es utilizada para medir la depresión anhedónica (falta de placer en actividades habituales) que, según los autores, es el elemento patológico central de la depresión y responde bien a la medicación con antidepresivos. Puntuaciones de siete o menos son consideradas no casos, ocho a diez como dudosos, y más de once como casos definidos. La selección inicial de los ítems para la escala se ha basado en la experiencia clínica y ha sido validada en una muestra de individuos con un diagnóstico psiquiátrico (Bennett, 2002).

La independencia de los ítems que pueden confundir los problemas mentales con consecuencias de problemas de salud física, tal como el cansancio o la fatiga, ha sido confirmado por Zigmond y Snaith (1983) que verificaron que las puntuaciones del HADS en pacientes con enfermedad física que no sufrían de perturbación del humor eran semejantes a los de una muestra de individuos sin enfermedad.

La subescala de ansiedad está compuesta por 7 ítems con una escala de 4 categorías (0-3). La subescala permite un resultado total que varía de 0 a 27 , en el sentido de una mayor ansiedad.

Las características psicométricas de la escala HADS original han sido evaluadas en una muestra de enfermos en ambiente hospitalario con diversas patologías, habiendo sido encontradas correlaciones de .41 a .76 para la subescala de ansiedad y de .30 a .60 para la subescala de depresión (Zigmond \& Snaith, 1983).

En un estudio portugués de las características psicométricas de la escala en una muestra de pacientes con Esclerosis Múltiple, los resultados que revela el análisis de los valores de $\alpha$ de Cronbach, indican que el HADS-total tiene una buena fiabilidad (.87), así 
como una buena consistencia interna de las dos subescalas HADS-A (.81) y HADS-D (.78). La escala mostró que tiene una estructura factorial de dos factores, tal como fue defendido por los autores originales (Sousa \& Pereira, 2008).

\subsubsection{Escala multidimensional de la ansiedad de Endler (EMAS)}

La Escala Multidimensional de la Ansiedad de Endler (Endler, Edwards, \& Vitelli, 1991) ha sido desarrollada para evaluar ansiedad rasgo y estado, como constructos multidimensionales.

EI EMAS-S (EMAS State Anxiety Scale) tiene dos subescalas (síntomas emocionales autonómicos y cognición-preocupación). Consta de 20 ítems, 10 por cada subescala, con una puntuación de 1 (nada) a 5 (mucho). Los elementos emocionales de los síntomas autonómicos son $1,3,5,6,9,11,14,16,17$ y 20 y los otros son de la cogniciónpreocupación. La subescala permite dos totales que van de 10 a 50, y un valor total de entre 20 y 100, en un sentido de más ansiedad estado.

El EMAS-T (EMAS Trait Anxiety Scale) tiene cuatro subescalas para evaluar la predisposición a experimentar el nivel de ansiedad en cuatro tipos de situaciones: la evaluación social, peligro físico, ambiguas y rutinas diarias. Los ítems de la ansiedad (por ejemplo, taquicardia, sensación de incomodidad) son idénticos para cada tipo de situación. Cada tipo de situación es evaluada por 15 ítems, con una puntuación del 1 (nada) a 5 (mucho), y revocó los ítems 1, 4, 6, 8, 10, 12 y 14 de cada situación. La subescala permite cuatro totales que van de 15 a 75 dentro de un sentido de los rasgos de más ansiedad, y no tiene un valor total.

EI EMAS-P (EMAS Perception Scale) tiene cuatro ítems para evaluar la percepción subjetiva del tipo y grado de amenaza provocada por cuatro tipos de situaciones: la evaluación social, peligro físico, ambiguas y rutinas diarias, y un quinto punto que evalúa el 
grado de la amenaza de la situación inmediata. Cada uno de estos ítems se clasifica en una escala de Likert de 1 (nada) a 5 (mucho), con cada ítem tratado por separado, pues no tiene un total. Además se hacen 3 preguntas abiertas sobre la situación inmediata, que no se puntúan (Endler, Edwards, \& Vitelli, 1991).

En cuanto a las características psicométricas de la EMAS-S, los valores $\alpha$ de Cronbach para las subescalas de la cognición-preocupación y síntomas autonómicos, van desde .78 a .91 y para el total de la ansiedad estado van de .88 a .94 , presentando una alta consistencia interna. La fiabilidad test-retest de un mes osciló entre .35 a .46 para los hombres y de .14 a .48 para las mujeres. Para el EMAS-T, los valores a de Cronbach van .82 a .96, mostrando una consistencia interna muy alta. La fiabilidad test-retest se presentó en diversos estudios, relativamente estable en el tiempo (Endler, 1986; Zegler, 1987).

La consistencia interna del EMAS-P no se calculó como siendo 5 puntos separados, pero la fiabilidad test-retest presentó valores de .03 a .72 para los hombres y .22 a .47 para las mujeres durante un periodo de un mes (Endler, et al., 1991).

En el estudio de validación para Portugal, en una muestra de adolescentes, encontramos a de Cronbach para el EMAS-S, similar a la versión original y la EMAS-T ligeramente inferior, pero sin embargo, suficiente (Cardoso, 2005). 


\subsection{Problemas en la evaluación de la ansiedad}

Una de las dificultades más comúnmente encontradas en la evaluación de la ansiedad está en la superposición de ésta con síntomas depresivos. Muchos investigadores tienen dificultad en separar ansiedad y depresión, tanto en muestras clínicas (Prusoff \& Kerman, 1974) como no clínicas (Gotlib, 1984), y sugieren que los dos constructos pueden ser componentes de un proceso de estrés psicológico general.

Otra posibilidad es que esa superposición se deba a las limitaciones psicométricas de las escalas utilizadas. Por ejemplo, Endler, Cox, Parker y Bagby (1992), aplicando varias escalas de ansiedad y depresión, encontraron una alta correlación entre depresión y ansiedad medidas por el Inventario de la Depresión de Beck (BDI) y el STAI.

Clark y Watson (1991) resumen las limitaciones encontradas en la evaluación de la ansiedad y de la depresión:

1. Las escalas de autoevaluación de la ansiedad y depresión presentan una correlación que está entre .40 y .70, tanto en muestras de pacientes como en personas normales.

2. Las escalas de ansiedad que se correlacionan tanto con escalas de depresión como con otras escalas de ansiedad y las escalas de depresión también presentan esa falta de especificidad.

3. La evaluación clínica de la ansiedad y la depresión también muestra esa superposición.

4. Solamente la mitad de los pacientes con ansiedad y depresión presenta cuadros puros.

El modelo que mejor parece explicar a superposición (alta correlación y baja validez discriminante) entre escalas que cuantifican ansiedad y depresión es el modelo tripartito propuesto por Watson y Clark (1984), que ha sido expuesto anteriormente. 
Utilizando el concepto del modelo tripartito de Watson y Clark (1984), se han desarrollado algunas escalas para evaluar la ansiedad teniendo en cuenta tanto su multidimensionalidad como la superposición de síntomas ansiosos con síntomas depresivos.

Un buen ejemplo es el BAI, que fue diseñado para diferenciar los síntomas conductuales, emocionales y fisiológicos en personas con ansiedad y depresión, incorporando elementos específicos de los síntomas fisiológicos y de la ansiedad cognitiva específica que fueran independientes de la depresión (Leyfer, Ruberg, \& Woodruff-Borden, 2006). Así, presenta una correlación con el BDI más baja que otras escalas de ansiedad (STAI, Escala de ansiedad de Zung, Escala de ansiedad manifiesta de Taylor (Beck, Brown, Epstein, \& Steer, 1988; Spielberger, Gorsuch, \& Lushene, 1970; Taylor, 1953; Zung, 1971). 


\subsection{Consideraciones adicionales}

De acuerdo con los estudios revisados por Keedwell y Snaith (1996), las escalas de Hamilton y de Beck están entre las escalas de evaluación clínica más utilizadas. EI STAI y la subescala de ansiedad del "Symptom Checklist" (SCL-90) son los instrumentos de autoevaluación más utilizados.

Con base en la separación de los síntomas de la ansiedad en cognitivos, afectivos, conductuales y fisiológicos de Beck y Emery (1985), presentados anteriormente, se realizó una evaluación, ítem a ítem, de las escalas a ser utilizadas en esta investigación - BAI, STAI y Zung - así para ver el porcentaje de ítems en cada tipo de síntomas. Los datos son presentados en la Tabla 10.

Tabla 10. Porcentaje de ítems del total en cada tipo de síntomas de la ansiedad

\begin{tabular}{lcccc}
\hline & $\begin{array}{c}\text { Síntomas } \\
\text { cognitivos }\end{array}$ & $\begin{array}{c}\text { Síntomas } \\
\text { afectivos }\end{array}$ & $\begin{array}{c}\text { Síntomas } \\
\text { conductuales }\end{array}$ & $\begin{array}{c}\text { Síntomas } \\
\text { fisiológicos }\end{array}$ \\
\hline BAI & $10 \%$ & $24 \%$ & $5 \%$ & $61 \%$ \\
STAI-E & $25 \%$ & $60 \%$ & $5 \%$ & $10 \%$ \\
STAI-T & $45 \%$ & $55 \%$ & - & - \\
ZUNG & $20 \%$ & $5 \%$ & $5 \%$ & $70 \%$ \\
\hline
\end{tabular}

De acuerdo con los diferentes aspectos de la ansiedad medidos por las escalas descritas, observamos que las escalas de Zung y de Beck tienen constructos semejantes, con énfasis en los aspectos somáticos de la ansiedad, lo que está de acuerdo con el estudio de Andrade y Gorenstein (1998). Los mismos autores refieren que el STAl tiene una gran proporción de sus ítems que miden aspectos inespecíficos que pueden estar presentes en cualquier situación de estrés (Andrade \& Gorenstein, 1998). En nuestro análisis estos ítems inespecíficos fueron contenidos en los síntomas afectivos, por estar más cerca de ellos. 
CAPÍTULO V

EL MODELO DE RASCH Y EL MODELO DE ESCALAS DE

CALIFICACIÓN 
La Teoría Clásica de los Tests ha sido el principal modelo psicométrico empleado en la construcción y análisis de los tests. Sin embargo, sus limitaciones han llevado a la propuesta de modelos alternativos, de los cuales el más parsimonioso es el modelo de Rasch, que permite la medición conjunta de personas e ítems en una misma dimensión o constructo (Prieto \& Delgado, 2003; Stone, 2003). Así, es el único que proporciona la objetividad específica para la construcción de escalas, permitiendo la independencia de las estimaciones con respecto a la distribución del atributo en las personas en que es medido (Bond \& Fox, 2001).

Existen diversos modelos de Rasch, tales como "Binomial Trials", "Poisson counts", "Rating Scale Model", "Partial Credit Model", "Ranks Model", etc. Estos modelos proporcionan una solución completa para casi todos los problemas de medición encontrados en las distintas ciencias, ya sea con datos dicotómicos o politómicos, y son especialmente aptos para las ciencias sociales, donde los datos son conceptualmente más vagos (Stone, 2003; Wright \& Mok, 2004).

El modelo de Rasch tiene como base la idea de que la medición útil implica la evaluación de una persona en un determinado momento en una línea jerárquica que va de menos a más (Bond \& Fox, 2001).

El modelo propuesto por Georg Rasch (1960) se fundamenta en dos supuestos principales: el atributo que se pretende medir puede representarse en una dimensión donde sólo se situarían conjuntamente las personas y los ítems; el nivel de la persona en el atributo y la dificultad del ítem son los únicos determinantes de la probabilidad de que la respuesta sea correcta. Si el control de la situación es adecuado, esta expectativa es razonable y puede ser representada matemáticamente a través del modelo.

Rasch presenta una fórmula para modelizar esta relación:

$$
\ln \left(P_{\text {is }} / 1-P_{\text {is }}\right)=\left(B_{s}-D_{i}\right)
$$


Esta ecuación indica que el cociente entre la probabilidad de una respuesta correcta y la probabilidad de una respuesta incorrecta a un ítem (Pis / 1 - Pis), es una función de la diferencia en el atributo entre el nivel de la persona $\left(B_{s}\right)$ y el nivel del ítem $\left(D_{i}\right)$. Así, cuando una persona responde a un ítem equivalente a su competencia, tendrá la misma probabilidad de una respuesta correcta o incorrecta (Pis / $1-\mathrm{Pis}=0.50 / 0.50)$. En este caso, el logaritmo natural de (Pis / 1 - Pis), refleja que la dificultad del ítem es equivalente al nivel de competencia del sujeto $\left(B_{s}-D_{i}=0\right)$. Si la competencia de la persona es mayor que la requerida por el ítem $\left(B_{s}-D_{i}>0\right)$, la probabilidad de una respuesta correcta será mayor que la de una respuesta incorrecta. Lo contrario también ocurre, pues si la competencia de la persona es menor que la requerida por el ítem $\left(B_{s}-D_{i}<0\right)$, la probabilidad de una respuesta incorrecta será mayor que la de una respuesta correcta (Bond \& Fox, 2001; Prieto \& Delgado, 2003; Stone, 2003).

Las principales ventajas de este modelo en comparación con otros son la medición conjunta, la objetividad específica, las propiedades de intervalo y la especificidad del error típico de medida.

Hablamos de medición conjunta porque los parámetros, tanto de las personas como de los ítems, se expresan en las mismas unidades y se localizan en el mismo continuo. Como no todos los ítems miden la misma cantidad de constructo, con esta formulación se obtiene más realismo. Por otro lado lo que importa no es la norma referida a un grupo sino la identificación de los ítems que la persona tiene una alta o baja probabilidad de resolver correctamente. Por consiguiente se diagnostica mejor.

La objetividad específica es la propiedad por la que la diferencia entre dos personas en un atributo no depende de los ítems específicos con los que es estimada y la diferencia entre dos ítems no depende de las personas que se utilizan para cuantificarla. Así las comparaciones entre personas son independientes de los ítems administrados y las estimaciones de los parámetros de los ítems no son influidas por la distribución de la muestra que se usa para la calibración. 
Por ser una escala logit, el modelo tiene propiedades de intervalo, al contrario que la Teoría Clásica de los Tests. Una escala logit (unidad log odds) es una escala de intervalo en que las unidades en las que se miden las distancias entre las localizaciones en el mapa de la persona-ítem tienen un valor o significado consistente. De esta forma, a diferencias iguales entre un sujeto y un ítem le corresponden probabilidades idénticas de una respuesta correcta. Esta propiedad tiene gran importancia, puesto que es una condición necesaria para usar con rigor los análisis paramétricos más frecuentemente empleados en las ciencias sociales (análisis de varianza, regresión, etc.) y garantiza la invarianza de las puntuaciones diferenciales a lo largo del continuo (un requisito imprescindible en el análisis del cambio).

En la Teoría Clásica de los Tests se supone que los tests miden con la misma fiabilidad en todas las regiones de la variable, pero el modelo de Rasch tiene como propiedad la especificidad del error típico de medida. Así, permite cuantificar la cantidad de información con la que se mide en cada punto de la dimensión y permite seleccionar los ítems que permiten incrementar la información en regiones del atributo previamente especificadas (Bond \& Fox, 2001; Prieto \& Delgado, 2003). Esta propiedad es especialmente útil en los tests en los que se emplean puntos de corte, puesto que se puede concretar la precisión con la que se mide en esos puntos y establecer bandas de error más específicas que las establecidas a partir de la Teoría Clásica de los Tests.

El modelo de Rasch puede ser usado tanto con datos dicotómicos como con datos politómicos, aunque su utilización sea un poco más compleja. Una de las formas de presentar este tipo de datos, más utilizadas por psicólogos, son las escalas tipo Likert. El modelo establece la dificultad de cada punto del ítem, desde los ítems más bajos hasta los más altos. Así, cada ítem tiene una dificultad estimada. El modelo también estima los valores de las categorías de la escala para dar una estructura de calificación a la escala, que es compartida por todos los ítems que la componen.

Con datos dicotómicos, cada ítem tiene una estimación de dificultad y un error de estimación asociado. Con datos politómicos, no sólo cada ítem tiene una dificultad estimada 
sino que además la escala tiene una serie de umbrales (pasos o puntos de transición) entre las categorías sucesivas. Podemos presentar una extensión del modelo básico de Rasch para escalas con categorías ordenadas según el Modelo de Escalas de Calificación (Rating Scale Model, Andrich, 1978):

$\ln \left(P_{\text {nik }} / P_{\text {ni(k-1) }}\right)=B_{n}-D_{i}-F_{k}$

Donde:

$P_{\text {nik }}$ es la probabilidad de que la persona $n$, ante el ítem $i$ sea observada, o responda, en la categoría $k$;

$\mathrm{P}_{\text {ni(k-1) }}$ es la probabilidad de que la observación o la respuesta estén en la categoría $k$ 1

$\mathrm{B}_{\mathrm{n}}$ es la habilidad, actitud, etc., de la persona $n$;

$D_{i}$ es la localización del ítem $i$

$F_{k}$ es el punto de transición (paso) entre la categoría $k$ y la categoría $k-1$, i.e. el késimo paso de calibración, donde las categorías se numeran $0, m$.

El Modelo de Escalas de Calificación es el más usado en el análisis de escalas con formato tipo Likert, en las que todos los ítems se contestan con el mismo conjunto de categorías ordenadas. 
CAPÍTULO VI OBJETIVOS 


\subsection{Justificación}

La justificación de este trabajo radica en la necesidad de disponer de instrumentos breves de medida de la ansiedad en portugués.

De acuerdo con los estudios revisados por Keedwell y Snaith (1996), la escala de Beck es una de las dos escalas de evaluación clínica de la ansiedad más utilizadas en el mundo. Sin embargo, esta escala no se utiliza en Portugal, porque aún no existen estudios de validación.

\subsection{Objetivos}

\subsubsection{Objetivos Generales}

Llevar a cabo un estudio de validación del Inventario de Ansiedad de Beck (BAl) en Portugal.

\subsubsection{Objetivos Específicos}

a) Analizar el Inventario de Ansiedad de Beck con el Modelo de las Escalas de Calificación (Andrich, 1978); el Modelo de Escalas de Calificación es una extensión del modelo de Rasch (1960) para ítems politómicos. Este análisis implica:

a1) Analizar la calidad psicométrica de las categorías de respuesta del BAI. 
a2) Estimar los parámetros del modelo y analizar su precisión y el grado de ajuste de los datos de BAI.

a3) Poner a prueba la unidimensionalidad y la ausencia de Funcionamiento Diferencial de los Ítems de BAI.

b) Comparar las puntuaciones de BAI con las de otros marcadores de la ansiedad empleados en Portugal: STAI rasgo, STAI estado, Zung y ASI. Este análisis implica previamente al análisis de las correlaciones:

b1) Analizar la calidad psicométrica de las categorías de respuesta de los marcadores.

b2) Estimar los parámetros del modelo y analizar su precisión y el grado de ajuste de los datos de los marcadores.

b3) Poner a prueba la unidimensionalidad y la ausencia de Funcionamiento Diferencial de los Ítems de los marcadores. 


\section{CAPÍTULO VII}

METODOLOGIA 


\subsection{Participantes}

La muestra, de conveniencia, estaba integrada por 1160 adultos de la población general, 427 hombres y 733 mujeres, con una edad media de 33.39 años ( $D E=11.85$ ).

La Tabla 11 muestra las características demográficas de la muestra.

Tabla 11. Características demográficas por género

\begin{tabular}{|c|c|c|c|c|c|}
\hline & \multicolumn{2}{|c|}{$\begin{array}{l}\text { Varones } \\
(\mathrm{N}=427)\end{array}$} & \multicolumn{2}{|c|}{$\begin{array}{l}\text { Mujeres } \\
(\mathrm{N}=733)\end{array}$} & \multirow[t]{2}{*}{$\chi^{2}$} \\
\hline & $\mathrm{N}$ & $\%$ & $\mathrm{~N}$ & $\%$ & \\
\hline Residencia & & & & & 3.859 \\
\hline Medio urbano & 361 & 84.9 & 617 & 85.2 & \\
\hline Medio rural & 53 & 12.5 & 99 & 13.7 & \\
\hline Otro & 11 & 2.6 & 8 & 1.1 & \\
\hline Etnia & & & & & $6.830^{*}$ \\
\hline Caucásica & 358 & 88.4 & 638 & 93.0 & \\
\hline Negra & 34 & 8.4 & 34 & 5.0 & \\
\hline Otra & 13 & 3.2 & 14 & 2.0 & \\
\hline Nivel académico & & & & & 2.362 \\
\hline $\begin{array}{l}\text { Escuela primaria } \\
\text { incompleta }\end{array}$ & 4 & .9 & 6 & .8 & \\
\hline $\begin{array}{l}\text { Escuela primaria } \\
\text { completa }\end{array}$ & 25 & 5.9 & 29 & 4.0 & \\
\hline Hasta 9ำ año & 23 & 5.4 & 40 & 5.5 & \\
\hline Hasta $12^{\circ}$ año & 85 & 20.0 & 155 & 21.2 & \\
\hline $\begin{array}{l}\text { Universidad (más } \\
\text { del 12ํaño) }\end{array}$ & 289 & 67.8 & 502 & 68.6 & \\
\hline
\end{tabular}


Tabla 11 (Cont.)

\begin{tabular}{|c|c|c|c|c|c|}
\hline & \multirow{2}{*}{\multicolumn{2}{|c|}{$\begin{array}{l}\text { Varones } \\
(\mathrm{N}=427)\end{array}$}} & \multirow{2}{*}{\multicolumn{2}{|c|}{$\begin{array}{l}\text { Mujeres } \\
(\mathrm{N}=733)\end{array}$}} & \multirow{3}{*}{$\chi^{2}$} \\
\hline & & & & & \\
\hline & \multirow[t]{2}{*}{$\mathrm{N}$} & \multirow[t]{2}{*}{$\%$} & \multirow[t]{2}{*}{$\mathrm{N}$} & \multirow[t]{2}{*}{$\%$} & \\
\hline Religión & & & & & $12.917^{\star \star *}$ \\
\hline Sin religión & 133 & 31.2 & 159 & 21.9 & \\
\hline Católica & 262 & 61.5 & 495 & 68.3 & \\
\hline Otra & 31 & 7.3 & 71 & 9.8 & \\
\hline Estado civil & & & & & $31.112^{* \star *}$ \\
\hline Soltero & 254 & 59.5 & 317 & 4.3 & \\
\hline Casado o unión de & 147 & 34.4 & 336 & 45.9 & \\
\hline \multicolumn{6}{|l|}{ hecho } \\
\hline Separado o & 26 & 6.1 & 73 & 10.0 & \\
\hline \multicolumn{6}{|l|}{ divorciado } \\
\hline Viudo & & & 6 & .8 & \\
\hline Profesión & & & & & $39.963^{\star \star \star}$ \\
\hline Desempleado & 36 & 8.4 & 51 & 7.0 & \\
\hline Trabajador por & 174 & 40.7 & 423 & 58.0 & \\
\hline \multicolumn{6}{|l|}{ cuenta ajena } \\
\hline Trabajador por & 40 & 9.4 & 69 & 9.5 & \\
\hline \multicolumn{6}{|l|}{ cuenta propia } \\
\hline Estudiante & 161 & 37.7 & 161 & 22.1 & \\
\hline Jubilado & 16 & 3.7 & 25 & 3.4 & \\
\hline
\end{tabular}


Tabla 11 (Cont.)

\begin{tabular}{lccccc}
\hline & \multicolumn{2}{c}{ Varones } & \multicolumn{2}{c}{ Mujeres } & \\
& \multicolumn{2}{c}{$(\mathrm{N}=427)$} & & $(\mathrm{N}=733)$ & \\
& $\mathrm{M}$ & $\mathrm{DE}$ & $\mathrm{M}$ & $\mathrm{DE}$ & \\
\cline { 2 - 5 } & 31.83 & 12.06 & 34.30 & 11.64 & $-3.440^{* * *}$ \\
\hline Edad & .63 & 1.00 & .89 & 1.04 & $-4.073^{* * *}$ \\
Número de hijos & & & & & \\
\hline${ }^{*} \mathrm{p} \leq .05 ;{ }^{* *} \mathrm{p} \leq .01 ;{ }^{* * *} \mathrm{p} \leq .001$. & & & & &
\end{tabular}

La mayoría de los participantes vivía en zonas urbanas, era de la etnia caucásica, con un nivel educativo de educación universitaria, de religión católica, soltero o casado y trabajador por cuenta ajena.

Se encontraron diferencias de género estadísticamente significativas para la etnia $\chi 2$ $(2)=6.830 ; p=.033$, para la religión $\chi 2(2)=12.917 ; p=.002 ;$ para el estado civil $\chi 2(3)=$ 31.112; $p<.001$; para la profesión $\chi 2(4)=39.963 ; p<.001$, para la edad $t(1154)=-3.440 ; p=$ .001 , y para el número de hijos $t(1141)=-4.073 ; p<.001$. Aunque ambos sexos se refieren más a la raza caucásica y la religión católica, más hombres que mujeres dicen ser de otra raza y no tener religión. La mayoría de los hombres eran solteros y la mayoría de las mujeres eran casadas o solteras. Para la profesión, la mayoría de los hombres estaban empleados por cuenta ajena o eran estudiantes y la mayoría de las mujeres estaban trabajando por cuenta ajena. Las mujeres tenían una edad mayor y más hijos que los hombres de la muestra. 


\subsection{Materiales}

Se utilizó un cuestionario demográfico diseñado para esta investigación, que preguntó sobre género, edad, lugar de residencia, origen étnico, nivel educativo, religión, estado civil, número de hijos y ocupación.

Ansiedad. Se utilizaron las escalas de ansiedad BAI, STAl y de Zung, como se describe anteriormente.

Sensibilidad a la Ansiedad. Evaluada por el Índice de Sensibilidad a la Ansiedad (ASI, acrónimo inglés que usaremos en este trabjo; Peterson \& Reiss, 1987).

El índice de sensibilidade a la ansiedad es una escala compuesta por 16 ítems que evalúan hasta qué punto una persona considera que sus sentimientos relacionados con la ansiedad pueden ser catastróficos o temibles. Sus ítems se centran en el miedo en diferentes aspectos de la ansiedad como el miedo de las sensaciones físicas (temblores, mareos, náuseas, falta de aliento, palpitaciones, malestar estomacal y sensaciones corporales inusuales) y creencias acerca de las reacciones que sugieren falta de control mental (efectos de nerviosismo, falta de concentración) (Peterson \& Plehn, 1999).

Dada la importancia que la sensibilidad a la ansiedad tiene en la etiología de las reacciones de la ansiedad, es importante determinar los mecanismos base de la sensibilidad a la ansiedad. El análisis factorial es un método para hacerlo y son varios los estudios que lo han hecho.

Hasta el momento actual, el ASI se ha empleado principalmente como medida unidimensional (general) de la sensibilidad a la ansiedad. Sin embargo, la naturaleza multidimensional de esta escala sugiere, para algunos autores, la posibilidad y conveniencia de derivar al menos tres subescalas sobre los tres componentes de sensibilidad a la 
ansiedad aislados (Sandín, et al., 2005). Otros estudios apuntan a dos o tres factores de primer orden y un factor de orden superior para el ASI (Bernstein et al., 2007; Citrón, Carter, Suchday, Sbrocco, \& Gray, 2005; Sandín, Chorot, Valiente, Santed, \& Lostao, 2004; Taylor, 1996).

En relación a sus propiedades psicométricas, los coeficientes a de la versión española indican que la consistencia interna es excelente para la escala total con un valor de $\alpha$ de Cronbach de .84 , y para la subescala somática con un valor de $\alpha$ de Cronbach de .83, buena para la subescala cognitiva con un valor de $\alpha$ de Cronbach de .77, y moderada para la subescala social con un valor de $\alpha$ de Cronbach de .50. Al comparar las puntuaciones medias entre los grupos de varones y mujeres, los autores observaron medias significativamente más elevadas en el grupo de mujeres para el ASI total y para la dimensión somática y cognitiva, no existiendo diferencias entre ambos grupos en la subescala social. Las correlaciones entre las tres subescalas de sensibilidad a la ansiedad fueron: .51 (somática y cognitiva), .38 (somática y social) y .36 (cognitivo y social). Las correlaciones son moderadas y podrían indicar que se trata de tres constructos diferentes, aunque correlacionados (Sandín, et al, 2005). En cualquier caso, la evidencia no es concluyente.

No se encontraron trabajos acerca de las características psicométricas del ASI en Portugal, por lo que se hará ese estudio en este trabajo. 


\subsection{Procedimiento}

Fue solicitada la autorización para validar el inventario de ansiedad de Beck para Portugal, al Departamento de Investigación y Producción de pruebas de la Casa do Psicólogo en São Paulo, Brasil, que es el titular directo de la publicación de las escalas de Beck (de Harcourt Assessment, Inc.) en idioma portugués. El permiso fue concedido el 23 de enero de 2007 (Anexo 1).

La traducción se hizo a partir de la versión brasileña, modificando únicamente tres términos en los que había diferencias culturales. La sustitución de las tres palabras se realizó mediante traducción inversa de estos ítems (Inglés-Portugués-Inglés).

La aplicación se llevó a cabo en diversas universidades, empresas e instalaciones públicas. Se pidió la colaboración desinteresada de los participantes de forma oral y por escrito, con información previa del objetivo de estudio pretendido y del tipo de participación pretendida, de la confidencialidad y anonimato, de la posibilidad de renuncia durante la elaboración de la evaluación, así como de la inexistencia de respuestas correctas o incorrectas.

La recogida de la muestra transcurrió durante los meses de mayo de 2008 y abril de 2009, en diversas universidades e instalaciones públicas de la ciudad de Lisboa y alrededores, tardando en ser rellenado cada protocolo una media de 20 minutos. 


\subsection{Codificación y análisis de los datos}

En primer lugar, una vez recogidos los datos, se recodificaron estos de manera que las categorías correspondientes a ítems que medían en sentido inverso fueron en el sentido de la variable medida.

Todos los participantes que no cumplían con al menos un ítem del Inventario de Ansiedad de Beck fueron retirados de la base de datos. En las restantes medidas utilizadas los valores en falta fueron sustituidos por la moda de cada ítem.

Los datos fueron analizados con el programa Winsteps (Linacre \& Wright, 2000).

Se realizó el análisis de la funcionalidad de las categorías de respuesta, de acuerdo con los siguientes criterios propuestos por Linacre (2002):

1. Frecuencia suficiente y distribución regular de las elecciones de las categorías: las frecuencias bajas no son útiles para estimar las calibraciones de los pasos $\left(F_{k}\right)$. La situación ideal es una distribución uniforme, pero también es adecuada una distribución unimodal o bimodal con las frecuencias mayores en las categorías de los extremos.

2. Las categorías no deben presentar un desajuste elevado con el modelo.

Para poner a prueba el ajuste de las personas, ítems y categorías, se usan las medias de los residuos (diferencias entre las respuestas observadas y las esperadas) Outfit (media de los cuadrados de los residuos estandarizados) e Infit (media de los cuadrados de los residuos estandarizados, ponderados con la función de información) son las medias que indican el grado de ajuste. Outfit es muy sensible a los patrones de respuesta inesperados (outliers), que tienen menos influencia en el Infit (Wright \& Mok, 2004). El valor esperado para las dos medias es la unidad. Valores altos indican patrones aberrantes con respecto al modelo, y valores bajos indican patrones deterministas de respuesta (Wright, 1996). Los valores de infit o outfit, superiores a 1,5 e inferiores a 2, indican que el desajuste de los datos empíricos es moderadamente alto, pero no degradan gravemente las medidas. Sin embargo, los valores superiores a 2 revelan un alto desajuste (Linacre, 2002). 
3. Los puntos de transición (pasos) entre las categorías sucesivas (Fk) deben aumentar monotónicamente.

En el MEC (cuestiones de elección múltiple), la probabilidad de seleccionar una categoría depende del nivel en el constructo de la persona. Es deseable que exista algún intervalo en el continuo en el que cada categoría sea la elección más probable (Linacre, 2002). Si esto sucede, los puntos de transición (Fk) están ordenados monotónicamente. Es decir, $\mathrm{F} 1<\mathrm{F} 2<\mathrm{F} 3$, etc.

Se analizó también la unidimensionalidad de las escalas con objeto de comprender si se adecuaban a un sólo factor.

La unidimensionalidad estricta es más un concepto mitológico que la realidad alcanzable para la mayoría de los constructos psicológicos (Zickar \& Broadfoot, 2009). De acuerdo con Linacre (2010), lo importante no es comprobar si los datos son totalmente unidimensionales, porque en realidad nunca lo son, sino que se trata de determinar si la falta de unidimensionalidad en los datos es suficientemente grande para amenazar la validez de los resultados.

Zickar y Broadfoot (2009) dicen que, en general, tal vez sería mejor pensar la unidimensionalidad como un continuo (una cuestión de grado) que emplear una categorización nominal (unidimensional/no unidimensional). Los mismos autores refieren que niveles estrictos de unidimensionalidad no son necesarios para los modelos de la Teoría de Respuesta al ítem con altos niveles de precisión.

Reckase (1979) encontró que siempre que el primer factor explique el $20 \%$ de la varianza de la escala y no haya un segundo factor dominante, los modelos de la Teoría de Respuesta al Ítem funcionan adecudamente.

Se ha acuñado el concepto de unidimensionalidad esencial (suficiente) para representar la unidimensionalidad que no siendo perfecta, es aceptable para el uso de modelos de la Teoría de Respuesta al ítem (Zickar \& Broadfoot, 2009). 
El programa Winsteps permite contrastar la unidimensionalidad mediante un análisis de componentes principales de los residuos (las diferencias entre las respuestas observadas y las predichas por el modelo). De acuerdo con Linacre (2010), existe una unidimensionalidad suficiente si el porcentaje explicado por las medidas derivadas del modelo es superior al 50 por ciento y si la varianza explicada por los ítems es más de cuatro veces la varianza explicada por el primer contraste (el primer autovalor de los residuos).

El funcionamiento diferencial de los ítems (DIF) es una evidencia de la falta de validez de las medidas. Se produce cuando existen factores ajenos al constructo que se pretende medir que afectan espuriamente a las respuestas. En presencia de DIF puede suceder que sujetos con el mismo nivel en el constructo, pero pertenecientes a diferentes grupos sociodemográficos (por ejemplo, hombres y mujeres), tengan distinta probabilidad de una respuesta (Draba, 1977). De acuerdo con los supuestos de los modelos tipo Rasch, la probabilidad de la respuesta a un ítem sólo ha de depender de la diferencia en el atributo entre el parámetro de la persona y el parámetro del ítem. Esto implica, por ejemplo, que la probabilidad de .50 de estar de acuerdo con un ítem corresponde a un valor en la variable que ha de ser el mismo para las personas de distintos grupos sociales. En caso contrario, la probabilidad de la respuesta está determinada por factores ajenos al constructo medido. En consecuencia, las medidas obtenidas con los ítems carecerían de la validez requerida.

En la actualidad el análisis del DIF es un paso obligado en los programas de validación de un test. En consecuencia, se ha llevado a cabo un análisis del funcionamiento diferencial de los ítems del MEC relacionado con el sexo y la edad.

Se han propuesto muchos procedimientos para detectar el DIF. En el contexto de los modelos tipo Rasch, se suele emplear un contraste estadístico de las diferencias entre los parámetros de localización del ítem obtenidos en los grupos en estudio (en este caso, hombres y mujeres y entre dos grupos de edad, 30 años o menos y más de 30 años) una vez equiparadas en la misma escala las puntuaciones de ambos grupos. 
El procedimiento implementado en Winsteps consiste en estimar en cada ítem la diferencia entre el parámetro de dificultad en cada grupo (focal y de referencia). El contraste se lleva a cabo mediante la fórmula propuesta por Wrigt y Panchapakesan (1969):

$$
t=B_{f}-B_{r} /\left(S E_{f}^{2}+S E_{r}^{2}\right)^{1 / 2}
$$

Donde $B_{f}-B_{r}$ son los parámetros de localización del ítem para el grupo focal y el grupo de referencia, y $S^{2}{ }_{f}$ y $S E^{2}$ son los cuadrados de sus errores típicos.

Un valor absoluto superior a 2 del estadístico de contraste se suele considerar una evidencia de DIF significativa estadísticamente. Siguiendo a Wright y Douglas (1975), los valores de DIF que degradan las medidas corresponden a diferencias $\left(B_{f}-B_{r}\right)$ superiores a 0,5 logit.

Sin embargo, para determinar si la diferencia es significativa estadísticamente se empleó la corrección de Bonferroni. Por la corrección de Bonferroni la presencia de DIF se detecta cuando p es menor o igual a .05 dividido por el número de contrastes, ítems en nuestro caso (Linacre, 2010). En general, esta corrección se emplea para que el error tipo I corresponda a $\alpha$.

Para poner a prueba el DIF asociado a la edad se ha transformado una variable numérica en dicotómica, dividiendo las edades de 30 ó menos años y más de 30 años. Varios meta-análisis han demostrado que existen apenas pequeñas diferencias de edad en la personalidad a lo largo de la vida adulta (Roberts, Walton, \& Viechtbauer, 2006). La edad de 30 años fue, así, seleccionada por existir evidencia empírica de que a esta edad, según el punto de vista evolutivo, la personalidad ya está establecida.

Dicotomizar una variable numérica no es muy recomendable, pero como en este caso no se tenía intención de hacer un análisis de correlación, sino la evaluación del DIF, no parecía haber ningún impedimento.

Para estudiar la correlación entre las distintas medidas de la ansiedad utilizadas y la edad, se tomaron las puntuaciones Rasch de todos los participantes en las escalas. De este modo, se creó una base de datos en SPSS (Statistical Package for the Social Sciences, 
versión 17.0), con el ID (identificación del participante), las puntuaciones Rasch para cada medida y la edad del participante. Se verificaron los supuestos para el uso de pruebas paramétricas, se confirmando la normalidad y homoscedasticidad. Por lo tanto, se utilizó el coeficiente de correlación de Pearson.

Utilizando la misma base de datos en SPSS se realizó un análisis de varianza factorial con las puntuaciones del modelo de Rasch (variables dependientes) y el sexo y la edad (variables independientes). Para comparar los resultados también se realizó el mismo análisis con las puntuaciones directas (clásicas). Previamente se había corroborado que las variables cumplían los supuestos para el uso de pruebas paramétricas, esto es, distribución normal (prueba de Kolmogorov-Smirnov) y homogeneidad de varianzas (test de Levene). 
CAPÍTULO VIII RESULTADOS 


\subsection{Análisis de las medidas utilizadas mediante el Modelo de Rasch}

\subsubsection{Inventario de ansiedad de Beck}

En primer lugar, se analizó la calidad psicométrica de las categorías de respuesta, de acuerdo con los criterios de Linacre (2002). Tal como se puede observar en la Tabla 12, el sistema de cuatro categorías, analizado con el Rating Scale Model, es adecuado.

Tabla 12. Estadísticos correspondientes a las categorías del BAI

\begin{tabular}{lccccc}
\hline Categoría & Elecciones & B & Infit & Outfit & Paso \\
\hline 1 = Absolutamente não & $15498(68 \%)$ & -2.88 & 1.03 & 1.02 & -- \\
2 = Levemente & $4721(21 \%)$ & -1.61 & .94 & .79 & -1.08 \\
3 = Moderadamente & $2121(9 \%)$ & -.70 & 1.04 & 1.08 & -.37 \\
4 = Gravemente & $403(2 \%)$ & -.03 & 1.24 & 1.37 & 1.45 \\
\hline
\end{tabular}

Puede observarse que las categorías cumplen los criterios propuestos por Linacre (2002): el número de elecciones y su distribución son adecuados, no hay un desajuste elevado en ninguna categoría (Outfit $<2$ ), los pasos (step) entre las categorías sucesivas están ordenados de forma creciente y hay una ordenación monotónica de las medidas de B. Como se ha indicado con anterioridad, la ordenación creciente de los pasos es un indicador de que todas las categorías de respuesta son funcionales en el sentido de que cada categoría es la más probable en algún rango de la variable.

La figura 2 muestra el funcionamiento de las cuatro categorías. 


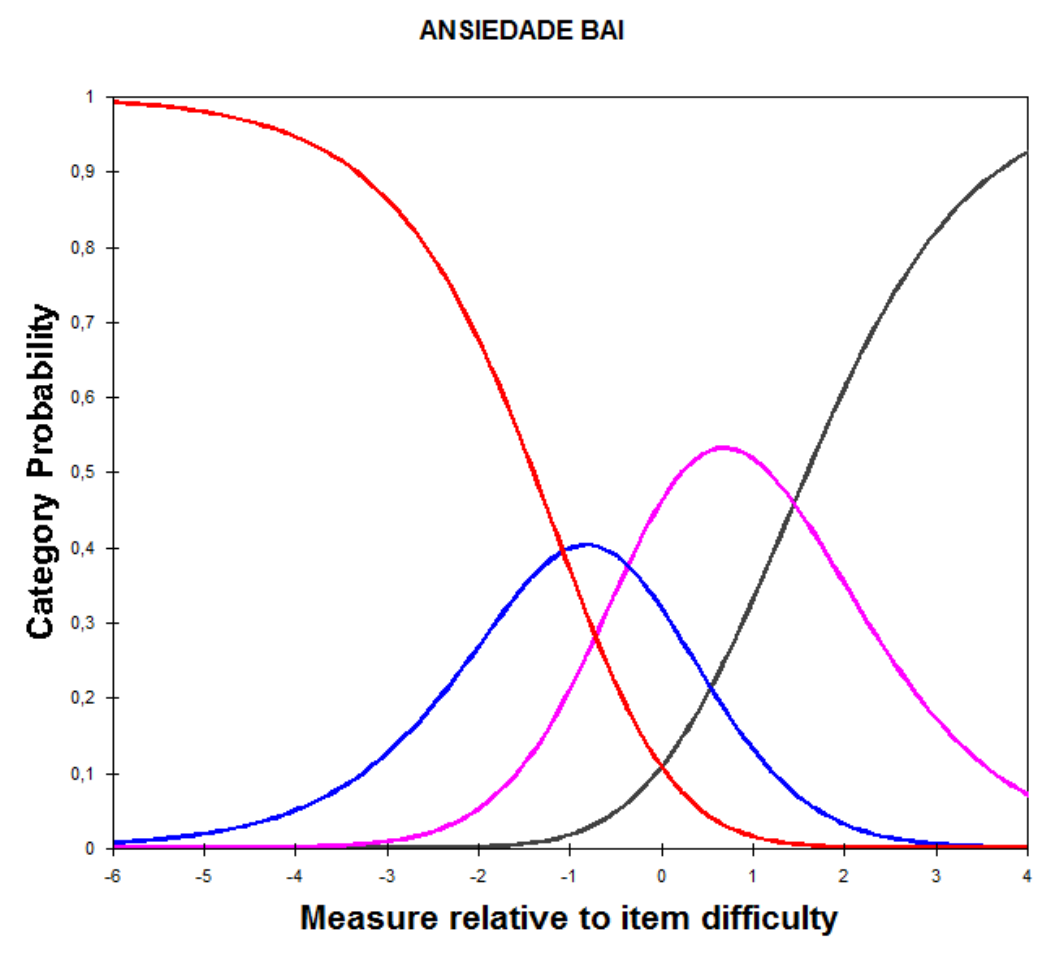

Figura 2. Representación gráfica de las curvas características de las categorías del BAI.

Una vez comprobada la adecuación de las categorías, se analizó el ajuste de los ítems y de las personas, se estimaron sus parámetros y se evaluó su fiabilidad. En la Tabla 13 aparecen los estadísticos de ajuste (Infit y Outfit), la localización (Di) y el error típico de medida de los ítems (SE). 
Tabla 13. Características psicométricas de los ítems del BAI

\begin{tabular}{|c|c|c|c|c|}
\hline Ítem (1) & Infit & Outfit & $\mathrm{Di}$ & SE \\
\hline 1 (Dormência ou formigueiro) & 1.15 & 1.37 & .05 & .06 \\
\hline 2 (Sensação de calor) & 1.13 & 1.23 & -.86 & .05 \\
\hline 3 (Tremores nas pernas) & 1.18 & .99 & .44 & .06 \\
\hline 4 (Incapaz de relaxar) & .92 & .95 & -1.32 & .04 \\
\hline 5 (Medo que aconteça o pior) & .99 & .93 & -1.16 & .04 \\
\hline 6 (Atordoado ou tonto) & 1.01 & .92 & -.17 & .05 \\
\hline 7 (Palpitação ou aceleração do coração) & .87 & .87 & -.96 & .04 \\
\hline 8 (Sem equilíbrio) & 1.18 & .99 & .64 & .07 \\
\hline 9 (Aterrorizado) & 1.10 & .66 & 1.02 & .08 \\
\hline 10 (Nervoso) & .71 & .74 & -1.69 & .04 \\
\hline 11 (Sensação de sufocação) & 1.04 & .69 & .84 & .07 \\
\hline 12 (Tremores nas mãos) & 1.05 & .91 & .37 & .06 \\
\hline 13 (Trémulo) & .98 & .77 & .80 & .07 \\
\hline 14 (Medo de perder o controlo) & .99 & .86 & -.20 & .05 \\
\hline 15 (Dificuldade de respirar) & 1.09 & .98 & .55 & .07 \\
\hline 16 (Medo de morrer) & 1.52 & 1.37 & .51 & .07 \\
\hline 17 (Assustado) & .88 & .75 & -.05 & .05 \\
\hline 18 (Indigestão ou desconforto no abdómen) & 1.27 & 1.25 & -.54 & .05 \\
\hline 19 (Sensação de desmaio) & 1.05 & .87 & 1.09 & .08 \\
\hline 20 (Rosto afogueado) & 1.17 & .92 & .55 & .07 \\
\hline 21 (Suor (não devido ao calor)) & 1.17 & 1.09 & .09 & .06 \\
\hline Media & 1.07 & .96 & .00 & .06 \\
\hline DT & .16 & .20 & .79 & .01 \\
\hline
\end{tabular}


Se puede observar que no hay ítems con valores de infit y/o outfit superiores a 1.5 (excepto el ítem 16 - medo de morrer- con un valor de 1.52) lo que revela que los ítems no se desajustan de forma severa (ningún ítem presenta valores superiores a 2.00). Los restantes ítems presentan valores en torno a la unidad, un valor que indica un ajuste perfecto (Linacre \& Wright, 2000).

En la columna Di, referente a la dificultad o localización de los ítems, podemos ver que el ítem 19 ("Sensação de desmaio") es el indicador de mayor nivel de ansiedad y el ítem 10 ("Nervoso") es el de menor nivel.

Los errores típicos de medida de los ítems oscilan entre .04 a .08, lo que indica que la fiabilidad de los ítems es muy buena, dado que los errores típicos son bajos. La fiabilidad global de las estimaciones de los ítems puede ser evaluada mediante el estadístico denominado Item Separation Reliability, que indica la proporción de la varianza observada de los ítems no explicada por el error de medida (Smith \& Smith, 2004).

La tabla 14 nos muestra los valores para el BAI. 
Tabla 14. Resumen de los resultados del BAI.

\begin{tabular}{lccccc}
\hline Estadísticos & Max. & Min. & Media & DT & Valor \\
\hline Infit de los ítems & 1.52 & .71 & 1.07 & .16 & --- \\
Outfit de los ítems & 1.37 & .66 & .96 & .20 & --- \\
\% ítems con desajuste moderado (1) & --- & --- & --- & --- & $4.76 \%(1)$ \\
\% ítems con alto desajuste (2) & --- & --- & --- & --- & $0 \%$ \\
Infit de las personas & 4.16 & .26 & .97 & .42 & --- \\
Outfit de las personas & 5.40 & .22 & .96 & .58 & --- \\
\% personas con desajuste moderado & --- & --- & --- & --- & $9.31 \%(108)$ \\
(1) & & & & & \\
\% personas con alto desajuste (2) & --- & --- & --- & --- & $5,60 \%(65)$ \\
Parámetro de los ítems & 1.09 & -1.69 & .00 & .79 & --- \\
Fiabilidad de los ítems & --- & --- & --- & --- & .99 \\
Parámetro personas & 1.73 & -4.46 & -2.36 & 1.09 & --- \\
Fiabilidad de personas & --- & --- & --- & --- & .79 \\
\hline
\end{tabular}

(1) Infit $y /$ o outfit $>1.5 y<2$; (2) Infit $y / 0$ outfit $>2$; (3) $p<.05$

Como se puede observar en la tabla 14, la fiabilidad de los ítems es muy alta (.99).

El ajuste de las personas al modelo es razonable, pues los valores de la media y de la desviación típica son respectivamente de .97 y .42 (infit), y .96 y .58 (outfit). El $9.31 \%$ de las personas presentan desajuste moderado (infit $\mathrm{y} / \mathrm{o}$ outfit $>1.5 \mathrm{y}<2$ ) y el $5.60 \%$ alto desajuste (infit y/o outfit $>2$ ).

Los parámetros de las personas van de -4.46 a 1.73 con una media de -2.36 y una desviación típica de 1.09. Los errores típicos de medida de las personas van de .28 a 1.83. La fiabilidad global de las personas (.79) no es excelente, pero razonable (porcentaje de la 
varianza de las personas no explicada por el error). Este valor tiene cierta similitud con el $\alpha$ de Cronbach de la teoría clásica.

La Tabla 15 muestra una representación conjunta persona-ítem, denominada "mapa de Wright", donde se puede observar la posición de los ítems y de las personas en la variable. Dado que la media de las personas (-2.36) es muy inferior a la de los ítems (.00), se puede considerar que el nivel de ansiedad de los sujetos analizados es muy bajo. Además, la mayor parte de las personas se encuentran por debajo del rango de la variable en el que los ítems se sitúan. En consecuencia, se observa que los ítems de la escala no permiten medir con alta precisión a las personas con niveles bajos de ansiedad. Esto sucede porque el nivel de las personas es bajo y la escala sólo tiene ítems situados en el rango superior del constructo. 
Tabla 15. Representación conjunta de personas e ítems del BAI

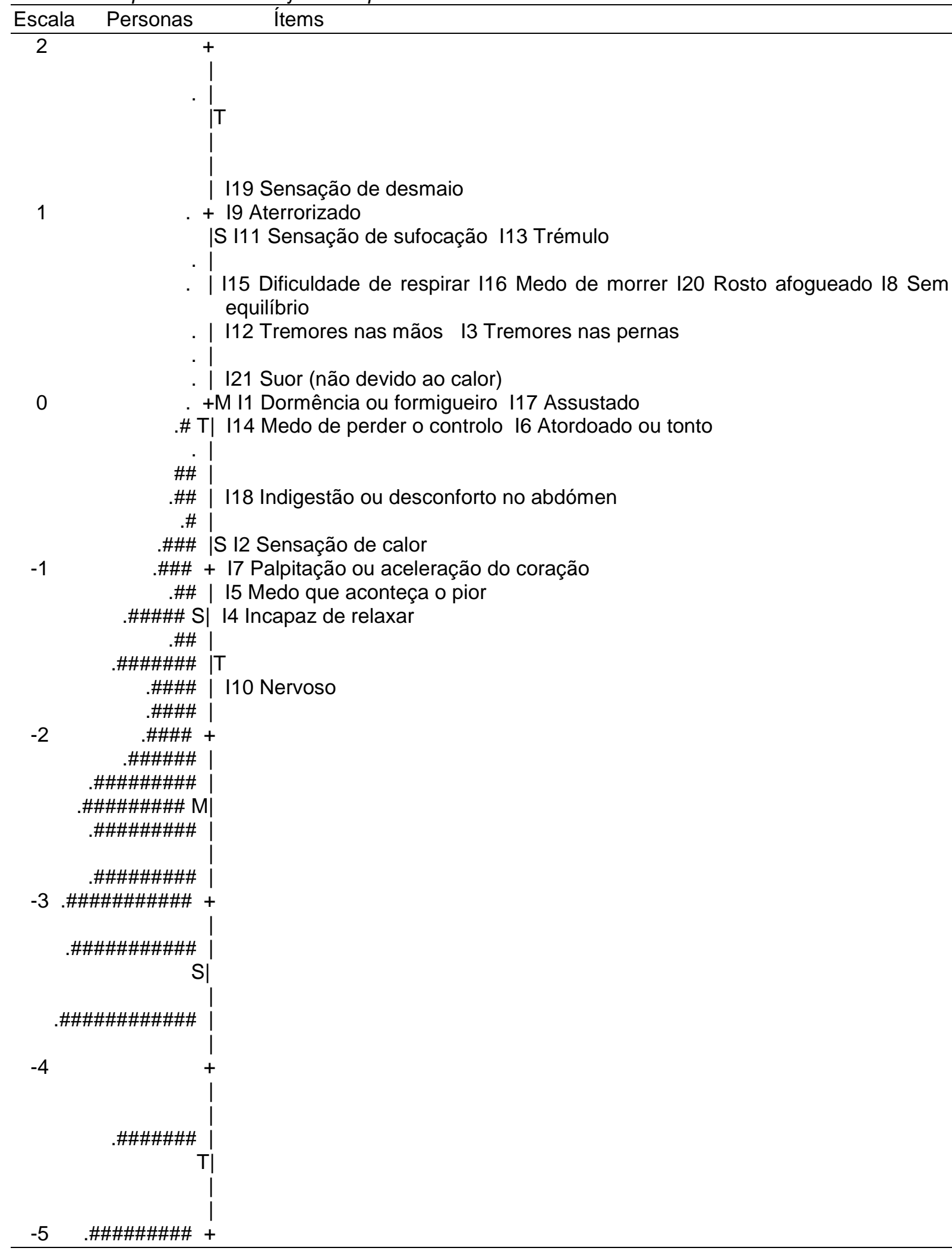

Nota: Cada \# son 8 personas; Cada '.' es 1 a 7. 
Se puso igualmente a prueba la unidimensionalidad del Inventario de ansiedad de Beck. Según Linacre (2010), la dimensión Rasch explica el $41.2 \%$, lo que no es óptimo $(<50 \%)$, pero es un valor cercano a lo aceptable. La varianza explicada por los ítems es del $27.5 \%$, que es cuatro veces mayor que el autovalor del primer contraste $(27.5 \%>$ $4 \times 5.5 \%=22 \%$ ), lo que es aceptable. Así, se muestra que los datos se explican básicamente por una dimensión, no habiendo amenaza a la validez de los resultados.

En la Tabla 16 se presentan los resultados del análisis del DIF asociado al sexo. 
Tabla 16. Funcionamiento diferencial de los ítems asociado al sexo para el BAI.

\begin{tabular}{|c|c|c|c|c|}
\hline Ítem & $\mathrm{DM}-\mathrm{DH}$ & SE & $\mathrm{t}$ & $p$ \\
\hline 1 & .00 & .12 & .00 & 1.000 \\
\hline 2 & -.29 & .09 & -3.13 & .002 \\
\hline 3 & -.07 & .13 & -.53 & .595 \\
\hline 4 & .12 & .09 & 1.33 & .183 \\
\hline 5 & -.20 & .09 & -2.21 & .027 \\
\hline 6 & .42 & .12 & 3.58 & .000 \\
\hline 7 & -.14 & .09 & -1.46 & .145 \\
\hline 8 & .11 & .15 & .73 & .467 \\
\hline 9 & .07 & .17 & .40 & .688 \\
\hline 10 & .13 & .09 & 1.51 & .132 \\
\hline 11 & .16 & .16 & 1.03 & .305 \\
\hline 12 & -.31 & .13 & -2.40 & .017 \\
\hline 13 & -.24 & .15 & -1.63 & .103 \\
\hline 14 & -.22 & .11 & -2.04 & .041 \\
\hline 15 & .07 & .14 & .48 & .632 \\
\hline 16 & .12 & .14 & .87 & .382 \\
\hline 17 & .02 & .12 & .20 & .843 \\
\hline 18 & .10 & .10 & .98 & .328 \\
\hline 19 & .83 & .20 & 4.22 & .000 \\
\hline 20 & .14 & .14 & .95 & .344 \\
\hline 21 & -.14 & .12 & -1.19 & .234 \\
\hline
\end{tabular}

Existen 3 ítems que presentan diferencia entre géneros en sus parámetros de localización: los ítems 2 (sensação de calor), 6 (atordoado) y 19 (sensação de desmaio) 
(valores p inferiores a .0024 (.05/21 ítems) - correlación de Bonferroni), pero las diferencias son inferiores a .50 logits, lo que manifiesta que la diferencia no es notable.

La figura 3 presenta las diferencias entre los parámetros de localización de los ítems en la muestra de varones y de mujeres.

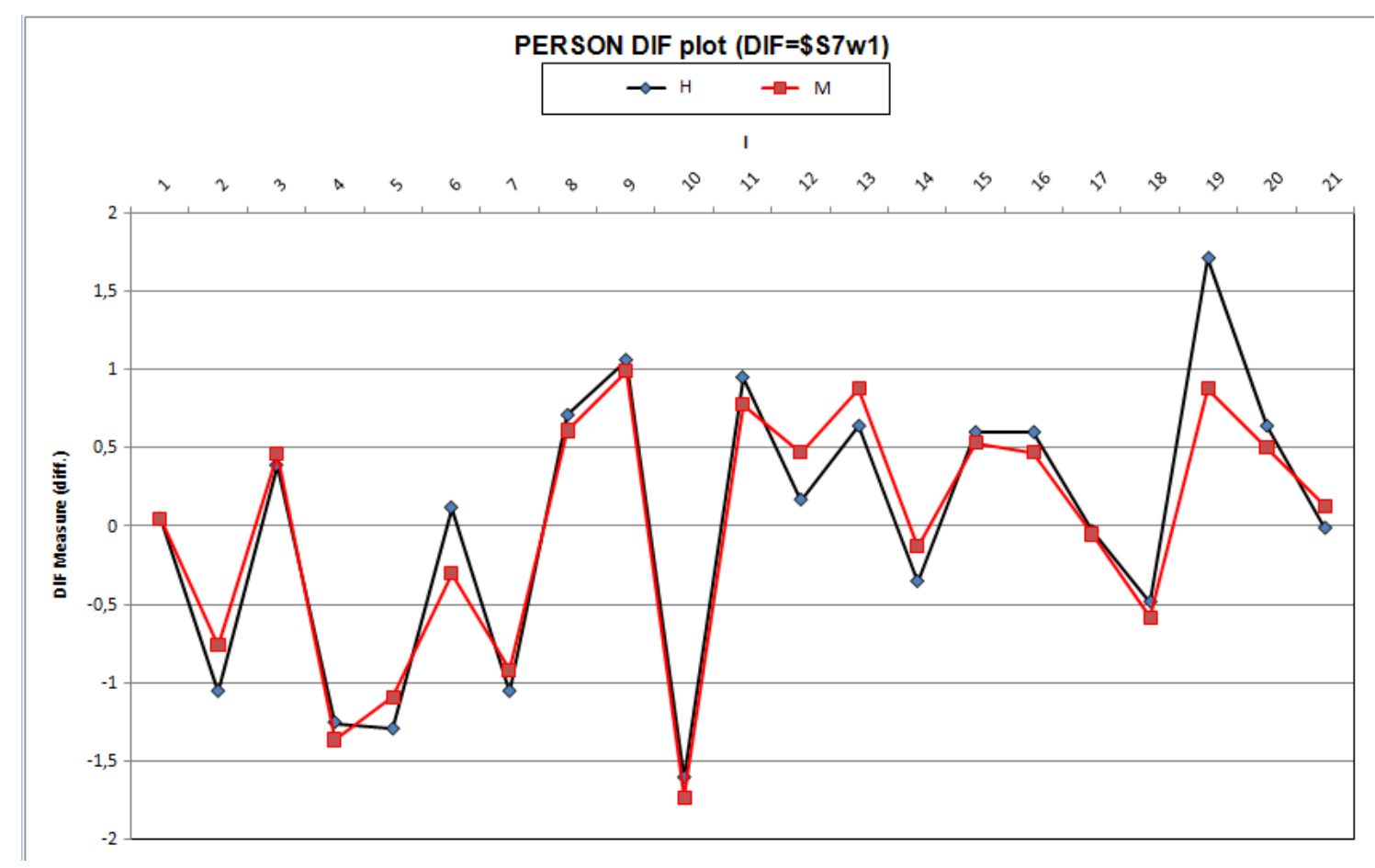

Figura 3 - Diferencias entre los parámetros de localización de los ítems del BAl de los varones y las mujeres.

En la Tabla 17 se presentan los resultados del análisis de Funcionamiento Diferencial de los Ítems asociado a la edad. 
Tabla 17. Funcionamiento Diferencial de los Ítems asociado a la edad para el BAI.

\begin{tabular}{|c|c|c|c|c|}
\hline Ítem & $D+E-D-E$ & SE & $\mathrm{t}$ & $p$ \\
\hline 1 & .16 & .11 & 1.38 & .167 \\
\hline 2 & -.45 & .09 & -4.94 & .000 \\
\hline 3 & -.25 & .13 & -1.97 & .049 \\
\hline 4 & .00 & .08 & .00 & 1.000 \\
\hline 5 & -.02 & .09 & -.24 & .812 \\
\hline 6 & .17 & .11 & 1.62 & .106 \\
\hline 7 & -.10 & .09 & -1.12 & .265 \\
\hline 8 & .09 & .14 & .68 & .495 \\
\hline 9 & -.15 & .16 & -.95 & .344 \\
\hline 10 & .09 & .08 & 1.07 & .287 \\
\hline 11 & .07 & .15 & .49 & .627 \\
\hline 12 & -.40 & .12 & -3.21 & .001 \\
\hline 13 & -.22 & .14 & -1.56 & .119 \\
\hline 14 & .18 & .10 & 1.73 & .084 \\
\hline 15 & .13 & .13 & 1.00 & .318 \\
\hline 16 & .41 & .13 & 3.11 & .002 \\
\hline 17 & -.06 & .11 & -.54 & .588 \\
\hline 18 & .18 & .10 & 1.89 & .060 \\
\hline 19 & .12 & .16 & .75 & .451 \\
\hline 20 & .28 & .13 & 2.11 & .035 \\
\hline 21 & -.08 & .11 & -.72 & .473 \\
\hline
\end{tabular}

Nota: $+\mathrm{E}-$ más de 30 años; -E - 30 años o menos.

Existen 3 ítems que presentan diferencia entre edades, los ítems 2 (sensação de calor), 12 (tremores nas mãos) y 16 (medo de morrer) (valores p inferiores a .0024 (.05/21 
ítems) - correlación de Bonferroni), pero las diferencias son pequeñas (inferiores a .50 logits), lo que manifiesta la diferencia no es relevante.

La figura 4 presenta las diferencias entre los parámetros de localización de los ítems en las muestras con diferente edad.

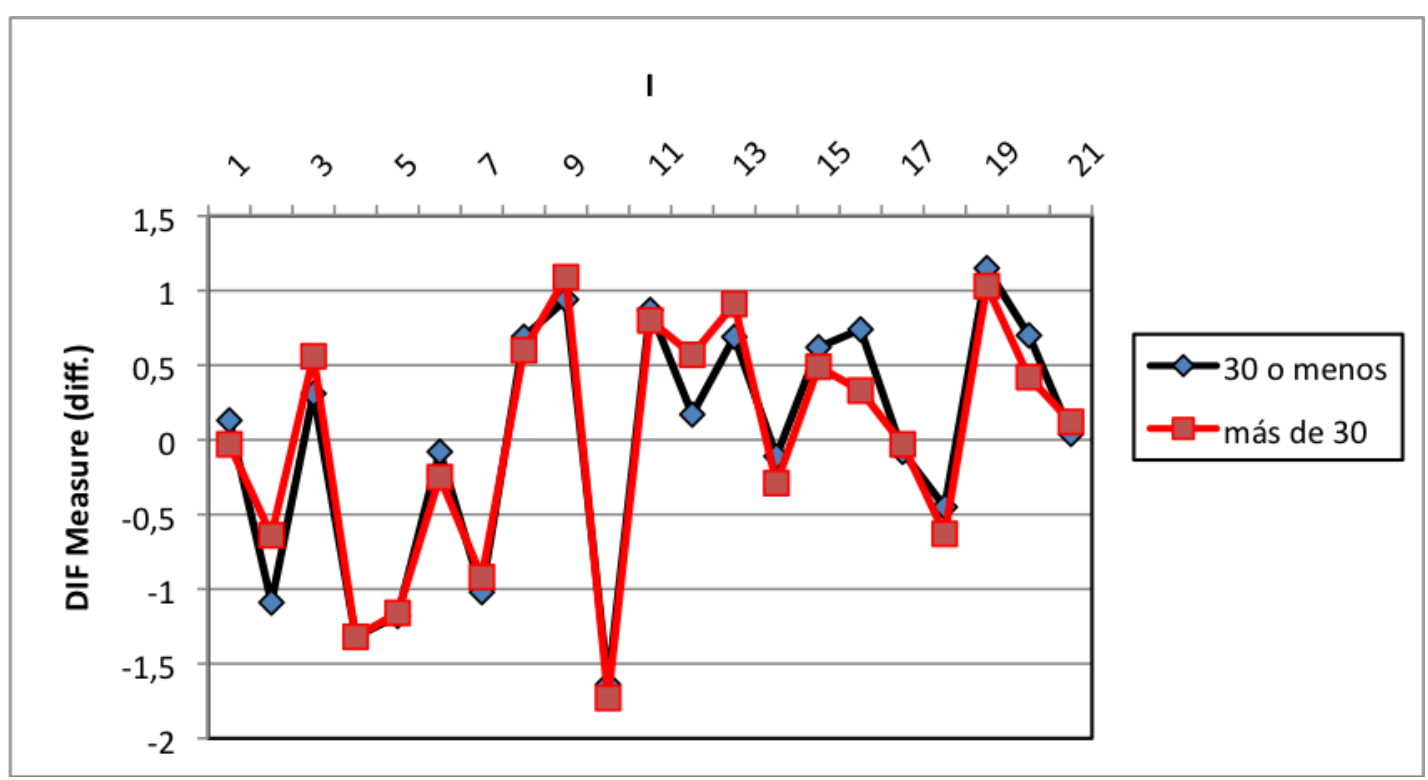

Figura 4 - Diferencias entre edades para el total del BAl.

En el tabla 18 se presenta la correspondencia entre las puntuaciones clásicas y los valores logit, con su error estándar, así como los baremos en percentiles y en puntuaciones típicas derivadas con su correspondiente error estándar (normed con Media 500 y Desviación Típica 100). 
Tabla 18. Correspondencia entre las puntuaciones clásicas y los valores Rasch para el BAI.

\begin{tabular}{|c|c|c|c|c|c|c|}
\hline Puntuación & Medida & SE & PT Derivada & SEPT & Frecuencia & Percentil \\
\hline 0 & $-5.67 E$ & 1.83 & 269 & 137 & 77 & 3 \\
\hline 1 & -4.46 & 1.00 & 359 & 75 & 63 & 9 \\
\hline 2 & -3.76 & .72 & 412 & 54 & 97 & 16 \\
\hline 3 & -3.34 & .59 & 443 & 44 & 90 & 24 \\
\hline 4 & -3.03 & .52 & 466 & 39 & 89 & 32 \\
\hline 5 & -2.79 & .47 & 485 & 35 & 78 & 39 \\
\hline 6 & -2.58 & .44 & 500 & 33 & 74 & 46 \\
\hline 7 & -2.40 & .41 & 513 & 31 & 78 & 52 \\
\hline 8 & -2.24 & .39 & 525 & 29 & 73 & 59 \\
\hline 9 & -2.10 & .37 & 536 & 28 & 49 & 64 \\
\hline 10 & -1.97 & .36 & 546 & 27 & 38 & 68 \\
\hline 11 & -1.84 & .35 & 556 & 26 & 35 & 71 \\
\hline 12 & -1.72 & .34 & 564 & 25 & 37 & 74 \\
\hline 13 & -1.61 & .33 & 573 & 25 & 30 & 77 \\
\hline 14 & -1.51 & .32 & 580 & 24 & 28 & 79 \\
\hline 15 & -1.41 & .31 & 588 & 24 & 22 & 82 \\
\hline 16 & -1.31 & .31 & 595 & 23 & 20 & 83 \\
\hline 17 & -1.22 & .30 & 602 & 23 & 22 & 85 \\
\hline 18 & -1.13 & .30 & 609 & 22 & 22 & 87 \\
\hline 19 & -1.04 & .29 & 616 & 22 & 15 & 89 \\
\hline 20 & -.95 & .29 & 622 & 22 & 14 & 90 \\
\hline 21 & -.87 & .29 & 628 & 22 & 12 & 91 \\
\hline 22 & -.79 & .29 & 634 & 21 & 18 & 92 \\
\hline 23 & -.71 & .28 & 640 & 21 & 9 & 94 \\
\hline
\end{tabular}


Tabla 18 (Cont.)

\begin{tabular}{|c|c|c|c|c|c|c|}
\hline Puntuación & Medida & SE & PT Derivada & SEPT & Frecuencia & Percentil \\
\hline 24 & -.63 & .28 & 646 & 21 & 11 & 94 \\
\hline 25 & -.55 & .28 & 652 & 21 & 10 & 95 \\
\hline 26 & -.47 & .28 & 658 & 21 & 12 & 96 \\
\hline 27 & -.40 & .28 & 664 & 21 & 4 & 97 \\
\hline 28 & -.32 & .28 & 670 & 21 & 3 & 97 \\
\hline 29 & -.24 & .28 & 675 & 21 & 3 & 98 \\
\hline 30 & -.17 & .28 & 681 & 21 & 3 & 98 \\
\hline 31 & -.09 & .28 & 687 & 21 & 6 & 98 \\
\hline 32 & -.02 & .28 & 692 & 21 & 2 & 99 \\
\hline 33 & .06 & .28 & 698 & 21 & 2 & 99 \\
\hline 34 & .14 & .28 & 704 & 21 & 2 & 99 \\
\hline 35 & .22 & .28 & 710 & 21 & 2 & 99 \\
\hline 36 & .29 & .28 & 716 & 21 & 2 & 99 \\
\hline 37 & .37 & .28 & 722 & 21 & 2 & 99 \\
\hline 38 & .45 & .28 & 728 & 21 & 0 & 99 \\
\hline 39 & .54 & .29 & 734 & 22 & 2 & 99 \\
\hline 40 & .62 & .29 & 740 & 22 & 0 & 99 \\
\hline 41 & .70 & .29 & 746 & 22 & 1 & 99 \\
\hline 42 & .79 & .30 & 753 & 22 & 0 & 99 \\
\hline 43 & .88 & .30 & 760 & 23 & 0 & 99 \\
\hline 44 & .97 & .31 & 767 & 23 & 2 & 99 \\
\hline 45 & 1.07 & .31 & 774 & 23 & 0 & 99 \\
\hline 46 & 1.17 & .32 & 781 & 24 & 0 & 99 \\
\hline 47 & 1.27 & .32 & 789 & 24 & 0 & 99 \\
\hline
\end{tabular}


Tabla 18 (Cont.)

\begin{tabular}{lcccccc}
\hline Puntuación & Medida & SE & PT Derivada & SEPT & Frecuencia & Percentil \\
\hline 48 & 1.38 & .33 & 797 & 25 & 0 & 99 \\
49 & 1.49 & .34 & 805 & 25 & 0 & 99 \\
50 & 1.60 & .35 & 814 & 26 & 0 & 99 \\
51 & 1.73 & .36 & 823 & 27 & 1 & 99 \\
\hline
\end{tabular}

\subsubsection{Escala STAI Estado}

En primer lugar, se analizó la calidad psicométrica de las categorías de respuesta, de acuerdo con los criterios de Linacre (2002). Tal como se puede observar en la Tabla 19, el sistema de cuatro categorías, analizado con el Rating Scale Model, es adecuado.

Tabla 19. Estadísticos correspondientes a las categorías del STAI Estado

\begin{tabular}{lccccc}
\hline Categoría & Elecciones & B & Infit & Outfit & Paso \\
\hline 1 = Nada & $8151(36 \%)$ & -2.43 & .96 & .97 & -- \\
2 = Um pouco & $9127(40 \%)$ & -.92 & .90 & .82 & -1.75 \\
$3=$ Moderadamente & $4090(18 \%)$ & -.01 & 1.01 & 1.08 & .31 \\
$4=$ Muito & $1530(7 \%)$ & .79 & 1.20 & 1.38 & 1.44 \\
& & & & &
\end{tabular}

Puede observarse que las categorías cumplen los criterios propuestos por Linacre (2002): el número de elecciones y su distribución son adecuados, no hay un desajuste en ninguna categoría (Outfit < 1.5), los pasos (step) entre las categorías sucesivas están ordenados de forma creciente y hay una ordenación monotónica de las medidas de B. 
La figura 5 muestra el funcionamiento de las cuatro categorías.

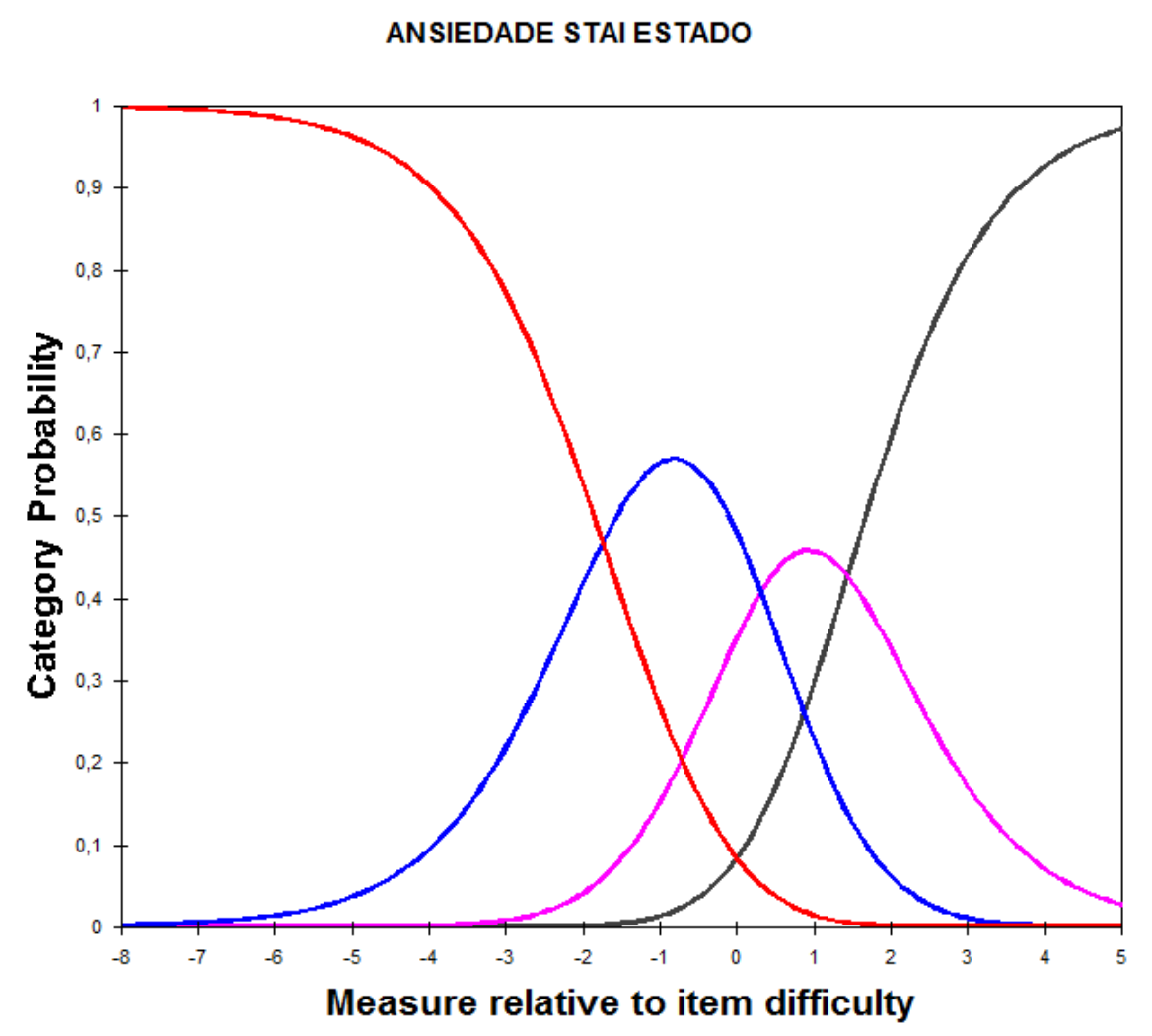

Figura 5. Representación gráfica de las curvas características de las categorías de la escala STAI Estado.

Una vez comprobada la adecuación de las categorías, se analizó el ajuste de los ítems y de las personas, se estimaron sus parámetros y se evaluó su fiabilidad. En la Tabla 20 aparecen los estadísticos de ajuste (Infit y Outfit), la localización (Di) y el error típico de medida de los ítems (SE). 
Tabla 20. Características psicométricas de los ítems del STAI Estado

\begin{tabular}{|c|c|c|c|c|}
\hline Ítem (1) & Infit & Outfit & $\mathrm{Di}$ & SE \\
\hline 1 (Sinto-me calmo(a)) & .84 & .86 & -.34 & .04 \\
\hline 2 (Sinto-me seguro(a)) & .71 & .73 & -.35 & .04 \\
\hline 3 (Estou tenso(a)) & 1.28 & 1.32 & .08 & .05 \\
\hline 4 (Sinto-me cansado(a)) & 1.43 & 1.54 & -1.14 & .04 \\
\hline 5 (Sinto-me à vontade) & 1.08 & 1.04 & -.22 & .04 \\
\hline 6 (Sinto-me perturbado(a)) & 1.17 & 1.05 & 1.10 & .05 \\
\hline \multicolumn{5}{|c|}{7 (Presentemente, preocupo-me com } \\
\hline possíveis desgraças) & 1.57 & 1.63 & -.07 & .05 \\
\hline 8 (Sinto-me satisfeito(a)) & .79 & .82 & -.61 & .04 \\
\hline 9 (Sinto-me amedrontado(a)) & 1.28 & 1.17 & 1.44 & .06 \\
\hline 10 (Sinto-me confortável) & .72 & .74 & -.48 & .04 \\
\hline 11 (Sinto-me auto-confiante) & .80 & .80 & -.65 & .04 \\
\hline 12 (Sinto-me nervoso(a)) & 1.00 & .98 & .32 & .05 \\
\hline 13 (Sinto-me trémulo(a)) & 1.38 & 1.04 & 2.55 & .08 \\
\hline 14 (Sinto-me indeciso(a)) & 1.38 & 1.32 & .58 & .05 \\
\hline 15 (Sinto-me descontraído(a)) & .82 & .83 & -.83 & .04 \\
\hline 16 (Sinto-me contente) & .75 & .77 & -.53 & .04 \\
\hline 17 (Estou preocupado(a)) & 1.04 & 1.09 & -.70 & .04 \\
\hline 18 (Sinto-me confuso(a)) & 1.24 & 1.18 & .85 & .05 \\
\hline 19 (Sinto-me firme) & .90 & .90 & -.76 & .04 \\
\hline 20 (Sinto-me bem)) & .64 & .62 & -.22 & .04 \\
\hline Media & 1.04 & 1.02 & .00 & .05 \\
\hline DT & .28 & .27 & .89 & .01 \\
\hline
\end{tabular}


Se puede observar que hay sólo dos ítems con valores de infit y/o outfit superiores a 1.5 (ítem 4 - Sinto-me cansado(a); y ítem 7 - Presentemente, preocupo-me com possíveis desgraças) lo que revela que los ítems no se desajustan de forma severa (ningún ítem presenta valores superiores a 2,00). Los restantes ítems presentan valores en torno a la unidad, un valor que indica un ajuste perfecto (Linacre \& Wright, 2000).

En la columna Di, referente a la dificultad o localización de los ítems, podemos ver que el ítem 13 (“Sinto-me trémulo(a)") es el indicador de mayor nivel de ansiedad y el ítem 4 (“Sinto-me cansado(a)") es el de menor nivel.

Los errores típicos de medida de los ítems oscilan entre .04 a .08, lo que indica que la fiabilidad de los ítems es muy buena, dado que los errores típicos son bajos.

La tabla 21 nos muestra los valores para la subescala ansiedad estado del STAI. 
Tabla 21. Resumen de los resultados del STAI- Estado.

\begin{tabular}{|c|c|c|c|c|c|}
\hline Estadísticos & Max. & Min. & Media & DT & Valor \\
\hline Infit de los ítems & 1.57 & .64 & 1.04 & .28 & --- \\
\hline Outfit de los ítems & 1.63 & .62 & 1.02 & .27 & --- \\
\hline$\%$ ítems con desajuste & --- & --- & --- & --- & $10 \%(2)$ \\
\hline \multicolumn{6}{|l|}{ moderado (1) } \\
\hline$\%$ ítems con alto desajuste & --- & --- & --- & --- & $0 \%$ \\
\hline \multicolumn{6}{|l|}{ (2) } \\
\hline Infit de las personas & 3.85 & .13 & 1.02 & .56 & --- \\
\hline Outfit de las personas & 7.85 & .16 & 1.02 & .63 & --- \\
\hline$\%$ personas con desajuste & --- & --- & --- & --- & $9.83 \%(114)$ \\
\hline moderado (1) & & & & & \\
\hline$\%$ personas con alto & --- & --- & --- & --- & $8.19 \%(95)$ \\
\hline \multicolumn{6}{|l|}{ desajuste (2) } \\
\hline Parámetro de los ítems & 2.55 & -1.14 & .00 & .89 & --- \\
\hline Fiabilidad de los Ítems & --- & --- & --- & --- & 1.00 \\
\hline Parámetro personas & 3.69 & -4.96 & -1.18 & 1.25 & --- \\
\hline Fiabilidad de personas & --- & --- & --- & --- & .91 \\
\hline
\end{tabular}

(1) Infit $y / 0$ outfit $>1.5 y<2$; (2) Infit $y / 0$ outfit $>2$; (3) $p<.05$

Como se puede observar en la tabla 21, la fiabilidad de los ítems es muy alta (1.00).

El ajuste de las personas al modelo es razonable, pues los valores de la media y de la desviación típica son respectivamente de 1.02 y .56 (infit), y 1.02 y .63 (outfit). El 9.83\% de las personas presentan desajuste moderado (infit y/o outfit $>1.5$ y $<2$ ) y $8.19 \%$ alto desajuste (infit y/o outfit $>2$ ). 
Los parámetros de las personas van de -4.96 a 3.69 con una media de -1.18 y una desviación típica de 1.25. Los errores típicos de medida de las personas van de .19 a 1.83. La fiabilidad global de las personas es muy buena (.91).

La Tabla 22 muestra una representación conjunta persona-ítem, denominada "mapa de Wright", donde se puede observar la posición de los ítems y de las personas en la variable. Dado que la media de las personas (-1.18) es muy inferior a la de los ítems (.00), se puede considerar que el nivel de ansiedad de los sujetos analizados es muy bajo. Además, la mayor parte de las personas se encuentran por debajo del rango de la variable en el que los ítems se sitúan. En consecuencia, se observa que los ítems de la escala no permiten medir con alta precisión a las personas con niveles bajos de ansiedad. Esto sucede porque el nivel de las personas es bajo y la escala sólo tiene ítems situados en el rango superior del constructo. 
Tabla 22. Representación conjunta de personas e ítems del STAI Estado

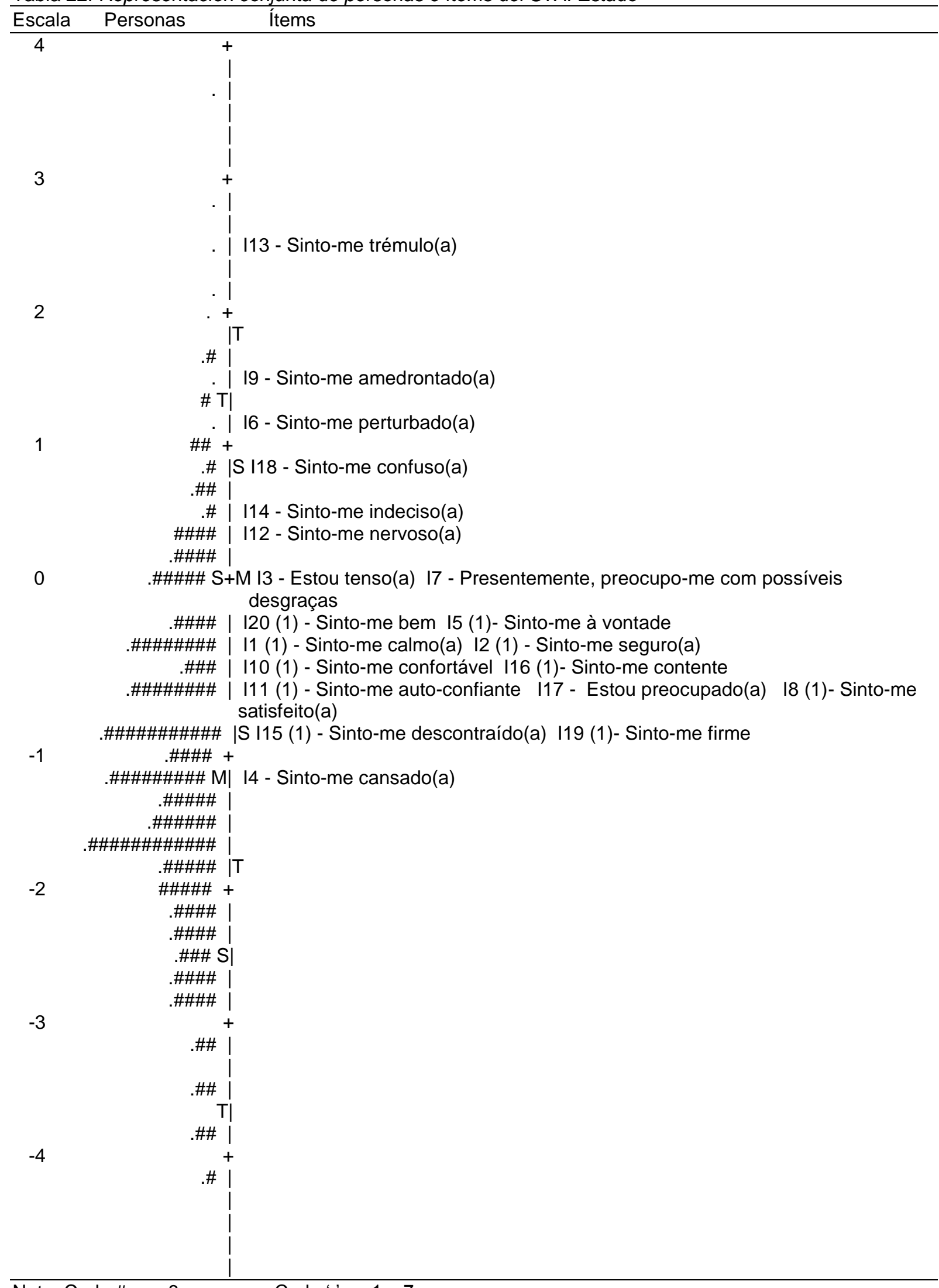

Nota: Cada \# son 8 personas; Cada '. es 1 a 7.

(1) Ítems invertidos, de manera que las mayores puntuaciones indican mayor ansiedad. 
Se analizó la unidimensionalidad del STAI Estado y, según Linacre (2010), los resultados muestran que la dimensión Rasch explica el $47.6 \%$, lo que está muy cerca del mínimo considerado como bueno $(<50 \%)$ y que la varianza explicada por los ítems es del $26.7 \%$, que no es mayor a cuatro veces el valor del primer contraste $(26.7 \%<4 x$ 8.6\%=34.4\%). Pero, de acuerdo a los criterios de Reckase (1979), más flexibles, el porcentaje explicado por la medida derivada del modelo es superior a $20 \%$ y no hay un segundo factor dominante, lo que muestra que los datos se adecuan suficientemente a una estructura unidimensional, de manera que no provocan problemas para la validez de los resultados.

En la Tabla 23 se presentan los resultados del análisis de Funcionamiento Diferencial de los Ítems asociado al sexo. 
Tabla 23. Funcionamiento Diferencial de los Ítems asociado al sexo para el STAI Estado

\begin{tabular}{|c|c|c|c|c|}
\hline Ítem & $\mathrm{DM}-\mathrm{DH}$ & SE & $\mathrm{T}$ & $p$ \\
\hline 1 & .10 & .09 & 1.07 & .283 \\
\hline 2 & .00 & .09 & .00 & 1.000 \\
\hline 3 & .00 & .10 & .00 & 1.000 \\
\hline 4 & .32 & .09 & 3.71 & .000 \\
\hline 5 & -.08 & .09 & -.86 & .393 \\
\hline 6 & .07 & .11 & .62 & .534 \\
\hline 7 & -.22 & .09 & -2.37 & .018 \\
\hline 8 & -.10 & .09 & -1.16 & .247 \\
\hline 9 & .16 & .12 & 1.26 & .209 \\
\hline 10 & -.17 & .09 & -1.92 & .055 \\
\hline 11 & .09 & .09 & 1.06 & .290 \\
\hline 12 & .23 & .10 & 2.32 & .021 \\
\hline 13 & -.20 & .16 & -1.26 & .209 \\
\hline 14 & -.23 & .10 & -2.26 & .024 \\
\hline 15 & .17 & .09 & 1.93 & .054 \\
\hline 16 & -.29 & .09 & -3.24 & .001 \\
\hline 17 & .00 & .09 & .00 & 1.000 \\
\hline 18 & -.19 & .11 & -1.78 & .076 \\
\hline 19 & .25 & .09 & 2.79 & .005 \\
\hline 20 & -.03 & .09 & -.33 & .741 \\
\hline
\end{tabular}

Existen 2 ítems que presentan diferencia entre géneros, los ítems 4 (sinto-me cansado(a)) y 16 (sinto-me contente) (valores p inferiores a .0025 (.05/20 ítems) correlación de Bonferroni), pero las diferencias son inferiores a .50 logits, lo que indica que no son notables. 
La figura 6 presenta las diferencias entre los parámetros de localización de los ítems entre los géneros.

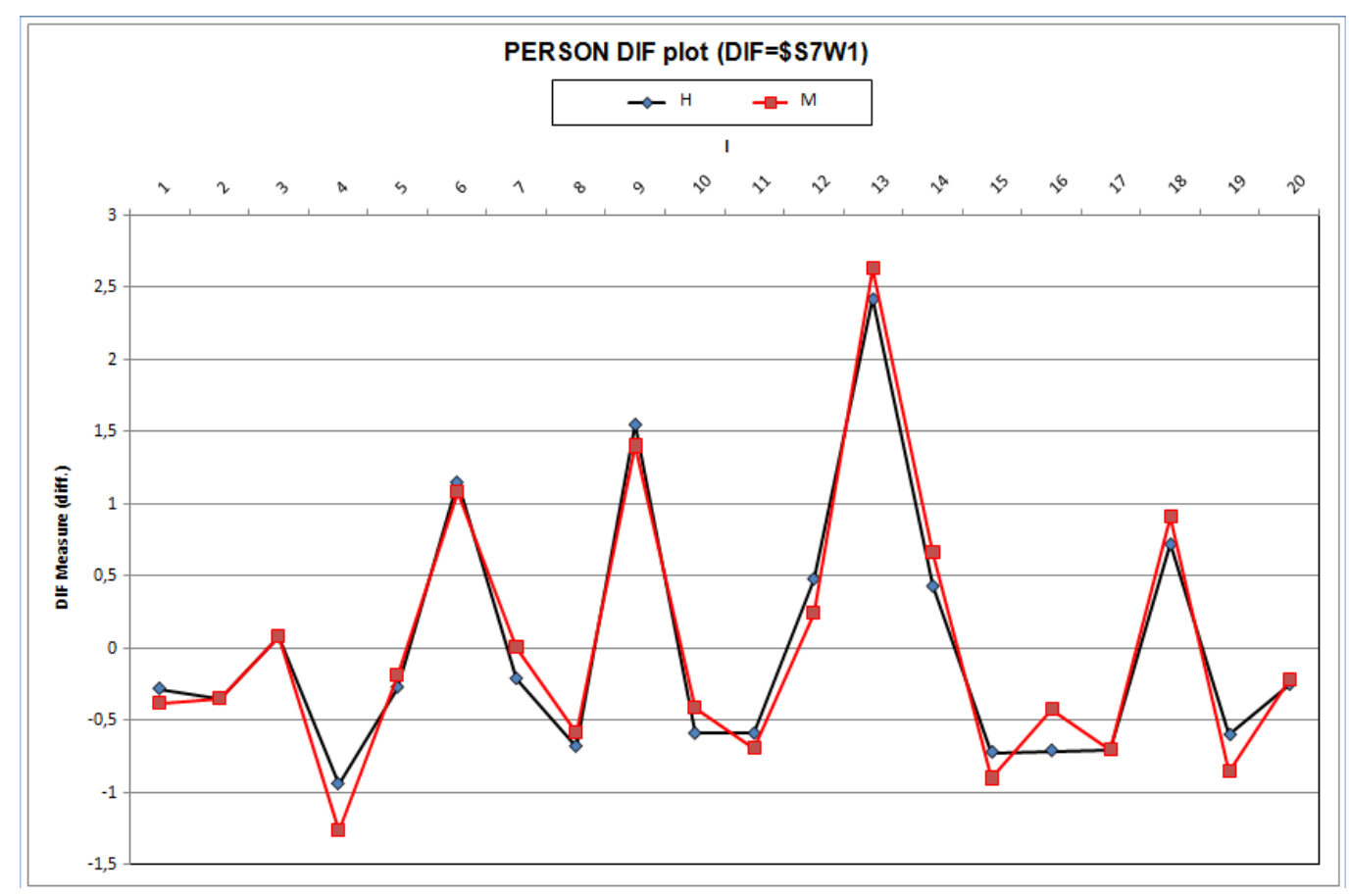

Figura 6 - Diferencias entre los parámetros de localización de los ítems entre los géneros.

En la Tabla 24 se presentan los resultados del análisis de Funcionamiento Diferencial de los Ítems asociado a la edad. 
Tabla 24. Funcionamiento Diferencial de los Ítems asociado a la edad para el STAI Estado

\begin{tabular}{|c|c|c|c|c|}
\hline Ítem & $D+E-D-E$ & SE & $\mathrm{t}$ & $p$ \\
\hline 1 & .00 & .09 & .00 & 1.000 \\
\hline 2 & -.07 & .09 & -.80 & .425 \\
\hline 3 & .00 & .09 & .00 & 1.000 \\
\hline 4 & .17 & .08 & 1.97 & .049 \\
\hline 5 & .03 & .09 & .31 & .758 \\
\hline 6 & .34 & .11 & 3.13 & .002 \\
\hline 7 & .33 & .09 & 3.63 & .000 \\
\hline 8 & .11 & .09 & 1.32 & .188 \\
\hline 9 & .41 & .12 & 3.50 & .001 \\
\hline 10 & .07 & .09 & .75 & .453 \\
\hline 11 & -.22 & .09 & -2.58 & .010 \\
\hline 12 & .19 & .10 & 2.03 & .043 \\
\hline 13 & .00 & .16 & .00 & 1.000 \\
\hline 14 & -.38 & .10 & -3.81 & .000 \\
\hline 15 & .00 & .09 & .00 & 1.000 \\
\hline 16 & .02 & .09 & .27 & .785 \\
\hline 17 & .12 & .09 & 1.37 & .171 \\
\hline 18 & -.65 & .10 & -6.37 & .000 \\
\hline 19 & -.43 & .09 & -4.99 & .000 \\
\hline 20 & .06 & .09 & .66 & .510 \\
\hline
\end{tabular}

Existen 5 ítems que presentan diferencia entre los participantes con 30 ó menos años y los que tienen más de 30 años, los ítems 6 (sinto-me perturbado(a)), 7 (presentemente preocupo-me com possíveis desgraças), 9 (sinto-me amedrontado(a)), 18 (sinto-me confuso(a)) y 19 (sinto-me firme) (valores p inferiores a .0025 (.05/20 ítems) - 
correlación de Bonferroni), pero las diferencias presentan valores inferiores a .50 logits, lo que muestra que no son notables, con la excepción del ítem 18, que tiene un valor superior (-.65), indicando una gran diferencia entre los dos grupos de edad. Los resultados muestran que el ítem 18 no funciona igualmente para los participantes con 30 ó menos años y los que tienen más de 30 años aunque tengan el mismo nivel de ansiedad. En consecuencia, este ítem presenta DIF y debería ser excluido si esta evidencia se replicase en posteriores estudios.

La figura 7 presenta las diferencias entre los parámetros de localización de los ítems entre los grupos de diferente edad.

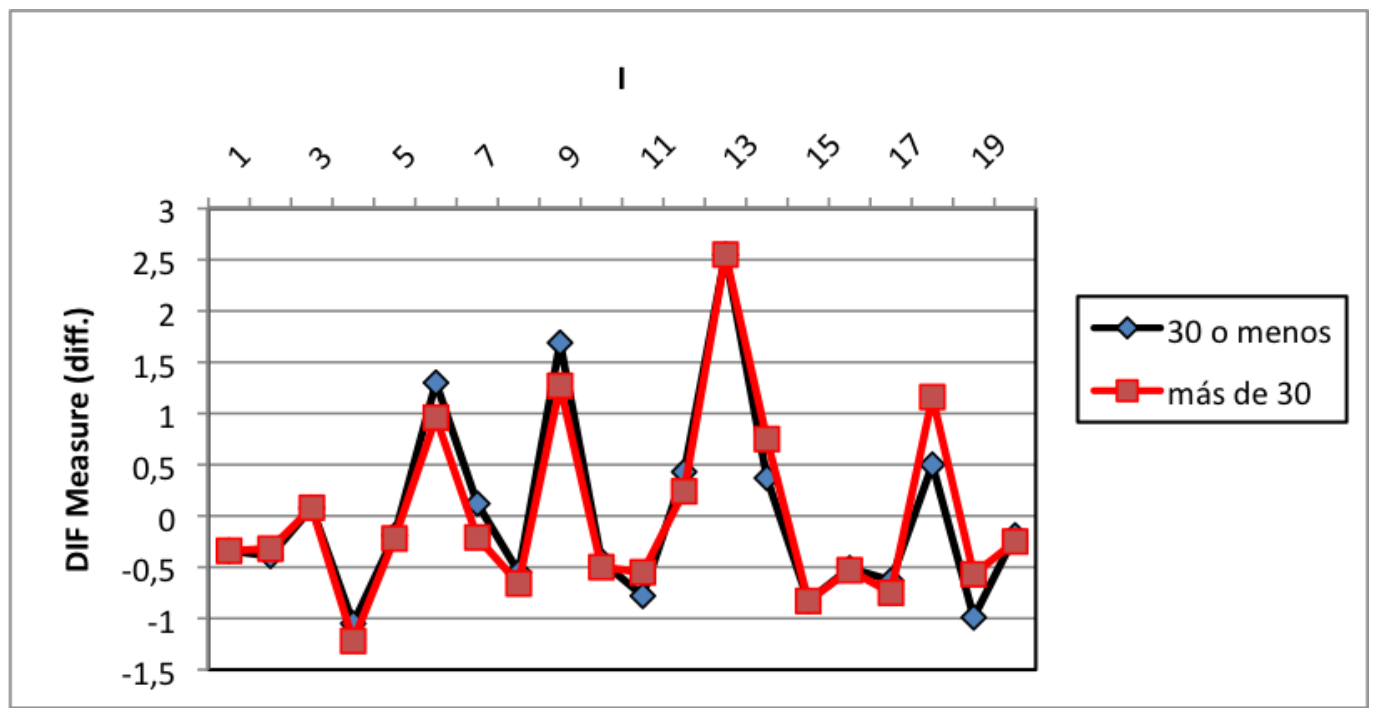

Figura 7 - Diferencias entre los parámetros de localización de los ítems entre los grupos de diferente edad de la prueba STAI-Estado.

En la tabla 25 se presenta la correspondencia entre las puntuaciones clásicas y los valores logit, con su error estándar, así como los baremos en percentiles y en puntuaciones típicas derivadas con su correspondiente error estándar (normed con media 500 y Desviación Típica 100). 
Tabla 25. Correspondencia entre las puntuaciones clásicas y los valores Rasch para el STAI Estado

\begin{tabular}{|c|c|c|c|c|c|c|}
\hline Puntuación & Medida & SE & PT Derivada & SEPT & Frecuencia & Percentil \\
\hline$\overline{20}$ & $-6.21 E$ & 1.84 & 137 & 134 & 15 & 1 \\
\hline 21 & -4.97 & 1.03 & 228 & 75 & 8 & 2 \\
\hline 22 & -4.22 & .74 & 282 & 54 & 10 & 2 \\
\hline 23 & -3.76 & .62 & 316 & 45 & 22 & 4 \\
\hline 24 & -3.42 & .55 & 341 & 40 & 21 & 6 \\
\hline 25 & -3.15 & .50 & 361 & 37 & 22 & 8 \\
\hline 26 & -2.91 & .47 & 378 & 34 & 33 & 10 \\
\hline 27 & -2.70 & .45 & 394 & 33 & 34 & 13 \\
\hline 28 & -2.51 & .43 & 408 & 31 & 26 & 15 \\
\hline 29 & -2.34 & .41 & 420 & 30 & 34 & 18 \\
\hline 30 & -2.18 & .40 & 432 & 29 & 37 & 21 \\
\hline 31 & -2.02 & .38 & 443 & 28 & 40 & 24 \\
\hline 32 & -1.88 & .37 & 454 & 27 & 41 & 28 \\
\hline 33 & -1.74 & .37 & 464 & 27 & 47 & 32 \\
\hline 34 & -1.61 & .36 & 473 & 26 & 51 & 36 \\
\hline 35 & -1.48 & .35 & 483 & 26 & 50 & 40 \\
\hline 36 & -1.36 & .35 & 492 & 25 & 44 & 44 \\
\hline 37 & -1.25 & .34 & 500 & 25 & 41 & 48 \\
\hline 38 & -1.13 & .33 & 508 & 24 & 38 & 51 \\
\hline 39 & -1.02 & .33 & 516 & 24 & 36 & 54 \\
\hline 40 & -.91 & .33 & 524 & 24 & 62 & 59 \\
\hline 41 & -.81 & .32 & 532 & 23 & 33 & 63 \\
\hline 42 & -.71 & .32 & 539 & 23 & 37 & 66 \\
\hline
\end{tabular}


Tabla 25 (Cont.)

\begin{tabular}{|c|c|c|c|c|c|c|}
\hline Puntuación & Medida & SE & PT Derivada & SEPT & Frecuencia & Percentil \\
\hline$\overline{43}$ & -.61 & .31 & 547 & 23 & 31 & 69 \\
\hline 44 & -.51 & .31 & 554 & 23 & 30 & 71 \\
\hline 45 & -.41 & .31 & 561 & 23 & 32 & 74 \\
\hline 46 & -.32 & .31 & 568 & 22 & 35 & 77 \\
\hline 47 & -.23 & .30 & 575 & 22 & 20 & 79 \\
\hline 48 & -.13 & .30 & 581 & 22 & 19 & 81 \\
\hline 49 & -.04 & .30 & 588 & 22 & 27 & 83 \\
\hline 50 & .05 & .30 & 595 & 22 & 20 & 85 \\
\hline 51 & .14 & .30 & 601 & 22 & 11 & 86 \\
\hline 52 & .23 & .30 & 608 & 22 & 22 & 88 \\
\hline 53 & .32 & .30 & 614 & 22 & 16 & 89 \\
\hline 54 & .41 & .30 & 621 & 22 & 16 & 91 \\
\hline 55 & .50 & .30 & 627 & 22 & 11 & 92 \\
\hline 56 & .59 & .30 & 634 & 22 & 14 & 93 \\
\hline 57 & .68 & .30 & 641 & 22 & 7 & 94 \\
\hline 58 & .77 & .31 & 647 & 22 & 3 & 94 \\
\hline 59 & .86 & .31 & 654 & 23 & 11 & 95 \\
\hline 60 & .96 & .31 & 661 & 23 & 9 & 96 \\
\hline 61 & 1.06 & .31 & 668 & 23 & 7 & 97 \\
\hline 62 & 1.16 & .32 & 676 & 23 & 3 & 97 \\
\hline 63 & 1.26 & .32 & 683 & 24 & 4 & 97 \\
\hline 64 & 1.37 & .33 & 691 & 24 & 4 & 98 \\
\hline 65 & 1.48 & .34 & 699 & 25 & 6 & 98 \\
\hline 66 & 1.59 & .34 & 707 & 25 & 5 & 98 \\
\hline
\end{tabular}


Tabla 25 (Cont.)

\begin{tabular}{lcccccc}
\hline Puntuación & Medida & SE & PT Derivada & SEPT & Frecuencia & Percentil \\
\hline 67 & 1.71 & .35 & 716 & 26 & 8 & 99 \\
68 & 1.84 & .36 & 726 & 26 & 0 & 99 \\
69 & 1.97 & .37 & 735 & 27 & 1 & 99 \\
70 & 2.11 & .38 & 746 & 28 & 2 & 99 \\
71 & 2.27 & .40 & 757 & 29 & 0 & 99 \\
72 & 2.44 & .42 & 769 & 31 & 2 & 99 \\
73 & 2.62 & .44 & 783 & 32 & 0 & 99 \\
74 & 2.83 & .47 & 798 & 34 & 1 & 99 \\
75 & 3.07 & .51 & 815 & 37 & 0 & 99 \\
76 & 3.35 & .56 & 836 & 41 & 0 & 99 \\
77 & 3.69 & .63 & 861 & 46 & 1 & 99 \\
\hline
\end{tabular}

\subsubsection{Escala STAI Rasgo}

En primer lugar, se analizó la calidad psicométrica de las categorías de respuesta, de acuerdo con los criterios de Linacre (2002). Tal como se puede observar en la Tabla 26, el sistema de cuatro categorías, analizado con el Rating Scale Model, es adecuado.

Tabla 26. Estadísticos correspondientes a las categorías

\begin{tabular}{lccccc}
\hline Categoría & Elecciones & B & Infit & Outfit & Paso \\
\hline 1 = Quase nada & $7601(33 \%)$ & -2.51 & -.99 & .99 & -- \\
2 = Algumas vezes & $9903(43 \%)$ & -1.12 & .89 & .86 & -2.03 \\
$3=$ Frequentemente & $4378(19 \%)$ & -.05 & .82 & .83 & .24 \\
$4=$ Quase sempre & $1133(5 \%)$ & .94 & 1.42 & 1.85 & 1.79 \\
\hline
\end{tabular}


Puede observarse que las categorías cumplen los criterios propuestos por Linacre (2002), pues el número de elecciones y su distribución son adecuados, no hay un desajuste elevado en ninguna categoría (Outfit $<2$ ), los pasos (step) entre las categorías sucesivas están ordenados de forma creciente y hay una ordenación monotónica de las medidas de B.

La figura 8 muestra el funcionamiento de las cuatro categorías.

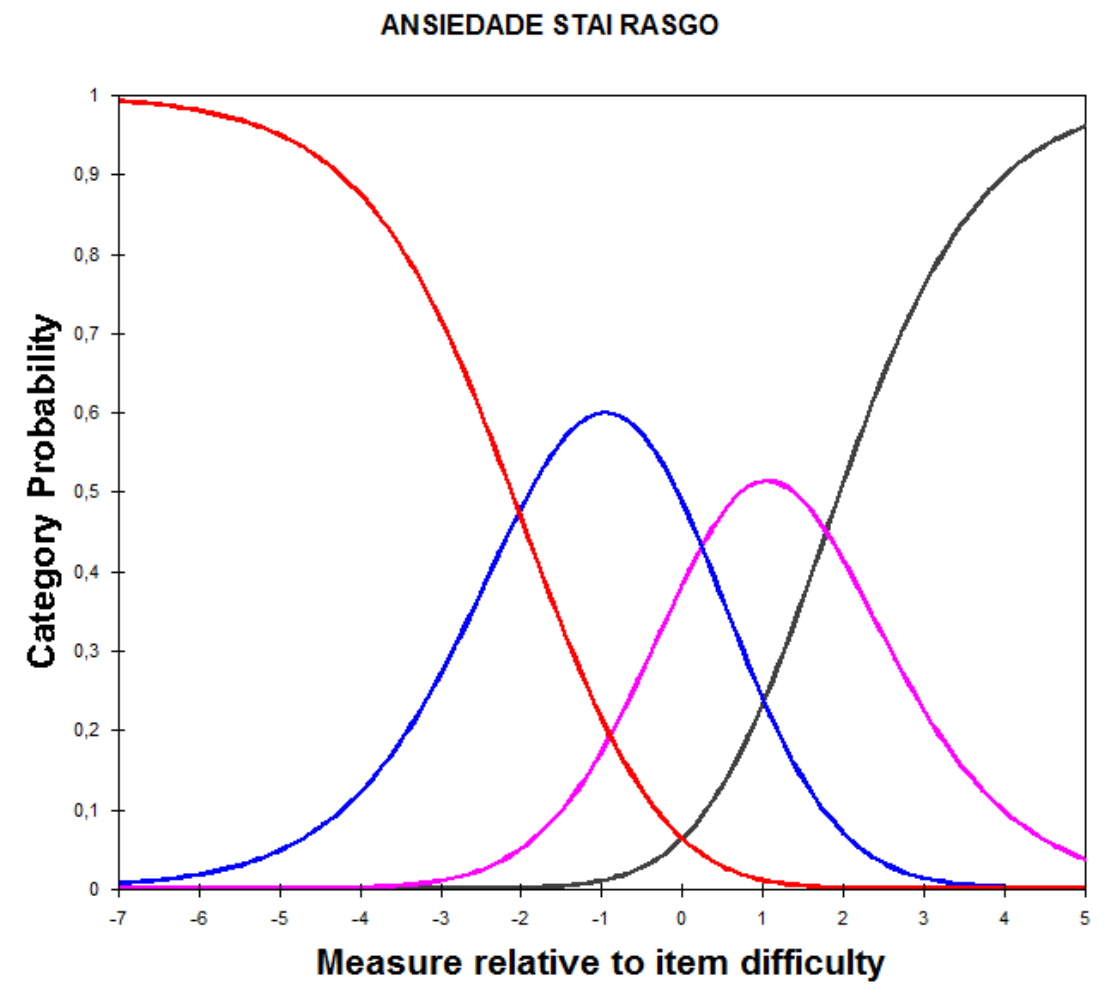

Figura 8. Representación gráfica de las curvas características de las categorías de la escala STAI Rasgo.

Una vez comprobada la adecuación de las categorías, se analizó el ajuste de los ítems y de las personas, se estimaron sus parámetros y se evaluó su fiabilidad. En la Tabla 27 se muestran los estadísticos de ajuste (Infit y Outfit), la localización (Di) y el error típico de medida de los ítems (SE). 
Tabla 27. Características psicométricas de los ítems del STAI Rasgo

\begin{tabular}{|c|c|c|c|c|}
\hline Ítem (1) & Infit & Outfit & $\mathrm{Di}$ & SE \\
\hline 21 (Sinto-me bem) & .71 & .70 & -.01 & .05 \\
\hline 22 (Sinto-me nervoso(a) e agitado(a)) & .86 & .93 & -.19 & .05 \\
\hline 23 (Sinto-me satisfeito(a) comigo mesmo(a)) & .72 & .77 & -.39 & .05 \\
\hline \multicolumn{5}{|l|}{24 (Gostava de poder ser tão feliz como os } \\
\hline outros parecem ser) & 1.78 & 2.15 & .06 & .05 \\
\hline 25 (Sinto-me falhado(a)) & 1.02 & .98 & 1.73 & .06 \\
\hline 26 (Sinto-me tranquilo(a)) & .80 & .78 & -.62 & .04 \\
\hline 27 (Estou "calmo(a), fresco(a) & & & & \\
\hline concentrado(a)") & .81 & .82 & -1.01 & .04 \\
\hline \multicolumn{5}{|l|}{28 (Sinto que as dificuldades se acumulam de } \\
\hline tal forma que não as consigo ultrapassar) & .97 & 1.03 & .53 & .05 \\
\hline \multicolumn{5}{|l|}{29 (Preocupo-me demais com as coisas que } \\
\hline na realidade não têm importância) & 1.20 & 1.21 & .01 & .05 \\
\hline 30 (Estou feliz) & .88 & .86 & -.22 & .05 \\
\hline 31 (Tenho pensamentos que me perturbam) & .95 & .93 & .28 & .05 \\
\hline 32 (Falta-me auto-confiança) & 1.10 & 1.19 & .30 & .05 \\
\hline 33 (Sinto-me seguro(a)) & .89 & .92 & -.74 & .04 \\
\hline 34 (Tomo decisões facilmente) & 1.19 & 1.23 & -1.14 & .04 \\
\hline 35 (Sinto-me inadequado(a)) & 1.26 & 1.29 & 1.49 & .06 \\
\hline 36 (Estou contente) & .80 & .79 & -.20 & .05 \\
\hline 37 (Passam-me pela cabeça pensamentos & & & & \\
\hline sem importância que me perturbam) & 1.16 & 1.13 & .58 & .05 \\
\hline
\end{tabular}


Tabla 27 (Cont.)

\begin{tabular}{lcccc}
\hline Ítem (1) & Infit & Outfit & Di & SE \\
\hline 38 (As contrariedades afectam-me de modo & & & \\
tão intenso que não consigo afastá-las da & & & & \\
minha mente) & 1.05 & .99 & .56 & .05 \\
39 (Sou uma pessoa firme) & .90 & .91 & -.55 & .05 \\
40 (Fico tenso(a) e perturbado(a) quando & & & & \\
penso nas minhas preocupações e interesses & & & & \\
actuais) & 1.13 & 1.16 & -.48 & .05 \\
\hline$\quad$ Media & 1.01 & 1.04 & .00 & .05 \\
$\quad$ DT & .24 & .30 & .72 & .00 \\
\hline
\end{tabular}

Se puede observar que sólo hay un ítem con valores de infit y/o outfit superiores a 2 (el ítem 24 - "Gostava de poder ser tão feliz como os outros parecem ser") lo que revela que la mayoría de los ítems no se desajustan de forma severa. Los restantes ítems presentan valores en torno a la unidad, un valor que indica un ajuste perfecto (Linacre \& Wright, 2000).

En la columna Di, referente a la dificultad o localización de los ítems, podemos ver que el ítem 25 ("Sinto-me falhado(a)") es el indicador de mayor nivel de ansiedad y el ítem 27 (“Estou calmo(a), fresco(a) e concentrado(a)") es el de menor nivel.

Los errores típicos de medida de los ítems oscilan entre .04 a .06, lo que indica que la fiabilidad de los ítems es muy buena, dado que los errores típicos son bajos.

La tabla 28 nos muestra los valores para la escala STAI Rasgo. 
Tabla 28. Resumen de los resultados del STAI Rasgo.

\begin{tabular}{lccccc}
\hline Estadísticos & Max. & Min. & Media & DT & Valor \\
\hline Infit de los ítems & 1.78 & .71 & 1.01 & .24 & --- \\
Outfit de los ítems & 2.15 & .70 & 1.04 & .30 & --- \\
\% ítems con desajuste moderado (1) & --- & --- & --- & --- & $0 \%$ \\
\% ítems con alto desajuste (2) & --- & --- & --- & --- & $5.00 \%(1)$ \\
Infit de las personas & 4.41 & .18 & 1.02 & .65 & --- \\
Outfit de las personas & 9.21 & .21 & 1.04 & .72 & --- \\
\% personas con desajuste moderado & --- & --- & --- & --- & $8.19 \%(95)$ \\
(1) & & & & & \\
\% personas con alto desajuste (2) & --- & --- & --- & --- & $8.71 \%(101)$ \\
Parámetro de los ítems & 1.73 & -1.14 & .00 & .72 & --- \\
Fiabilidad de los Ítems & --- & --- & --- & --- & 1.00 \\
Parámetro personas & 3.82 & -5.18 & -1.26 & 1.33 & --- \\
Fiabilidad de personas & --- & --- & --- & --- & .91 \\
\hline
\end{tabular}

(1) Infit $y / 0$ outfit $>1.5 y<2$; (2) Infit $y / 0$ outfit $>2$; (3) $p<.05$

Como se puede observar en la tabla 28 la fiabilidad de los ítems es muy alta (1.00).

El ajuste de las personas al modelo es razonable, pues los valores de la media y de la desviación típica son respectivamente de .1 .02 y .65 (infit), y 1.04 y .72 (outfit). El 8.19\% de las personas muestran un desajuste moderado (infit $y / 0$ outfit $>1.5$ y $<2$ ) y el $8.71 \%$ un alto desajuste (infit y/o outfit $>2$ ).

Los parámetros de las personas van de -1.14 a 1.73 con una media de .00 y una desviación típica de .72. Los errores típicos de medida de las personas van de .32 a 1.84. La fiabilidad global de las personas (.91) es muy alta (porcentaje de la varianza de las personas no explicada por el error). 
La Tabla 29 muestra una representación conjunta persona-ítem, denominada "mapa de Wright", donde se puede observar la posición de los ítems y de las personas en la variable. Dado que la media de las personas (-1.26) es muy inferior a la de los ítems (.00), se puede considerar que el nivel de ansiedad de los sujetos analizados es muy bajo. Además, la mayor parte de las personas se encuentran por debajo del rango de la variable en el que los ítems se sitúan. En consecuencia, se observa que los ítems de la escala no permiten medir con alta precisión a las personas con niveles bajos de ansiedad. Esto sucede porque el nivel de las personas es bajo y la escala sólo tiene ítems situados en el rango superior del constructo. 
Tabla 29. Representación conjunta de personas e ítems del STAI Rasgo

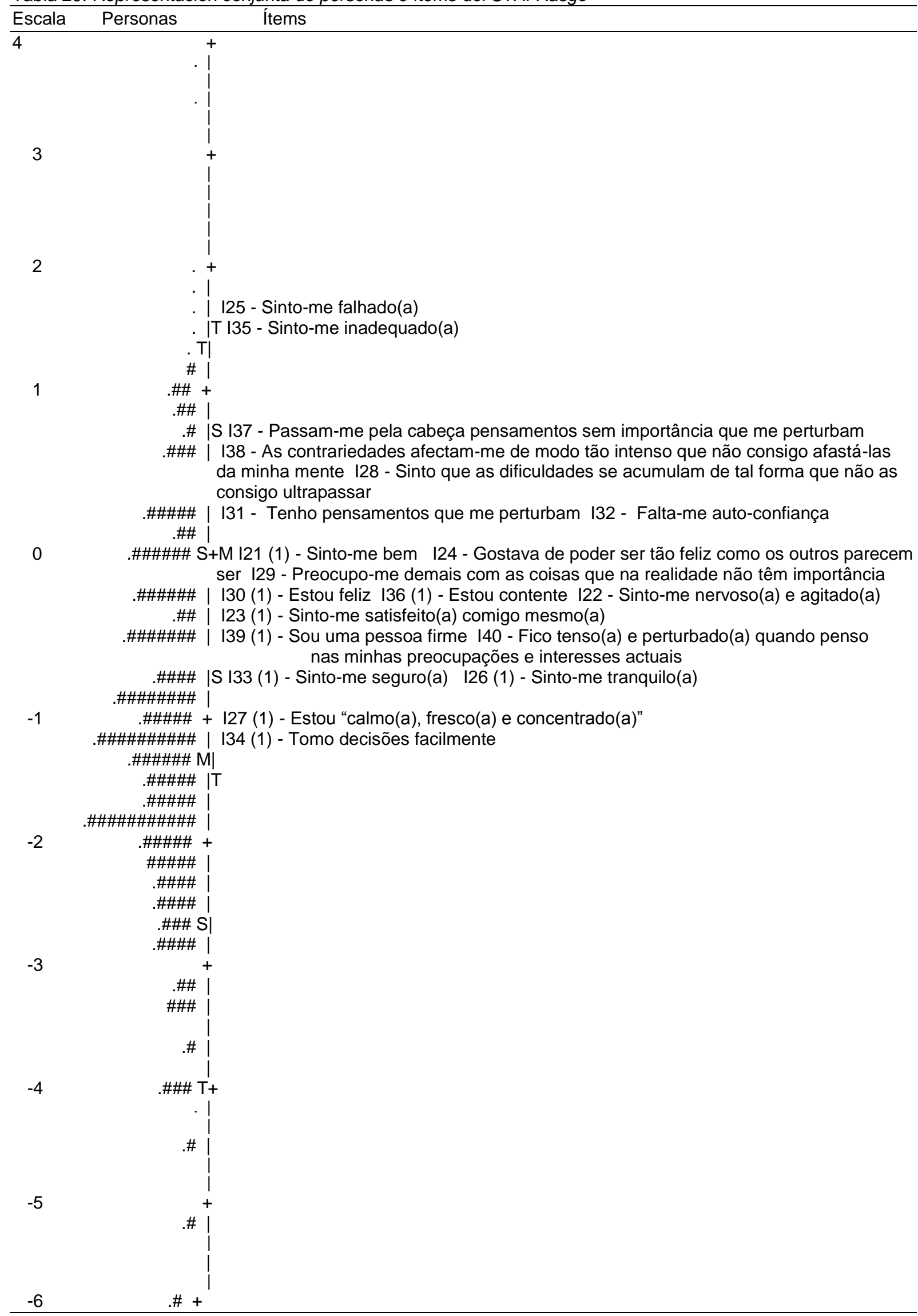

Nota: Cada \# son 8 personas; Cada '.' es 1 a 7.

(1) Ítems invertidos de manera que las mayores puntuaciones indiquen mayor ansiedad. 
El estudio de la unidimensionalidad del STAI Rasgo también se mostró adecuado. Según Linacre (2010), la dimensión Rasch explica el 46.2\%, que está muy cerca del mínimo considerado como bueno (50\%). Pero la varianza explicada por los ítems es del $22.6 \%$, no es mayor a cuatro veces el valor del primer contraste $(22.6 \%<4 \times 8.5 \%=34.0 \%)$. Sin embargo, de acuerdo con los criterios de Reckase (1979), el porcentaje explicado por la medida derivada del modelo es superior a $20 \%$ y en el STAI Estado no existe un segundo factor dominante, lo que induce a pensar que los datos se adecuan suficientemente a una estructura unidimensional, no provocando dificultades al nivel de la validez de los resultados.

En la Tabla 30 se presentan los resultados del análisis de Funcionamiento Diferencial de los Ítems asociado al sexo. 
Tabla 30. Funcionamiento Diferencial de los Ítems asociado al sexo para el STAI Rasgo.

\begin{tabular}{|c|c|c|c|c|}
\hline Ítem & $\mathrm{DM}-\mathrm{DH}$ & SE & $\mathrm{t}$ & $p$ \\
\hline 21 & -.15 & .10 & -1.49 & .1378 \\
\hline 22 & .20 & .10 & 2.07 & .0386 \\
\hline 23 & .03 & .10 & .34 & .7335 \\
\hline 24 & -.49 & .10 & -4.99 & .0000 \\
\hline 25 & -.42 & .13 & -3.37 & .0008 \\
\hline 26 & .18 & .09 & 1.86 & .0638 \\
\hline 27 & .20 & .09 & 2.15 & .0321 \\
\hline 28 & -.26 & .10 & -2.47 & .0137 \\
\hline 29 & .14 & .10 & 1.37 & .1724 \\
\hline 30 & -.25 & .10 & -2.60 & .0096 \\
\hline 31 & -.16 & .10 & -1.55 & .1220 \\
\hline 32 & .21 & .10 & 2.07 & .0384 \\
\hline 33 & .26 & .09 & 2.73 & .0064 \\
\hline 34 & .13 & .09 & 1.47 & .1430 \\
\hline 35 & -.37 & .12 & -3.06 & .0023 \\
\hline 36 & -.03 & .10 & -.28 & .7818 \\
\hline 37 & .02 & .11 & .20 & .8405 \\
\hline 38 & .12 & .11 & 1.12 & .2613 \\
\hline 39 & .20 & .09 & 2.08 & .0376 \\
\hline 40 & .00 & .09 & .00 & 1.000 \\
\hline
\end{tabular}

Existen 3 ítems que presentan diferencia entre géneros, los ítems 24 (Gostava de poder ser tão feliz como os outros parecem ser), 25 (sinto-me falhado(a)) y 35 (sinto-me inadequado(a)) (valores p inferiores a .0025 (.05/20 ítems) - correlación de Bonferroni), sin embargo las dif son inferiores a .50 logits. 
La figura 9 presenta las diferencias de los parámetros de localización de los ítems entre géneros para la escala de ansiedad rasgo.

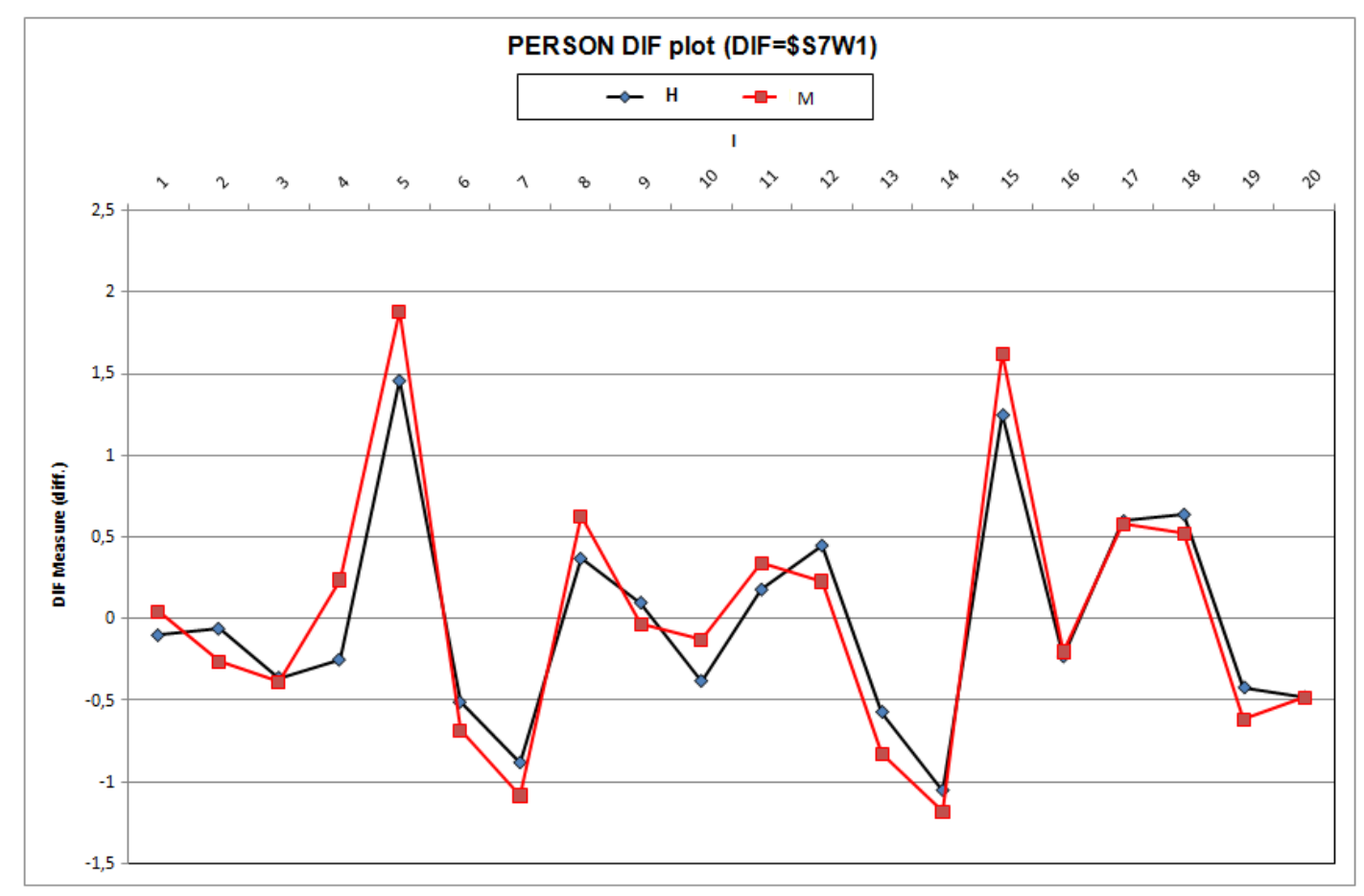

Figura 9 - Diferencias de los parámetros de localización de los ítems entre géneros para el STAI Rasgo.

En la Tabla 31 se presentan los resultados del análisis de Funcionamiento Diferencial de los Ítems asociado a la edad. 
Tabla 31. Funcionamiento Diferencial de los Ítems asociado a la edad para el STAI Rasgo.

\begin{tabular}{|c|c|c|c|c|}
\hline Ítem & $D+E-D-E$ & SE & $\mathrm{t}$ & $p$ \\
\hline 21 & .31 & .09 & 3.29 & .001 \\
\hline 22 & .13 & .09 & 1.35 & .178 \\
\hline 23 & -.05 & .09 & -.60 & .552 \\
\hline 24 & .22 & .10 & 2.32 & .020 \\
\hline 25 & .00 & .12 & .00 & 1.000 \\
\hline 26 & .30 & .09 & 3.31 & .001 \\
\hline 27 & .11 & .09 & 1.27 & .204 \\
\hline 28 & .09 & .10 & .92 & .360 \\
\hline 29 & -.18 & .09 & -1.92 & .055 \\
\hline 30 & .43 & .09 & 4.61 & .000 \\
\hline 31 & -.31 & .10 & -3.15 & .002 \\
\hline 32 & -.54 & .10 & -5.55 & .000 \\
\hline 33 & .12 & .09 & 1.28 & .199 \\
\hline 34 & -.16 & .09 & -1.81 & .071 \\
\hline 35 & -.36 & .12 & -3.10 & .002 \\
\hline 36 & .23 & .09 & 2.43 & .015 \\
\hline 37 & -.36 & .10 & -3.62 & .000 \\
\hline 38 & -.06 & .10 & -.59 & .557 \\
\hline 39 & -.14 & .09 & -1.58 & .114 \\
\hline 40 & .00 & .09 & .00 & 1.000 \\
\hline
\end{tabular}

Existen 7 ítems que presentan diferencia entre los grupos de edad, los ítems 21 (Sinto-me bem), 26 (sinto-me tranquilo(a)), 30 (estou feliz), 31 (tenho pensamentos que me perturbam), 32 (falta-me confiança), 35 (sinto-me inadequado(a)) y 37 (passam-me pela cabeço pensamentos sem importancia que me perturbam (valores p inferiores a .0025 
(.05/20 ítems) - correlación de Bonferroni), sin embargo las dif son inferiores a .50 logits, excepto el ítem 32 con un logit superior (-.54), que expresa una diferencia notable. Los resultados muestran que el item 32 es más difícil para los jóvenes que para los mayores, aun cuando tuvieran el mismo nivel de ansiedad.

La figura 10 presenta las diferencias entre los participantes con 30 años o menos y los de más de 30 años, para la escala de ansiedad rasgo.

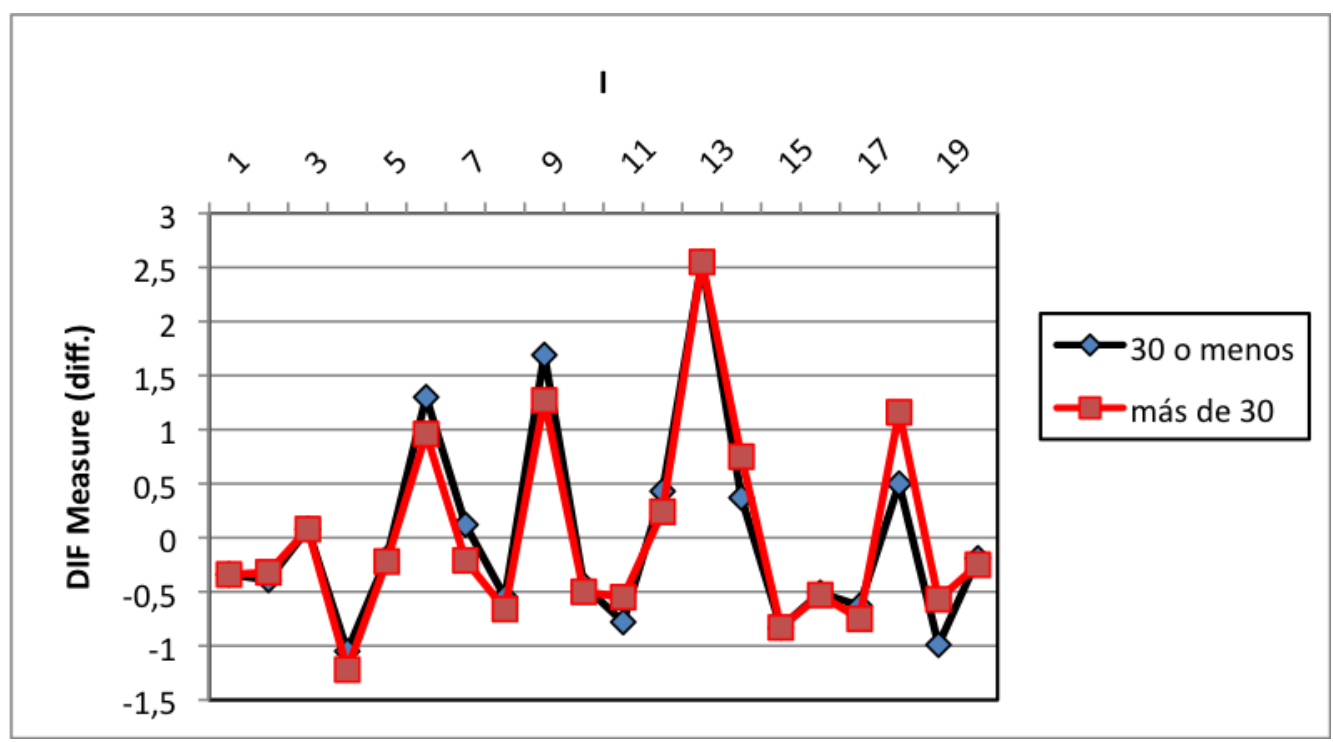

Figura 10 - Diferencias entre los parámetros de localización de los ítems entre los grupos de diferente edad de la prueba STAI Rasgo.

En la tabla 32 se presenta la correspondencia entre las puntuaciones clásicas y los valores logit, con su error estándar, así como los baremos en percentiles y en puntuaciones típicas derivadas con su correspondiente error estándar (normed con media 500 y Desviación Típica 100) de cada puntuación directa. 
Tabla 32. Correspondencia entre las puntuaciones clásicas y los valores Rasch para el STAI Rasgo.

\begin{tabular}{|c|c|c|c|c|c|c|}
\hline Puntuación & Medida & SE & PT Derivada & SEPT & Frecuencia & Percentil \\
\hline 20 & $-6.43 E$ & 1.84 & 133 & 132 & 9 & 1 \\
\hline 21 & -5.19 & 1.03 & 222 & 74 & 9 & 1 \\
\hline 22 & -4.44 & .75 & 276 & 53 & 14 & 2 \\
\hline 23 & -3.97 & .62 & 309 & 45 & 27 & 4 \\
\hline 24 & -3.63 & .55 & 334 & 40 & 15 & 6 \\
\hline 25 & -3.35 & .51 & 354 & 36 & 24 & 7 \\
\hline 26 & -3.11 & .48 & 371 & 34 & 18 & 9 \\
\hline 27 & -2.89 & .45 & 386 & 32 & 33 & 11 \\
\hline 28 & -2.70 & .43 & 400 & 31 & 29 & 14 \\
\hline 29 & -2.52 & .42 & 413 & 30 & 33 & 17 \\
\hline 30 & -2.35 & .40 & 425 & 29 & 38 & 20 \\
\hline 31 & -2.19 & .39 & 437 & 28 & 40 & 23 \\
\hline 32 & -2.04 & .38 & 447 & 28 & 45 & 27 \\
\hline 33 & -1.90 & .38 & 458 & 27 & 37 & 30 \\
\hline 34 & -1.76 & .37 & 468 & 26 & 55 & 34 \\
\hline 35 & -1.62 & .36 & 477 & 26 & 44 & 39 \\
\hline 36 & -1.49 & .36 & 487 & 26 & 46 & 43 \\
\hline 37 & -1.36 & .35 & 496 & 25 & 52 & 47 \\
\hline 38 & -1.24 & .35 & 505 & 25 & 46 & 51 \\
\hline 39 & -1.12 & .35 & 513 & 25 & 38 & 55 \\
\hline 40 & -1.00 & .34 & 522 & 24 & 47 & 58 \\
\hline 41 & -.88 & .34 & 530 & 24 & 35 & 62 \\
\hline 42 & -.77 & .34 & 538 & 24 & 34 & 65 \\
\hline
\end{tabular}


Tabla 32 (Cont.)

\begin{tabular}{|c|c|c|c|c|c|c|}
\hline Puntuación & Medida & $\mathrm{SE}$ & PT Derivada & SEPT & Frecuencia & Percentil \\
\hline 43 & -.66 & .33 & 546 & 24 & 35 & 68 \\
\hline 44 & -.55 & .33 & 554 & 24 & 33 & 71 \\
\hline 45 & -.44 & .33 & 562 & 23 & 29 & 73 \\
\hline 46 & -.34 & .32 & 569 & 23 & 22 & 76 \\
\hline 47 & -.23 & .32 & 577 & 23 & 26 & 78 \\
\hline 48 & -.13 & .32 & 584 & 23 & 24 & 80 \\
\hline 49 & -.03 & .32 & 591 & 23 & 31 & 82 \\
\hline 50 & .07 & .32 & 599 & 23 & 20 & 84 \\
\hline 51 & .17 & .32 & 606 & 23 & 17 & 86 \\
\hline 52 & .27 & .32 & 613 & 23 & 25 & 88 \\
\hline 53 & .37 & .32 & 620 & 23 & 18 & 90 \\
\hline 54 & .47 & .32 & 627 & 23 & 12 & 91 \\
\hline 55 & .57 & .32 & 634 & 23 & 17 & 92 \\
\hline 56 & .67 & .32 & 641 & 23 & 12 & 93 \\
\hline 57 & .77 & .32 & 649 & 23 & 17 & 95 \\
\hline 58 & .87 & .32 & 656 & 23 & 6 & 96 \\
\hline 59 & .98 & .32 & 663 & 23 & 10 & 96 \\
\hline 60 & 1.08 & .32 & 671 & 23 & 7 & 97 \\
\hline 61 & 1.18 & .32 & 678 & 23 & 8 & 98 \\
\hline 62 & 1.29 & .33 & 686 & 23 & 4 & 98 \\
\hline 63 & 1.40 & .33 & 693 & 24 & 1 & 98 \\
\hline 64 & 1.51 & .34 & 701 & 24 & 5 & 99 \\
\hline 65 & 1.63 & .34 & 710 & 24 & 3 & 99 \\
\hline 66 & 1.74 & .35 & 718 & 25 & 3 & 99 \\
\hline
\end{tabular}


Tabla 32 (Cont.)

\begin{tabular}{|c|c|c|c|c|c|c|}
\hline Puntuación & Medida & SE & PT Derivada & SEPT & Frecuencia & Percentil \\
\hline 67 & 1.87 & .36 & 727 & 25 & 4 & 99 \\
\hline 68 & 2.00 & .36 & 736 & 26 & 1 & 99 \\
\hline 69 & 2.13 & .37 & 746 & 27 & 0 & 99 \\
\hline 70 & 2.28 & .39 & 756 & 28 & 0 & 99 \\
\hline 71 & 2.43 & .40 & 767 & 29 & 0 & 99 \\
\hline 72 & 2.60 & .42 & 779 & 30 & 0 & 99 \\
\hline 73 & 2.78 & .44 & 792 & 31 & 0 & 99 \\
\hline 74 & 2.98 & .46 & 807 & 33 & 0 & 99 \\
\hline 75 & 3.21 & .50 & 823 & 36 & 0 & 99 \\
\hline 76 & 3.49 & .55 & 843 & 39 & 1 & 99 \\
\hline 77 & 3.83 & .62 & 867 & 44 & 1 & 99 \\
\hline 78 & 4.28 & .74 & 900 & 53 & 0 & 100 \\
\hline 79 & 5.03 & 1.03 & 953 & 73 & 0 & 100 \\
\hline 80 & $6.27 \mathrm{E}$ & 1.84 & 1042 & 132 & 0 & 100 \\
\hline
\end{tabular}




\subsubsection{Escala de ansiedad de Zung}

En primer lugar, se analizó la calidad psicométrica de las categorías de respuesta, de acuerdo con los criterios de Linacre (2002). Tal como se puede observar en la Tabla 33, el sistema de cuatro categorías, analizado con el Rating Scale Model, es adecuado.

Tabla 33. Estadísticos correspondientes a las categorías de la Zung

\begin{tabular}{lccccc}
\hline Categoría & Elecciones & B & Infit & Outfit & Paso \\
\hline 1 = Nenhuma ou raras vezes & $11954(52 \%)$ & -1.78 & 1.07 & 1.12 & -- \\
2 = Algumas vezes & $6637(29 \%)$ & -.86 & 1.02 & .82 & -.75 \\
$3=$ Uma boa parte do tempo & $2765(12 \%)$ & -.29 & .96 & .86 & .25 \\
$4=$ A maior parte ou a & $1784(8 \%)$ & .26 & 1.13 & 1.11 & .50 \\
totalidade do tempo & & & & & \\
\end{tabular}

Puede observarse que las categorías cumplen los criterios propuestos por Linacre (2002), pues el número de elecciones y su distribución son adecuados, no hay un desajuste elevado en ninguna categoría (Outfit <2), los pasos (step) entre las categorías sucesivas están ordenados de forma creciente (aunque no hay una diferencia suficientemente grande entre las categorías 3 y 4) y hay una ordenación monotónica de las medidas de B.

La figura 11 muestra el funcionamiento de las cuatro categorías. 


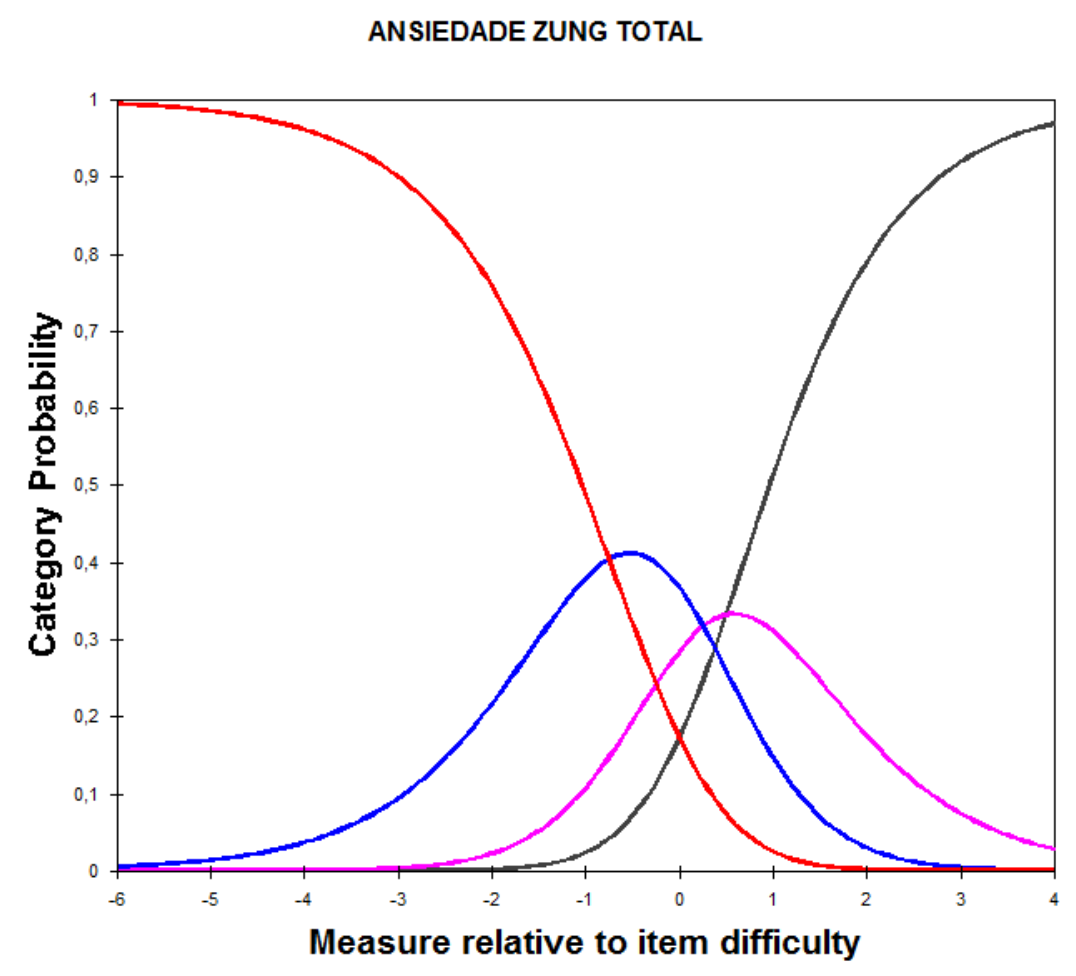

Figura 11. Representación gráfica de las curvas características de las categorías de la escala Zung.

Una vez comprobada la adecuación de las categorías, se analizó el ajuste de los ítems y de las personas, se estimaron sus parámetros y se evaluó su fiabilidad. En la Tabla 34 se muestran los estadísticos de ajuste (Infit y Outfit), la localización (Di) y el error típico de medida de los ítems (SE). 
Tabla 34. Características psicométricas de los ítems de la Zung

\begin{tabular}{lllll}
\hline Ítem (1) Infit & Outfit & $\mathrm{Di}$ & $\mathrm{SE}$
\end{tabular}

1 (Sinto-me mais nervoso(a) e ansioso(a) do que o costume)

2 (Sinto-me com medo sem nenhuma razão para isso)

3 (Sinto-me facilmente perturbado(a) ou em pânico)

4 (Sinto-me como se estivesse para "rebentar")

.85

.05

5 (Sinto que tudo corre bem e que nada de mal acontecerá)

6 (Sinto os braços e as pernas a tremer)

7 (Tenho dores de cabeça, de pescoço e de costas que me incomodam)

8 (Sinto-me fraco(a) e fico facilmente cansado(a))

9 (Sinto-me calmo(a) e com facilidade me posso sentar e ficar sossegado(a))

10 (Sinto o meu coração a bater mais depressa)

11 (Tenho crises de tonturas que me incomodam)

12 (Tenho crises de desmaio ou a sensação de que vou desmaiar) 
Tabla 34 (Cont.)

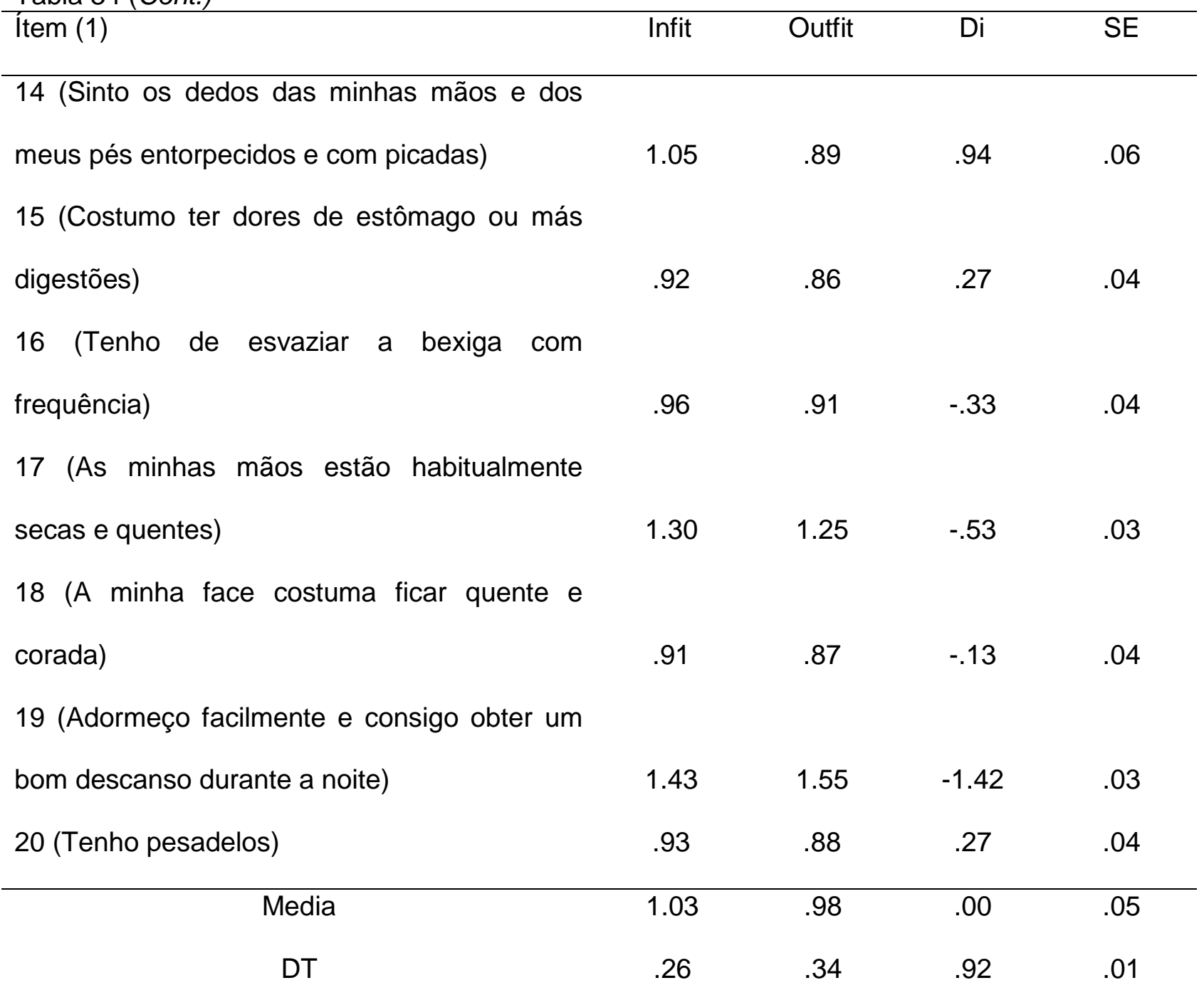

Se puede observar que sólo hay un ítem con valores de infit y/o outfit superiores a 2 (el ítem 13 - "Posso inspirar e expirar com facilidade") y un ítem con valores de infit y/o outfit superiores a 1.5 (el ítem 19 - "Adormeço facilmente e consigo obter um bom descanso durante a noite") lo que revela que la mayoría de los ítems no se desajustan de forma severa. Los restantes ítems presentan valores en torno a la unidad, un valor que indica un ajuste perfecto (Linacre \& Wright, 2000).

En la columna Di, referente a la dificultad o localización de los ítems, podemos ver que el ítem 6 ("Sinto os braços e as pernas a tremer") es el indicador de mayor nivel de ansiedad y el ítem 13 ("Posso inspirar e expirar com facilidade") es el de menor nivel. 
Los errores típicos de medida de los ítems oscilan entre .03 a .08, lo que indica que la fiabilidad de los ítems es muy buena, dado que los errores típicos son bajos.

La tabla 35, nos muestra los valores para la escala de Ansiedad de Zung.

Tabla 35. Resumen de los resultados de la Zung

\begin{tabular}{|c|c|c|c|c|c|}
\hline Estadísticos & Max. & Min. & Media & DT & Valor \\
\hline Infit de los ítems & 1.82 & .71 & 1.03 & .26 & --- \\
\hline Outfit de los ítems & 2.15 & .67 & .98 & .34 & --- \\
\hline$\%$ ítems con desajuste moderado (1) & --- & --- & --- & --- & $5.00 \%(1)$ \\
\hline \% ítems con alto desajuste (2) & --- & --- & --- & --- & $5.00 \%(1)$ \\
\hline Infit de las personas & 3.52 & .23 & 1.07 & .52 & --- \\
\hline Outfit de las personas & 5.21 & .28 & .98 & .60 & --- \\
\hline $\begin{array}{l}\text { \% personas con desajuste moderado } \\
\text { (1) }\end{array}$ & --- & --- & --- & --- & $9.91 \%(115)$ \\
\hline$\%$ personas con alto desajuste (2) & --- & --- & --- & --- & $\begin{array}{l}11.21 \% \\
(130)\end{array}$ \\
\hline Parámetro de los ítems & 1.75 & -2.20 & .00 & .92 & --- \\
\hline Fiabilidad de los Ítems & --- & --- & --- & --- & 1.00 \\
\hline Parámetro personas & 1.15 & -3.45 & -1.18 & .62 & --- \\
\hline Fiabilidad de personas & --- & --- & --- & --- & .71 \\
\hline
\end{tabular}

(1) Infit $y /$ o outfit $>1.5 \mathrm{y}<2$; (2) Infit $\mathrm{y} / \mathrm{o}$ outfit $>2$; (3) $\mathrm{p}<.05$

Como se puede observar en la tabla 35 la fiabilidad de los ítems es muy alta (1.00).

El ajuste de las personas al modelo es razonable, pues los valores de la media y de la desviación típica son respectivamente de 1.07 y .52 (infit), y .98 y .60 (outfit). El $9.91 \%$ de 
las personas se encuentran con desajuste moderado (infit y/o outfit $>1.5 \mathrm{y}<2$ ) y el $11.21 \%$ de las personas con alto desajuste (infit y/o outfit $>2$ ).

Los parámetros de las personas van de -3.45 a 1.15 , con una media de -1.18 y una desviación típica de .62. Los errores típicos de medida de las personas van de .26 a 1.84. La fiabilidad global de las personas (.71) no es elevada, pero es adecuada (porcentaje de la varianza de las personas no explicada por el error).

La Tabla 36 muestra una representación conjunta persona-ítem, denominada "mapa de Wright", donde se puede observar la posición de los ítems y de las personas en la variable. Dado que la media de las personas $(-1.18)$ es inferior a la de los ítems (.00), se puede considerar que el nivel de ansiedad de los sujetos analizados es bajo. Además, la mayor parte de las personas se encuentran por debajo del rango de la variable en el que los ítems se sitúan. En consecuencia, se observa que los ítems de la escala no permiten medir con alta precisión a las personas con niveles bajos de ansiedad. Esto sucede porque el nivel de las personas es bajo y la escala sólo tiene ítems situados en el rango superior del constructo. 
Tabla 36. Representación conjunta de personas e ítems de la Zung

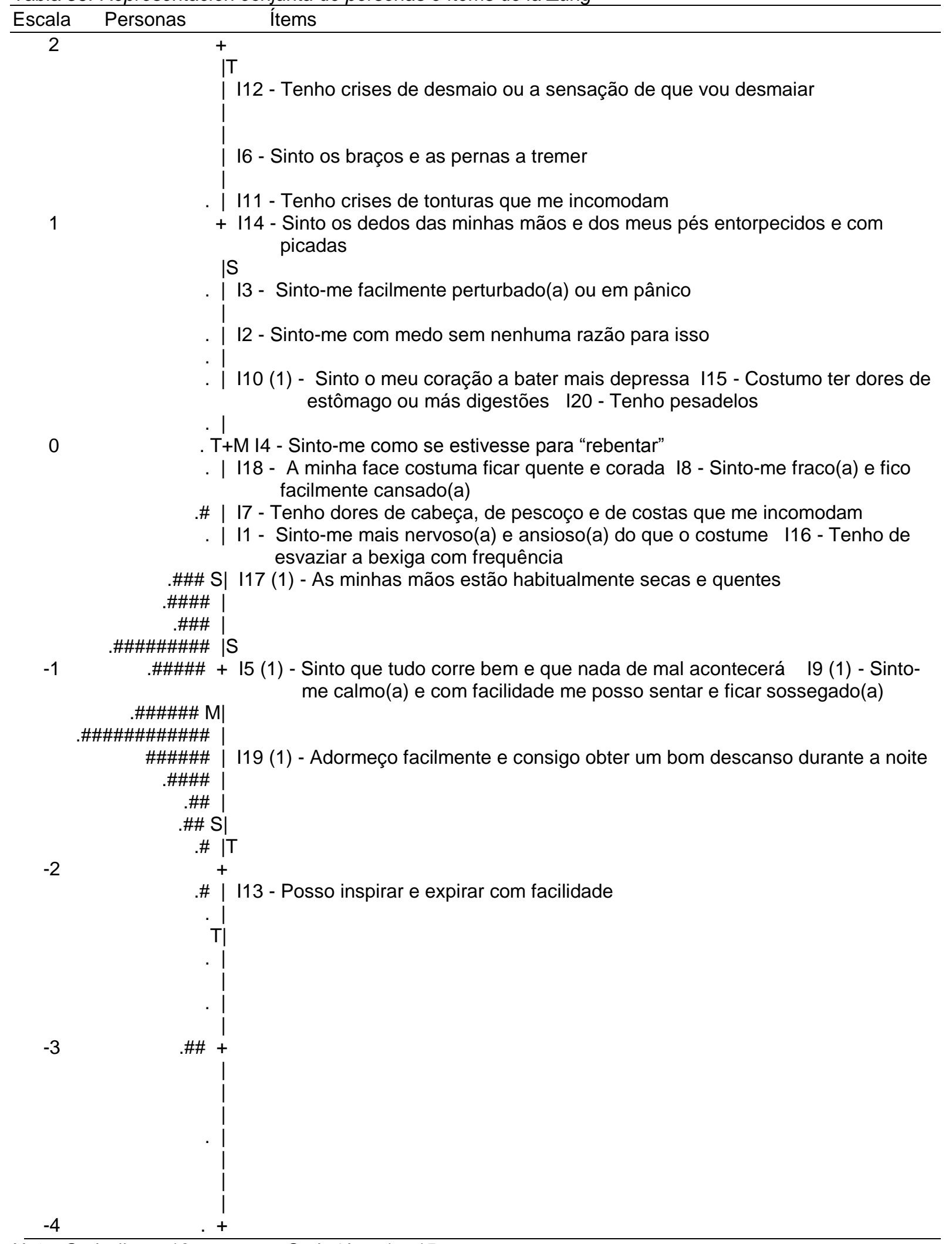

Nota: Cada \# son 16 personas; Cada '. es 1 a 15.

(1) Ítems invertidos de manera que las mayores puntuaciones indiquen mayor ansiedad. 
En relación al estudio de la unidimensionalidad de la Escala de Ansiedad de Zung, los resultados muestran que la dimensión Rasch explica el 38.9\% (<50\%) y la varianza explicada por los ítems es del $34.3 \%$, que no es mayor a cuatro veces el valor del primer contraste $(34.3 \%<4 \times 12.8 \%=51.2 \%)$. No cumple asi los criterios de Linacre (2010) para la unidimensionalidad. Sin embargo, según Reckase (1979), que presenta criterios mas flexibles, el porcentaje explicado por la medida derivada del modelo es superior a $20 \%$ y no hay un segundo factor dominante, lo que muestra que los datos se adecuan suficientemente a una estructura unidimensional, no provocando dificultades a nivel de la validez de los resultados, y como la escala en la versión original tiene subescalas con muy pocos ítems, es más adecuada una estructura unidimensional.

En la Tabla 37 se presentan los resultados del análisis de Funcionamiento Diferencial de los Ítems asociado al sexo. 
Tabla 37. Funcionamiento Diferencial de los Ítems asociado al sexo para la Zung.

\begin{tabular}{|c|c|c|c|c|}
\hline Ítem & $\mathrm{DM}-\mathrm{DH}$ & $M$ & $\mathrm{t}$ & $p$ \\
\hline 1 & .19 & .08 & 2.52 & .0119 \\
\hline 2 & .19 & .11 & 1.78 & .0762 \\
\hline 3 & .33 & .12 & 2.75 & .0061 \\
\hline 4 & .17 & .09 & 1.99 & .0470 \\
\hline 5 & -.36 & .07 & -5.33 & .0000 \\
\hline 6 & .13 & .15 & .86 & .3875 \\
\hline 7 & .43 & .08 & 5.36 & .0000 \\
\hline 8 & .38 & .08 & 4.54 & .0000 \\
\hline 9 & -.48 & .07 & -7.20 & .0000 \\
\hline 10 & .11 & .09 & 1.15 & .2496 \\
\hline 11 & .29 & .14 & 2.10 & .0362 \\
\hline 12 & .00 & .18 & .00 & 1.000 \\
\hline 13 & -.13 & .08 & -1.70 & .0894 \\
\hline 14 & .32 & .13 & 2.48 & .0134 \\
\hline 15 & .11 & .09 & 1.15 & .2523 \\
\hline 16 & .13 & .08 & 1.70 & .0898 \\
\hline 17 & -.39 & .07 & -5.45 & .0000 \\
\hline 18 & .09 & .08 & 1.13 & .2575 \\
\hline 19 & -.35 & .07 & -5.25 & .0000 \\
\hline 20 & .32 & .10 & 3.32 & .0009 \\
\hline
\end{tabular}

Existen 7 ítems que presentan diferencia entre géneros, los ítems 5 (Sinto que tudo corre bem e que nada de mal acontecerá), 7 (Tenho dores de cabeça, de pescoço e de costas que me incomodam), 8 (Sinto-me fraco(a) e fico facilmente cansado(a)), 9 (Sinto-me calmo(a) e com facilidade me posso sentar e ficar sossegado(a)), 17 (As minhas mãos estão 
habitualmente secas e quentes), 19 (Adormeço facilmente e consigo obter um bom descanso durante a noite) y 20 (Tenho pesadelos) (valores p inferiores a $.0025(.05 / 20$ ítems) - correlación de Bonferroni). Sin embargo, como las diferencias son inferiores a .50 logits, se considera que no tiene importancia sustantiva.

La figura 12 presenta las diferencias de los parámetros de localización de los ítems entre los géneros para la escala de ansiedad de Zung.

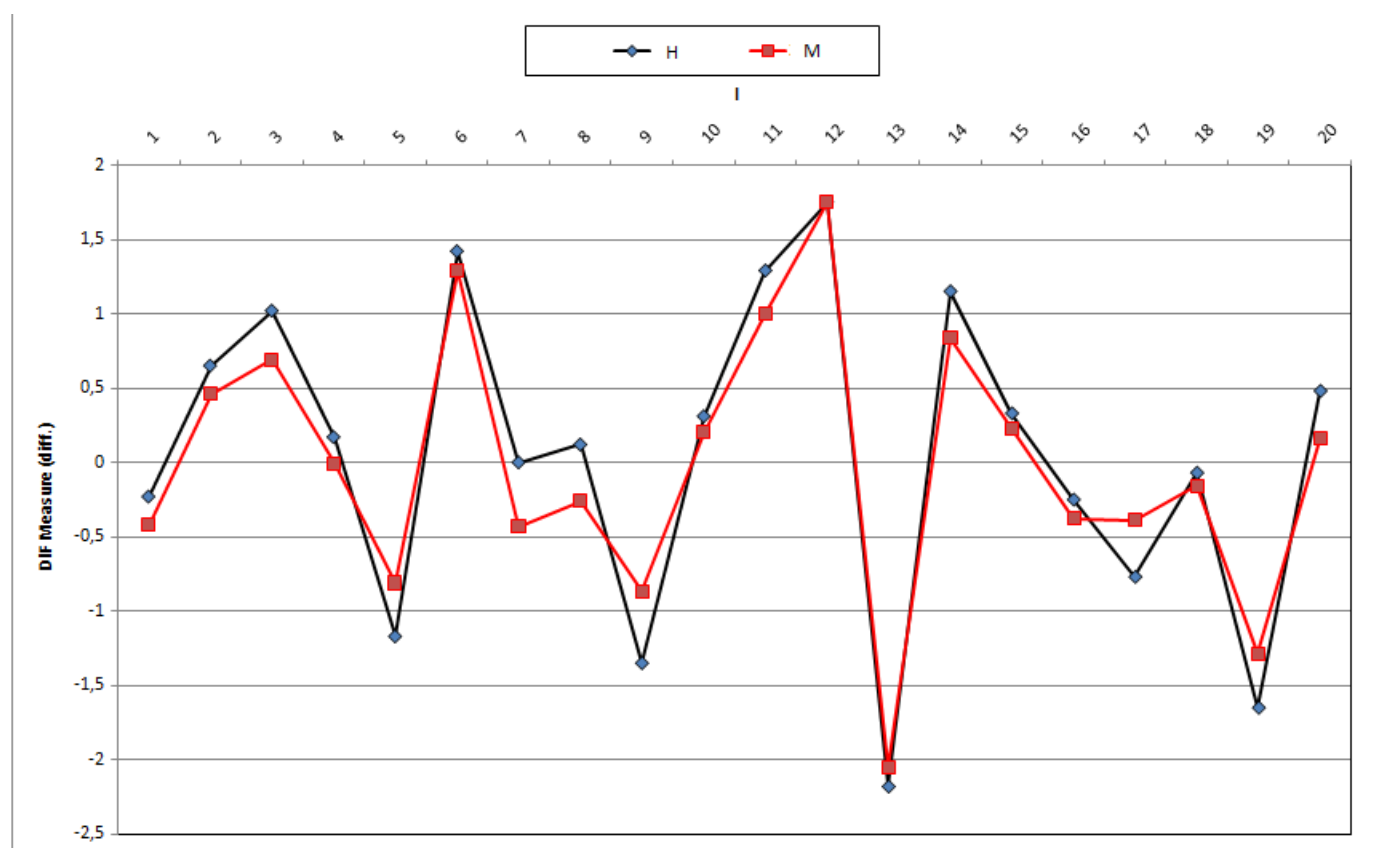

Figura 12 - Diferencias de los parámetros de localización de los ítems entre los géneros para la escala de ansiedad de Zung.

En la Tabla 38 se presentan los resultados del análisis de Funcionamiento Diferencial de los Ítems asociado a la edad. 
Tabla 38. Funcionamiento Diferencial de los Ítems asociado a la edad para la Zung.

\begin{tabular}{|c|c|c|c|c|}
\hline Ítem & $D+E-D-E$ & $M$ & $\mathrm{t}$ & $p$ \\
\hline 1 & -.10 & .07 & -1.36 & .1749 \\
\hline 2 & -.14 & .10 & -1.45 & .1475 \\
\hline 3 & -.24 & .11 & -2.21 & .0272 \\
\hline 4 & -.17 & .08 & -2.01 & .0446 \\
\hline 5 & .16 & .07 & 2.38 & .0177 \\
\hline 6 & -.20 & .14 & -1.44 & .1491 \\
\hline 7 & .07 & .07 & .97 & .3324 \\
\hline 8 & .08 & .08 & .97 & .3320 \\
\hline 9 & .05 & .07 & .74 & .4570 \\
\hline 10 & -.10 & .09 & -1.13 & .2605 \\
\hline 11 & .00 & .13 & .00 & 1.000 \\
\hline 12 & .00 & .17 & .00 & 1.000 \\
\hline 13 & .00 & .07 & .00 & 1.000 \\
\hline 14 & .25 & .12 & 2.08 & .0376 \\
\hline 15 & -.06 & .09 & -.63 & .5293 \\
\hline 16 & .00 & .07 & .00 & 1.000 \\
\hline 17 & .18 & .07 & 2.56 & .0106 \\
\hline 18 & -.27 & .08 & -3.51 & .0005 \\
\hline 19 & .26 & .07 & 3.93 & .0001 \\
\hline 20 & -.25 & .09 & -2.85 & .0045 \\
\hline
\end{tabular}

Existen 2 ítems que presentan diferencias en los parámetros de localización entre grupos de edad, los ítems 18 (A minha face costuma ficar quente e corada) y 19 (Adormeço facilmente e consigo obter um bom descanso durante a noite) (valores p inferiores a .0025 
(.05/20 ítems) - correlación de Bonferroni), sin embargo, como las diferencias son inferiores a .50 logits, se considera que no tiene importancia sustantiva.

La figura 13 presenta las diferencias de los parámetros de localización de los ítems entre los participantes con 30 años o menos y los que tienen más de 30 años, para la escala de ansiedad de Zung.

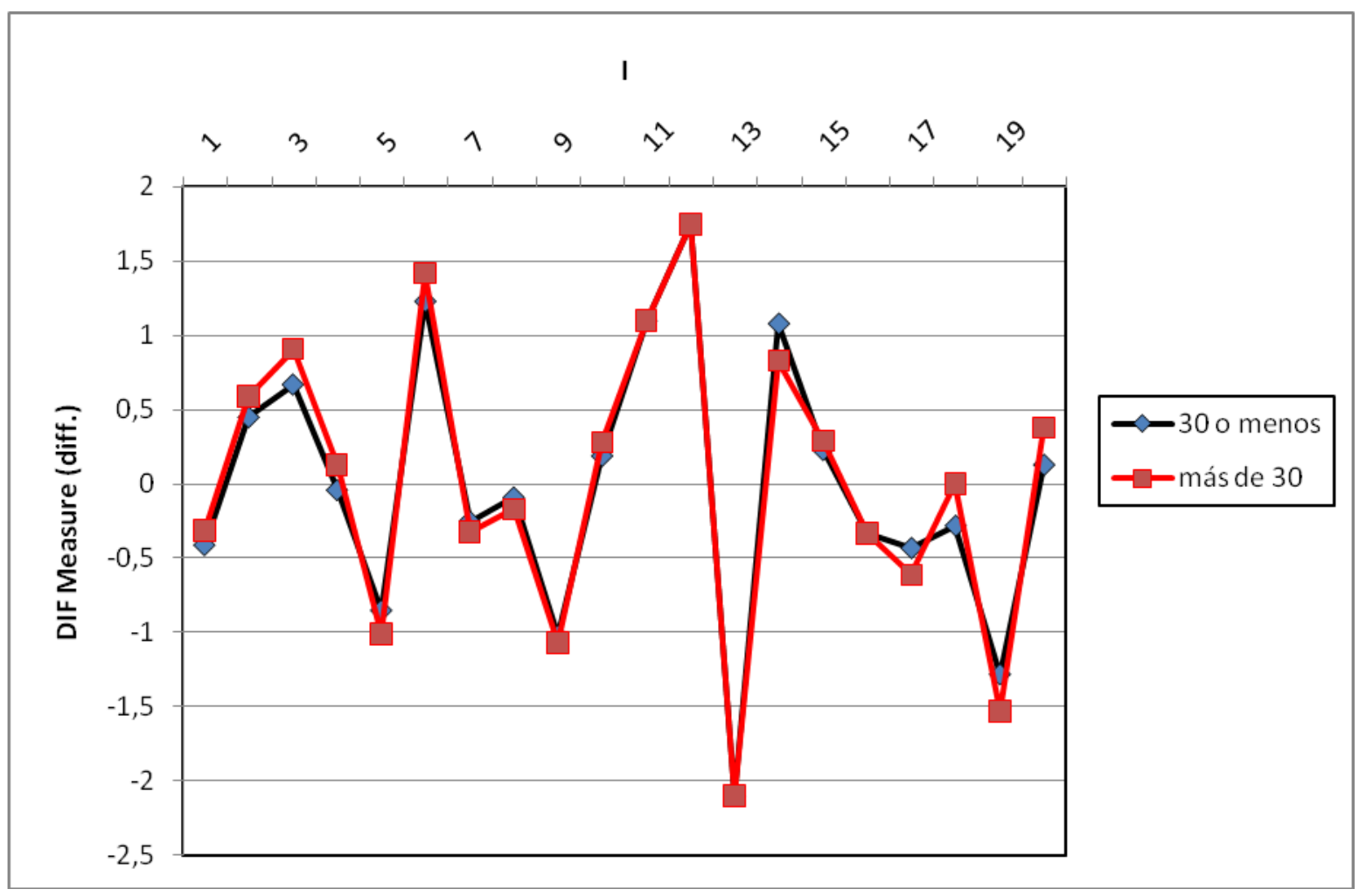

Figura 13 - Diferencias de los parámetros de localización de los ítems entre grupos de edad para la Zung.

En la tabla 39 se presenta la correspondencia entre las puntuaciones clásicas y los valores logit, con su error estándar, así como los baremos en percentiles y en puntuaciones típicas derivadas con su correspondiente error estándar (normed con media 500 y Desviación Típica 100) de cada puntuación directa. 
Tabla 39. Correspondencia entre las puntuaciones clásicas y los valores Rasch para la Zung

\begin{tabular}{|c|c|c|c|c|c|c|}
\hline Puntuación & Medida & SE & PT Derivada & SEPT & Frecuencia & Percentil \\
\hline 20 & $-5.39 \mathrm{E}$ & 1.83 & -143 & 281 & 3 & 1 \\
\hline 21 & -4.17 & 1.01 & 44 & 155 & 0 & 1 \\
\hline 22 & -3.45 & .72 & 154 & 111 & 2 & 1 \\
\hline 23 & -3.02 & .60 & 220 & 91 & 47 & 2 \\
\hline 24 & -2.71 & .52 & 267 & 80 & 3 & 5 \\
\hline 25 & -2.46 & .47 & 305 & 72 & 4 & 5 \\
\hline 26 & -2.26 & .44 & 337 & 67 & 14 & 6 \\
\hline 27 & -2.08 & .41 & 364 & 63 & 19 & 7 \\
\hline 28 & -1.92 & .39 & 388 & 59 & 25 & 9 \\
\hline 29 & -1.78 & .37 & 410 & 57 & 34 & 12 \\
\hline 30 & -1.65 & .35 & 430 & 54 & 38 & 15 \\
\hline 31 & -1.52 & .34 & 449 & 52 & 71 & 19 \\
\hline 32 & -1.41 & .33 & 466 & 51 & 96 & 27 \\
\hline 33 & -1.30 & .32 & 482 & 49 & 91 & 35 \\
\hline 34 & -1.20 & .31 & 498 & 48 & 111 & 43 \\
\hline 35 & -1.11 & .31 & 513 & 47 & 106 & 53 \\
\hline 36 & -1.01 & .30 & 527 & 46 & 90 & 61 \\
\hline 37 & -.93 & .29 & 540 & 45 & 72 & 68 \\
\hline 38 & -.84 & .29 & 553 & 44 & 74 & 74 \\
\hline 39 & -.76 & .28 & 566 & 44 & 52 & 80 \\
\hline 40 & -.68 & .28 & 578 & 43 & 39 & 84 \\
\hline 41 & -.60 & .28 & 590 & 42 & 30 & 87 \\
\hline 42 & -.53 & .27 & 602 & 42 & 26 & 89 \\
\hline 43 & -.45 & .27 & 613 & 42 & 29 & 92 \\
\hline
\end{tabular}


Tabla 39 (Cont.)

\begin{tabular}{|c|c|c|c|c|c|c|}
\hline Puntuación & Medida & $\mathrm{SE}$ & PT Derivada & SEPT & Frecuencia & Percentil \\
\hline 44 & -.38 & .27 & 624 & 41 & 13 & 93 \\
\hline 45 & -.31 & .27 & 635 & 41 & 15 & 95 \\
\hline 46 & -.24 & .27 & 646 & 41 & 14 & 96 \\
\hline 47 & -.17 & .26 & 657 & 40 & 9 & 97 \\
\hline 48 & -.10 & .26 & 668 & 40 & 6 & 97 \\
\hline 49 & -.03 & .26 & 678 & 40 & 7 & 98 \\
\hline 50 & .04 & .26 & 689 & 40 & 3 & 98 \\
\hline 51 & .11 & .26 & 699 & 40 & 3 & 99 \\
\hline 52 & .18 & .26 & 710 & 40 & 2 & 99 \\
\hline 53 & .25 & .26 & 720 & 40 & 3 & 99 \\
\hline 54 & .32 & .26 & 731 & 40 & 3 & 99 \\
\hline 55 & .39 & .26 & 741 & 40 & 1 & 99 \\
\hline 56 & .46 & .27 & 752 & 41 & 1 & 99 \\
\hline 57 & .53 & .27 & 763 & 41 & 1 & 99 \\
\hline 58 & .60 & .27 & 774 & 41 & 0 & 99 \\
\hline 59 & .67 & .27 & 785 & 42 & 0 & 99 \\
\hline 60 & .74 & .27 & 796 & 42 & 2 & 99 \\
\hline 61 & .82 & .28 & 808 & 42 & 0 & 99 \\
\hline 62 & .90 & .28 & 820 & 43 & 0 & 99 \\
\hline 63 & .98 & .28 & 832 & 44 & 0 & 99 \\
\hline 64 & 1.06 & .29 & 845 & 44 & 0 & 99 \\
\hline 65 & 1.15 & .29 & 858 & 45 & 1 & 99 \\
\hline
\end{tabular}




\subsection{5. Índice de sensibilidad a la ansiedad}

En primer lugar, se analizó la calidad psicométrica de las categorías de respuesta, de acuerdo con los criterios de Linacre (2002). Tal como se puede observar en la Tabla 40, el sistema de cuatro categorías, analizado con el Rating Scale Model, es adecuado.

Tabla 40. Estadísticos correspondientes a las categorías del ASI

\begin{tabular}{lccccc}
\hline Categoría & Elecciones & B & Infit & Outfit & Paso \\
\hline $0=$ Muito pouco & $6541(37 \%)$ & -1.99 & .93 & .99 & -- \\
$1=$ Pouco & $4312(24 \%)$ & -1.07 & .95 & .80 & -1.12 \\
$2=$ Nem pouco nem & $3522(20 \%)$ & -.44 & .97 & .92 & -.65 \\
muito & & & & & \\
$3=$ Muito & $2563(14 \%)$ & .19 & .99 & 1.00 & .13 \\
$4=$ Muitíssimo & $869(5 \%)$ & .57 & 1.49 & 1.44 & 1.63 \\
\hline
\end{tabular}

Puede observarse que las categorías cumplen los criterios propuestos por Linacre (2002), pues el número de elecciones y su distribución son adecuados, no hay un desajuste en ninguna categoría (Outfit < 1.5), los pasos (step) entre las categorías sucesivas están ordenados de forma creciente y hay una ordenación monotónica de las medidas de B.

La figura 14 muestra el funcionamiento de las cuatro categorías. 


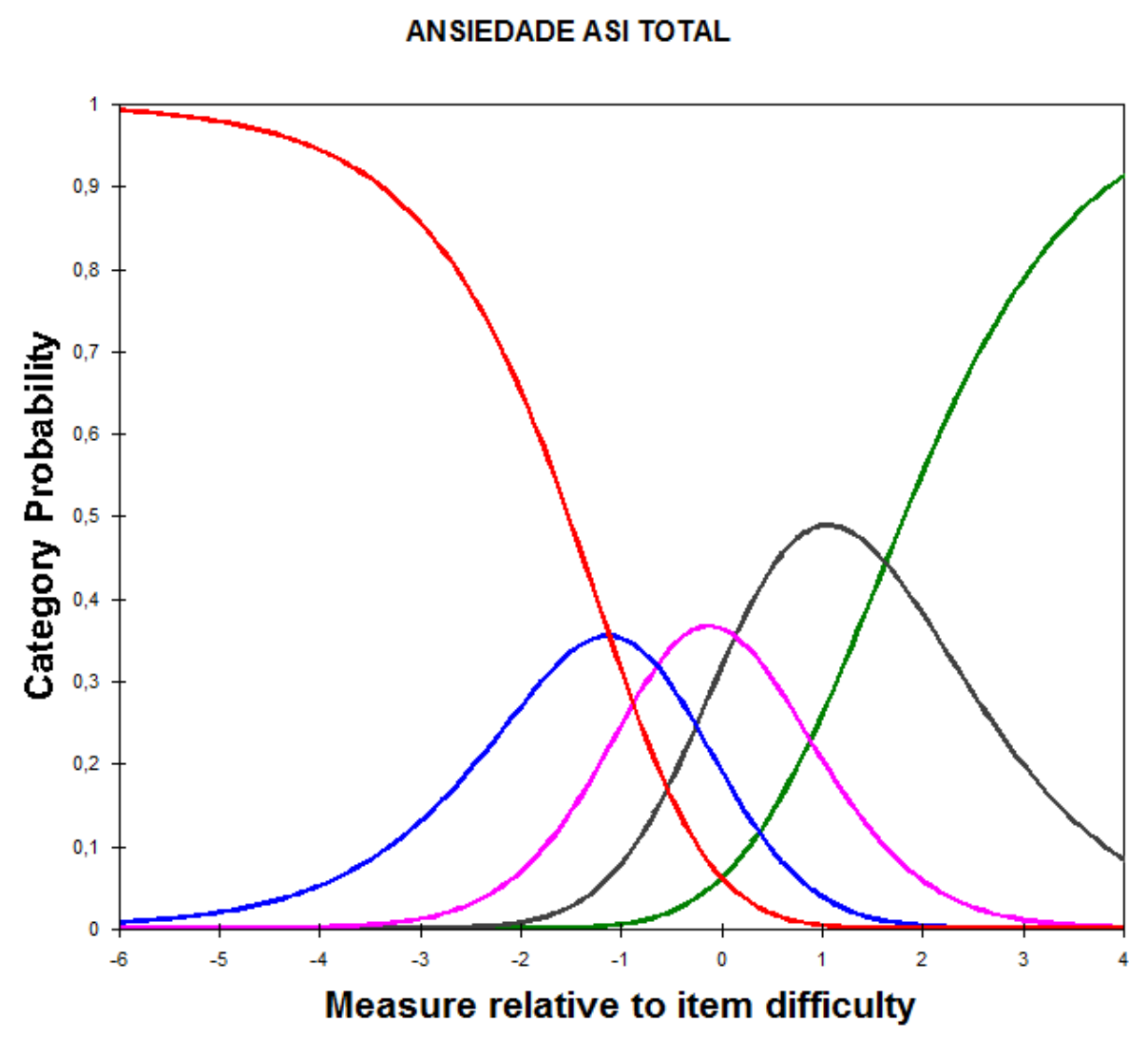

Figura 14. Representación gráfica de las curvas características de las categorías del ASI.

Una vez comprobada la adecuación de las categorías, se analizó el ajuste de los ítems y de las personas, se estimaron sus parámetros y se evaluó su fiabilidad. En la Tabla 41 se muestran los estadísticos de ajuste (Infit y Outfit), la localización (Di) y el error típico de medida de los ítems (SE). 
Tabla 41. Características psicométricas de los ítems del ASI

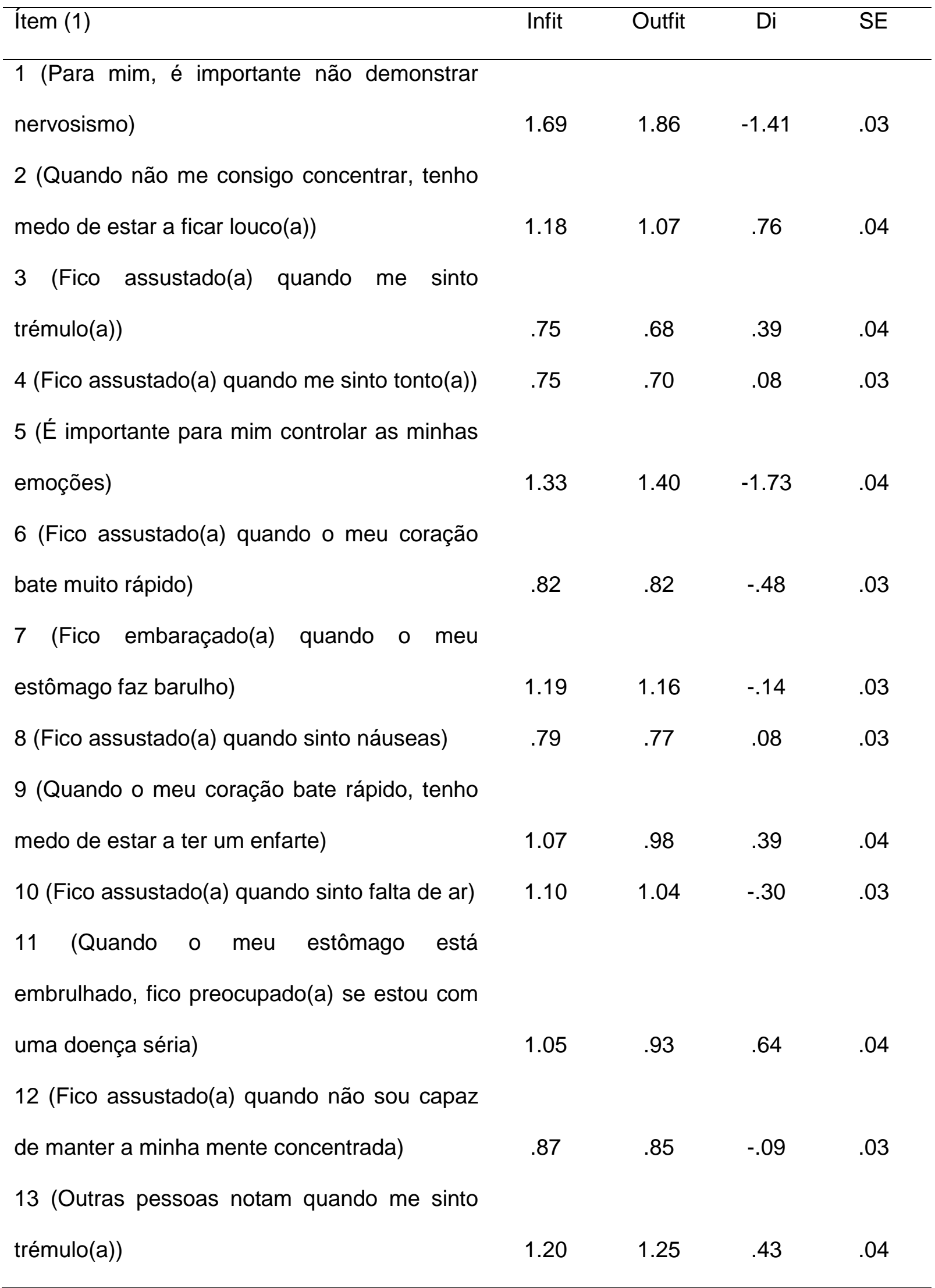


Tabla 41 (Cont.)

\begin{tabular}{|c|c|c|c|c|}
\hline Ítem (1) & Infit & Outfit & $\mathrm{Di}$ & SE \\
\hline 14 (As sensações corporais incomuns & & & & \\
\hline assustam-me) & .77 & .78 & -.03 & .03 \\
\hline estou nervoso(a) fico & & & & \\
\hline preocupado(a) se estou com alguma doença & & & & \\
\hline mental) & 1.08 & .82 & 1.06 & .04 \\
\hline assustado(a) quando estou & & & & \\
\hline nervoso(a)) & .80 & .75 & .35 & .04 \\
\hline Media & 1.03 & .99 & .00 & .04 \\
\hline DT & .25 & .30 & .71 & .00 \\
\hline
\end{tabular}

Se puede observar que sólo hay un ítem con valores de infit y/o outfit superiores a 1.5 (el ítem 1 - "Para mim, é importante não demonstrar nervosismo"), lo que revela que la mayoría de los ítems no se desajustan de forma severa. Los restantes ítems presentan valores en torno a la unidad, un valor que indica un ajuste perfecto (Linacre \& Wright, 2000).

En la columna Di, referente a la dificultad o localización de los ítems, podemos ver que el ítem 15 (“Quando estou nervoso(a) fico preocupado(a) se estou com alguma doença mental") es el indicador de mayor nivel de ansiedad y el ítem 5 (“É importante para mim controlar as minhas emoções") es el de menor nivel.

Los errores típicos de medida de los ítems oscilan entre .03 a .04. lo que indica que la fiabilidad de los ítems es muy buena, dado que los errores típicos son bajos.

La tabla 42, nos muestra los valores para el índice de sensibilidad a la ansiedad. 
Tabla 42. Resumen de los resultados del ASI

\begin{tabular}{lccccc}
\hline Estadísticos & Max. & Min. & Media & DT & Valor \\
\hline Infit de los ítems & 1.69 & .75 & 1.03 & .25 & --- \\
Outfit de los ítems & 1.86 & .68 & .99 & .30 & --- \\
\% ítems con desajuste moderado (1) & --- & --- & --- & --- & $6.25 \%(1)$ \\
\% ítems con alto desajuste (2) & --- & --- & --- & --- & $0 \%$ \\
Infit de las personas & 4.17 & .10 & 1.03 & .57 & --- \\
Outfit de las personas & 4.32 & .11 & .99 & .60 & --- \\
\% personas con desajuste moderado & --- & --- & --- & --- & $12.59 \%$ \\
(1) & & & & & $(146)$ \\
\% personas con alto desajuste (2) & --- & --- & --- & --- & $7.24 \%(84)$ \\
Parámetro de los ítems & 1.06 & -1.76 & .00 & .71 & --- \\
Fiabilidad de los Ítems & ---- & --- & --- & --- & 1.00 \\
Parámetro personas & 2.18 & -4.23 & -1.02 & .98 & --- \\
Fiabilidad de personas & --- & --- & --- & --- & .89 \\
\hline
\end{tabular}

(1) Infit $y /$ o outfit $>1.5 y<2$; (2) Infit $y / 0$ outfit $>2$; (3) $p<.05$

Como se puede observar en la tabla 42 la fiabilidad de los ítems es muy alta (1.00).

El ajuste de las personas al modelo es razonable, pues los valores de la media y de la desviación típica son respectivamente de 1.03 y .99 (infit), y .99 y .60 (outfit). El 12.59\% de las personas presentan un desajuste moderado (infit y/o outfit $>1.5$ y $<2$ ) y el $7.24 \%$ un alto desajuste (infit y/o outfit $>2$ ).

Los parámetros de las personas van de -4.23 a 2.18 con una media de -1.02 y una desviación típica de .98. Los errores típicos de medida de las personas van de .26 a 1.82. La fiabilidad global de las personas (.89) es elevada (porcentaje de la varianza de las personas no explicada por el error). 
La Tabla 43 muestra una representación conjunta persona-ítem, denominada "mapa de Wright", donde se puede observar la posición de los ítems y de las personas en la variable. Dado que la media de las personas (-1.02) es inferior a la de los ítems (.00), se puede considerar que el nivel de sensibilidad a la ansiedad de los sujetos analizados es bajo. Además, la mayor parte de las personas se encuentran por debajo del rango de la variable en el que los ítems se sitúan. En consecuencia, se observa que los ítems de la escala no permiten medir con alta precisión a las personas con niveles bajos de sensibilidad a la ansiedad. Esto sucede porque el nivel de las personas es bajo y la escala sólo tiene ítems situados en el rango superior del constructo. 
Tabla 43. Representación conjunta de personas e ítems del ASI

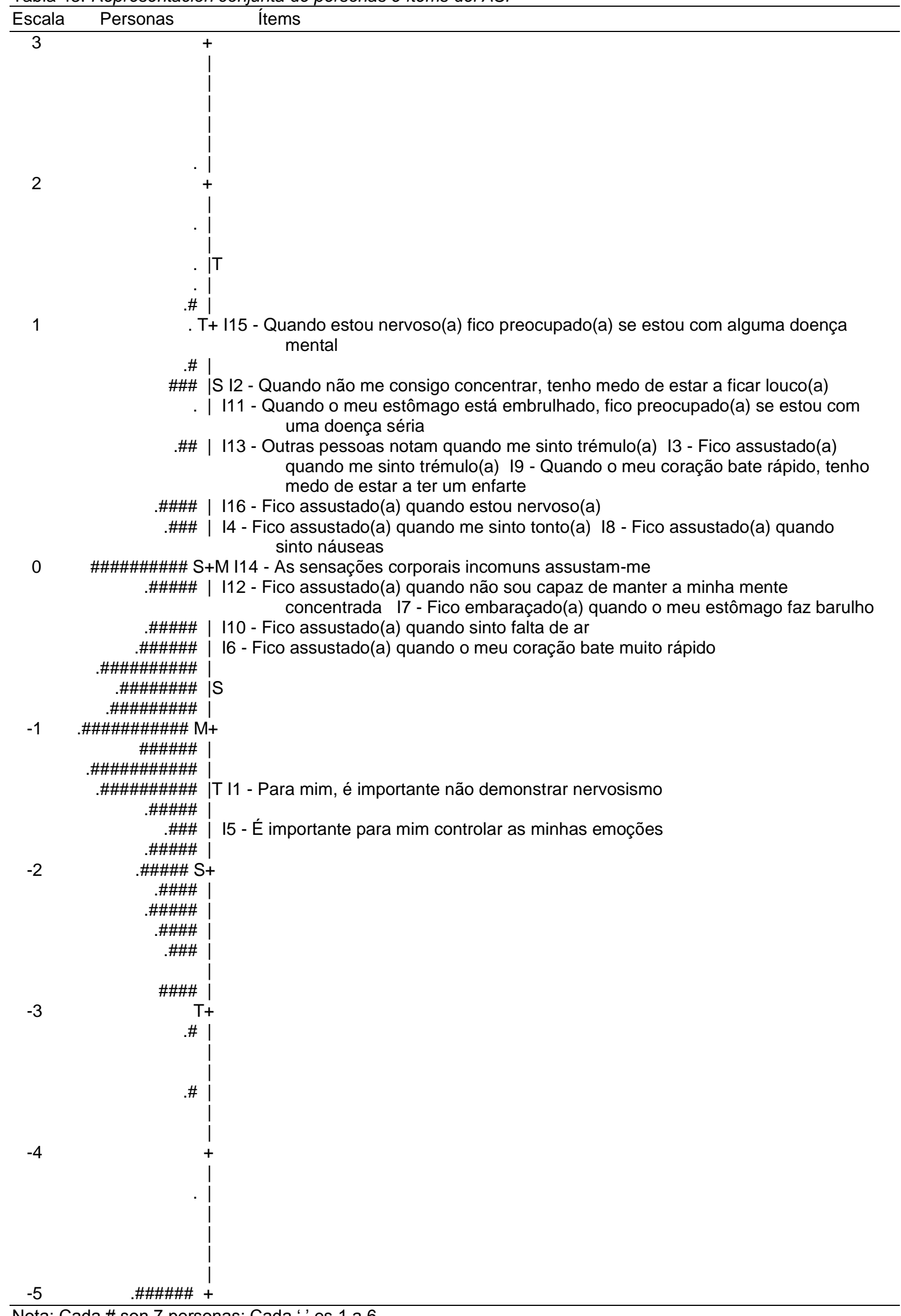

Nota: Cada \# son 7 personas; Cada '.' es 1 a 6. 
El análisis de la dimensionalidad de el índice de sensibilidad a la ansiedad mostró que los datos se adecuan a una estructura unidimensional. La dimensión Rasch explica el $52.0 \%(>50 \%)$ y la varianza explicada por los ítems es del $32.8 \%$, mayor a cuatro veces el valor del primer contraste $(32.8 \%>4 \times 6.6 \%=26.4 \%)$, lo que es adecuado a una estructura unidimensional.

En la Tabla 44 se presentan los resultados del análisis de Funcionamiento Diferencial de los Ítems asociado al sexo.

Tabla 44. Funcionamiento Diferencial de los Ítems asociado al sexo para el ASI.

\begin{tabular}{|c|c|c|c|c|}
\hline Ítem & $\mathrm{DM}-\mathrm{DH}$ & $M$ & $\mathrm{t}$ & $p$ \\
\hline 1 & -.21 & .07 & -3.05 & .0024 \\
\hline 2 & .00 & .08 & .00 & 1.000 \\
\hline 3 & .21 & .08 & 2.67 & .0076 \\
\hline 4 & .16 & .07 & 2.26 & .0243 \\
\hline 5 & -.29 & .07 & -4.01 & .0001 \\
\hline 6 & .09 & .07 & 1.27 & .2029 \\
\hline 7 & .12 & .07 & 1.70 & .0894 \\
\hline 8 & .22 & .07 & 3.06 & .0023 \\
\hline 9 & .00 & .08 & .00 & 1.000 \\
\hline 10 & .17 & .07 & 2.46 & .0141 \\
\hline 11 & -.26 & .08 & -3.29 & .0010 \\
\hline 12 & -.03 & .07 & -.38 & .7005 \\
\hline 13 & -.14 & .08 & -1.77 & .0766 \\
\hline 14 & .00 & .07 & .00 & 1.000 \\
\hline 15 & -.21 & .09 & -2.31 & .0209 \\
\hline 16 & .00 & .08 & .00 & 1.000 \\
\hline
\end{tabular}


Existen 4 ítems que presentan diferencia entre géneros, los ítems 1 (Para mim, é importante não demonstrar nervosismo), 5 (É importante para mim controlar as minhas emoções), 8 (Fico assustado(a) quando sinto náuseas) y 11 (Quando o meu estômago está embrulhado, fico preocupado(a) se estou com uma doença séria) (valores p inferiores a .0031 (.05/16 ítems) - correlación de Bonferroni); sin embargo, como las diferencias son inferiores a .50 logits, se considera que no tiene importancia sustantiva.

La figura 15 presenta las diferencias entre los parámetros de los ítems entre los géneros para el índice de sensibilidad a la ansiedad.

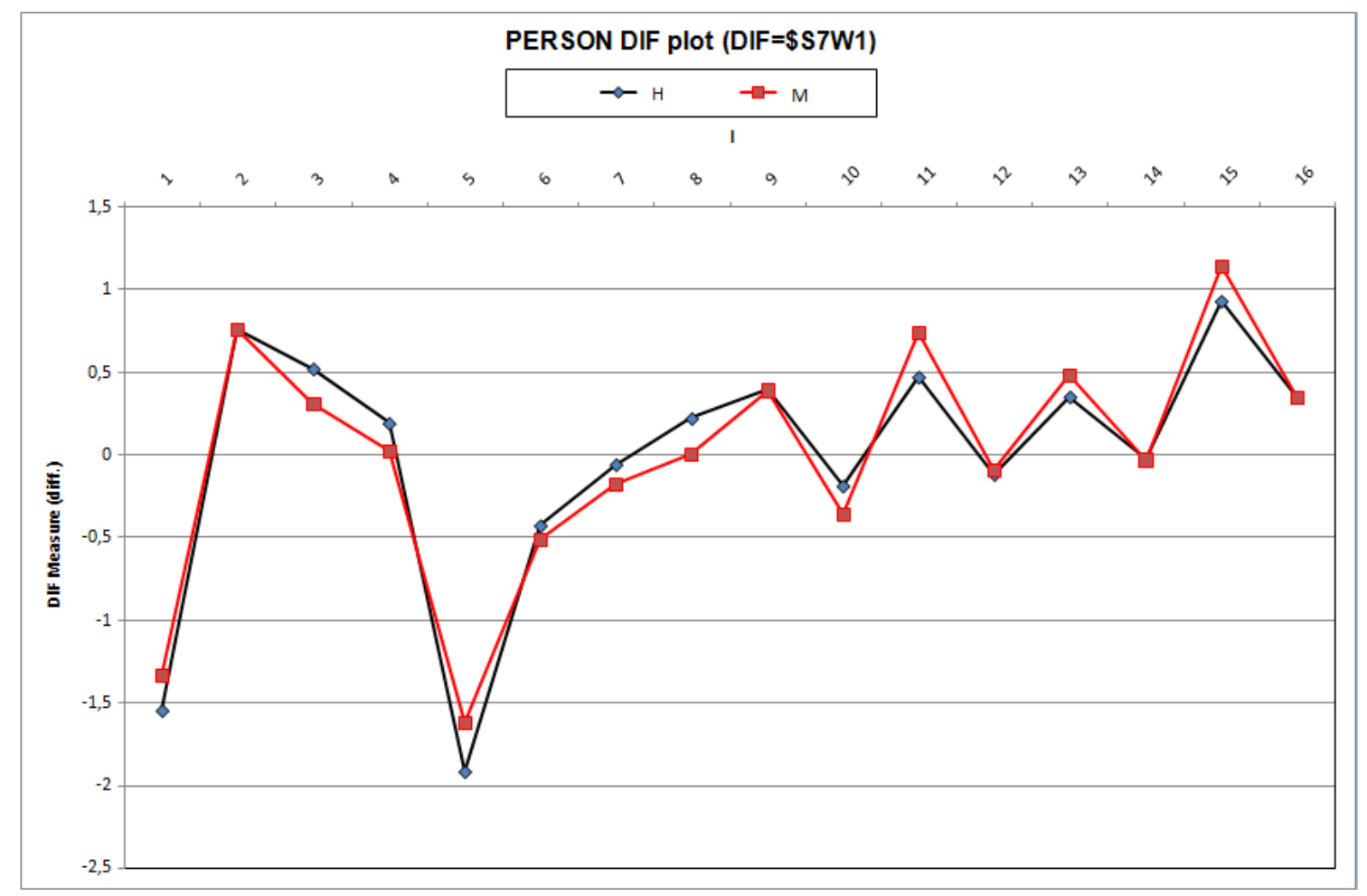

Figura 15 - Diferencias entre los parámetros de los ítems entre los géneros para el ASI

En la Tabla 45 se presentan los resultados del análisis de Funcionamiento Diferencial de los Ítems asociado a la edad. 
Tabla 45. Funcionamiento Diferencial de los Ítems asociado a la edad para el ASI.

\begin{tabular}{|c|c|c|c|c|}
\hline Ítem & $D+E-D-E$ & $\mathrm{M}$ & $\mathrm{t}$ & $p$ \\
\hline 1 & -.22 & .07 & -3.18 & .0015 \\
\hline 2 & -.16 & .08 & -1.99 & .0468 \\
\hline 3 & .00 & .07 & .00 & 1.000 \\
\hline 4 & .00 & .07 & .00 & 1.000 \\
\hline 5 & .00 & .07 & .00 & 1.000 \\
\hline 6 & .18 & .07 & 2.73 & .0065 \\
\hline 7 & -.10 & .07 & -1.49 & .1376 \\
\hline 8 & -.03 & .07 & -.37 & .7084 \\
\hline 9 & .45 & .07 & 6.03 & .0000 \\
\hline 10 & -.02 & .07 & -.34 & .7354 \\
\hline 11 & .12 & .08 & 1.51 & .1311 \\
\hline 12 & .00 & .07 & .00 & 1.000 \\
\hline 13 & -.18 & .07 & -2.41 & .0159 \\
\hline 14 & -.09 & .07 & -1.27 & .2047 \\
\hline 15 & .18 & .09 & 2.08 & .0376 \\
\hline 16 & .05 & .07 & .62 & .5367 \\
\hline
\end{tabular}

Existen 2 ítems que presentan diferencia entre grupos de edad, los ítems 1 (Para mim, é importante não demonstrar nervosismo) y 9 (Quando o meu coração bate rápido, tenho medo de estar a ter um enfarte) (valores $p$ inferiores a .0031 (.05/16 ítems) correlación de Bonferroni); sin embargo, como las diferencias son inferiores a .50 logits, se considera que no tiene importancia sustantiva.

La figura 16 presenta las diferencias entre los parámetros de los ítems de los grupos etários para el índice de sensibilidad a la ansiedad. 


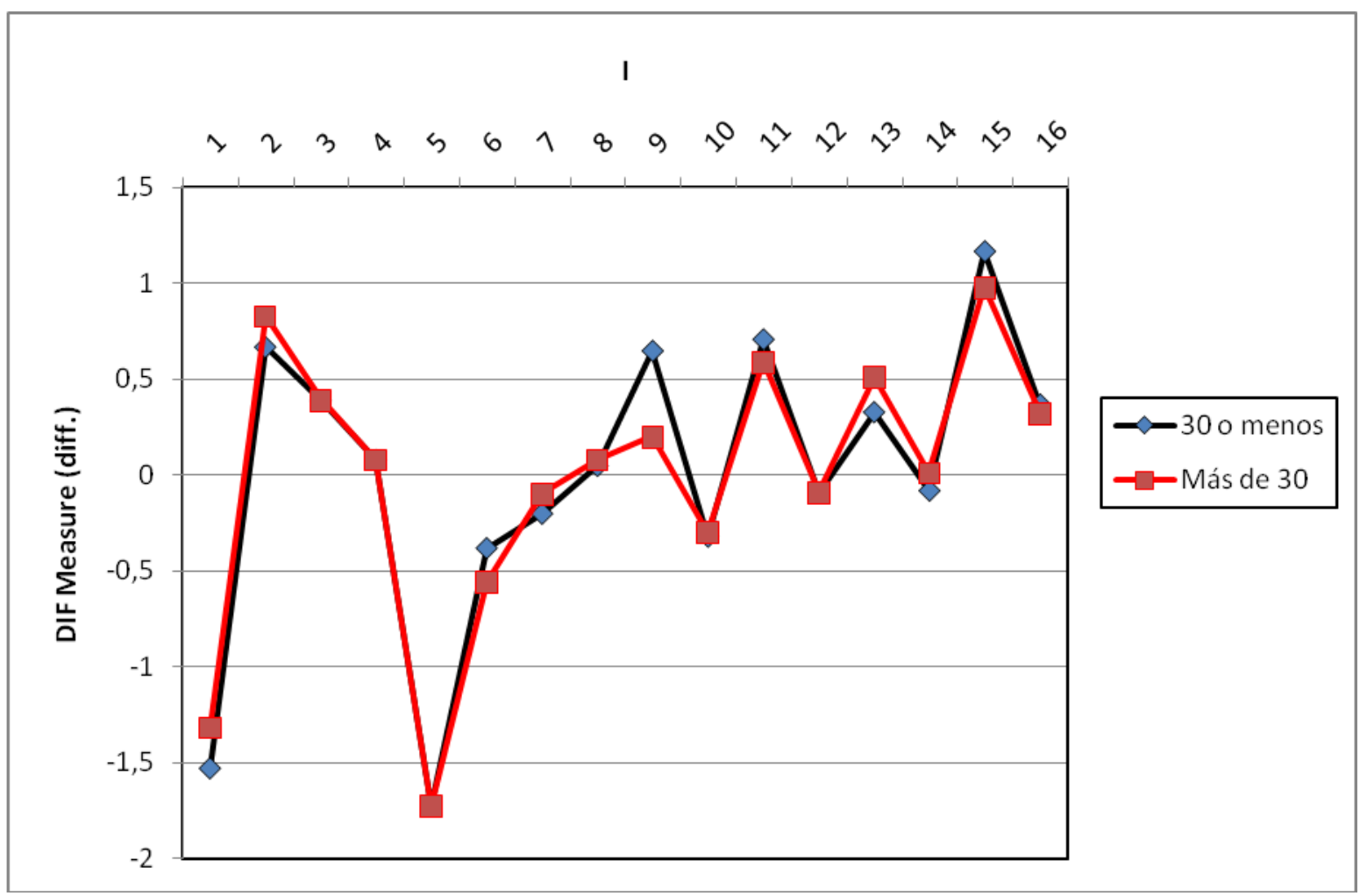

Figura 16 - Diferencias entre los parámetros de localización de los ítems de los grupos de edad para el ASI

En la tabla 46 se presenta la correspondencia entre las puntuaciones clásicas y los valores logit, con su error estándar, así como los baremos en percentiles y en puntuaciones típicas derivadas con su correspondiente error estándar (normed con media 500 y Desviación Típica 100) de cada puntuación directa. 
Tabla 46. Correspondencia entre las puntuaciones clásicas y los valores Rasch para el ASI

\begin{tabular}{|c|c|c|c|c|c|c|}
\hline Puntuación & Medida & SE & PT Derivada & SEPT & Frecuencia & Percentil \\
\hline 0 & $-5.42 \mathrm{E}$ & 1.82 & 174 & 141 & 47 & 2 \\
\hline 1 & -4.23 & .99 & 266 & 77 & 2 & 4 \\
\hline 2 & -3.54 & .70 & 319 & 54 & 12 & 5 \\
\hline 3 & -3.14 & .58 & 350 & 45 & 10 & 6 \\
\hline 4 & -2.84 & .51 & 373 & 39 & 28 & 7 \\
\hline 5 & -2.61 & .46 & 391 & 36 & 23 & 10 \\
\hline 6 & -2.41 & .43 & 406 & 33 & 31 & 12 \\
\hline 7 & -2.24 & .40 & 419 & 31 & 38 & 15 \\
\hline 8 & -2.09 & .38 & 431 & 29 & 33 & 18 \\
\hline 9 & -1.95 & .36 & 442 & 28 & 41 & 21 \\
\hline 10 & -1.82 & .35 & 452 & 27 & 37 & 24 \\
\hline 11 & -1.71 & .34 & 461 & 26 & 23 & 27 \\
\hline 12 & -1.60 & .33 & 469 & 25 & 39 & 30 \\
\hline 13 & -1.49 & .32 & 477 & 24 & 32 & 33 \\
\hline 14 & -1.40 & .31 & 485 & 24 & 39 & 36 \\
\hline 15 & -1.31 & .30 & 492 & 23 & 38 & 39 \\
\hline 16 & -1.22 & .29 & 499 & 23 & 41 & 43 \\
\hline 17 & -1.13 & .29 & 505 & 22 & 42 & 46 \\
\hline 18 & -1.05 & .28 & 511 & 22 & 40 & 50 \\
\hline 19 & -.97 & .28 & 517 & 22 & 41 & 53 \\
\hline 20 & -.90 & .27 & 523 & 21 & 27 & 56 \\
\hline 21 & -.82 & .27 & 529 & 21 & 37 & 59 \\
\hline 22 & -.75 & .27 & 535 & 21 & 27 & 62 \\
\hline 23 & -.68 & .27 & 540 & 21 & 32 & 64 \\
\hline
\end{tabular}


Tabla 46 (Cont.)

\begin{tabular}{|c|c|c|c|c|c|c|}
\hline Puntuación & Medida & SE & PT Derivada & SEPT & Frecuencia & Percentil \\
\hline 24 & -.61 & .26 & 546 & 20 & 34 & 67 \\
\hline 25 & -.54 & .26 & 551 & 20 & 37 & 70 \\
\hline 26 & -.47 & .26 & 556 & 20 & 21 & 73 \\
\hline 27 & -.41 & .26 & 561 & 20 & 27 & 75 \\
\hline 28 & -.34 & .26 & 567 & 20 & 21 & 77 \\
\hline 29 & -.27 & .26 & 572 & 20 & 20 & 78 \\
\hline 30 & -.20 & .26 & 577 & 20 & 26 & 80 \\
\hline 31 & -.14 & .26 & 582 & 20 & 13 & 82 \\
\hline 32 & -.07 & .26 & 587 & 20 & 24 & 84 \\
\hline 33 & .00 & .26 & 592 & 20 & 23 & 86 \\
\hline 34 & .06 & .26 & 598 & 20 & 23 & 88 \\
\hline 35 & .13 & .26 & 603 & 20 & 15 & 89 \\
\hline 36 & .20 & .26 & 608 & 20 & 9 & 90 \\
\hline 37 & .27 & .27 & 614 & 21 & 20 & 92 \\
\hline 38 & .34 & .27 & 619 & 21 & 12 & 93 \\
\hline 39 & .42 & .27 & 625 & 21 & 8 & 94 \\
\hline 40 & .49 & .27 & 631 & 21 & 8 & 95 \\
\hline 41 & .57 & .28 & 637 & 21 & 3 & 95 \\
\hline 42 & .64 & .28 & 643 & 22 & 11 & 96 \\
\hline 43 & .72 & .29 & 649 & 22 & 10 & 97 \\
\hline 44 & .81 & .29 & 655 & 22 & 8 & 97 \\
\hline 45 & .89 & .30 & 662 & 23 & 5 & 98 \\
\hline 46 & .98 & .30 & 669 & 23 & 6 & 98 \\
\hline 47 & 1.07 & .31 & 676 & 24 & 3 & 99 \\
\hline
\end{tabular}


Tabla 46 (Cont.)

\begin{tabular}{lcccccc}
\hline Puntuación & Medida & SE & PT Derivada & SEPT & Frecuencia & Percentil \\
\hline 48 & 1.17 & .31 & 683 & 24 & 5 & 99 \\
49 & 1.27 & .32 & 691 & 25 & 2 & 99 \\
50 & 1.38 & .33 & 699 & 26 & 3 & 99 \\
51 & 1.49 & .34 & 708 & 26 & 0 & 99 \\
52 & 1.61 & .35 & 717 & 27 & 0 & 99 \\
53 & 1.73 & .36 & 727 & 28 & 1 & 99 \\
54 & 1.87 & .37 & 737 & 29 & 0 & 99 \\
55 & 2.01 & .39 & 749 & 30 & 0 & 99 \\
56 & 2.17 & .41 & 761 & 32 & 2 & 99 \\
\hline
\end{tabular}




\subsection{Correlaciones con las puntuaciones del Modelo de Rasch}

En la Tabla 47 se muestran los coeficientes de correlación de Pearson entre las puntuaciones Rasch de las escalas utilizadas.

Tabla 47 - Correlaciones entre las puntuaciones Rasch de cada escala

\begin{tabular}{|c|c|c|c|c|}
\hline & $\mathrm{BAI}$ & STAI Estado & STAI Rasgo & Zung \\
\hline STAI Estado & $.59^{\star \star \star}$ & & & \\
\hline STAI Rasgo & $.55^{\star \star *}$ & $.77^{\star \star \star}$ & & \\
\hline Zung & $.42^{\star \star \star}$ & $.31^{* \star *}$ & $.32^{\star \star \star}$ & \\
\hline ASI & $.39^{* * *}$ & $.35^{\star \star \star}$ & $.43^{\star \star *}$ & $.48^{* * *}$ \\
\hline
\end{tabular}

El Bai se correlaciona de forma positiva y estadísticamente significativa con todas las otras escalas, con valores de correlación entre $r=.39 ; p<.001$ (ASI) y $r=.59 ; p<.001$ (STAI Estado). Los resultados mostraron que un valor más alto de ansiedad en el BAI corresponde a un valor más alto en todas las otras medidas de ansiedad y en la sensibilidad a la ansiedad.

EI STAI Estado se correlaciona de forma positiva y estadísticamente significativa con todas las otras escalas, con valores de correlación entre $r=35 ; p<.001$ (ASI) y $r=.77$; $\mathrm{p}<.001$ (STAI Rasgo). Los resultados mostraron que un valor más alto de ansiedad en el STAI Estado corresponde a un valor más alto en todas las otras medidas de ansiedad y en la sensibilidad a la ansiedad.

EI STAI Rasgo se correlaciona de forma positiva y estadísticamente significativa con la Zung y ASI, con valores de correlación entre $r=32 ; p<.001$ e $r=.43 ; p<.001$, 
respectivamente. Los resultados mostraron que un valor más alto de ansiedad en el STAI Rasgo corresponde a un valor más alto en todas las otras medidas de ansiedad y en la sensibilidad a la ansiedad.

La Zung se correlaciona de forma positiva y estadísticamente significativa con el ASI, con un valor de correlación de $r=48 ; p<.001$. Los resultados mostraron que un valor más alto de ansiedad en la Zung corresponde a un valor más alto en todas las otras medidas de ansiedad y en la sensibilidad a la ansiedad. 


\subsection{Análisis de Varianza Factorial con las puntuaciones del Modelo de Rasch}

En la Tabla 48 se muestran los resultados obtenidos a través de la ANOVA factorial por sexo y grupo de edad tomando como variable dependiente las puntuaciones del modelo de Rasch para cada escala utilizada.

Tabla 48 - Análisis de Varianza Factorial

\begin{tabular}{|c|c|c|c|c|c|c|c|c|c|c|c|}
\hline & \multicolumn{4}{|c|}{ Masculino } & \multicolumn{4}{|c|}{ Femenino } & \multirow{2}{*}{$\begin{array}{c}\mathrm{F} \\
\text { Sexo }\end{array}$} & \multirow{2}{*}{$\begin{array}{c}\mathrm{F} \\
\text { Edad }\end{array}$} & \multirow{2}{*}{$\begin{array}{c}\mathrm{F} \\
\text { Interac } \\
\text {-ción }\end{array}$} \\
\hline & $\mathrm{M}$ & DP & $M$ & DP & $M$ & DP & $\mathrm{M}$ & DP & & & \\
\hline $\mathrm{BAI}$ & 8.70 & 8.01 & 6.55 & 6.48 & 10.30 & 7.89 & 8.84 & 7.93 & $16.784^{\star \star \star}$ & $14.511^{* * *}$ & .517 \\
\hline STAI & 36.92 & 9.82 & 37.39 & 10.43 & 40.76 & 10.49 & 39.35 & 10.80 & $20.273^{\star \star \star}$ & .535 & 2.125 \\
\hline \multicolumn{12}{|l|}{ Esta- } \\
\hline \multicolumn{12}{|l|}{ do } \\
\hline STAI & 38.33 & 10.39 & 36.41 & 10.08 & 41.61 & 10.08 & 38.90 & 9.96 & $21.466^{\star \star \star}$ & $13.862^{* * *}$ & .415 \\
\hline \multicolumn{12}{|l|}{ Ras- } \\
\hline \multicolumn{12}{|l|}{ go } \\
\hline Zung & 34.49 & 5.97 & 34.29 & 5.6 & 36.01 & 6.22 & 35.21 & 5.49 & $11.728^{* * *}$ & 1.949 & .681 \\
\hline ASI & 18.13 & 10.50 & 19.01 & 12.15 & 20.19 & 11.86 & 19.75 & 11.69 & $3.839^{*}$ & .096 & .857 \\
\hline
\end{tabular}

Existe efecto principal del factor sexo en todas las medidas, con valores entre $\mathrm{F}(1$; $1156)=3.839 ; p=.050(\mathrm{ASI})$ y $\mathrm{F}(1 ; 1156)=21.466 ; \mathrm{p}<.001$ (STAI Rasgo), pero sólo existe efecto principal del factor edad (30 años o menos; más de 30 años) en el BAl y en el STAI rasgo, con valores de $F(1 ; 1156)=14.511 ; p<.001$ y $F(1 ; 1156)=14.511 ; p<.001$ (BAl), respectivamente. 
No existe efecto de interacción entre el sexo y los grupos de edad $(p>.05)$. De este modo, se realizó un análisis de varianza por cada una de las variables (sexo y edad) por separado.

En la Tabla 49 se muestran los resultados obtenidos a través del ANOVA por sexo tomando como variable dependiente las puntuaciones del modelo de Rasch para cada escala utilizada.

Tabla 49 - Análisis de Varianza Factorial por Sexo - puntuaciones Rasch

\begin{tabular}{|c|c|c|c|c|c|}
\hline & \multicolumn{4}{|c|}{ Sexo } & \multirow{3}{*}{$\mathrm{F}$} \\
\hline & \multicolumn{2}{|c|}{ Masculino } & \multicolumn{2}{|c|}{ Femenino } & \\
\hline & $\mathrm{M}$ & DP & $\mathrm{M}$ & DP & \\
\hline BAI & 7.69 & 7.41 & 9.40 & 7.94 & $13.028^{\star \star \star}$ \\
\hline STAI Estado & 37.14 & 10.10 & 39.89 & 10.70 & $18.611^{\star \star \star}$ \\
\hline STAI Rasgo & 37.43 & 10.28 & 39.93 & 10.84 & $16.314^{\star \star \star}$ \\
\hline Zung & 34.39 & 5.82 & 35.52 & 5.79 & $10.101^{\star *}$ \\
\hline ASI & 18.55 & 11.30 & 19.92 & 11.75 & 3.801 \\
\hline
\end{tabular}

Se encontraron diferencias estadísticamente significativas entre los géneros para el BAI con $F(1 ; 1158)=13.028 ; p<.001$, para el STAI Estado con $F(1 ; 1158)=18.611 ; p<.001$, para el STAI Rasgo con $F(1 ; 1158)=16.314 ; p<.001$ y para la Zung con $F(1 ; 1158)=$ 10.101; $p=.002$. Los resultados muestran que los participantes masculinos presentan menos ansiedad en todas las escalas de ansiedad, pero no hay diferencia entre los géneros para la sensibilidad a la ansiedad. 
En la Tabla 50 se presentan los resultados obtenidos a través del ANOVA por edad (30 años o menos; más de 30 años), tomando como variable dependiente las puntuaciones del modelo de Rasch para cada escala utilizada.

Tabla 50 - Análisis de Varianza Factorial por grupos de edad - puntuaciones Rasch

\begin{tabular}{|c|c|c|c|c|c|}
\hline & \multicolumn{4}{|c|}{ Grupos de Edad } & \multirow{3}{*}{$\mathrm{F}$} \\
\hline & \multicolumn{2}{|c|}{$\leq 30$ años } & \multicolumn{2}{|c|}{ > 30 años } & \\
\hline & $\mathrm{M}$ & DP & $\mathrm{M}$ & DP & \\
\hline BAI & 9.58 & 7.98 & 8.14 & 7.59 & $9.930^{\star *}$ \\
\hline STAI Estado & 39.04 & 10.36 & 38.75 & 10.72 & .213 \\
\hline STAI Rasgo & 40.14 & 10.34 & 38.14 & 10.05 & $11.044^{\star \star \star}$ \\
\hline Zung & 35.33 & 6.15 & 34.93 & 5.56 & 1.323 \\
\hline ASI & 19.27 & 11.31 & 19.53 & 11.83 & .142 \\
\hline
\end{tabular}

Sólo fueran encontradas diferencias estadísticamente significativas entre los grupos de edad para el BAI con $F(1 ; 1158)=9.930 ; p=.002$ y para el STAI Rasgo con $F(1 ; 1158)$ $=11.044 ; p=.001$. Los resultados muestran que los participantes más jóvenes presentan más ansiedad tanto midiendo con el BAI como con el STAI Rasgo.

Para analizar las mismas diferencias pero con las puntuaciones directas, las tablas 51 y 52 presentan los resultados de la ANOVA por sexo y por grupo de edad. 
Tabla 51 - Análisis de Varianza Factorial por sexo - puntuaciones directas

\begin{tabular}{|c|c|c|c|c|c|}
\hline & \multicolumn{4}{|c|}{ Sexo } & \multirow{3}{*}{$\mathrm{F}$} \\
\hline & \multicolumn{2}{|c|}{ Masculino } & \multicolumn{2}{|c|}{ Femenino } & \\
\hline & $\mathrm{M}$ & DP & $\mathrm{M}$ & DP & \\
\hline $\mathrm{BAI}$ & 7.69 & 7.40 & 9.40 & 7.94 & $13.028^{\star \star \star}$ \\
\hline STAI Estado & 37.17 & 10.07 & 39.89 & 10.70 & $18.207^{\star \star \star}$ \\
\hline STAI Rasgo & 37.43 & 10.28 & 39.93 & 10.08 & $16.314^{\star \star \star}$ \\
\hline Zung & 33.83 & 6.22 & 35.36 & 6.51 & $15.336^{\star * \star}$ \\
\hline ASI & 18.55 & 11.30 & 19.96 & 11.80 & $3.980^{*}$ \\
\hline
\end{tabular}

Se encontraron diferencias estadísticamente significativas entre los géneros para el BAI con $F(1 ; 1158)=13.028 ; p=.000$, para el STAI Estado con $F(1 ; 1158)=18.207$; $p<.001$, para el STAI Rasgo con $F(1 ; 1158)=16.314 ; p<.001$, para la Zung con $F(1 ; 1158)$ $=15.336 ; p<.001 \mathrm{y}$ para el ASI con $\mathrm{F}(1 ; 1158)=3.980 ; p=.046$. Los resultados muestran que los participantes masculinos presentan menos ansiedad en todas las escalas de ansiedad y en la sensibilidad a la ansiedad. 
Tabla 52 - Análisis de Varianza Factorial por grupos de edad - puntuaciones directas

\begin{tabular}{|c|c|c|c|c|c|}
\hline & \multicolumn{4}{|c|}{ Grupos de Edad } & \multirow{3}{*}{$\mathrm{F}$} \\
\hline & \multicolumn{2}{|c|}{$\leq 30$ años } & \multicolumn{2}{|c|}{$>30$ años } & \\
\hline & $M$ & DP & $\mathrm{M}$ & DP & \\
\hline $\mathrm{BAI}$ & 9.58 & 7.98 & 8.14 & 7.59 & $9.930^{\star *}$ \\
\hline STAI Estado & 39.07 & 10.33 & 38.75 & 10.72 & .256 \\
\hline STAI Rasgo & 40.14 & 10.34 & 38.14 & 10.05 & $11.044^{\star \star \star}$ \\
\hline Zung & 35.26 & 6.82 & 34.44 & 6.12 & $4.602^{\star *}$ \\
\hline ASI & 19.27 & 11.31 & 19.57 & 11.88 & .188 \\
\hline
\end{tabular}

Se encontraron diferencias estadísticamente significativas entre los grupos de edad para el BAI con $F(1 ; 1158)=9.930 ; p=.002$, para el STAI Rasgo con $F(1 ; 1158)=11.044$; $p=.001$ y para la Zung con $F(1 ; 1158)=4.602 ; p=.032$. Los resultados muestran que los participantes más jóvenes presentan más ansiedad tanto midiendo con el BAI, como con el STAI Rasgo y la Zung.

Para comprobar si la correlación de la edad (variable numérica) seguía el mismo patrón que la variable edad por grupos de edad dicotómicos, se analizó la correlación de la edad con los totales de todas las escalas utilizadas (puntuaciones Rasch). La Tabla 53 muestra los resultados obtenidos. 
Tabla 53. Correlaciones con la edad (puntuaciones Rasch)

\begin{tabular}{lc}
\hline & Edad \\
\hline BAI & $-.07^{*}$ \\
STAI Estado & -.01 \\
STAI Rasgo & $-.08^{* *}$ \\
Zung & -.01 \\
ASI & .02 \\
\hline${ }^{*} \mathrm{p} \leq .05 ;{ }^{* *} p \leq .01$. &
\end{tabular}

La edad se correlacionó de forma negativa, débil y estadísticamente significativa con el BAI y con el STAI Rasgo, con valores de correlación de $r=-.07 ; p=.028$ y $r=-.08$ : $p=$ .006, respectivamente. Los resultados muestran que cuanto más jóvenes son los participantes más ansiedad tienen, aunque la asociación es de tamaño muy pequeño. 
CAPÍTULO IX DISCUSIÓN 
El Inventario de Ansiedad de Beck es una escala ampliamente utilizada, con aceptables propiedades psicométricas de fiabilidad y validez, pero que no se utiliza para la investigación en Portugal, porque no hay ningún estudio de sus características psicométricas, o de validación en la población portuguesa.

Por lo tanto, se pretendió con este trabajo analizar las características psicométricas del Inventario de Ansiedad de Beck y compararlas con las características psicométricas de otras medidas de ansiedad validadas para la población portuguesa, y al mismo tiempo evaluar las relaciones existentes entre las diferentes escalas utilizadas.

Se ha utilizado un modelo psicométrico con óptimas propiedades (el Modelo de Escalas de Calificación), que, entre otras utilidades permite analizar el funcionamiento de las categorías tipo Likert propuestas por los autores de los instrumentos. Este aspecto no suele ser tomado en consideración por la Teoría Clásica de los Tests, dado que en ésta la determinación de las categorías se realiza a priori. De este modo, se pondrá a prueba la calidad Inventario de Ansiedad de Beck.

Por otro lado, de una forma indirecta, las amenazas a la validez del constructo son amenazas a la validez interna, pues hacen difícil separar las influencias causales (Delgado \& Prieto, 2008). El sexo y la edad pueden desempeñar un papel de contaminadores, convirtiéndose en amenazas a la validez interna.

Así, otro objetivo consistió en evaluar el funcionamiento diferencial de los ítems asociado al género y a la edad.

El carácter de esta investigación fue transversal, correlacional, y de análisis de las características psicométricas.

Como se ha indicado, los datos fueron analizados mediante el modelo de Escalas de Calificación (Wright \& Masters, 1982), una extensión para ítems dicotómicos del modelo de Rasch, que tiene excelentes propiedades métricas. 
Todos los análisis se llevaron a cabo mediante el programa Winsteps, y cuando se utilizó el SPSS los análisis se realizaron con las puntuaciones logits.

\subsection{Interpretación de los resultados obtenidos}

\subsubsection{Análisis del Inventario de ansiedad de Beck con el modelo de las escalas de calificación}

Fue objetivo de esta investigación analizar la calidad psicométrica de las categorías de respuesta del BAl; estimar los parámetros del modelo, analizar su precisión y el grado de ajuste de los datos de BAl; y poner a prueba la unidimensionalidad y la ausencia de Funcionamiento Diferencial de sus Ítems.

En términos globales, el BAI muestra ser una medida de ansiedad muy adecuada.

Su sistema de cuatro categorías es adecuado, dado que se cumplen los criterios propuestos por Linacre (2002). Así, el número de elecciones y su distribución son adecuados; no hay un desajuste elevado en ninguna categoría; los pasos están ordenados de forma creciente mostrando que las categorías de respuesta son funcionales en el sentido de que cada categoría es más probable en algún rango de variable; y hay una ordenación monotónica de las medidas B (Linacre, 2002).

En relación a los ítems del BAI, la fiabilidad es muy alta. De hecho, los errores típicos de medida de los ítems son muy bajos, lo que indica que la fiabilidad de los ítems es muy buena, según lo defendido por Smith y Smith (2004).

El ajuste de las personas al modelo es razonable. La fiabilidad global de las personas no es excelente, aunque resulta adecuada. Este valor es similar al a de Cronbach de la teoría clásica, pudiendo así decirse que está de acuerdo con los resultados de la fiabilidad clásica del BAI presentados en algunos estudios (Beck, Brown, Epstein, \& Steer, 1988; 
Cunha, 2001; Sanz \& Navarro, 2003), aunque sea más reducido que el que aparece en estos estudios, que presentan un valor $\alpha$ de Cronbach entre .86 a .88 (la fiabilidad global de las personas en la presente investigación ha sido de .79).

Sin embargo, como se puede ver en la validación del estudio brasileño del BAI (Cunha, 2001), es natural que la escala presente mayor fiabilidad en las muestras clínicas que en las no-clínicas.

Como la media de las personas es inferior a la de los ítems, se puede verificar que el nivel de ansiedad de los sujetos analizados es muy bajo y que la mayor parte de las personas se encuentran por debajo del rango de la variable en el que los ítems se sitúan. En conclusión, se observa que los ítems de la escala no permiten medir con alta precisión a las personas con niveles bajos de ansiedad, lo que sucede porque el nivel de las personas es bajo y la escala sólo tiene ítems situados en el rango superior del constructo.

De todos modos, la escala se diseñó para medir la intensidad de los síntomas de la ansiedad, especialmente síntomas fisiológicos (Beck, Brown, Epstein, \& Steer, 1988; Pérez \& Lago, 2000; Leyfer, Ruberg, \& Woodruff-Borden, 2006), luego, sería de esperar que no fuera fácil de distinguir a las personas sin síntomas fisiológicos de ansiedad o con pocos de éstos. En este sentido, Keedwell y Snaith (1996) confirman que el BAI es una de las escalas de evaluación clínica más utilizadas, aunque no es uno de los instrumentos de autoevaluación de la ansiedad más usados.

Así, para Leyfer y colegas (2006) que examinaron si el valor del BAl difería en pacientes con cinco diferentes diagnósticos de ansiedad y un grupo control sin ansiedad, los resultados del BAI difieren significativamente entre los participantes sin un diagnóstico y los participantes con algún diagnóstico de ansiedad. Sin embargo, el valor promedio de la escala es significativamente mayor para los participantes con diagnóstico de trastorno de pánico que para las personas con trastorno de ansiedad generalizada, fobia o sin diagnóstico. 
Estos resultados pueden deberse al hecho de que el BAI se ha creado no sólo para evaluar la ansiedad, sino para obtener medidas no contaminadas por los síntomas de la depresión, ya que excluye a los síntomas que se superponen a los de la depresión (Leyfer, et al., 2006). Así, es posible que los ítems que se superponen a los de la depresión sean los ítems que se situarían en el rango inferior del constructo, justificando la existencia de estos en el BAI.

Los datos muestran, igualmente, que la medida se adecúa a una dimensión básica, no habiendo amenaza a la validez de los resultados si es usada como un instrumento unidimensional.

Sin embargo, hay varios estudios que señalan la existencia de varios factores (Beck, et al., 1988; Beck \& Steer, 1990, 1991; Steer, Ranieri, Beck, \& Clarck, 1993; Cox, Cohen, Direnfeld y Swinson, 1996), aunque se trata de estudios hechos con muestras no clínicas.

Un análisis factorial confirmatorio conducido por Osman, Barrios, Aukes, Osman y Markway (1993) fue incapaz de generalizar el modelo de dos factores de Beck y colegas (1988) a una muestra no clínica. Sin embargo, cuando ellos condujeron un análisis de componentes, los ítems BAI saturaron en cuatro factores, que explicaron el $64.6 \%$ de la varianza total. Este dato puede deberse al método de extracción de factores empleado (criterio de Kaiser) que, como es sabido, sobrestima el número de dimensiones.

Otro estudio (Sanz \& Navarro, 2003) examinó las propiedades psicométricas de una versión española del Inventario de Ansiedad de Beck en una muestra de estudiantes universitarios españoles. Los análisis factoriales revelaron una dimensión de ansiedad general formada por dos factores muy interrelacionados, correspondientes a síntomas somáticos y afectivo-cognoscitivos.

Aunque varios estudios señalan la existencia de dos a cuatro factores, las muestras estudiadas proceden de poblaciones diversas, por lo que la generalización es arriesgada. Desde un punto de vista práctico, tratar un instrumento como unidimensional también tiene 
sentido cuando uno de los factores es claramente dominante o bien cuando existen varios factores muy correlacionados (i.e., un factor de segundo orden).

El género y la edad no se presentan como amenazas a la validez del BAI, pues sólo aparecen tres ítems que presentan funcionamiento diferencial asociado al sexo y tres ítems que presentan funcionamiento diferencial asociado a la edad. No obstante, el DIF no es notable en ningún ítem.

En lo que se refiere al impacto (diferencias en el constructo entre grupos de edad y géneros), los resultados manifiestan, igualmente, que no existe un efecto de interacción entre el sexo y los grupos de edad (30 ó menos años, o más de 30 años).

Sin embargo, los resultados muestran que los participantes masculinos presentan menos ansiedad evaluada por el BAl, lo que es coherente con lo mencionado en la literatura, que defiende que las mujeres tienen más ansiedad que los varones (Costello, et al., 2004; Muris \& Meesters, 2004; Abdel-Khalek \& Lester, 2006; Alansari, 2006; Altemus, 2006; Bekker \& Mens-Verhuslst, 2007; Grillon, 2008; Kohort \& Worthman, 2009).

Lo mismo ocurre en relación a la edad, dado que los participantes más jóvenes (con 30 ó menos años) presentan más ansiedad evaluada con el BAI. También estos resultados están en consonancia con la literatura, que defiende que la ansiedad es mayor en las personas jóvenes (Laurent \& Ettelson, 2001; Mesman \& Koot, 2001; Spence, Rapee, McDonald, \& Inaram, 2001; Merikangas \& Pine, 2002).

\subsubsection{Comparación de las puntuaciones del BAl con las de otros marcadores de la ansiedad empleados en Portugal: STAI Estado, STAI Rasgo, Zung y ASI.}

El BAI mostró una buena validez convergente, ya que presenta una correlación significativa con todas las medidas de ansiedad utilizadas (STAI Estado, STAI Rasgo y Zung) y con la medida de la sensibilidad a la ansiedad (ASI). 
Los resultados están de acuerdo con lo defendido por otros autores (Osman, Kopper, Barrios, Osman, \& Wade, 1997; Cunha, 2001; Citrón, Carter, Suchday, Sbrocco, \& Gray, 2005); sin embargo hay que destacar que, contrariamente a lo esperado, debido a que son los instrumentos con el mayor porcentaje de ítems con síntomas fisiológicos, la correlación entre el BAI y la escala de la ansiedad de Zung no es la más fuerte.

Para considerar relevantes las comparaciones del BAI con otros marcadores de la ansiedad, se analizó si éstos tenían una suficiente calidad. Por ello, fue un objetivo de este trabajo analizar la calidad psicométrica de las categorías de respuesta, estimar los parámetros del modelo y analizar su precisión y el grado de ajuste de los datos, y poner a prueba la unidimensionalidad y la ausencia de funcionamiento diferencial de los Ítems de los marcadores, comparados con el BAI.

Todas las escalas evaluadas muestran que el número de categorías de la versión utilizada es adecuado, cumpliendo todas ellas los criterios de Linacre (2002).

En las escalas BAI, STAI Estado y ASI no hay ítems que desajusten de forma severa, habiendo en todas las escalas usadas una fiabilidad de los ítems elevada (.99-1.00). También hay que señalar que las escala que presentan un mayor desajuste, aunque sea pequeño, son la escala de ansiedad de Zung (com el ítem 13 con un desajuste severo) y el STAI Rasgo (con el ítem 24 con un desajuste severo).

En cuanto al ajuste de las personas al modelo, se ha de concluir que es razonable en todas las medidas (en todos los casos el porcentaje de personas con severo desajuste es inferior al 10\%). Asímismo, la precisión con la que se estiman los parámetros de las personas es elevada: los valores de fiabilidad, que se corresponden con el valor de la consistencia interna de la Teoría Clásica de los Tests, oscilan entre .71 (Escala de Ansiedad de Zung) y .91 (STAI Estado y STAI Rasgo).

Se ha de notar que, aunque las medidas del BAI no tengan mayor fiabilidad (Person Separation Reliability) que los marcadores, sin embargo este instrumento presenta el 
porcentaje total más bajo de desajuste de los ítems al modelo y también el menor porcentaje de personas con alto desajuste.

Dado que la muestra analizada es no clínica, en todas las medidas de ansiedad y en el índice de sensibilidad a la ansiedad, la mayor parte de las personas se encuentran por debajo del rango de la variable en el que los ítems se sitúan. Así, ninguna permite medir con alta precisión a las personas con niveles bajos de ansiedad y de sensibilidad a la ansiedad. A pesar de esto, la Escala de Ansiedad de Zung tiene una representación conjunta de las personas e ítems un poco diferente de los demás, porque casi todas las personas se situaron en el mismo rango, cerca del valor promedio.

El Inventario de Ansiedad de Beck y el Índice de Sensibilidad a la Ansiedad son las escalas que más se adecúan a una estructura unidimensional. A pesar de que las otras escalas muestran menos evidencia de unidimensionalidad, es suficiente para que no existan problemas de validez de los resultados. En cuanto a la Escala de Ansiedad de Zung, aunque se adecua lo suficiente a una estructura unidimensional, es, de todos los marcadores evaluados, el que más se aparta de esta propiedad. Sin embargo, este desajuste no es suficiente para cuestionar la validez de los resultados y, por otro lado, como en la versión original el análisis factorial de esta escala muestra que varios factores estarían constituidos por muy pocos ítems, se optó por considerarla como unidimensional en este estudio. De esta forma, por razones práticas y dado que no se alejan mucho de los criterios, se han tratado todas las medidas como si fueran unidimensionales.

Tampoco el funcionamiento diferencial de los ítems asociado al género y la edad se muestra como una amenaza a la validez interna en ninguna escala. Únicamente se halló un ítem con DIF asociado a la edad en el STAI rasgo y otro en el STAI estado.

Cuando se estudió el impacto por género y por grupo de edad, sólo en el índice de sensibilidad a la ansiedad no se encontraron diferencias entre los géneros. En el resto de las escalas, las mujeres presentaron en promedio valores superiores en ansiedad. En relación a los grupos de edad, sólo se encontraron diferencias entre grupos en el Inventario de 
Ansiedad de Beck, en el STAI Rasgo y en la Zung (presentando los más jóvenes valores superiores de ansiedad). 


\subsection{Limitaciones de la investigación y sugerencias para futuros estudios}

Por último, se discuten las limitaciones de este estudio. Independientemente de la consistencia de los resultados obtenidos mediante el análisis de las propiedades psicométricas del Inventario de Ansiedad de Beck y de las otras medidas utilizadas, estos resultados presentan algunas limitaciones, especialmente en lo que respecta a la naturaleza de la muestra, no clínica, y la falta de resultados sobre la estabilidad temporal de la medida.

Así, aunque los resultados han apoyado el uso del Inventario de Ansiedad de Beck como una medida adecuada para la evaluación de la ansiedad en la población en general, el estudio de la relación entre la ansiedad y otras dimensiones psicológicas y de comportamiento puede conducir a resultados que justifiquen su uso clínico. De particular interés, dada su calidad, sería su uso en la investigación neuropsicológica.

No siendo el objetivo de este estudio, se sugiere, sin embargo, que en futuros estudios se realicen análisis de las propiedades psicométricas del Inventario de Ansiedad de Beck mediante modelos de Rasch en poblaciones clínicas.

Además, dado que la naturaleza transversal de este estudio no permite la interpretación de estos resultados en función de los aspectos del desarrollo de la ansiedad, se sugiere que los estudios futuros examinen longitudinalmente la continuidad de este constructo. Estos estudios deben examinar las diferencias entre grupos clínicos y no clínicos, relativamente homogéneos (mediante, por ejemplo, la equiparación de casos, dependiendo de las principales características socio-demográficas).

Sería interesante, también, que futuros estudios compararan el Inventario de Ansiedad de Beck con las otras medidas utilizadas en este estudio, el nivel de la comorbilidad de la ansiedad con otros trastornos y síntomas, como la depresión y el estrés, pues existe un estudio que informó que el Inventario de Ansiedad de Beck tiene una menor 
correlación con las escalas de depresión que otras escalas de ansiedad, como el STAI y la Zung (Beck, Brown, Epstein, \& Steer, 1988). 


\subsection{Principales contribuciones de la investigación}

Como se mencionó anteriormente, el Inventario de Ansiedad de Beck es una medida ampliamente utilizada en la investigación internacional, pero no se utiliza en Portugal por falta de evaluación de sus características psicométricas.

En Portugal, después de una búsqueda en bases de datos en Internet, las principales revistas portuguesas en el campo de la psicología y de la psiquiatría, se desprende que la medida más utilizada en términos de investigación sobre la ansiedad es el InEstado-Rasgo (STAI), que fue creado por Spielberger, Gorsuch y Lushene (1970). Sin embargo, existen algunos estudios que indican la existencia de lagunas en esta medida de investigación de la ansiedad. Las medidas originales de Rasgo y Estado del STAI han sido criticadas porque el STAI de Rasgo no evalúa la ansiedad pura, por su incapacidad para discriminar suficientemente entre los síntomas de ansiedad y depresión; sus propiedades psicométricas en poblaciones más jóvenes y menos cultas; y su estructura de dos factores de ansiedadpresente y ansiedad-ausente. A pesar de una revisión para tratar con algunas de estas preocupaciones (Spielberger, 1983), las críticas al STAI han continuado (Bieling, Antony y Swinson, 1998; Caci, Bayle, Dossios, Robert, \& Boyer, 2003; Fioravanti, Santos, Maisonette, Cruz, \& Landeira-Fernández, 2006).

Así, la mayor aportación de esta investigación consiste en permitir que la investigación futura en Portugal utilice el BAI como una herramienta para la evaluación de la ansiedad, como constructo en general. Esto es de gran importancia, ya que la ansiedad se ha asociado con un mayor riesgo para contraer otras enfermedades, y desempeña un papel importante en la calidad de vida en general, así como en relación a la capacidad para conducirse en la vida diaria normal. Además, los trastornos de ansiedad implican elevados costes individuales y sociales, tienden a ser crónicos, y pueden ser tan incapacitantes como los trastornos somáticos (Lepine, 2002). Además, los trastornos de ansiedad representan un 
coste significativo para el sistema de salud, así como para los empleadores a través de beneficios y cobertura de los días perdidos por incapacidad. En comparación con quienes sufren otros trastornos psiquiátricos, las personas con trastornos de ansiedad recurren con más frecuencia a los médicos generalistas que a los profesionales psiquiátricos, provocando una tensión en el sistema de atención de salud y/o en los planes privados de seguro. Los costes económicos de los trastornos de ansiedad incluyen costes psiquiátricos y atención de emergencia no psiquiátricas, hospitalización, medicamentos recetados, reducción de la productividad; el absentismo laboral, y el suicidio (Cooley, et al., 2009;Lepine, 2002).

Así, es urgente implementar medios adecuados para realizar buena investigación, lo que es una condición necesaria para que existan planes de prevención y de intervención eficaces.

En resumen, los resultados obtenidos en este estudio muestran que, en general, el Inventario de Ansiedad de Beck es una escala con buenas características psicométricas, y en algunos contextos más apropiada que otras escalas más utilizadas en Portugal, por ejemplo en las investigaciones de cariz más clínico, en que los síntomas fisiológicos son importantes. Su uso en la investigación neuropsicológica es también deseable, tanto para caracterizar a los pacientes cuyo daño cerebral pudiera estar asociado a la ansiedad, como para profundizar en la investigación de las bases neuropsicológicas de la ansiedad en países de habla portuguesa.

Con el análisis de sus características psicométricas en la población portuguesa de adultos, esperamos haber contribuido de forma positiva a la futura investigación sobre la ansiedad en Portugal. 


\section{REFERENCIAS BIBLIOGRÁFICAS}


Abdel-Khalek, A. M., \& Lester, D. (2006). Anxiety in Kuwaiti and American college students. Psychological Reports, 99, 512-514.

Akirav, I., \& Maroun, M. (2007) The role of the medial prefrontal cortex-amygdala circuit in stress effects on the extinction of fear. Neural Plasticity, 30873.

Alansari, B. M. (2006). Gender differences in anxiety among undergraduates from sixteen islamic countries. Social Behavior and Personality, 34, 651-659.

Alheid, G.F. (2003) Extended amygdala and basal forebrain. Annals of the New York Academy of Sciences, 985, 185-205.

Alonso, J., Angermeyer, M. C., Bernert, S., Bruffaerts, R., Brugha, T. S., Bryson, H., et al. (2004). Prevalence of mental disorders in Europe: results from de European study of epidemiology of mental disorders (ESEMeD) project. Acta Psychiatrica Scandinavica, 109, 21-27.

Altemus, M. (2006). Sex differences in depression and anxiety disorders: Potencial biological determinants. Hormones and Behavior, 50, 534-538.

Altemus, M., Redwine, L., Leong, Y. M., Yoshikawa, T., Yehuda, R., Detera-Wadleigh, S., \& Murphy, D. L. (1997). Reduced sensitivity to glucorticoid feedback and reduced glucocorticoid receptor mRNA expression in the luteal phase of the menstrual cycle. Neuropsychopharmacology, 17, 100-109.

Alves, G., Carvalho, M., \& Baptista, A. (1999). Estudo das características de uma escala de depressão, ansiedade e stress em jovens adultos. In A. P. Soares, S. Araújo, \& S. Caires (Eds.)., Avaliação psicológica: Formas e contextos. (pp. 267-275). Braga: APPORT.

American Psychiatric Association. (2002). DSM-IV-TR. Manual de diagnóstico e estatística das perturbações mentais. Lisboa: Climepsi Editores.

Andlin-Sobocki, P., \& Wittchen, H. U. (2005). Cost of anxiety disorders in Europe. European Journal of Neurology, 12, 39-44. 
Andrade, L. H. S. G., \& Gorenstein, C. (1998). Aspectos gerais das escalas de avaliação de ansiedade. Revista de PsiquiatriaClínica, 67, 285-290.

Andrich, D. A. (1978). A rating formulation for ordered response categories. Psychometrika, 43, 561-573.

Ansorge, M. S., Zhou, M., Lira, A., Hen, R., \& Gingrich, J. A. (2004). Early-life blockade of the 5-HT transporter alters emotional behavior in adult mice. Science, 306, 879-881.

Apóstolo, J. L. A., Mendes, A. C., \& Azeredo, I . A. (2006). Adaptation to portuguese of the depression, anxiety and stress scales (DASS). Revista Latino-Americana de Enfermagem, 6, 863-871.

Apóstolo, J., Ventura, A., Caetano, C, \& Costa, S. (2008). Depressão, ansiedade e stress em utentes de cuidados de saúde primários. Referência, 8, 45-49.

Armony, J. L., Corbo, V., Clement, M-H., \& Brunet, A. (2005). Amygdala response in pations with acute PTSD to masked and unmasked emotional facial expressions. American Journal of Psychiatry, 10, 1961-1963.

Auerbach, S. M., \& Gramling, S. E. (1998). Stress management psychological foundations. New Jersey: Prentice Hall, Inc.

Avenevoli, S., Stolar, M., Li, J., Dierker, L., \& Merikangas, K. R. (2001). Comorbidity of depression in children and adolescents: Models and evidence form a prospective high-risk study. Biological Psychiatry,49, 1071-1081.

Balestrieri, M., Isola, M., Quartaroli, M., Roncolato, M., \& Bellantuono, C. (2010). Assessing mixed anxiety-depressive disorder. A national primary care survey. Psychiatry Research, 176, 197-201.

Bannerman, D. M., Rawlins, J. N. P., McHugh, S. B., Deacon, R. M. J., Yee, B. K., \& Bast, T. (2004). Regional dissociations within the hippocampus-memory and anxiety. Neuroscience \& Biobehavioral Reviews, 28, 273-283. 
Banich, M. T. (2003). Interaction between the hemispheres and its implications for the processing capacity of the brain. In K. Hugdahl \& R. J. Davidson (Eds.), The asymmetrical brain (pp. 261-302). Cambridge, MA: MIT Press.

Baptista, A. (1993). A génese da perturbação de pânico - a importância dos factores familiares e ambientais durante a infância e adolescência. Tese de doutoramento não publicada, Instituto de Ciências Biomédicas Abel Salazar, Porto.

Baptista, A. (2000). Perturbações do medo e da Ansiedade: Uma perspectiva evolutiva e desenvolvimental. In I. Soares (Ed.) Psicopatologia do Desenvolvimento: Trajectórias adaptativas ao longo da vida (pp. 89-141). Coimbra: quarteto Editora.

Bar-Haim, Y., Lamy, D., Pergamin, L., Bakermans-Kranenburg, M. J., \& van ljzendoorn, M. H. (2007). Threat-related attentional bias in anxious and nonanxious individuals: A meta-analytic study. Psychological Bulletin, 133, 1-24.

Barlow, D. H. (1988). Anxiety and its disorders. New York: The Guilford Press.

Barnes, L. L. B., Harp, D., \& Jung, W. S. (2002). Reliability generalization of scores on the Spielberger state-trait anxiety inventory. Educational and Psychological Measurement, 62, 603-618.

Barr, C. S., Newman, T. K., Becker, M. L., Parker, C. C., Champoux, M., et al. (2003). The utility of the non-human primate; model for studying gene by environment interactions in behavioral research. Genes, Brain and Behavior, 2, 336-40

Beck, A. T. (1967). Depression: Causes and treatment. Philadelphia: University of Pennsylvania Press.

Beck, A. T. (1976). Cognitive therapy of the emocional disorders. New York: New Amkerican Library.

Beck, A. T. (1985). Theoretical perspectives on clinical anxiety. In A. H. Tuma \& J. D. Maser (Eds.), Panic: Psychological perspectivas. Hillsdale, NJ: Erlbaum.

Beck, A.T., Brown, G., Epstein, N., \& Steer, R.A. (1988). An Inventory for Measuring Clinical Anxiety. Journal of Consulting and Clinical Psychology, 56, 893-897. 
Beck, A. T., Brown, G., Steer, R., Eidelson, J. I., \& Riskind, J. H. (1987). Differentiating anxiety and depression: A test of the content-specificity hypothesis. Journal of Abnormal Psychology, 96, 179-183.

Beck, A. T., \& Clark, D. A. (1997). An information processing model of anxiety: Automatic and strategic processes. Behavior Research and Therapy, 35, 49-58.

Beck, A. T., \& Emery, G. (1985). Anxiety disorders and phobias: A cognitive perspective. New York: Basic Books.

Beck, A. T., Emery, G., \& Greenberg, R. L. (1985). Anxiety disorders and phobias: A cognitive perspective. New York: Basic Books.

Beck, A. T., \& Steer, R. A. (1990). Manual for the Beck anxiety inventory. San Antonio, TX: Psychological Corporation.

Beck, A. T., \& Steer, R. A. (1991). Relationship between the Beck anxiety inventory and the Hamilton anxiety rating scale with anxious outpatients. Journal of Anxiety Disorders, $5,213-223$.

Beck, A. T., \& Steer, R. A. (1993). Beck anxiety inventory. Manual. San Antonio, TX: Psychological Corporation.

Beck, T., Steer, R. A., \& Garbin, M. G. (1988). Psychometric properties of the beck depression inventory: Twenty-five years of evaluation. Clinical Psychology Review, 8, 77-100.

Beesdo, K., Lau, J. Y. F., Guyer, A. E., McClure-Tone, E. B., Monk, C. S., Nelson, E. E., et al. (2009). Common and distinct amygdale-function perturbations in depressed vs anxious adolescents. Archives of General Psychiatry, 3, 275-285.

Bekker, M. H. J., \& Mens-Verhulst, J. (2007). Anxiety disorders: sex differences in prevalence, degree, and background, but gender-neutral treatment. Gender Medicine, 4, 178-193.

Bennett, P. (2002). Introdução clínica à psicologia da saúde. Lisboa: Climepsi Editores. 
Bernstein, D. A. (1981). Anxiety Management. In W. E. Craighead, A. E. Kazdin, \& M. J. Mahoney (Eds.) Behavior Modification. Principles, issues, and applications (pp. 205222). Boston: Houghton Mifflin Company.

Bernstein, A., Zvolensky, M. J., Schmidt, N. B., Forsyth, J. P., Feldner, M. T., Leen-Feldner, E. W., et al. (2007). Taxonometric and factor analytic models of anxiety sensivity: Integrating approaches to latent structural research. Psychological Assessment, 1, 74-87.

Bernstein, A., Zvolensky, M. J., Stewart, S. H., Comeau, M. N., \& Leen-Felder, E.W. (2006). Anxiety sensitivity taxonicity across gender among youth. Behaviour Research and Therapy, 5, 679-698.

Bertoglio, L. J., Joca, S. L., \& Guimarães, F. S. (2006). Further evidence that anxiety and memory are regionally dissociated within the hippocampus. Behavioural Brain Research, 175, 183-188.

Bessa, J.M., Oliveira, M., Cerqueira, J.J., Almeida, O.F., \& Sousa, N. (2005) Age-related qualitative shift in emotional behaviour: paradoxical findings after re-exposure of rats in the elevated-plus maze. Behavioral Brain Research, 162, 135-142.

Biederman, J., Hirshfeld-Becker, D. R., Rosenbaum, J. F., Friedman, D., Snidman, N., Kagan, J., et al. (2001). Further evidence of association between behavioral inhibition and social anxiety in children. American Journal of Psychiatry, 158, 1673-1679.

Bieling, P. J., Antony, M. M., \& Swinson, R. P. (1998). The state-trait anxiety inventory, trait version: structure and content re-examined. Behaviour Research and Therapy, 36, 777-788.

Bishop, S.J. (2007). Neurocognitive mechanisms of anxiety: an integrative account. Trends in Cognitive Sciences, 11, 307-316.

Bond, T. G., \& Fox, C. M. (2001). Applying the Rasch model. Mahwah, NJ: LEA.

Bondi, C.O., Rodriguez, G., Gould, G.G., Frazer, A., \& Morilak, D.A. (2007). Chronic unpredictable stress induces a cognitive deficit and anxiety-like behavior in rats that is 
prevented by chronic antidepressant drug treatment. Neuropsychopharmacology, 33, 320-331.

Borkovec, T. D., Alcaine, O. M., \& Behar, E. (2004). Avoidance theory of worry and generalized anxiety disorder. In R. G. Heimberg, C. L. Turk, \& D. S. Mennin (Eds.), Generalized anxiety disorder: Advances in research and practice (pp. 77-108). New York: Guilford Press.

Bosquet, M., \& Egeland, B. (2006). The development and maintenance of anxiety symptoms from infancy through adolescence in a longitudinal sample. Development and Psychopathology, 18, 517-550.

Bowlby, J. (1973). Attachment and loss (vol II). New York: Basic Books.

Brown, T. A., Chorpita, B. F., \& Barlow, D. H. (1998). Structural relationships among dimensions of the DSM-IV anxiety and mood disorder and dimensions of negative affect, positive affect, and autonomic arousal. Journal of Abnormal Psychology, 107, 179-192.

Brown, T. A., Di Nardo, P. A., \& Barlow, D. H. (1994). Anxiety disorders interview schedule for DSM-IV. Clinician's manual. New York: Graywind Publications Incorporated.

Burns, D. D., \& Eidelson, R. J. (1998). Why are depression and anxiety correlated? A test of the tripartite model. Journal of Consulting and Clinical Psychology, 66, 461-473.

Caci, H., Bayle, F. J., Dossios, C., Robert, P., \& Boyer, P. (2003). The Spielberger trait anxiety inventory measures more than anxiety. European Psychiatry, 18, 394-400.

Calvo, M., \& Cano-Vindel, A. (1997). The nature of trait anxiety: Cognitive and biological vulnerability. European Psychologist, 4, 301-312.

Calvo, M. G., \& González, M. D., G. (2000). Ansiedad y cognición: un marco integrado. Revista Espanola de Motivación y Emoción, 1, 67-118.

Campbell, S. B. (1986). Developmental issues in childhood anxiety. In Gittelman (Eds.). Anxiety disorders in childhood. New York: John Wiley. 
Campbell-Sills, L., Barlow, D. H., Brown, T. A., \& Hofmann, S. G. (2006). Acceptability and suppression of negative emotion in anxiety and mood disorders. Emotion, 6, 587-595.

Cardoso, S. M. (2005). Validação e aferição da escala de ansiedade - Endler multidimensional anxiety scales (EMAS) em adolescentes portugueses - Portugal continental. Saúde Pública, 7.

Carpenito, L. J. (1997). Diagnóstico de Enfermagem: Aplicação à prática clínica. Porto Alegre: Arte Médica.

Castro-Sierra, E., León, F. C. P., Domíngues, L. F. G., \& Riviera, A. P. (2007). Neurotransmissors del sistema límbico. Hipocampo. GABA y memoria. Segunda parte. Salud Mental, 5, 47-54.

Cattell, R.B., \& Scheier, I.H. (1961). The Meaning and Measurement of Neuroticism and Anxiety. New York: Ronald Press.

Charney, D. S. (2003). Neuroanatomical circuits modulating fear and anxiety behaviors. Acta Psychiatrica Scandinavica, 108, 38-50.

Choi, D.C., Furay, A.R., Evanson, N.K., Ostrander, M.M., Ulrich-Lai, Y.M., \& Herman, J.P. (2007). Bed nucleus of the stria terminalis subregions differentially regulate hypothalamicpituitary-adrenal axis activity: implications for the integration of limbic inputs. The Journal of Neuroscience, 27, 2025-2034.

Chorpita, B. F., Albano, A. M., \& Barlow, D. H. (1998). The structure of negative emotions in a clinical simple of children and adolescents. Journal of Abnormal Psychology, 107, 74-85.

Chorpita, B. F., Plummer, C. M., \& Moffitt, C. E. (2000). Relations of tripartite dimensions of emotion to childhood anxiety and mood disorders. Journal of Abnormal Child Psychology, 28, 299-310.

Citrón, J. A., Carter, M. M., Suchday, S., Sbrocco, T., \& Gray, J. (2005). Factor structure and construct validity of the anxiety sensivity index among island puerto ricans. Journal of Anxiety Disorders, 19, 51-68. 
Claghorn, J. (1970). The anxiety-depression syndrome. Psychosomatics, 11, 438-441.

Clark, D. A. (1986). Cognitive-affective interaction: A test of the "specificity" and "generality" hypotheses. Cognitive Therapy and Research, 10, 607-623.

Clark, D. A., Beck, A. T., \& Brown, G. (1989). Cognitive mediation in general psychiatric outpatients: A test of the content-specificity hypothesis. Journal of Personality and Social Psychology, 56, 938-964.

Clark, I. A., \& Watson, D. (1991). Tripartite model of anxiety and depression: Psychometric evidence and taxonomic implications. Journal of Abnormal Psychology, 100, 316-336.

Clark, D. A., Steer, R. A., \& Beck, A. T. (1994). Commom and specific dimensions of selfreported anxiety and depression: implications for the cognitive and tripartite models. Journal of Abnormal Psychology, 103, 645-654.

Clarke, P., MacLeod, C., \& Shirazee, N. (2008). Prepared for the worst: Readiness to acquire threat bias ans susceptibility to elevate trait anxiety. Emotion, 1, 47-57.

Cloninger, C. R. (1986). A unified biosocial theory of personality and its role in the development of anxiety status. Psychiatric Developments, 5, 167-226.

Coan, J. A., \& Allen, J. J. B. (2003). The state and trait nature of frontal EEG asymmetry in emotion. In K. Hugdahl, \& R. J. Davidson (Eds.), The asymmetrical brain (pp. 565615). Cambridge, MA: MIT Press.

Compton, R. J., Carp, J., Chaddock, L., Fineman, S. L., Quandt, L. C., \& Ratlift, J. B. (2008). Trouble crossing the bridge: altered interhemispheric communication of emotional images in anxiety. Emotion, 5, 684-692.

Compton, R. J., Wilson, K., \& Wolf, K. (2004). Mind the gap: Interhemispheric communication about emotional faces. Emotion, 4, 219-232.

Conrad, C. R., Magarinos, A. M., LeDoux, J. E., \& McEwen, B. S. (1999). Repeated restraint stress facilitates fear conditioning, independently of causing hippocampal CA3 dendritic atrophy. Behaviour Neuroscience, 113, 902-913. 
Cook, J.M., Orvaschel, H., Simco, E., Hersen, M., \& Joiner, T. (2004). A testo f the tripartite modelo f depression and anxiety in older adult psychiatric outpatients. Psychology and Aging, 3, 444-451.

Cooley, K., Szczurko, O., Perri, D., Mills, E. J., Bernhardt, B., Zhou, Q., \& Slely, D. (2009). Naturopathic care for anxiety: a randomized controlled trial ISRCTN78958974. PLoS One, 4, e6628.

Costello, E. J., Egger, H. L., \& Angold, A. (2004). Developmental epidemiology of anxiety disorders. In T. H. Ollendick \& J. S. March (Eds.), Phobic and anxiety disorders in children and adolescents (pp. 61-91). New Cork: Oxford University Press.

Costello, E. J., Mustillo, S., Erkanli, A., Keeler, G., \& Angold, A. (2003). Prevalence and development of psychiatric disorders in childhood and adolescence. Archives of General Psychiatry, 60, 837-844.

Cox, B. J. (1996). The nature and assessment of catastrophic thoughts in panic disorder. Behaviour Research and Therapy, 34, 363-374.

Cox, B. J., Cohen, E., Direnfeld, D. M., \& Swinson, R. P. (1996). Does the Beck anxiety inventory measure anything beyond panic attack symptoms? Behavior Research and Therapy, 34, 949-961.

Craig, A. D. (2005). Forebrain emotional asymmetry: A neuroanatomical basis? Trends in Cognitive Sciences, 9, 566-571.

Crawley, J. N. (2000). What's wrong with my mouse? Behavioral phenotyping of transgenic and knockout mice. New York:Wiley-Liss.

Creamer, M., Foran, J., \& Bell, R. (1995). The beck anxiety inventory in a non-clinical sample. Behaviour Research and Therapy, 33, 477-485.

Cruz, M. A. C. (2008). Ansiedade e bem-estar na transição para o ensino superior: o papel do suporte social. Dissertação apresentada à Faculdade de Psicologia e de Ciências da Educação da Universidade do Porto, para obtenção do grau de Mestre em 
Psicologia da Saúde, orientada por Anne Marie Fontaine, Porto. Retirado em 23, Outubro, 2009, de http://hdl.handle.net/10216/10820.

Cunha, J. A. (2001). Manual da versão em português das escalas beck. São Paulo: Casa do Psicólogo.

Cunha, C., Monfils, M-H., \& LeDoux, J. E. (2010). GABAc receptores in the lateral amygdala: a possible novel target fotr the treatment of fear and anxiety disorders? Frontiers in Behavioral Neuroscience, 4, 1-9.

Dalton, K. M., Kalin, N. H., Grist, T. M., \& Davidson, R. J. (2005). Neural-cardiac coupling in threat-evoked anxiety. Journal of Cognitive Neuroscience, 17, 969-980.

Darwin, C. (1872). The expresión of emotions in man and animals. Oxford: Oxford University Press.

De Graaf, R., Bijl, R. V., Have, M., Beekman, A. T., \& Vollebergh, W. A. (2004). Pathways to comorbidity: The transition of pure mood, anxiety and substance use disorders into comorbid conditions in a longitudinal population-based study. Journal of Affective Disorders, 82, 461-467.

De Olmos, J.S., Beltramino, C.A., \& Alheid, G. (2004). Amygdala and extended amygdala of the rat: a cytoarchitectonical, fibroarchitectonical and chemoarchitectonical survey. In Paxinos, G. (Ed.). The Rat Nervous System. Amsterdam: Elsevier.

Dehon, C., Weems, C. F., Stickle, T. R., Costa, N. M., \& Berman, S. L. (2005). A cross sectional evaluation of factorial invariance of anxiety sensitivity in adolescents and young adults. Behavior Research and Therapy, 6, 799-810.

Delgado, A.R. \& Prieto, G. (2008). Stereotype Threat as Validity Threat: The Anxiety-SexThreat Interaction. Intelligence, 36, 635-640.

Dell'Osso, L., Rucci, P., Ducci, F., Ciapparelli, A., Vivarelli, L., Carlini, M., et al. (2003). Social anxiety spectrum. European Archives of Psychiatry and Clinical Neuroscience, 253, 286-291. 
Derogatis, L.R., \& Lazarus, L. (1994). SCL-90-R, brief symptom inventory and matching clinical rating scales. In M. E. Marnish (Ed.). The use of psychological testing for treatment planning and outcome assessment. UK: Erlbaum.

Deacon, B. J., Abramowitz, J. S., Woods, C. M., \& Tolin, D. F. (2003). The anxiety sensitivity index — revised: Psychometric properties and factor structure in two nonclinical samples. Behaviour Research and Therapy, 12, 1427-1449.

Dong, H.W., Petrovich, G.D., \& Swanson, L.W. (2001) Topography of projections from amygdale to bed nuclei of the stria terminalis. Brain Research Reviews, 38, 192-246.

Dong, H.W., \& Swanson, L.W. (2004) Organization of axonal projections from the anterolateral area of the bed nuclei of the stria terminalis. The Journal of Comparative Neurology, 468, 277-298.

Dong, H.W., \& Swanson, L.W. (2006) Projections from bed nuclei of the stria terminalis, anteromedial area: cerebral hemisphere integration of neuroendocrine, autonomic, and behavioral aspects of energy balance. The Journal of Comparative Neurology, 494, $142-178$.

Downing, R. W., \& Rickels, K. (1974). Mixed anxiety-depression: Fact or myth? Archives of General Psychiatry, 30, 312-317.

Draba, R. E. (1977). The identification and interpretation of item bias. MESA Memorando, 25, $1-6$.

Dunn, A. J., Swiergiel, A. H. (1999). Behavioral responses to stress are intact in CRFdeficient mice. Brain Research, 1, 14-20.

Eley, T. C., \& Gregory, A. M. (2004). Behavioral genetics. In T. L. Morris, \& J. S. March (Eds.), Anxiety disorders in children and adolescents (pp. 71-97). New York: Guildford Press.

Eley, T. C., \& Stevenson, J. (1999). Exploring the covariation between anxiety and depression symptoms: a genetic analysis of the effects of age and sex. Journal of Child Psychology and Psychiatry, 40, 1273-1282. 
Endler, N. S. (1986). A process analysis of state and trait anxiety in an exam situation. Toronto: York University.

Endler, N.S., Cox, B.J., Parker, J.D.A., \& Bagby, R.M (1992). Self-Reports of Depression and Stait-Trait Anxiety: Evidence for Differential Assessment. Journal of Personality and Social Psychology, 63, 832-838.

Endler, N.S., Edwards, J.M., \& Vitelli, R. (1991). Endler Multidimentional Anxiety Scales (EMAS). Manual. Los Angeles: Western Psychological Services.

Engels, A. S., Heller, W., Mohanty, A., Herrington, J. D., Banich, M. T., Webb, A. G., et al. (2007). Specificity of regional brain activity in anxiety types during emotion processing. Psychophysiology, 44, 352-363.

Epperson, C. N., Haga, K., Mason, G. F., Sellers, E., Gucorguieva, R., Zhang, W., et al. (2002). Cortical gamma-aminobutyric acid levels across the menstrual cycle in healthy women and those with premenstrual dysphoric disorder: a proton magnetic resonance spectroscopy study. Archives of General Psychiatry, 59, 851-858.

Espejo, E. P., Hammen, C. L., Connolly, N. P., Brennan, P. A., Najman, J. M., \& Bor, W. (2006). Stress sensitization and adolescent depressive severity as a function of childhood adversity: A link to anxiety disorders. Journal of Abdormal Child Psychology, 303, 1-13.

Eysenck, H. J. (1967). The biological basis of personality. Springfield, IL: Charles C. Thomas.

Eysenck, H. J. (1981). A model for personality. New York: Springer-Verlag.

Eysenck, H. J., \& Eysenck, S.B.G. (1964). Manual of the Eysenck Personality Inventory. London: University of London Press.

Eysenk, M. W. (1992). Anxiety: The cognitive perspective. Hove, UK: Erlbaum.

Eysenck, M. W. (1997). Anxiety and cognition: A unified theory. Hove, UK: Psychology Press. 
Eysenck, M. W., Santos, R., Derakshan, N., \& Calvo, M. G. (2007). Anxiety and cognitive performance: attentional control theory. Emotion, 2, 336-353.

Farmer, A., Mahmood, A., Redman, K., Harris, T., Sadler, S., \& McGuffin, P. (2003). A sibpair study of the temperament and character inventory scales in major depression. Archives of General Psychiatry, 5, 490-496.

Fioravanti, A. C. M., Santos, L. F., Maisonette, S., Cruz, A. P. M., \& Landeira-Fernandez, J. (2006). Avaliação da estrutura factorial da escala de ansiedade-traço do IDATE. Avaliação Psicológica, 2, 217-224.

Flannery-Schroeder, E. C., \& Kendall, P. C. (2000). Group and individual cognitivebehavioral treatments for youth with anxiety disorders: a randomized clinical trial. Cognitive Therapy and Research, 24, 251-278.

Foot, M., \& Koszycki, D. (2004). Gender differences in anxiety-related traits in patients with panic disorder. Depression and Anxiety, 3, 123-130.

Freud, S. (1924). Collected papers, Vol. 1. London: Hogarth Press.

Freud, S. (1936). The problem of anxiety. New York: The Psychoanalytic Quarterly Press Broadway and W. W. Norton \& Company.

Fuchs, E., Flugge, G., \& Czeh, B. (2006). Remodeling of neuronal networks by stress. Frontiers in Bioscience, 11, 2746-2758.

Galea, L. M., McEwen, B. S., Tanapat, P., Deak, T., Spencer, R. L., \& Dhabhar, E. S. (1997). Sex differences in dendritic atrophy of CA3 pyramidal neurons in response to chronic restraint stress. Neuroscience, 81, 689-697.

Garcia, A. M. B., Madalena, A. C., Estanislao, C., Rico, J. L. R., Dias, H., Bassi, A., et al. (2007). Ansiedad y miedo: su valor adaptativo y maladaptaciones. Revista Latinoamericana de Psicología, 39, 75-81.

Gazzaley, A., Rissman, J., Cooney, J., Rutman, A., Seibert, T., Clapp, W., et al. (2007). Functional interactions between prefrontal and visual association cortex contribute to top-down modulation of visual processing. Cerebral Cortex, 17, 125-135. 
Gelder, W. A. (2001). The scientific foundations of cognitive behavior therapy. In D. M. Clark \& C. G. Fairburn (Eds.), Science and practice of cognitive behavior therapy (pp. 2746). Oxford: Oxford University Press.

Gilbertson, M. W., Shenton, M. E., Ciszewski, A., Kasai, K., Lasko, N. B., Orr, S. P., Pitman, R. K. (2002). Smaller hippocampal volume predicts pathologic vulnerability to psychological trauma. Nature Neuroscience, 5, 1242--1247.

Ginsburg, G., Riddle, M. D., \& Davies, M. (2006). Somatic symptoms in children and adolescents with anxiety disorders. Journal of American Academy of Child and Adolescent Psychiatry, 45, 1179-1187.

Ginsburg, G. S., \& Silverman, W. K. (2000). Gender role orientation and fearfulness in children with anxiety disorders. Journal of Anxiety Disorders, 14, 57-67.

Gladstone, G. L., Parker, G. B., Mitchell, P. B., Wilhelm, K. A., \& Malhi, G. S. (2005). Relationship between self-reported childhood behavioral inhibition and lifetime anxiety disorders in a clinical sample. Depression and Anxiety, 22, 103-113.

Gotlib, I.H. (1984). Depression and General Psychopathology in University Students. Journal of Abnormal Psychology, 93, 19-30.

Gotlib, I. H., Kasch, K. L., Traill, S., Arnow, B. A., Joormann, J., \& Johnson, S. L. (2004). Coherence and specificity of information-processing biases in depression and social phobia. Journal of Abnormal Psychology, 113, 386-398.

Gray, J. A. (1982). The neuropsychology of anxiety. New York: Oxford University Press.

Gray, J. A. (1988). The neuropsychological basis of anxiety. In C. G. Last \& M. Hersen (Eds.), Handbook of anxiety disorders (pp. 10-37). New Yourk: Pergamon Press.

Gray, J. A., \& McNaughton, N. (1996). The neuropsychology of anxiety: Reprise. In Hope, D.

A. (Ed.), Perspectivas on anxiety, panic, and fear. Nebraska symposium on motivation (pp. 61-134). Lincol, NE: University of Nebraska Press.

Gray, J. A., \& N. McNaughton (2000). The neuropsychology of anxiety: An enquiry into the functions of the septohippocampal system. Oxford: Oxford University Press. 
Grillon, C. (2008). Greater sustained anxiety but not dear in womene compared to men. Emotion, 3, 410-413.

Hackfort, D., \& Schwenkmezger, N. (1993). Anxiety. In Singer, R. (Ed.), Handbook of research on sport psychology, (pp 328-364). New York: Macmillan Publishing.

Halpern, D. F., Benbow, C. P., Geary, D. C., Gur, R. C., Hyde, J. S., \& Gernsbacher, M. A. (2007). The science of sex differences in science and mathmathics. Psychological Science in the Public Interest, 1, 1-51.

Hamilton, M. (1959). The Assessment of Anxiety States by Rating. British Journal of Medical Psychology, 32, 50-55.

Han, T. M., De Vries, G. J. (2003). Organizacional effects of testosterona, estradiol, and dihydrotestosterone on vasopressin mRNA expresión in the bed nucleus of the stria terminalis. Journal of Neurobiology, 54, 502-510.

Hannesdóttir, D. K., Doxie, J., Bell, M. A., Ollendick, T. H., \& Wolfe, C. D. (2010). A longitudinal study of emotion regulation and anxiety in middle childhood: Associations with frontal EEG asymmetry in early childhood. Developmental Psychobiology, 52, 197-204.

Hariri, A. R., Drabant, E. M., Munoz, K. E., Kolachana, B. S., Mattay, V. S., Egan, M. F., et al. (2005). A susceptibility gene for affective disorders and the response of the human amygdala. Archives of General Psychiatry, 2, 146-152.

Harvard School of Medicine. (2005). The world mental health survey iniciative. Retirado en 26, Marzo, 2010, de www.hcp.med.harvard.edu.

Hasler, G., Drevets, W. C., Manji, H. K., \& Charney, D. S. (2004). Discovering endophenotypes for major depression. Neuropsychopharmacology, 29, 1765-1781.

Hayward, C., Killen, J. D., Kraemer, H. C., \& Taylor, C. B. (2000). Predictors of panic attacks in adolescents. Journal of the American Academy of Chile and Adolescent Psychiatry, 39, 207-214. 
Heim, C., \& Nemeroff, C. B. (2001). The role of childhood trauma in the neurobiology of mood and anxiety disorders: Preclinical and clinical studies. Biological Psychiatry, 49, 1023-1039.

Heinrichs, M., Meinlsechmidt, G., Neumann, I., Wagner, S., Kirschbaum, C., Ehlert, U., \& Helhammer, D. H. (2001). Effects of sucking on hypothalamic-pituitary-adrenal axis responses to psychosocial stress in postpartum lactating women. The Journal of Clinical Endocrinology and Metabolism, 86, 4798-4504.

Heller, W., Koven, N. S., \& Miller, G. A. (2003). Regional brain activity in anxiety and depression, cognition/emotion interaction, and emotion regulation. In K. Hugdahl \& R. J. Davidson (Eds.), The asymmetrical brain (pp. 533-564). Cambridge, MA: MIT Press.

Helmchen, H., \& Linden, M. (2000). Subthreshold disorders in psychiatry: Clinical reality, methodological artifact, and the double-threshold problem. Comprehensive Psychiatry, 41, 1-7.

Hettema, J. M., Neale, M. C., \& Kendler, K. S. (2001). A review and meta-analisis of the genetic epidemiology of anxiety disorders. American Journal of Psychiatry, 158, 1568-1578.

Hettema, J. M., Prescott, C. A., Myers, J. M., Neale, M. C., \& Kendler, K. S. (2005). The structure of genetic and environmental risk factors for anxiety disorders in men and women. Archives of General Psychiatry, 62, 182-189.

Hiroi, R., \& Neumaier, J. F. (2005). Differential effects of ovarian steroids on anxiety versus fear as measured by open field test and fearpotentiated startle. Behavioral Brain Research, 66, 93-100.

Hirshfeld-Becker, D. R., Biederman, J., \& Rosenbaum, J. F. (2004). Behavioral inhibition. In T. L. Morris \& J. S. March (Eds.), Anxiety disorders in children and adolescents (pp. 27-58). New York: Guilford Press. 
Hoehn-Saric, R., Lee, J. S., McLeod, D. R., \& Wong, D. F. (2005). Effect of worry on regional cerebral blood flow in nonanxious subjects. Psychiatry Research-Neuroimaging, 140, 259-269.

Hofmann, S. G., Moscovitch, D. A., Litz, B. T., Kim, H-J., Davis, L. L., \& Pizzagalli, D. A. (2005). The worried mind: Autonomic and prefrontal activation during worrying. Emotion, 5, 464-475.

Holmes, A., Lit, Q., Murphy, D. L., Gold, E., Crawley, J. N. (2003). Abnormal anxiety-related behavior in serotonin transporter null mutant mice: the influence of genetic background. Genes, Brain and Behavior, 2, 365-380.

IEM, C. \& Nemeroff, C. B. (2001). The role of childhood trauma in the neurobiology of mood and anxiety disorders: Preclinical and clinical studies. Biological Psychiatry, 49, 10231039.

Itoi, K., \& Sugimnoto, N. (2010). The brainstem noradrenergic systems in stress, anxiety, and depression. Journal of Neuroendocrinology. Article accepted: 10.1111/j.13652826.2010.01988.x.

Jablensky, A. (1985). Approaches to the definition and clasification of anxiety and related disorders in europe psychiatry. In A. H. Tuma \& J. D. Maser (Eds.), Anxiety and the anxiety disorders. Hillsdale, NJ: Erlbaum.

Jackson, E., Payne, J., Nadel, L., \& Jacobs, W. J. (2005). Stress differentially modulates fear conditioning in healthy men and women. Biological Psychiatry, 59, 516-522.

James, A., Soler, A., \& Weatherall, R. (2005). Cognitive behavioural therapy for anxiety disorders in children and adolescents. The Cochrane Database of Systematic Reviews, 4, 1-12.

Jeannerod, M. (2005). O Cérebro Íntimo. Lisboa: Edições Piaget.

Jex, S., Adams, G. A., \& Ehler, M. L. (2002). Assessing the role of negative affectivity in occupational stress research: Does gender make a difference? In Nelson, D.L., 
Burke, J.B., (Eds.), Gender work stress and health (pp. 71-84). Washington, DC: American Psychological Association.

Kajantie, E., \& Phillips, D. I. (2006). The effects of sex and hormonal status on the physiological response to acute psychosocial stress. Psychoneuroendocrinology, 31, $151-178$.

Kalisch, R., Schubert, M., Jacob, W., Kessler, M. S., Hemauer, R., Wigger, A., et al. (2006). Anxiety and hippocampus volume in the rat. Neuropsychopharmacology, 31, 925932.

Kalisch, R., Wiech, K., Herrmann, K., \& Dolan, R. J. (2006). Neural correlatos of selfdistraction from anxiety and a process modelo f cognitive emotion regulation. Journal of Cognitive Neuroscience, 18, 1266-1276.

Kalueff, A. V., \& Nutt, D. J. (2007). Role of GABA in anxiety and depression. Depression and Anxiety, 24, 495-517.

Kaplan, H. I., \& Sadock, B. J. (1993). Compêndio de psiquiatria: ciencias comportamentais psiquiatria clínica. Porto Alegre: Artes médicas.

Keck, M. E., Holsboer, F., \& Muller, M. B. (2004). Mouse mutants for the study of corticotropinreleasing hormone receptor function: development of novel treatment strategies for mood disorders. Annals of the New York Academy of Sciences, 1018, 445-457.

Keedwell, P., \& Snaith, R.P. (1996). What do Anxiety Scales Measure? Acta Psychiatrica Scandinavica, 93, 177-180.

Kelly, M. M., Forsyth, J. P.,\& Karekla,M. (2006). Sex differences in response to a panicogenic biological challenge procedure: An experimental evaluation of panic vulnerability in a non-clinical sample. Behaviour Research and Therapy, 44, $1421-1430$. 
Kelly, M. M., Tyrka, A. R., Anderson, G. M., Price, L. H., \& Carpenter, L. L. (2008). Sex differences in emotional and physiological responses to the Trier Social Stress Test. Journal of Behavior Therapy and Experimental Psychiatry, 1, 87-98.

Kendall, E. (1954). The validity of Taylor's manifest anxiety scale. Journal of Consulting and Clinical Psychology, 18, 429-432.

Kendall, P. C., Reber, M., McLeer, S., Epps, J., \& Ronan, K. R. (1990). Cognitive-behavioral treatment of conduct-disordered children. Cognitive Therapy and Research, 14, 279297.

Kessler, R. C., Chiu, W. T., Demler, O., \& Walters, E. E. (2005). Prevalence, severity, and comorbidity of 12-month DSM-IV disorders in the national comorbidity survey replication. Archives of General Psychiatry, 62, 617-627.

Kessler, R. C. , Davis, C. G., \& Kendler, K. S. (1997). Childhood adversity and adult psychiatric disorder in the US Nacional Comorbidity Survey, Psychological Medicine, 27, 1101-1119.

Killgore, W. D. S., \& Yurgelun-Todd, D. A. (2005). Social anxiety predicts amygdale activation in adolescents viewing fearful faces. Neuroreport, 15, 1671-1675.

Kim, H. F. S., Braun, U., \& Kunik, M. E. (2001). Anxiety and depression in medically ill older adults. Journal of Clinical Geropsychology, 7, 117-130.

Kim, J.J., Song, E.Y., \& Kosten, T.A. (2006). Stress effects in the hippocampus: synaptic plasticity and memory. Stress, 9, 1-11.

Kirschbaum, C., Kudielka, B. M., Gaab, J., Schommer, N. C., \& Hellhammer, D. H. (1999). Impact of gender, menstrual cycle phase, and oral contraceptives on the activity of the hypothalamic-pituitary-adrenal axis. Psychosomatic Medicine, 61, 154-162.

Klemenhagen, K. C., Gordon, J. A., David, D. J., Hen, R., \& Gross, C. T. (2006). Increased fear response to contextual cues in mice lacking the 5-HT1A receptor. Neuropsychopharmacology, 1, 101-111. 
Kobak, K. A., Reynolds, W. M., \& Greist, J. H. (1993). Development and validation of a computer-administered version of the Hamilton Anxiety Scale. Psychological Assessment, 5, 487-492.

Kohort, B. A., \& Worthman, C. M. (2009). Gender and anxiety in nepal: the role of social support, stressful life events, and structural violence. CNS Neuroscience \& Therapeutics, 3, 237-248.

Komesaroff, P. A., Ester, M. D., \& Sudhir, K. (1999). Estrogen supplementation attenuates glucocorticoid and catecholamine responses to mental stress in perimenopausal women. The Journal of Clinical Endocrinology and Metabolism, 84, 606-612.

Kovacs, M., \& Devlin, B. (1998). Internalizing disorders in childhood. Journal of Child Psychology and Psychiatry, 39, 47-63.

Krasucki, C., Howard, R., \& Mann, A. (1998). The relationship between anxiety disorders and age. International Journal of Geriatry, 13, 79-99.

Kudielka, B., Buske-Kirschbaum, A., Hellhammer, D., \& Kirschbaum, C. (2004). HPA axis responses to laboratory psychosocial stress in healthy elderly adults, younger adults, and children: impact of age and gender. Psychoneuroendocrinology, 29, 83-98.

Lader, M.H., \& Marks, I.M. (1974). The Rating of Clinical Anxiety. Acta Psychiatrica Scandinavica, 50, 112-137.

Lang, P. J. (1979). Abio-informational theory of emotional imagery. Psychophysiology, 16, $495-512$.

Laurent, J., \& Ettelson, R. (2001). An examination of the tripartite model of anxiety and depression and its application to youth. Clinical Child and Family Psychology Review, 4, 209-230.

LeDoux, J. (2007). The amygdala. Current Biology, 17, R868-874.

Lee, L. O., \& Knight, B. G. (2009). Attentional bias for the threat in older adults: moderation of the positive bias by trait anxiety and stimulus modality. Psychology and Aging, 3, 741-747. 
Legrand, L. N., McGue, M., \& Lacono, W. C. (1999). A twin study of state and trait anxiety in childhood and adolescente. Journal of Chile Psychology and Psychiatry, 40, 953-958.

Lenze, E. J., Mulsant, B. H., Shear, M. K., Schulberg, H. C., Dew, M. A., \& Begley, A. (2000). Comorbid anxiety disorders in depressed elderly patients. American Journal of Psychiatry, 157, 722-728.

Leonardo, E. D., \& Hen, R. (2006). Genetics of affective and anxiety disorders. Annual Review of Psychology, 57, 117-137.

Lepine, J. P. (2002). The epidemiology of anxiety disorders: prevalence and societal costs. Journal of Clinical Psychiatry, 14, 4-8.

Lesch, K. P., Bengel, D., Heils, A., Zhang Sabol, S., Greenburg, B. D., Petri, S., et al. (1996). Association of anxiety-related traits with a polymorphism in the serotonin transporter gene regulatory region. Science, 274, 1527-1531.

Leyfer, O. T., Ruberg, J. L., \& Woodruff-Borden, J. (2006). Examination of the validity of the Beck anxiety inventory and its factors as a screener for anxiety disorders. Journal of Anxiety Disorders, 20, 444-458.

Lewinsohn, P. M., Gotlib, I. H., Lewinsohn, M., Seeley, J. R., \& Allen, N. B. (1998). Gender differences in anxiety disorders and anxiety symptoms in adolescents. Journal of Abnormal Psychology, 1, 109-117.

Lewinsohn, P. M., Zinbarg, R., Seeley, J. R., Lewinsohn, M., \& Sack, W. H. (1997). Lifetime comorbidity among anxiety disorders and between anxiety disorders and other mental disorders in adolescents. Journal of Anxiety Disorders, 11, 377-394.

Lewis, A. (1979). Problems Presented by the Ambigous Word "Anxiety" as Used in Psychopathology. Oxford: Oxford Universuty Press.

Linacre, J. M. (2002). Optimizing Rating Scale Category Effectiveness. Journal of Applied Measurement, 3, 85-106.

Linacre, J. M. (2010). A user's guide to winsteps ministep. Rasch-model computer programs. Retirado em 5, Abril, 2010, de www.winsteps.com. 
Linacre, J. M., \& Wright, B. D. (2000). WINSTEPS: Multiple-choice, rating scale, and partial credit Rasch análisis (Computer software). Chicago: MESA Press.

Lonigan, C. J., Phillips, B. M., \& Hooe, E. S. (2003). Relations of positive and negative affectivity to anxiety and depression in children: Evidence from a latent variable longitudinal study. Journal of Consulting and Clinical Psychology, 3, 465-481.

Lorenz, E. N. (1980). Attractor sets and quasi-geostrophic equilibrium. Journal of Atmospheric Sciences, 37, 1685-1699.

Lovibond, P.F., \& Lovibond, S.H. (1995). The Structure of Negative Emotional State: Comparison of the Depression Anxiety Stress Scales (DASS) with The Beck Depression and Anxiety Inventories. Behavior Research and Therapy, 33, 335-343. Lovibond, P.F., \& Lovibond, S.H. (1996). Manual for the depression anxiety stress scales. Sydney: Psychology Foundation Monograph.

Lüders, E., Narr, K. L., Thompson, P. M., Rex, D. E., Jancke, L., Steinmetz, H., Toga, A. W. (2004). Gender differences in cortical complexity. Nature Neuroscience, 7, 799-800.

Luine, V. (2002). Sex differences in chronic stress effects on memory in rats. Stress, 5, 205216.

Luten, A. G., Ralph, A. J., \& Mineka, S. (1997). Pessimistic atributional style: is it specific to depression versus anxiety versus negative affect?. Behaviour Research and Therapy, 35, 703-719.

Lydiard, R. B., \& Brawman-Mintzer, O. (1998). Anxious depression. Journal of Clinical Psychiatry, 18, 10-17.

Mackinaw-Koons, B., \& Vasey, M. W. (2000). Considering sex differences in anxiety and its disorders across the life span: a construct-validation approach. Applied and Preventive Psychology, 9, 191-209.

MacLeod, C. (1996). Anxiety and cognitive processes. In Sarason, I. G., Pierce, G. R., \& Sarason, B. R. (Eds.), Cognitive interferente: Theories, methods and findings. Mahwah, N. J: Erlbaum. 
MacLeod, C., \& Rutherford, E. (2004). Information-processing approaches: Assessing the selective functioning of attention, interpretation, and retrieval. In R. G. Heimberg, C. L. Turk, \& D. S. Mennin (Eds.), Generalized anxiety disorder: Advances in research and practice (pp. 109-142). New York: Guilford Press.

Maller, R. G., \& Reiss, S. (1992). Anxiety sensitivity in 1984 and panic attacks in 1987. Journal of Anxiety Disorders, 6, 241-247.

Manassis, K., Mendelowitz, S. L., Scapillato, D. C., Avery, D. C., Fiskenbaum, L., \& Freire, M. (2002). Group and individual cognitive-behavioral therapy for childhood anxiety disorders: a randomized control trial. Journal of the American Academy Child and Adolescent Psychiatry, 41, 1423-1430.

Maren, S., \& Quirk, G. J. (2004). Neuronal signalling of fear memory. Nature Reviews Neuroscience, 5, 844-852.

Margis, R., Picon, P., Cosner, A. F., \& Silveira, R. O. (2003). Relação entre estressores, estress e ansiedade. Revista de Psiquiatria, 1, 65-74.

Marks, I. M. (1969). Fears and phobias. London: Heinemann.

Marks, I. M. (1987). Fear phobias and rituals. Panic, anxiety and their disorders. New York: Oxford University Press.

Masi, G., Favilla, L., Millepiedi, S., \& Mucci, M. (2000). Somatic symptoms in children and adolescents referred for emocional and behavioral disorders. Psychiatry, 63, 140-149.

Mathersul, D., Williams, L. M., Hopkinson, P. J, \& Kemp, A. H. (2008). Investigating models of affect: Relationships among EEG alpha asymmetry, depression, and anxiety. Emotion, 4, 560-572.

Mathews, A. (2001). Information-processing biases in emotional disorders. In D. M. Clark \& C. G. Fairburn (Eds.), Science and practice of cognitive behavior therapy (pp. 47-66). Oxford, United Kingdom: Oxford University Press.

Mathews, A., \& Macleod, C. (2002). Induced processing biases have causal effects on anxiety. Cognition and Emotion, 16, 331-354. 
Mathews, A., \& MacLeod, C. (2005). Cognitive vulnerability to emotional disorders. Annual Review of Clinical Psychology, 1, 167-195.

Matthews, K. A., \& Rodin, J. (1992). Pregnancy alters blood pressure responses to psychological and physical challenge. Psychophysiology, 29, 232-240.

May, R. (1980). O significado da ansiedade. Rio de Janeiro: Editora Item ahar.

McClure, E. B., Adler, A., Monk, C. S., Cameron, J., Smith, S., Nelson, E. E., et al. (2006). fMRI predictors of treatment outcome in pediatric anxiety disorders. Psychopharmacology, 10, 542-551.

McCormik, C., Linkroum, W., Sallinen, B., \& Millar, N. (2002). Peripheral and central sex steroids have differential effects on the HPA axis of male and female rats. Stress, 5, 235-247.

McCormik, R. A., \& Strauss, M. E. (1995). Testing a tripartite model: II. Exploring the symptom structure of anxiety and depression in student, adult, and patient samples. Journal of Abnornormal Psychology, 104, 15-25.

McEwen, B.S. (2003). Mood disorders and allostatic load. Biological Psychiatry, 54, 200-207.

McEwen, B.S. (2007). Physiology and neurobiology of stress and adaptation: central role of the brain. Physiological Reviwes, 87, 873-904.

McLaughlim, K. A., \& Hatzenbuehler, M. L. (2009). Stressfull life events, anxiety sensivity, and internalizing symptoms in adolescents. Journal of Abnormal Psychology, 3, 659669.

McLean, C. P., \& Anderson, E. R. (2009). Brave men and timid women? A review of the gender differences in fear and anxiety. Clinical Psychology Review, 6, 496-505.

McNally, R. J., \& Eke, M. (1996). Anxiety sensitivity, suffocation fear, and breath-holding duration as predictors of response to carbon dioxide challenge. Journal of Abnormal Psychology, 105, 146-149. 
McNaughton, N., \& Corr, P.J. (2004). A two-dimensional neuropsychology of defense: fear/anxiety and defensive distance. Neuroscience \& Biobehavioral Reviews, 28, 285-305.

Merikangas, K. R., \& Pine, D. (2002). Genetic and other vulnerability factors for anxiety and stress disorders. In K. L. Davis, D. Charney, J. T. Coyle, \& C. Nemeroff (Eds.). Neuropsychopharmacology: The fifth generation of Progress (pp. 867-882). Philadelphia: Lippincott Williams \& Wilkins.

Merikangas, K. R., Item hang, H., Avenevoli, S., Acharyya, S., Neuenschwander, M., \& Angst, J. (2003). Longitudinal trajectories of depression and anxiety in a prospective community study. Archives of General Psychiatry, 60, 993-1000.

Mesman, J., \& Koot, H. M. (2001). Early preschool predictors of pread olescent internalizing and externalizing DSM-IV diagnoses. Journal of the American Academy of Child \& Adolescent Psychiatry, 40, 1029-1036.

Mirowsky, J., \& Schieman, S. (2008). Gender, age, and the trajectories and trends of anxiety and anger. Advances in Life Course Research, 13, 45-73.

Mezzacappa, E. S., Yu, A. Y., \& Myers, M. M. (2003). Lactation and weaning effects on physiological and behavioural responses to stressors. Physiology Behavior, 78, 1-9.

Mikels, J. A., \& Reuter-Lorenz, P. A. (2004). Neural gate keeping: The role of interhemispheric interactions in resource allocation and selective filtering Neuropsychology, 18, 328-339.

Milad, M. R., Quinn, B. T., Pitman, R. K., Orr, S. P., Fischl, B., \& Rauch, S. L. (2005). Thickness of ventromedial prefrontal cortex in humans is correlated with extinction memory. Proceedings of the National Academy of Sciences, 30,10706-10711.

Millar, M. A., Vician, L., Clifton, D. K., \& Dorsa, D. M. (1989). Sex differences in vasopressin neurons in the bed nucleus of the stria terminalis by in situ hybridization. Peptides, 10, 615-619. 
Miller, E. K., \& Cohen, J. D. (2001). An integrative theory of prefrontal cortex function. Annual Review of Neuroscience, 24, 167-202.

Miller, D. B., \& O'Callaghan, J. P. (2002). Neuroendocrine aspects of the response to stress. Metabolism, 6, 5-10.

Mineka, S., Rafaeli, E., \& Yovel, I. (2003). Cognitive biases in emotional disorders: Information processing and social-cognitive perspectives. In R. J. Davidson, K. R. Scherer, \& H. H. Goldsmith (Eds.), Handbook of affective sciences (pp. 976-1009). Oxford: Oxford University Press.

Mineka, S., Watson, D., \& Clark, L. A. (1998). Comorbidity of anxiety and unipolar mood disorders. Annual Review of Psychology, 49, 377-412.

Mobini, S, \& Grant, A. (2007). Clinical implications of attentional bias in anxiety disorders: an integrative literature review. Psychoteraphy: Theory, Research, Practice, Training, 4, 450-462.

Moes, P. E., Brown, W. S., \& Minnema, M. T. (2007). Individual differences in interhemispheric transfer time (IHTT) as measured by event related potentials. Neuropsychologia, 45, 2626-2630.

Moffatt, C.A. (2003). Steroid hormone modulation of olfactory processing in the context of sociosexual behaviors in rodents and humans. Brain Research Reviwes, 43, 192-206.

Mohlman, J. \& Price, R. (2006). Recognizing and treating late-life generalized anxiety disorder: distinguishing features and psychosocial treatment. Expert Review of Neurotherapeutics, 6, 1439-1445.

Monk, C. S. (2008). The development of emotion-related neural circuitry in health and psychopathology. Development and Psychopathology, 20, 1231-1250.

Moore, P. N., Kinsman, R. A., \& Dirks, J. F. (1984). Subscales to the taylor manifest anxiety scale in three chronically ill populations. Journal of Clinical Psychology, 6, 1431-1433.

Most, S. B., Chun, M. M., Johnson, M. R., \& Kiehl, K. A. (2006). Attentional modulation of the amygdala varies with personality. Neuroimage, 31, 934-944. 
Mountjoy, C. Q., \& Roth, M. (1982). Studies in the relationship between depressive disorders and anxiety states: II. Clinical items. Journal of Affective Disorders, 4, 149-169.

Muris, P. (2006). The pathogenesis of childhood anxiety disorders: Considerations from a developmental psychopathology perspective. International Journal of Behavioral Development, 30, 5-11.

Muris, P., Mayer, B., Bartelds, E., Tierney, S., \& Bogie, N. (2001). The revised version of the Screen for Child Anxiety Related Disorders (SCARED-R): treatment sensitivity in an early intervention trial for childhood anxiety disorders. British Journal of Clinical Psychology, 40, 323-326.

Muris, P., Merckelbach, H., Ollendick, T. H., King, N. J., \& Bogie, N. (2002). Three traditional and three new childhood anxiety questionnaires: their reliability and validity in a normal adolescent sample. Behaviour Research and Therapy, 40, 753-772.

Muris, P., \& Meesters, C. (2004). Children's somatization symptoms, correlations with trait anxiety, anxiety sensitivity, and learning experiences. Psychological Reports, 94, $1269-1275$.

Muris, P., Meesters, C., \& Van Melick, M. (2002). Treatment of childhood anxiety disorders: A preliminary comparison between cognitive-behavioral therapy and a psychological placebo intervention. Journal of Behavior Therapy and Experimental Psychiatry, 33, 143-158.

Muris, P., \& Ollendick, T. H. (2002). The assessment of contemporary fears in adolescents using a modified version of the fear survey schedule for children - revised. Journal of Anxiety Disorders, 16, 567-584.

Nauta, M. H., Scholing, A., Emmelkamp, P. M., \& Mindera, R. B. (2003). Cognitivebehavioral therapy for children with anxiety disorders in a clinical setting: no additional effect of a cognitive parent training. Journal Journal of the American Academy Child and Adolescent Psychiatry, 42, 1270-1278. 
Nitschke, J. B., Heller, W., \& Miller, G. A. (2000). The neuropsychology of anxiety. In J. C. Borod (Ed.), The neuropsychology of emotion (pp. 298-319). New York: Oxford University Press.

Norton, G. R., Dorward, J., \& Cox, B. J. (1986). Factors associated with panic attacks in nonclinical subjects. Behavior Therapy, 17, 239-252.

Oatley, K., \& Jenkins, J. M. (1996). Understanding emotion. Cambridge, United Kingdom: Blackwell.

Ollendick, T. H., King, N. J., \& Muris, P. (2002). Fears and phobias in children: Phenomenology, epidemiology, and aetiology. Chile and Adolescent Mental Health, 7, 98-106.

Osman, A., Barrios, F. X., Aukes, D., Osman, J. R., \& Markway, K. (1993). The Beck anxiety inventory: psychometric properties in a community population. Journal of Psychopathology and Behavioral Assessment, 15, 287-297.

Osman, A., Kopper, B. A., Barrios, F. X., Osman, J. R., \& Wade, T. (1997). The Beck anxiety inventory: reexamination of factor structure and psychometric properties. Journal of Clinical Psychology, 53, 7-14.

Pais-Ribeiro, J., Honrado, A., \& Leal, I. (2004). Contribuição para o estudo de adaptação portuguesa das escalas de ansiedade, depressão e stress (EADS) de 21 itens de Lovibond e Lovibond. Psicologia, Saúde \& Doenças, 2, 229-239.

Patston, L. L. M., Kirk, I. J., Rolfe, M. H. S., Corballis, M. C., \& Tippett, L. J. (2007). The unusual symmetry of musicians: Musicians have equilateral interhemispheric transfer for visual information. Neuropsychologia, 45, 2059-2065.

Paykel, E. S. (2003). Life events and affective disorders. Acta Psychiatrica Scandinavica (Suppl.), 61-66..

Pêgo, J. M. (2007). Inflence of stress in the structure and function of the amígdala. Tesis Doctoral presentada en la Universidade do Minho, orientada por Nuno Sousa, Braga. 
Pêgo, J. M., Morgado, P., Cerqueira, J. J., Almeida, O. F. X., \& Sousa, N. (2006). Mismatch between anxiety status and morphometric parameters in the amigdala and bed nucleus of the stria terminalis. Behavioural Brain Research, 173, 320-325.

Pêgo, J. M., Morgado, P., Pinto, L. G., Cerqueira, J. J., Almeida, O. F. X., \& Sousa, N. (2008). Dissociation of the morphological correlates of stress-induced anxiety and fear. European Journal of Neuroscience, 6, 1503-1516.

Pentkowski, N. S., Blanchard, D. C., Lever, C., Litvin, Y., \& Blanchard, R. J. (2006). Effects of lesions to the dorsal and ventral hippocampus on defensive behaviours in rats. The European Journal of Neuroscience, 23, 2185-2196.

Peregrino, A. (1996). Ansiedade normal e patológica. Jornal Brasileiro de Psiquiatria, 3, 129134.

Pérez, E. M. G., \& Lago, A. M. (2000). Escala Magallanes de ansiedad. Manual de referencia. Bizkaia: Grupo Albor-Cohs.

Perkins, A. M., Kemp, S. E., \& Corr, P. J. (2007). Fear and anxiety as separable emotions: an investigation of the revised reinforcement sensivity theory of personality. Emotion, 2, 252-261.

Peterson, R.A., \& Plehn, K. (1999). Measuring anxiety sensitivity. In S. Taylor (Ed.), Anxiety sensitivity: Theory, research, and treatment of the fear of anxiety (pp. 61-81). Mahwah, NJ: Lawrence Erlbaum Associates.

Peterson, R. A., \& Reiss, S. (1987). Anxiety Sensitivity Index Manual. Palos Heights, IL: Internacional Diagostic Systems.

Petrovich, G.D., Canteras, N.S. \& Swanson, L.W. (2001). Combinatorial amygdalar inputs to hippocampal domains and hypothalamic behavior systems. Brain Research Reviews, 38, 247-289.

Pezawas, L., Meyer-Lindenberg, A., Drabant, E. M., Verchinski, B. A., Munoz, K. E., Kolachana, B. S., et al. (2005). 5-HTTLPR polymorphism impacts human cingulate- 
amygdala interactions: a genetic susceptibility mechanism for depression. Nature Neuroscience, 8, 828-834.

Phillips, N. K., Hammen, C. L., Brennan, P. A., Najman, J. M., \& Bor, W. (2005). Early adversity and the prospective prediction of depressive and anxiety disorders in adolescents. Journal of Abdormal Child Psychology, 33, 13-24.

Ponciano, E., Serra, A., \& Relvas, J. (1982). Aferição da escala de auto-avaliação de ansiedade, de Item ung, numa amostra de população portuguesa - I - Resultados da aplicação numa amostra de população normal. Psiquiatria Clínica, 3, 192-202.

Prieto, G., \& Delgado, A. R. (2003). Análisis de un test mediante el modelo de Rasch. Psicothema, 15, 94-100.

Prusoff, B., \& Klerman, G. (1974). Differentiating Depressed from Anxious Neurotic OutPatients. Archives General Psychiatry, 30, 302-309.

Pum, M. E., Huston, J. P, \& Muller, C. P. (2009). The role of cortical serotonin in anxiety and locomotor activity in wistar rats. Behavioral Neuroscience, 2, 449-454.

Rabasquinho, C., \& Pereira, H. (2007). Género e saúde mental: uma abordagem epidemiológica. Análise Psicológica, 3, 439-454.

Rapaport, M. H. (2001). Prevalence, recognition, and treatment of comorbid depression and anxiety. Journal of Clinical Psychiatry, 62, 6-10.

Rapee, R. M., \& Coplan, R. J. (2010). Conceptual relations between anxiety disorder and fearful temperament. In H. Gazelle \& K. H. Rubin (Eds.), Social anxiety in childhood: bridging developmental and clinical perspectives. New Directions for Child and Adolescent Development, 127, 17-31. San Francisco: Jossey-Bass.

Rasch, G. (1960). Probabilistic Models for some intelligence and attainment tests. Copehagen: Institute for Educational Reseca.

Rasmusson, A. M., \& Friedman, M. J. (2002). The neurobiology of PTSD in women. In R. Kimerling, P. C. Ouimette, J. Wolfe (Eds.), Gender and PTSD (pp. 43-75). New York: Guilford. 
Reckase, M.D. (1979). Unifactor latent trait models applied to multifactor tests: Resulst and implications. Journal of Educational Statistics, 4, 207-230.

Reiss, S. (1991). Expectancy model of fear, anxiety and panic. Clinical Psychology Review, 11, 141-153.

Ribeiro, J. L. P. (2007). Avaliação em psicologia da saúde: Instrumentos publicados em Português. Série Psicologia e Saúde. Coimbra: Quarteto Editora.

Riedel-Heller, S.G., Busse, A., \& Angermeyer, M.C. (2006). The state of mental health in oldage across the 'old' european union-- a systematic review. Acta Psychiatrica Scandinavica, 113, 388-401.

Rivas-Vasquez, R. A., Saffa-Biller, D., Ruiz, I., Blais, M. A., \& Rivas-Vasquez, A. (2004). Current sigues in anxiety and Depression: Comorbid, mixed, and subthreshold disorders. Professional Psychology: Research and Practice, 1, 74-83.

Roberts, B.W., Walton, K. E., \& Viechtbauer, W. (2006). Patterns of mean-level change in personality traits across the life course: A meta-analysis of longitudinal studies. Psychological Bulletin, 132, 3-27.

Roca, C. A., Schmidt, P. J., Altemus, M., Deuster, P., Danaceau, M. A., Putnam, K., \& Rubinow, D. R. (2003). Differential menstrual cycle regulation of hypothalamicpituitart-adrenal axis in women with premenstrual syndrome and controls. The Journal of Clinical Endocrinology and Metabolism, 88, 3057-3063.

Rodrigo, C., Welgama, S., Gurusinghe, J., Wijeratne, T., Jayananda, G., \& Rajapakse, S. (2010). Symptoms of anxiety and depression in adolescents; a perspective from Sri Lanka. Child and Adolescent Psychiatry and Mental Heath, 4, 10.

Rodrigues, M. (1976). Psicología educacional: uma crônica do desenvolvimento humano. São Paulo: McGraw Hill do Brasil.

Rohrmann, S., Netter, P., Hennig, J., \& Hodapp, W. (2003). Repression-sensitization, gender, and discrepancies in psychobiological reactions to examination stress. Anxiety, Stress \& Coping: An International Journal, 3, 321-329. 
Roth, M., Curney, C., Garsige, R. F., \& Kerr, T. A. (1972). Studies in the classification of the affective disorders: The relationship between anxiety states and depressive illnesses. British Journal of Psychiatry, 121, 147-161.

Rucci, P., Gherardi, S., Tansella, M., Piccinelli, P., Berardi, D., Bisoffi, G., et al. (2003). Subthreshold psychiatric disorders in primary care: prevalence and associated characteristics. Journal of Affective Disorders, 76, 171-181.

Russell, D., Peplau, L. A., \& Cutrona, C. E. (1980). The revised UCLA loneliness scale: Concurrent and discriminant validity evidence. Journal of Personality and Social Psychology, 39, 472-480.

Sandín, B. (1997). Ansiedad, miedos y fobias en niños y adolescents. Madrid: Dykinson.

Sandín, B., Chorot, P., Valiente, R. M., Santed, M. A., \& Lostao, L. (2004). Dimensiones de la sensibilidad a la ansiedad: evidencia confirmatoria de la estrutura jerárquica. Revista de Psicopatología y Psicología Clínica, 9, 19-33.

Sandín, B., Valiente, R. M., Chorot, P., \& Santed, M. A. (2005). Propriedades psicométricas del índice de sensibilidad a la ansiedad. Psicothema, 17, 478-483.

Sanz, J., \& Navarro, M. E. (2003). Propriedades psicométricas de una versión española del inventario de ansiedad de Beck (BAI) en estudiantes universitarios. Ansiedad y Estrés, 1, 59-84.

Sareen, J., Cox, B. J., Clara, I., \& Asmundson, G. J. G. (2005). The relationship between anxiety disorders and physical disorders in the U. S. national comorbidity survey. Depression and Anxiety, 21, 193-202.

Schmidt, N. B., \& Koselka, M. (2000). Gender differences in patients with panic disorder: Evaluating cognitive mediation of phobic avoidance. Cognitive Therapy and Research, 5, 533-550.

Scmidt, N. B., Lerew, D. R., \& Jackson, R. J. (1999). Prospective evaluation of anxiety sensitivity in the pathogenesis of panic: Replication and extension. Journal of Abnormal Psychology, 108, 532-537. 
Schmidt, N. B., Lerew, D. R., \& Jackson, R. J. (1997). The role of anxiety sensitivity in the pathogenesis of panic: prospective evaluation of spontaneous panic attacks during acute stress. Journal of Abnormal Psychology, 106, 355-364.

Schmidt, N. B., Storey, J., Greenberg, B. D., Santiago, H. T., Li, Q., \& Murphy, D. L. (2000). Evaluating gene x psychological risk factor effects in the patogénesis of anxiety: A new model approach. Jornal of Abnormal Psychology, 2, 308-320.

Schmidt, N. B., Zvolensky, M. J., \& Maner, J. K. (2006). Anxiety sensitivity: Prospective prediction of panic attacks and axis I pathology, Manuscript, under review.

Schneider, T. R. (2004). The role of neuroticism on psychological and physiological stress responses. Journal of Experimental Social Psychology, 40, 795-804.

Serra, A., Ponciano, E., \& Relvas, J. (1982). Aferição da escala de auto-avaliação de ansiedade de Zung, numa amostra de população portuguesa - II - Sua avaliação como instrumento de medida. Psiquiatria Clínica, 3, 203-213.

Sharon, L., McCreary, B. T., Joiner, T. E., Schmidt, N. B., \& lalongo, N. S. (2004). Structure of anxiety and depression in urban youth: An examination of the tripartite model. Journal of Consulting and Clinical Psychology, 72, 904-908.

Shekhar, A., Truitt, W., Rainnie, D., \& Sajdyk, T. (2005). Role of stress, corticotrophin releasing factor (CRF) and amygdala plasticity in chronic anxiety. Stress, 8, 209-219.

Shors, T., Lewezyk, C., Pacynski, M., Mathew, P., \& Pickett, J. (1998). Stages of estrous mediate the stress-induced impairment of associative learning in the female rat. NeuroReport, 9, 419-423.

Sigurdsson, T., Doyere, V., Cain, C.K., \& LeDoux, J.E. (2007). Long-term potentiation in the amygdala: a cellular mechanism of fear learning and memory. Neuropharmacology, 52, 215-227.

Silberg, J. L., Rutter, M., \& Eaves, L. (2001). Genetic and environmental influences on the temporal association between earlier anxiety and later depression in girls. Biological Psychiatry, 49, 1040-1049. 
Silberg, J., Rutter, M., Neale, M., \& Eaves, L. (2001). Genetic moderation of environmental risk for depression and anxiety in adolescent girls. The British Journal of Psychiatry, 179, $116-121$.

Silva, D. R. (2006). O inventario de estado-traço de ansiedade (STAI). In M. M. Gonçalves, M. R. Simões, L. S. Almeida, \& C. Machado (Eds.), Avaliação psicológica Instrumentos validados para a população portuguesa (pp.45-60). Coimbra: Quarteto.

Skinner, B. F. (1938). The behavior of organisms: an experimental analysis. New York: Appleton Century Co.

Smith, E. V., \& Smith, R. M. (2004). Introduction to rasch measurement. Maple Grove, Mn: JAM Press.

Smoller, J. W., \& Tsuang, M. T. (1998). Panic and phobic anxiety: Defining phenotypes for genetic studies. American Journal of Psychiatry, 155, 1152-1162.

Sousa, C., \& Pereira, M. G. (2008). Morbilidade psicológica e representações de doença em pacientes com esclerose múltipla: estudo de validação da "Hospital Anxiety and Depression Scale" (HADS). Psicologia, Saúde e Doenças, 2, 283-298.

Spence, S. H., Rapee, R., McDonald, C., \& Ingram, M. (2001). The structure of anxiety symptoms among preschoolers. Behavior Research and Therapy, 39, 1293-1316.

Spielberger, C. D. (1966). Anxiety and behaviour. New York: Academia Press.

Spielberger, C. D. (1972). Anxiety as an emotional state. In Spielberger, C. D. (Ed.). Anxiety current trends in theory and research (pp. 23-49). New York: Academia Press.

Spielberger, C. D. (1983). Manual for the state-trait anxiety inventory. Palo Alto, CA: Mind Garden.

Spielberger, C.D., Gorsuch, R.L., \& Lushene, R.E. (1970). Manual for the Strait-Trait Anxiety Inventory. Palo Alto: Consulting Psychologists Press.

Spielberger, C.D., Gorsuch, R.L., \& Lushene, R.E, Vagg, P., \& Jacobs, G. (1983). Manual for the state-trait anxiety inventory, STAY (form Y) "self-evaluation". Questionnaire. Palo Alto: Consulting Psychologists Press. 
Stahl, S. M. (1997). Mixed depression and anxiety: Serotonin receptors as a common pharmacologic link. Journal of Clinical Psychiatry, 58, 20-26.

Steer, R. A., Beck, A. T., Clark, D. A., \& Ranieri, W. F. (1995). Commom and specific dimensions of self-reported anxiety and depression: A replication. Journal of Abnormal Psychology, 104, 542-545.

Steer, R. A., Clark, D. A., \& Ranieri, W. F. (1994). Symptom dimensions of the SCL-90-R: A test of the tripartite model of anxiety and depression. Journal of Personality Assessment, 62, 525-536.

Steer, R. A., Ranieri,W. F., Beck, A. T., \& Clark, D. A. (1993). Further evidence for the validity of the Beck anxiety inventory with psychiatric outpatients. Journal of Anxiety Disorders, 7, 195-205.

Stein, M. B., Fuetsch, M., Muller, N., Hofler, M., Lieb, R., \& Wittchen, H. (2001). Social anxiety disorder and the risk of depression: A prospective community study of adolescents and young adults. Archives of General Psychiatry, 58, 251-256.

Stein, M. B., Jang, K. L., \& Livesley, W. J. (1999). Herirability of anxiety sensitivity: A twin study. The American Journal of Psychiatry, 156, 246-251.

Stewart, S. H., Conrod, P. J., Gignac, M. L., \& Pihl, R. O. (1998). Selective processing biases in anxiety-sensitive men and women. Cognition Emotion, 12, 105-133.

Stewart, S. H., Taylor, S., \& Baker, J. M. (1997). Gender differences in dimensions of anxiety sensitivity. Journal of Anxiety Disorders, 11, 179-200.

Stone, M. H. (2003). Substantive scale construction. Journal of Applied Measurement, 4 , 282-297.

Straube, T., Mentzel, H-J., \& Miltner, W. H. R. (2006). Neural mechanisms of automatic and direct processing of phobogenic stimuli in specific phobia. Biological Psychiatry, 2, 162-170. 
Strobel, A., Gutknecht, L., Rothe, C., Broche, B., \& Lesch, K. P. (2005). Allelic variation in 5HT1A receptor expression associated with anxiety- and depression- related personality traits. Journal of Psychophysiology, 2, 147-148.

Strobel, A., Gutknecht, L., Rothe, C., Reif, A., Mossner, R., et al. (2003). Allelic variation in 5HT1A receptor expression is associated with anxiety- and depression-related personality traits. Journal of Neural Transmission, 110, 1445-1453.

Strohle, A., \& Holsboer, F. (2003). Stress responsive neurohormones in depression and anxiety. Pharmacopsychiatry, 3, 207-214.

Sullivan, P. F., Neale, M. C., \& Kendler, K. S. 2000. Genetic epidemiology of major depression: review and meta-analysis. American Journal of Psychiatry, 157, 15521562.

Swanson, L.W. (1998). Brain Maps: Structure of the rat brain. Amsterdam: Elsevier.

Swanson, L.W., \& Petrovich, G.D. (1998). What is the amygdala? Trends in Neurosciences, $21,323-331$.

Taylor, J.A. (1953). A Personality Scale of Manifest Anxiety. Journal of Abnormal Psychology, 48, 285-290.

Taylor, S. (1996). Nature and assessment of anxiety sensitivity. Journal of Anxiety Disorders, $10,425-451$.

Taylor, S. (1999). Anxiety sensitivity: Theory, research, and treatment of the fear of anxiety. Mahwah, NJ: Erlbaum.

Taylor, S., \& Cox, B. J. (1998). Anxiety sensitivity: multiple dimensions and hierarchic structure. Behaviour Research and Theraoy, 36, 37-51.

Thapar, A., \& McGuffin, P. (1997). Anxiety and depressive symptoms in childhood - a genetic study of comorbidity. Journal of Child Psychology and Psychiatry, 38, 651656. 
Thibodeau, R., Jorgensen, R. S., \& Kim, S. (2006). Depression, anxiety, and resting frontal EEG asymmetry: A meta-analytic review. Journal of Abnormal Psychology, 4, 715729.

Tirapu, J., Ríos, M., \& Maestú, F. (2008). Manual de neuropsicología. Barcelona: Viguera.

Toufexis, D. (2007). Region- and sex-specific modulation of anxiety behaviours in the rat. Journal of Neuroendocrinology, 19, 461-473.

Toufexis, D., Davis, C., Hammond, A., \& Davis, M. (2005). Sex differences in hormonal modulation of anxiety measured with Light-enhanced startle: Posible role for arginine vasopressin in male. The Journal of Neuroscience, 28, 9010-9016.

Universidade Católica (2004). Sondagem RTP/Público. Retirado em 22, Outubro, 2009, de www. Forumenfermagem.org.

Valiente, R. M., Sandín, B., \& Chorot, P. (2002). Miedos comunes en ninos y adolescentes: su relación con la sensibilidad a la ansiedad y otras emociones negativas. Psiquis, 23, 217-225.

Viau, V. (2002). Functional cross-talk between the hypothalamic-pituitary-gonodal and adrenal axes. Journal of Neuroendocrinology, 14, 506-513.

Voelz, Z. R., \& Joiner, T. E. (2002). The tripartite model of anxiety and depression: Implications for the assessment and treatment of depressed adults and adolescents. Primary Psychiatry, 9, 59-62.

Vuong, S. M., Oliver, H. A., Scholl, J. L., Oliver, K. M., \& Forster, G. L. (2010). Increased anxiety-like behavior of rats during amphetamine withdrawal is reversed by CRF2 receptor antagonism. Behavioural Brain Research, 208, 278-281.

Walker, D.L., Toufexis, D.J., \& Davis, M. (2003). Role of the bed nucleus of the stria terminalis versus the amygdala in fear, stress, and anxiety. European Journal of Pharmacology, 463, 199-216. 
Warren, S. L., Scmitz, S., \& Ende, R. N.. (1999). Behavioral genetic analyses of self-reported anxiety at 7 years of age. Journal of the American Academy of Child \& Adolescent Psychiatry, 38, 1403-1408.

Watson, D. (2000). Mood and temperament. New York: Guilford Press.

Watson, D., \& Clark, L. A. (1984). Negative Affectivity: the Disposition to Experience Aversive Emocional States. Psychology Bulletin, 96, 465-490.

Watson, D., Clark, L. A., Weber, K., Assenheimer, J. S., Strauss, M. E., \& McCormick, R. A. (1995). Testing a tripartite model: I. Evaluating the convergent and discriminant validity of anxiety and depression symptom scales. Journal of Abnormal Psychology, 104, 3-14.

Watson, D., \& Tellegan, A. (1985). Toward a consensual structure of mood. Psychological Bulletin, 98, 219-235.

Weems, C. F., Hayward, C., Killen, J., \& Taylor, C. B. (2002). A longitudinal investigation of anxiety sensitivity in adolescence. Journal of Abnormal Psychology, 111, 471-477.

Weissman, D. H., \& Banich, M. T. (2000). The cerebral hemispheres cooperate to perform complex but not simple tasks. Neuropsychology, 14, 41-59.

Weissman, J., \& Levine, S.R. (2007). Anxiety disorders and older women. Journal of Women \& Aging, 19, 79-101.

Wetherell, J. L., Gatz, M., \& Pedersen, N. L. (2001). A longitudinal análisis of anxiety and depressive symptoms. American Psychological Association, 2, 187-195.

Williams, J. M., Watts, F. N., MacLeod, C., \& Mathews, A. (1997). Cognitive psychology and emotional disorders. Chichester: Wiley.

Woodward, L. J., \& Fergusson, D.M. (2001). Life course outcomes of young people with anxiety disorders in adolescence. Journal of American Academy of Child and Adolescent Psychiatry, 40, 1086-1093.

World Health Organization. (2000). Cross-national comparisons of the prevalences and correlates of mental disorders. Bulletin of the World Heath Organization, 4, 413-426. 
World Mental Health Consortium. (2010). Primeiros resultados do estudo epidemiológico nacional de saúde mental. Comunicação apresentada na Faculdade de Ciências Médicas, Universidade Nova de Lisboa, Lisboa.

Wright, B. D. (1996) Reasonable mean-square fit values. In B.D. Wright, \& J.M. Linacre, (Eds.) Rasch measurement transactions. Part 2. Chicago: MESA Press.

Wright, B. D., \& Douglas, G. A. (1975). A better procedures for sample-free item analysis. Research Memorandum. Statistical Laboratory. Department of Education. University of Chicago.

Wright, B. D., \& Masters, G. N. (1982). Rating scale analysis. Chicago: MESA Press.

Wright, B. D., \& Mok, M. M. C. (2004). An overview of the family of Rasch measurement models. In E. V. Smith, \& R. M. Smith (Eds.) Introduction to Rasch measurement. Maple Grove: JAM Press.

Wright, B. D., \& Panchapakesan, N. (1969). A procedure for simple-free item análisis. Educational and Psychological Measurement, 29, 23-48.

Yalcin, B., Willis-Owen, S. A., Fullerton, J., Meesaq, A., Deacon, R. M., et al. (2004). Genetic dissection of a behavioral quantitative trait locus shows that Rgs2 modulates anxiety in mice. Nature Genetics, 36, 1197-1202.

Yamasue, H., Abe, O., suga, M., Yamada, H., Inove, H, Tochini, M., et al. (2008). Gendercommon and -specific neuroanatomical basis of human anxiety-related personality traits. Cerebral Cortex, 18, 46-52.

Young, E., Altemus, M., Parkinson, V., \& Shastry, S. (2001). Effects of estrogen antagonists and agonists on the $\mathrm{ACH}$ responses to restrait stress in female rats. Neuropsychopharmacology, 25, 881-891.

Young, E. A., Abelson, J. L., \& Cameron, O. G. (2004). Effect of comorbid anxiety disorder on the hypothalamic-pituitary-adrenal axis response to a social stressor in major depression. Biological Psychiatry, 56, 113-120. 
Zeiss, A. M., Lewinsohn, P. M., Rhode, P., \& Seeley, J. R. (1996). Relationship of physical disease and functional impairment to depression in older people. Psychology and Aging, 1, 1572-1582.

Zegler, M. (1987). State-trait anxiety in young, and middle-aged adults. Toronto: York University.

Zhang, S., \& Cranney, J. (2008). The role of GABA and anxiety in the reconsolidation of conditioned fear. Behavioral Neuroscience, 122, 1295-1305.

Zickar, M.J. \& Broadfoot, A.A. (2009). The partial revival f a dead horse? Comparing classical test theory and item response theory. En C. E. Lance \& R.J. Vandenberg (Eds.) Statistical and methodological myths and urban legends (pp. 37-61). New York: Routledge.

Zigmond, A., \& Snaith, R.P. (1983). The Hospital Anxiety and Depression Scale. Acta Psychiatrica Scandinavica, 67, 361-370.

Zung, W. (1971). A Rating Instrument for Anxiety Disorders. Psychossomatics, 6, 371-379.

Zvolensky, M. J., McNeil, D. W., Porter, C. A., \& Stewart, S. H. (2001). Assessment of anxiety sensitivity in young american Indians and Alaska natives. Behaviour Research and Therapy, 39, 477-493. 


\section{APÉNDICES}




\section{Apêndice I - Cuestionario de Evaluación}

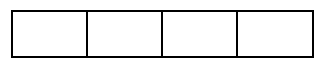

Pedimos a sua colaboração, para participar numa investigação que tem como objectivo o estudo da ansiedade.

É importante que responda a todas as questões o mais honestamente possível. Não existem respostas certas ou erradas. Leia as instruções com cuidado e se tiver questões não hesite em perguntar.

Se em qualquer altura sentir que prefere não continuar, é livre de desistir e de entregar o questionário. Os dados que nos facultar serão anónimos e confidenciais. Qualquer informação, incluindo as pessoais, será utilizada apenas para fins estatísticos. Estamos interessados em valores de grupos e não em resultados individuais.

Por razões éticas e experimentais, não deverá comparar as suas respostas com as dos seus parceiros ou parceiras.

Logo que terminar, pedimos-lhe que devolva os questionários.

Agradecemos a sua colaboração, assim como a sua disponibilidade.

\section{DADOS DEMOGRÁFICOS}

1 - Idade: Anos

2 - Sexo: $\square_{1}$ Masculino $\square_{2}$ Feminino

3 - Residência $\square_{1}$ Meio Urbano $\square_{2}$ Meio Rural $\square_{3}$ Outra:

4 - Etnia: $\square_{1}$ Caucasiana $\square_{2}$ Negra $\square_{3}$ Outra:

\section{5 - Habilitações literárias:}

$\square_{1}$ Ensino Primário Incompleto ou Nulo

$\square_{2}$ Ensino Primário Completo (6 anos de estudo)

$\square_{3}$ Ensino Médio ou Técnico Inferior (8 a 9 anos de estudo)

$\square_{4}$ Ensino Médio ou Técnico Superior (10 a 12 anos de estudo)

$\square_{5}$ Ensino Universitário ou Equivalente (+ 12 anos de estudo)

6 - Religião: $\square_{1}$ Sem Religião $\square_{2}$ Católica $\square_{3}$ Outra:

\section{7 - Estado civil:}
$\square_{1}$ Solteiro(a).
$\square_{2}$ Casado(a) / União de Facto
$\square_{3}$ Separado(a)/ Divorciado(a)
$\square_{4}$ Viúvo(a)

8 - Número de filhos

9 - Situação profissional:

$\square_{1}$ Desempregado(a)

$\square_{2}$ Trabalhador(a) por conta doutrem

$\square_{3}$ Trabalhador(a) por conta própria

$\square_{4}$ Estudante

$\square_{5}$ Reformado(a) 
BAI; Beck \& Steer, 1993.

Tradução: Quintão, 2008.

Abaixo está uma lista de sintomas comuns de ansiedade. Identifique o quanto se tem sentido incomodado por cada sintoma durante a última semana, incluindo hoje, colocando um circulo no espaço correspondente, na mesma linha de cada sintoma.

\begin{tabular}{|c|c|c|c|c|}
\hline & $\begin{array}{c}\text { Absoluta- } \\
\text { mente } \\
\text { não }\end{array}$ & $\begin{array}{c}\text { Levemente } \\
\text { Não me } \\
\text { incomodou } \\
\text { muito } \\
\end{array}$ & $\begin{array}{l}\text { Moderadamente } \\
\text { Foi muito } \\
\text { desagradável mas } \\
\text { pude suportar } \\
\end{array}$ & $\begin{array}{l}\text { Gravemente } \\
\text { Dificilmente } \\
\text { pude suportar }\end{array}$ \\
\hline 1. Dormência ou formigueiro & 0 & 1 & 2 & 3 \\
\hline 2. Sensação de calor & 0 & 1 & 2 & 3 \\
\hline 3. Tremores nas pernas & 0 & 1 & 2 & 3 \\
\hline 4. Incapaz de relaxar & 0 & 1 & 2 & 3 \\
\hline 5. Medo que aconteça o pior & 0 & 1 & 2 & 3 \\
\hline 6. Atordoado ou tonto & 0 & 1 & 2 & 3 \\
\hline $\begin{array}{l}\text { 7. Palpitação ou aceleração do } \\
\text { coração }\end{array}$ & 0 & 1 & 2 & 3 \\
\hline 8. Sem equilíbrio & 0 & 1 & 2 & 3 \\
\hline 9. Aterrorizado & 0 & 1 & 2 & 3 \\
\hline 10. Nervoso & 0 & 1 & 2 & 3 \\
\hline 11. Sensação de sufocação & 0 & 1 & 2 & 3 \\
\hline 12. Tremores nas mãos & 0 & 1 & 2 & 3 \\
\hline 13. Trémulo & 0 & 1 & 2 & 3 \\
\hline 14. Medo de perder o controlo & 0 & 1 & 2 & 3 \\
\hline 15. Dificuldade de respirar & 0 & 1 & 2 & 3 \\
\hline 16. Medo de morrer & 0 & 1 & 2 & 3 \\
\hline 17. Assustado & 0 & 1 & 2 & 3 \\
\hline $\begin{array}{l}\text { 18. Indigestão ou desconforto no } \\
\text { abdómen }\end{array}$ & 0 & 1 & 2 & 3 \\
\hline 19. Sensação de desmaio & 0 & 1 & 2 & 3 \\
\hline 20. Rosto afogueado & 0 & 1 & 2 & 3 \\
\hline 21. Suor (não devido ao calor) & 0 & 1 & 2 & 3 \\
\hline
\end{tabular}


STAI; Spielberger, Gorsuch, Clayden, Husain, \& Sipple, 1970.

Versão Portuguesa: Silva, 2006

Em baixo tem uma série de frases que são habitualmente usadas para descrever pessoas. Leia cada uma delas e assinale o algarismo da direita que melhor indica como se sente no momento.

\begin{tabular}{|l|c|c|c|c||}
\hline & Nada & $\begin{array}{c}\text { Um } \\
\text { pouco }\end{array}$ & Moderadamente & Muito \\
\hline 1. Sinto-me calmo(a) & 1 & 2 & 3 & 4 \\
\hline 2. Sinto-me seguro(a) & 1 & 2 & 3 & 4 \\
\hline 3. Estou tenso(a) & 1 & 2 & 3 & 4 \\
\hline 4. Sinto-me cansado(a) & 1 & 2 & 3 & 4 \\
\hline 5. Sinto-me à vontade & 1 & 2 & 3 & 4 \\
\hline 6. Sinto-me perturbado(a) & 1 & 2 & 3 & 4 \\
\hline $\begin{array}{l}\text { 7. Presentemente, preocupo-me com } \\
\text { possíveis desgraças }\end{array}$ & 1 & 2 & 3 & 4 \\
\hline 8. Sinto-me satisfeito(a) & 1 & 2 & 3 & 4 \\
\hline 9. Sinto-me amedrontado(a) & 1 & 2 & 3 & 4 \\
\hline 10. Sinto-me confortável & 1 & 2 & 3 & 4 \\
\hline 11. Sinto-me auto-confiante & 1 & 2 & 3 & 4 \\
\hline 12. Sinto-me nervoso(a) & 1 & 2 & 3 & 4 \\
\hline 13. Sinto-me trémulo(a) & 1 & 2 & 3 & 4 \\
\hline 14. Sinto-me indeciso(a) & 1 & 2 & 3 & 4 \\
\hline 15. Sinto-me descontraído(a) & 1 & 2 & 3 & 4 \\
\hline 16. Sinto-me contente & 1 & 2 & 3 & 4 \\
\hline 17. Estou preocupado(a) & 1 & 2 & 3 & 4 \\
\hline 18. Sinto-me confuso(a) & 1 & 2 & 3 & 4 \\
\hline 19. Sinto-me firme & 1 & 2 & 3 & 4 \\
\hline 20. Sinto-me bem & 1 & 2 & 3 & 4 \\
\hline
\end{tabular}


Em baixo tem uma série de frases que são habitualmente usadas para descrever pessoas. Leia cada uma delas e assinale o algarismo da direita que melhor indica como se sente habitualmente.

\begin{tabular}{|c|c|c|c|c|}
\hline & $\begin{array}{l}\text { Quase } \\
\text { nada }\end{array}$ & $\begin{array}{l}\text { Algumas } \\
\text { vezes }\end{array}$ & Frequentemente & $\begin{array}{l}\text { Quase } \\
\text { sempre }\end{array}$ \\
\hline 21. Sinto-me bem & 1 & 2 & 3 & 4 \\
\hline 22. Sinto-me nervoso(a) e agitado(a) & 1 & 2 & 3 & 4 \\
\hline $\begin{array}{l}\text { 23. Sinto-me satisfeito(a) comigo } \\
\text { mesmo(a) }\end{array}$ & 1 & 2 & 3 & 4 \\
\hline $\begin{array}{l}\text { 24. Gostava de poder ser tão feliz como os } \\
\text { outros parecem ser }\end{array}$ & 1 & 2 & 3 & 4 \\
\hline 25. Sinto-me falhado(a) & 1 & 2 & 3 & 4 \\
\hline 26. Sinto-me tranquilo(a) & 1 & 2 & 3 & 4 \\
\hline $\begin{array}{l}\text { 27. Estou "calmo(a), fresco(a) e } \\
\text { concentrado(a)" }\end{array}$ & 1 & 2 & 3 & 4 \\
\hline $\begin{array}{l}\text { 28. Sinto que as dificuldades se acumulam } \\
\text { de tal forma que não as consigo ultrapassar }\end{array}$ & 1 & 2 & 3 & 4 \\
\hline $\begin{array}{l}\text { 29. Preocupo-me demais com as coisas que } \\
\text { na realidade não têm importância }\end{array}$ & 1 & 2 & 3 & 4 \\
\hline 30. Estou feliz & 1 & 2 & 3 & 4 \\
\hline 31. Tenho pensamentos que me perturbam & 1 & 2 & 3 & 4 \\
\hline 32. Falta-me auto-confiança & 1 & 2 & 3 & 4 \\
\hline 33. Sinto-me seguro(a) & 1 & 2 & 3 & 4 \\
\hline 34. Tomo decisões facilmente & 1 & 2 & 3 & 4 \\
\hline 35. Sinto-me inadequado(a) & 1 & 2 & 3 & 4 \\
\hline 36. Estou contente & 1 & 2 & 3 & 4 \\
\hline $\begin{array}{l}\text { 37. Passam-me pela cabeça pensamentos } \\
\text { sem importância que me perturbam }\end{array}$ & 1 & 2 & 3 & 4 \\
\hline $\begin{array}{l}\text { 38. As contrariedades afectam-me de modo } \\
\text { tão intenso que não consigo afastá-las da } \\
\text { minha mente }\end{array}$ & 1 & 2 & 3 & 4 \\
\hline 39. Sou uma pessoa firme & 1 & 2 & 3 & 4 \\
\hline $\begin{array}{l}\text { 40. Fico tenso(a) e perturbado(a) quando } \\
\text { penso nas minhas preocupações e } \\
\text { interesses actuais }\end{array}$ & 1 & 2 & 3 & 4 \\
\hline
\end{tabular}


ASI; Peterson \& Reiss, 1987.

Tradução: Quintão, 2008.

Abaixo encontra-se uma lista de frases relacionadas com a ansiedade. Identifique o quanto cada frase o descreve.

\begin{tabular}{|lll}
\hline 0 - Muito pouco & 1 - Pouco & 2 - Nem pouco nem muito \\
$3-$ Muito & $4-$ Muitíssimo & \\
\hline
\end{tabular}

\begin{tabular}{|c|c|c|c|c|c|}
\hline 1 - Para mim, é importante não demonstrar nervosismo & 0 & 1 & 2 & 3 & 4 \\
\hline $\begin{array}{l}2 \text { - Quando não me consigo concentrar, tenho medo de estar a ficar } \\
\text { louco(a) }\end{array}$ & 0 & 1 & 2 & 3 & 4 \\
\hline 3 - Fico assustado(a) quando me sinto trémulo(a) & 0 & 1 & 2 & 3 & 4 \\
\hline 4 - Fico assustado(a) quando me sinto tonto(a) & 0 & 1 & 2 & 3 & 4 \\
\hline 5-É importante para mim controlar as minhas emoções & 0 & 1 & 2 & 3 & 4 \\
\hline 6 - Fico assustado(a) quando o meu coração bate muito rápido & 0 & 1 & 2 & 3 & 4 \\
\hline 7 - Fico embaraçado(a) quando o meu estômago faz barulho & 0 & 1 & 2 & 3 & 4 \\
\hline 8 - Fico assustado(a) quando sinto náuseas & 0 & 1 & 2 & 3 & 4 \\
\hline $\begin{array}{l}9 \text { - Quando o meu coração bate rápido, tenho medo de estar a ter um } \\
\text { enfarte }\end{array}$ & 0 & 1 & 2 & 3 & 4 \\
\hline 10 - Fico assustado(a) quando sinto falta de ar & 0 & 1 & 2 & 3 & 4 \\
\hline $\begin{array}{l}11 \text { - Quando o meu estômago está embrulhado, fico preocupado(a) se } \\
\text { estou com uma doença séria }\end{array}$ & 0 & 1 & 2 & 3 & 4 \\
\hline $\begin{array}{l}12 \text { - Fico assustado(a) quando não sou capaz de manter a minha mente } \\
\text { concentrada }\end{array}$ & 0 & 1 & 2 & 3 & 4 \\
\hline 13 - Outras pessoas notam quando me sinto trémulo(a) & 0 & 1 & 2 & 3 & 4 \\
\hline 14 - As sensações corporais incomuns assustam-me & 0 & 1 & 2 & 3 & 4 \\
\hline $\begin{array}{l}15 \text { - Quando estou nervoso(a) fico preocupado(a) se estou com alguma } \\
\text { doença mental }\end{array}$ & 0 & 1 & 2 & 3 & 4 \\
\hline 16 - Fico assustado(a) quando estou nervoso(a) & 0 & 1 & 2 & 3 & 4 \\
\hline
\end{tabular}


ZUNG; Zung, 1971.

Leia com atenção todas as frases seguidamente expostas. Em relação a cada uma delas assinale com um círculo no quadro respectivo aquilo que constitua a descrição mais aproximada da maneira como se sente actualmente.

\begin{tabular}{|ll}
\hline 1 - Nenhuma ou raras vezes & 2 - Algumas vezes \\
3 - Uma boa parte do tempo & $4-$ A maior parte ou a totalidade do tempo
\end{tabular}

\begin{tabular}{|l|c|c|c|c|}
\hline 1 - Sinto-me mais nervoso(a) e ansioso(a) do que o costume & 1 & 2 & 3 & 4 \\
\hline 2 - Sinto-me com medo sem nenhuma razão para isso & 1 & 2 & 3 & 4 \\
\hline 3 - Sinto-me facilmente perturbado(a) ou em pânico & 1 & 2 & 3 & 4 \\
\hline 4 - Sinto-me como se estivesse para "rebentar" & 1 & 2 & 3 & 4 \\
\hline 5 - Sinto que tudo corre bem e que nada de mal acontecerá & 1 & 2 & 3 & 4 \\
\hline 6 - Sinto os braços e as pernas a tremer & 1 & 2 & 3 & 4 \\
\hline 7 - Tenho dores de cabeça, de pescoço e de costas que me incomodam & 1 & 2 & 3 & 4 \\
\hline 8 - Sinto-me fraco(a) e fico facilmente cansado(a) & 1 & 2 & 3 & 4 \\
\hline 9 - Sinto-me calmo(a) e com facilidade me posso sentar e ficar sossegado(a) & 1 & 2 & 3 & 4 \\
\hline 10 - Sinto o meu coração a bater mais depressa & 1 & 2 & 3 & 4 \\
\hline 11 - Tenho crises de tonturas que me incomodam & 1 & 2 & 3 & 4 \\
\hline 12 - Tenho crises de desmaio ou a sensação de que vou desmaiar & 1 & 2 & 3 & 4 \\
\hline 13 - Posso inspirar e expirar com facilidade & 1 & 2 & 3 & 4 \\
\hline $\begin{array}{l}14 \text { - Sinto os dedos das minhas mãos e dos meus pés entorpecidos e com } \\
\text { picadas }\end{array}$ & 1 & 2 & 3 & 4 \\
\hline 15 - Costumo ter dores de estômago ou más digestões & & & & \\
\hline 16 - Tenho de esvaziar a bexiga com frequência & 1 & 2 & 3 & 4 \\
\hline 17 - As minhas mãos estão habitualmente secas e quentes & 1 & 2 & 3 & 4 \\
\hline 18 - A minha face costuma ficar quente e corada & 1 & 2 & 3 & 4 \\
\hline 19 - Adormeço facilmente e consigo obter um bom descanso durante a noite & 1 & 2 & 3 & 4 \\
\hline 20 - Tenho pesadelos & 1 & 2 & 3 & 4 \\
\hline
\end{tabular}




\section{ANEXOS}




\section{Anexo I - Autorización para validar el inventario de ansiedad de Beck para Portugal}

Casa do Psicólogo ${ }^{\circledR}$

All Books Livraria e Editora Ltda.

Rua Simão Álvares, 1020 - Vila Madalena

CEP. 05417- 020 - São Paulo - SP - Brasil

Fone / fax: (011) 3034-3600

email:casadopsicologo@casadopsicologo.com.b

São Paulo, 23 de Janeiro de 2007

\section{$\underline{\text { Autorizacão }}$}

A Casa do Psicólogo, detentora dos direitos de publicação no Brasil, do Inventário de Ansiedade - BAI - Escalas BECK (Harcourt Assessment, INC), autoriza a pesquisadora: Sônia dos Reis Quintão a utilizar o referido instrumento como parte de seu método de pesquisa, no projeto de doutorado: "Validação da Escala de Ansiedade de Beck - BAI - para Portugal".

Riléria Un. OD Delinón Fosi

Dra. Silésia M. V. Delphino Tosi

Departamento de Pesquisa e Produção de Testes 